\title{
ASSESSMENT OF CLOUD-PROPERTY INSTRUMENTATION FOR CALIBRATION OF ICING WIND TUNNELS
}

by

\author{
Daniel C. Knezevici \\ B.Eng. (Carleton University)
}

\begin{abstract}
A thesis submitted to
The Faculty of Graduate Studies and Research

In partial fulfillment of the requirements for the degree of

Master of Applied Science (Aerospace Engineering)
\end{abstract}

Ottawa-Carleton Institute for

Mechanical and Aerospace Engineering

Department of

Mechanical and Aerospace Engineering

Carleton University

Ottawa, Canada

\author{
(C) Copyright \\ 2004 - Daniel C. Knezevici
}




$\begin{array}{ll}\begin{array}{l}\text { Library and } \\ \text { Archives Canada }\end{array} & \begin{array}{l}\text { Bibliothèque et } \\ \text { Archives Canada }\end{array} \\ \begin{array}{l}\text { Published Heritage } \\ \text { Branch }\end{array} & \begin{array}{l}\text { Direction du } \\ \text { Patrimoine de l'édition }\end{array} \\ \begin{array}{l}\text { 395 Wellington Street } \\ \text { Ottawa ON K1A 0N4 }\end{array} & \begin{array}{l}\text { 395, rue Wellington } \\ \text { Ottawa ON K1A ON4 } \\ \text { Canada }\end{array} \\ \end{array}$

Your file Votre référence ISBN: 0-612-97491-X

Ourfile Notre référence

ISBN: 0-612-97491-X

NOTICE:

The author has granted a nonexclusive license allowing Library and Archives Canada to reproduce, publish, archive, preserve, conserve, communicate to the public by telecommunication or on the Internet, loan, distribute and sell theses worldwide, for commercial or noncommercial purposes, in microform, paper, electronic and/or any other formats.

The author retains copyright ownership and moral rights in this thesis. Neither the thesis nor substantial extracts from it may be printed or otherwise reproduced without the author's permission.
AVIS:

L'auteur a accordé une licence non exclusive permettant à la Bibliothèque et Archives Canada de reproduire, publier, archiver, sauvegarder, conserver, transmettre au public par télécommunication ou par l'Internet, prêter, distribuer et vendre des thèses partout dans le monde, à des fins commerciales ou autres, sur support microforme, papier, électronique et/ou autres formats.

L'auteur conserve la propriété du droit d'auteur et des droits moraux qui protège cette thèse. $\mathrm{Ni}$ la thèse ni des extraits substantiels de celle-ci ne doivent être imprimés ou autrement reproduits sans son autorisation.
In compliance with the Canadian

Privacy Act some supporting forms may have been removed from this thesis.

While these forms may be included in the document page count, their removal does not represent any loss of content from the thesis.
Conformément à la loi canadienne sur la protection de la vie privée, quelques formulaires secondaires ont été enlevés de cette thèse.

Bien que ces formulaires aient inclus dans la pagination, il n'y aura aucun contenu manquant. 
The undersigned recommend to

The Faculty of Graduate Studies and Research

Acceptance of this thesis

\title{
ASSESSMENT OF CLOUD-PROPERTY INSTRUMENTATION FOR CALIBRATION OF ICING WIND TUNNELS
}

\author{
Submitted by \\ Daniel C. Knezevici, B.Eng. \\ In partial fulfillment of the requirements for \\ The degree of Master of Applied Science (Aerospace Engineering) \\ J.C. Beddoes, Chair, \\ Department of Mechanical and Aerospace Engineering \\ R.J. Kind, Thesis Supervisor \\ Carleton University \\ September 18, 2004
}




\section{ABSTRACT}

A recent inter-facility comparison between six different icing wind tunnel facilities was performed under the auspices of the Society of Automotive Engineers sub committee AC-9C. This study indicated that calibration issues may be responsible for the substantial inconsistencies found in the volume of ice accreted on a standardized set of models for specified tunnel operating conditions. In light of this, the work presented in this thesis was undertaken to investigate the accuracy of instrumentation commonly used for the calibration of spray-cloud properties in icing wind tunnels. The suitability of the rotating multicylinder method for this purpose was also assessed.

Investigative comparisons of several instruments considered standard for the measurement of cloud properties were performed at the National Research Council of Canada's Altitude Icing Wind Tunnel (AIWT). These instruments include the single rotating cylinder, the icing blade, and the King probe for measuring cloud liquid water content (LWC), and the Malvern Spraytec and Phase Doppler Particle Analyzer (PDPA) for measuring cloud-droplet median volumetric diameter (MVD). A rotating multicylinder apparatus was also designed and assessed for the measurement of cloud properties in the test section of the AIWT. The comparison of measurements of these instruments revealed only minor discrepancies between them. The rotating multicylinder technique was found to give good results for LWC and MVD and it is 
recommended that it be adopted for benchmarking the much more complex lightscattering instruments such as the Malvern and PDPA, typically used for measuring MVD in icing wind tunnels. 


\section{ACRNOMLEDGEMENTS}

I wish to extend sincerest gratitude to Prof. Kind for his assistance and tutelage throughout this work. His confidence and faith in my abilities were essential to the completion of this project.

I would also like to thank Myron Oleskiw of the National Research Council for his expertise in the field of icing. His theoretical background and patience was a great asset in supervising this work.

I am grateful for all the help of Gislain Chevrette of the Altitude Icing Wind Tunnel. His machining and problem solving skills were essential in manufacturing the apparatuses of the icing blade and rotating multicylinder. I would also like to thank Gislain for his countless hours of help operating the wind tunnel and assisting in the collection of data.

I would like to thank the National Research Council of Canada for the use of the Altitude Icing Wind Tunnel for conducting the experiments presented herein.

Acknowledgements must be extended to $\operatorname{coX} \&$ Co. and the Arnold Engineering Development Center (AEDC) for the loan of the Malvern Spraytec and PDPA, respectively, used for measuring spray cloud MVD.

Finally I would like to thank my family and friends, especially my loving parents. Their support was reassuring throughout the hardships faced in completing this work. 


\section{TABLE OF CONTENTS}

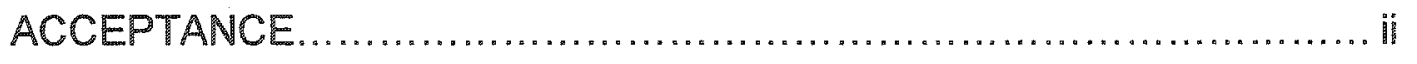

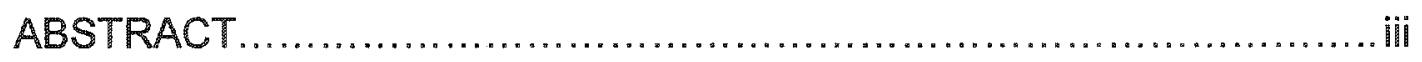

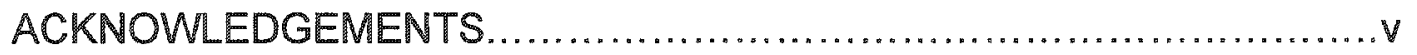

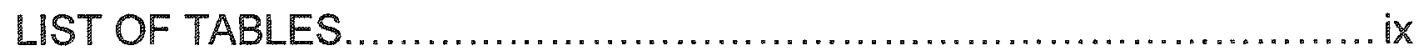

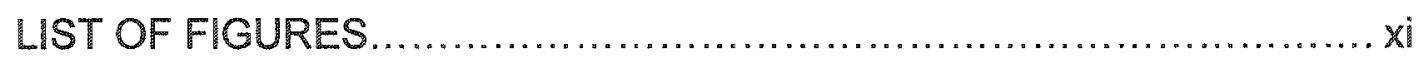

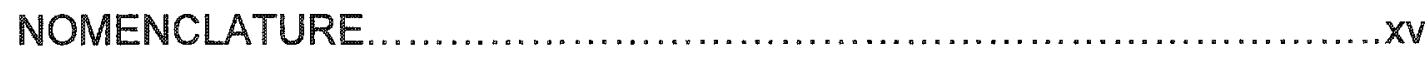

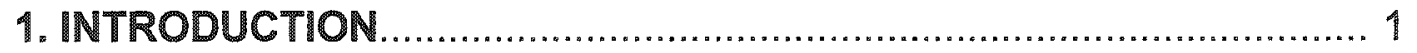

2. BACKGROUND AND LITERATURE REVIEW ................................. 4

2.1 IN-FLIGHT ICING AND FLIGHT CERTIFICATION ............... 4

2.2 DEFINITION OF ENVIRONMENTAL PARAMETERS............6

2.3 DESCRIPTION OF THE ICING PROCESS .................... 7

2.3.1 Droplet Collision Efficiency.......................... 8

2.3.2 Types of Ice Accretion................................... 9

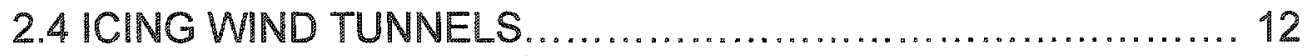

2.5 INSTRUMENTATION FOR MEASURING CLOUD

PROPERTIES ..................................................... 14

2.5.1 Instrumentation for Measuring LWC ................... 15

2.5.1.1 loing Blade.................................... 15

2.5.1.2 Single Rotating Cylinder........................ 18

2.5.1.3 King Probe.......................................22

2.5.2 Instrumentation for Measuring MVD .................... 24

2.5.2.1 Light Scattering Instruments.................. 24

2.5.2.2 Multi-Rotating Cylinder Method................. 30 
2.6 CALIBRATION OF ICING WIND TUNNELS .................... 33

3. DESCRIPTION OF INITIAL AIWT EXPERIMENTS ......................36

3.1 REPLICATION OF INTER-FACILITY COMPARISON

STUDY RESULTS FOR THE 1.5" DIAMETER CYLINDER ........... 39

3.2 PROCEDURES FOR ICING BLADE LWC VS. SINGLE

ROTATING CYLINDER LWC MEASUREMENTS

3.3 PROCEDURES FOR SINGLE ROTATING CYLINDER

VS. KING PROBE LWC MEASUREMENTS.

4. DESIGN, CONSTRUCTION AND USE OF THE ROTATING MULTICYLINDER APPARATUS.

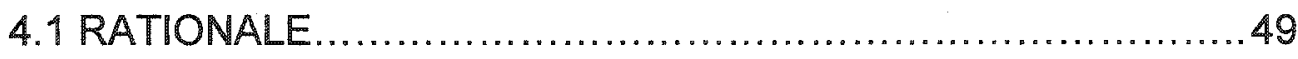

4.2 DESIGN AND DESCRIPTION OF THE APPARATUS ............51

4.3 SIMULATION STUDIES FOR THE DESIGN AND

DEVELOPMENT OF DATA REDUCTION METHODS.

4.4 EXPERIMENTAL PROCEDURES AND DATA

REDUCTION METHODS.

4.5 DESCRIPTION OF ROTATING MULTICYLINDER

EXPERIMENTS IN THE AIWT

5. RESULTS AND DISCUSSION 68

5.1 COMPARISON OF ICE PROFILE TRACINGS WITH RESULTS OF THE INTER-FACILITY COMPARISON STUDY 68

5.2 ICING BLADE LWC VS. SINGLE ROTATING CYLINDER LWC RESULTS.

5.3 SINGLE ROTATING CYLINDER LWC vS. KING PROBE LWC RESULTS. 79

5.4 RESULTS OF ROTATING MULTICYLINDER EXPERIMENTS TO DETERMINE SPRAY CLOUD LWC AND MVD. 83

5.5 FURTHER DISCUSSION OF RESULTS 90 


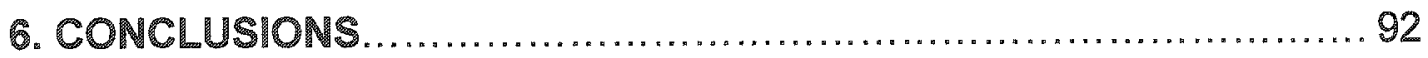

7. RECOMMENDATIONS ............................................... 96

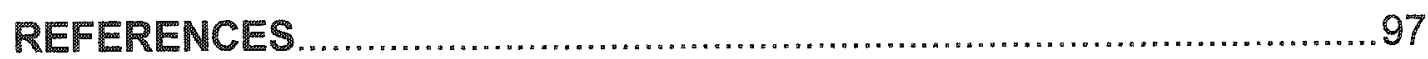

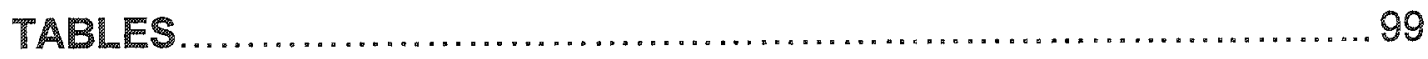

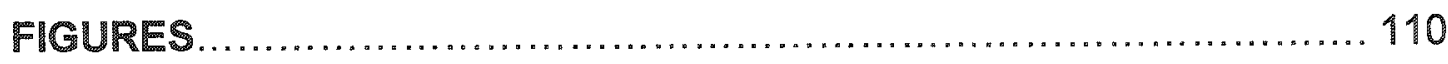

Appendix A: Computation of Collision Efficiency for a Cylinder

in Cross-Flow.............................................................. 139

Appendix B: Modified Version of Makkonen's Model for Modeling Ice Accretion on Wires...................................................... 143

Appendix C: Weighted Least-Squares Linear Regression of a 2-Dimensional Cartesian System through the Origin..................... 148

Appendix D: Procedure used in the Replication of the Inter-Facility Comparison Study 


\section{LIST OF TABLES}

Table

Description

Page

2.1 Computed values of $N \lambda_{s}$ as determined by equations

(2.5) and (2.6).

3.1 Test Point Conditions Replicated from the SAE Facility Inter-Comparison Study.

4.1 Diameters of stock pipe considered for use in the

multicylinder set.

4.2 Droplet Size Spectra Used at the Mt. Washington

Observatory

100

4.3 Results of the Investigation into the Effect of Droplet Size Spectrum on MVD returned by the Solution Algorithm.

4.4 Results of the Investigation determining the effect of a potential measurement error or inaccuracy in the collected sample

5.1 Test Points Used in the Replication of SAE Case 1 of the Inter-Facility Comparison

5.2 Test Points Used in the Replication of SAE Case 3 of the Inter-Facility Comparison

5.3 Test Points Used in the Replication of SAE Case 9 of the Inter-Facility Comparison

5.4a Test Points and Results for the Comparison of the Icing Blade with the Single Rotating Cylinder Method for Measuring Spray cloud LWC

5.4b Test Points and Results for the Comparison of the lcing Blade with the Single Rotating Cylinder Method for Measuring Spray Cloud LWC

5.5a Test Point Conditions and Results for the Comparison of the Single Rotating Cylinder with the King Probe

Test points taken at $30 \mathrm{~m} / \mathrm{s}$ 
$5.5 \mathrm{~b}$ Test Point Conditions and Results for the Comparison of the Single Rotating Cylinder with the King Probe

Test points taken at $50 \mathrm{~m} / \mathrm{s}$

5.5c Test Point Conditions and Results for the Comparison of the Single Rotating Cylinder with the King Probe

Test points taken at $70 \mathrm{~m} / \mathrm{s}$

5.5d Test Point Conditions and Results for the Comparison of the Single Rotating Cylinder with the King Probe

Test points taken at $90 \mathrm{~m} / \mathrm{s}$

5.6a Nozzle Flow Rates and Congruent Results Measured with the Rotating Multicylinder, the Malvern Spraytec and the PDPA. Test points were taken at $30 \mathrm{~m} / \mathrm{s}$

5.6b Nozzle Flow Rates and Congruent Results Measured with the Rotating Multicylinder, the Malvern Spraytec and the PDPA. Test points were taken at $50 \mathrm{~m} / \mathrm{s}$ 


\section{List of Figures}

Figure

Description

Page

2.1 Droplet Trajectory Approaching a Cylinder in Cross-Flow

2.2 Collision Efficiency vs. Cylinder Radius as Computed by Finstad et al., (1988)

2.3 Mean Surface Temp vs. Velocity for Fixed LWC $\left(0.5 \mathrm{~g} / \mathrm{m}^{3}\right)$ and MVD (15um)

2.4 Cross Sectional Tracing of a Mixed Ice Accretion Grown on a Cylinder with a Diameter of $1.5^{\prime \prime}$

2.5 Photograph of Ice Accretion on a Cylinder with a Diameter of $1.5 " 112$

2.6 Schematic of the NRC-AIWT as shown in Oleskiw et al., (2001) 112

2.7 Internal Mixing Nozzle and External Mixing Nozzle 113

2.8 AIWT External Mixing Nozzle $\quad 113$

2.9 Working Drawing of the NASA Icing Blade 113

2.10 Collision Efficiency of a $1 / 8$ " thick icing blade for various MVDs 114

2.11 Working Drawing of the King Probe 114

2.12 Working Drawing of the King Probe Hot-Wire 115

2.13 Photograph of the Malvern Spraytec Apparatus 115

2.14 Schematic Diagram of the Optical Components for the PDPA 116

$\begin{array}{ll}2.15 & \text { Doppler Burst Signal } \\ & 116\end{array}$

2.15 Effect of Droplet Diameter on the Phase Shift Measured by the PDPA Detectors

3.1 Items Used in the Replication Study 117

3.2 lcing Blade Apparatus 117

4.1 Mt. Washington Rotating Multicylinder Apparatus 118 
Figure

Description

Page

4.2 Time variation of LWC along the AIWT Centerline Measured with the King Probe

4.3 Time variation of MVD in the AWT Test Section Measured with the Malvern Spraytec

4.4 Difference in Collision Efficiency Between Smallest and Largest Cylinder

4.5 Rotating Multicylinder Apparatus 120

4.6 Apparatus Configuration for Cylinder \#2 120

4.7 Apparatus Configuration for Cylinder \#5 121

4.8 Results of Simulation Study Investigating the Accuracy of the Solution Algorithm Presented in Section 2.5.2.2

4.9 Results of Simulation Study Investigating the Effect of a Potential Measurement Error on Cylinders 1 and \#5.

4.10 Graphical Representation of Droplet Spectra Shown in Table 4.2

4.11a Results of the Investigation into the Effect of Droplet Size Spectrum on MVD returned by the Solution Algorithm.

Theoretical mass accreted using spectrum $A$ and solution algorithm using spectrum $B$

4.11b Results of the Investigation into the Effect of Droplet Size Spectrum on MVD returned by the Solution Algorithm.

Theoretical mass accreted using spectrum $A$ and solution algorithm using spectrum J

4.11c Results of the Investigation into the Effect of Droplet Size Spectrum on MVD retumed by the Solution Algorithm.

Theoretical mass accreted using spectrum $J$ and solution algorithm using spectrum $B$

4.11d Results of the Investigation into the Effect of Droplet Size Spectrum on MVD returned by the Solution Algorithm. Theoretical mass accreted using spectrum $J$ and solution algorithm using spectrum $J$ 
Figure

4.12 Threshold to Ensure Rime Icing on the Rotating Multicylinder

Set as Determined by Computing the Average Surface

Temperature and Freezing Fraction for Each Cylinder

4.13 Specimen Box used to Remove Cylinders 1 and 2 from the Shaft of the Gun. (Cylinder $\$ 2$ shown)

5.1 Tracings of Ice Profiles Generated by the Various Facilities for SAE Case 1.

5.2 Tracings of lce Profiles Generated by the Various Facilities tor SAE Case 3

5.3 Tracings of Ice Profiles Generated by the Various Facilities for SAE Case 9

5.4 Results of the Comparison between the Icing Blade and the Single Rotating Cylinder

5.5a Time Averaged King Probe LWC vs. Single Rotating Cylinder LWC. Test points at $30 \mathrm{~m} / \mathrm{s}$

5.5b Time Averaged King Probe LWC vs. Single Rotating Cylinder LWC. Test points at $50 \mathrm{~m} / \mathrm{s}$

5.5c Time Averaged King Probe LWC vs. Single Rotating Cylinder LWC. Test points at $70 \mathrm{~m} / \mathrm{s}$

5.5d Time Averaged King Probe LWC vs. Single Rotating Cylinder LWC. Test points at $90 \mathrm{~m} / \mathrm{s}$

5.6a Effect of MV on the Test Section LWC as Measured by the Single Rotating Cylinder Method. Test Points at $30 \mathrm{~m} / \mathrm{s}$

5.6b Effect of MVD on the Test Section LWC as Measured by the Single Rotating Cylinder Method. Test Points at $50 \mathrm{~m} / \mathrm{s}$

5.6c Effect of MVD on the Test Section LWC as Measured by the Single Rotating Cylinder Method. Test Points at $70 \mathrm{~m} / \mathrm{s}$

5.6d Effect of MVD on the Test Section LWC as Measured by the Single Rotating Cylinder Method. Test Points at $90 \mathrm{~m} / \mathrm{s}$ 
Figure

5.7a Single Cylinder LWC vs. Rotating Multicylinder LWC for Test Points Conducted at $30 \mathrm{~m} / \mathrm{s}$.

5.7b Single Cylinder LWC vs. Rotating Multicylinder LWC for Test Points Conducted at $50 \mathrm{~m} / \mathrm{s}$.

5.8a Experimental Observed Mass vs. Theoretically Computed Mass on the Four Cylinders in the Rotating Multicylinder Set.

Test points at $30 \mathrm{~m} / \mathrm{s}$.

5.8b Experimental Observed Mass vs. Theoretically Computed Mass on the Four Cylinders in the Rotating Multicylinder Set.

Test points at $50 \mathrm{~m} / \mathrm{s}$.

5.9a Computed Rotating Multicylinder MVD vs. Measured Malvern Spraytec MVD. Test points at $30 \mathrm{~m} / \mathrm{s}$.

5.9b Computed Rotating Multicylinder MVD vs. Measured Malvern Spraytec MVD. Test points at $50 \mathrm{~m} / \mathrm{s}$.

5.10a Computed Rotating Multicylinder MVD vs. Measured PDPA MVD. Test points at $30 \mathrm{~m} / \mathrm{s}$.

5.10b Computed Rotating Multicylinder MVD vs. Measured PDPAMVD. Test points at $50 \mathrm{~m} / \mathrm{s}$.

5.11 Measured PDPA MVD vs. Measured Malvern MVD at various airspeeds.

5.12 Overlay of Malvern and PDPA measurements of Droplet Spectrum for Test Point 26 of Table $5.6 b$.

5.12 Overlay of Malvern and PDPA measurements of Droplet Spectrum for Test Point 5 of Table $5.6 a$. 


\section{NOMENCLATURE}

$c_{i} \quad$ specific heat of ice

$c_{p} \quad$ specific heat of air at constant pressure

$c_{w} \quad$ specific heat capacity of water

$D_{c} \quad$ cylinder diameter

$D_{d} \quad$ droplet diameter

$D_{K} \quad$ King probe wire diameter

$D_{\text {mean }}$ mean diameter of accretion $=1 / 2\left(r_{c f}+r_{c i}\right)$

E overall collision efficiency

Eblade collision efficiency of the icing blade

$E_{c y l}$ collision efficiency of the rotating cylinder

$E_{K} \quad$ collision efficiency of King probe wire

$e_{a} \quad$ saturation water vapor pressures over liquid water at $T_{a i r}$

$e_{i} \quad$ saturation water vapor pressure over ice at $T_{s}$

$e_{0} \quad$ saturation water vapor pressures over liquid water at $0^{\circ} \mathrm{C}$

h convective heat transfer coefficient

K Stokes number (equation A1.1)

$k_{a} \quad$ molecular thermal conductivity of air

$L_{f} \quad$ latent heat of fusion of water

$L_{s} \quad$ latent heat of sublimation of water

$L_{v} \quad$ latent heat of vaporization of water

Ik King probe wire length

Nu Nusselt number (equation B1.4)

$n \quad$ freezing fraction (equation $\mathrm{B1} .2$ )

$P_{\text {atm }}$ atmospheric pressure

$P_{K} \quad$ King probe power

$P_{d r y} \quad$ dry power term

$R e_{d}$ free stream Reynolds number based on droplet diameter, $=U \cdot D_{d} \cdot \rho_{a} / \mu$

$R_{c y l}$ radius of cylinder

$r$ overall recovery factor 
$r_{\text {of }}$ final radius of cylinder (outside diameter of ice accretion)

$r_{c i}$ initial radius of cylinder (before exposure)

TAS true airspeed

Tair air temperature

To absolute temperature at which water evaporates

$T_{s} \quad$ mean surface temperature

$t$ time step duration

$u$ free stream velocity

$\mu \quad$ dynamic viscosity of air

$\rho_{a}$ density of air

$\rho_{d} \quad$ density of droplet

Pice density of ice

$\sigma \quad$ Stefan-Boltzmann constant $\left(\sigma=5.670 \times 10^{-8} \mathrm{~J}^{\circ} \mathrm{K}^{-4} \mathrm{~m}^{-2} \mathrm{~s}^{-1}\right)$

I exposure time

Tice ice thickness

$T_{\text {ice }}$ average thickness of ice

$\Phi \quad$ Langmuir's parameter $=R_{e}^{2} / K$

ASTM American Society for Testing and Materials

FAA Federal Aviation Administration

i.e. id est (Latin, that is)

JAA Joint Airworthiness Authority

LWC liquid water content

MVD median volumetric diameter

PDPA Phase Doppler Particle Analyzer

RSA real time signal analyzer

SAE Society of Automotive Engineers 


\section{INTRODUCTION}

This thesis reports an experimental assessment of the comparability of several different instruments used for measuring cloud properties in icing wind tunnels. In particular, it includes a careful assessment of the suitability of the multi-rotating-cylinder method for determining median volumetric diameter (MVD) of the cloud droplets in icing tunnels. The experimental work was carried out in the National Research Council's Altitude Icing Wind Tunnel (AIWT) and was motivated by a desire to better understand the AlWT's short and long term repeatability characteristics and calibration methods used for the AIWT. This effort arose because recent inter-facility comparisons between a number of icing

wind tunnels have suggested that improved calibration and benchmarking standards are required to assure that testing and certification work carried out at one facility can be accurately and reliably repeated elsewhere.

The Society of Automotive Engineers (SAE) Aerospace Recommended Practices (ARP) document number 5905 outlines currently recommended calibration and acceptance practices for icing wind tunnel facilities. The ARP 5905 endorses the use of several instruments for use in the baseline calibration of icing wind tunnels. These instruments are used to measure the liquid water content (LWC) and median volumetric diameter (MVD) of icing clouds (see section 2.2 for definitions of LWC and MVD). The accepted instruments for measuring cloud LWC are the icing blade, the single rotating cylinder, and hot 
wire probes such as the King probe. Detailed descriptions of each instrument are presented in section 2.5.1. It was a goal of this research to compare the results of these instruments in order to ascertain any performance limitations that one method may have with respect to the others.

The ARP 5905 endorses the use of several light scattering instruments for the measurement of MVD. Of these, two became available for investigation. These were the Malvern Instruments Spraytec system ('Malvern'), and the TSI Incorporated Phase Doppler Particle Analyzer ('PDPA'); their detailed descriptions can be found in section 2.5.2. Both the Malvern and the PDPA use a laser beam of known wavelength and frequency as well as complicated optics in order to accomplish their measurements. As a result the setup and alignment of the instruments can be tedious, and may cause serious accuracy problems if done incorrectly. It would be desirable to have an MVD measurement technique that is based on simpler physics and that is more directly related to the ice accretion process. Such a technique would be very useful as a primary calibration standard, in much the same way that icing blades or single rotating cylinders serve as calibration standards for the heated sensor instruments commonly used to determine LWC in icing tunnels (ARP-5905). With this in mind, the rotating multicylinder method that was used in early icing studies (Brun et al., 1955 and Howe, 1991) was investigated to see if it could be suitable for use in icing wind tunnels and to examine the robustness and repeatability of the technique. The rotating multicylinder technique is described in section 2.5.2.2 
and the apparatus design as well as the experiments conducted are found chapter 4.

Chapter 3 describes the initial AIWT experiments and begins with a replication of the some of the tests carried out for the inter-facility comparison study mentioned above. Tests using an icing blade, a single rotating cylinder and a King probe are then outlined. As previously mentioned, Chapter 4 presents the multi-cylinder work. It includes comparisons between MVD results obtained with the multi-cylinder method and the aforementioned Malvern and PDPA instruments.

Chapter 5 contains a summary of the results of each of the experiments and a discussion of the findings. Chapter 6 and 7 contain the conclusions and recommendations respectively. 


\section{BACKGROUND AND LITERATURE REVIEW}

This chapter provides background information on the in-flight ice accretion, the icing process, types of ice accretions, and instrumentation used for measuring cloud properties.

\subsection{IN-FLIGHT ICING AND FLIGHT CERTIFICATION}

In-flight icing occurs when an aircraft passes through a cloud of supercooled water droplets. Water droplets can exist in a supercooled liquid state (with a temperature less than $0^{\circ} \mathrm{C}$ ) when there is a lack of nucleation sites to trigger phase transition from liquid to solid (Schulz, 1997). In the case of aircraft icing, the surface of the aircraft causes heterogeneous freezing of the water droplets as they collide with the surface. The resulting ice accretion can cause many serious problems for an aircraft's aerodynamic and mechanical performance.

Ice accretion on the wings, control surfaces and high-lift devices causes a degradation in their aerodynamic performance. An iced airfoil at given angle of attack will produce less lift and more drag than an identical clean airfoil (Van Hengst et al., 1997). The iced airfoil will also have a lower maximum lift coefficient and possibly a more abrupt stall. These aerodynamic penalties lead to potential performance, stability and control problems particularly when the 
aircraft is flying at slow speeds such as during take-off, loiter and landing. Unfortunately, these are the flight regimes that tend to have the highest occurrence of natural icing conditions since the aircraft is often forced to pass through altitudes containing clouds of supercooled liquid water.

Ice tends to build up primarily on the aircraft's leading edges because the curvature of the streamlines is most extreme there. The momentum of the droplets tends to keep them traveling in their original direction and causes them to impinge on the leading edge. Further downstream of the leading edge, the curvature of the streamlines is much less, and the droplets are able to follow the contour around the aircraft's structure.

Aircraft sensors such as pressure and temperature probes protrude into the freestream and tend to become coated with ice, rendering them inoperable. A malfunctioning Pitot probe, coupled with the abrupt stall phenomenon mentioned above can lead to a catastrophic accident, especially if the pilot is unaware of the severity of the icing conditions. As a result, ice detection instruments as well as anti/de-icing devices must be installed and certified on all aircraft that expect to fly through potential icing conditions.

The Federal Aviation Administration (FAA) of the United States, Transport Canada (TC) and the Joint Airworthiness Authority (JAA) of the European Union have issued requirements which must be met by aircraft that are to be certified 
for flight into known icing conditions. These requirements include environmental condition envelopes that must be met for certification purposes (Jeck, 1997); these conditions are based on a large experimental database of weather conditions accumulated over many years of measurements.

\subsection{DEFINITION OF ENVIRONMENTAL PARAMETERS}

There are several environmental parameters that are used to describe the requirements to be met. They are: the cloud liquid water content (LWC), the droplet median volumetric diameter (MVD), the air temperature, and the horizontal extent of icing clouds. The duration of the accretion process is also important of course. The duration of the accretion process is computed by determining the horizontal extent of the cloud that the aircraft is designed to fly through and dividing that value by the velocity at which the aircraft would fly during the particular phase of flight when the cloud is encountered. The cloud LWC is defined as the amount of liquid water (in grams) in a cubic meter of air. It is essentially the density of liquid water contained in the air and has units of $\mathrm{g} / \mathrm{m}^{3}$. The water contained in a cloud is spread over a spectrum or range of droplet sizes. The droplet MVD is defined as the median droplet diameter based on volume, that is, half of the total droplet volume of the cloud is contained in droplets having a diameter less than the MVD and half the total volume in

droplets having a diameter greater than the MVD. The MVD has been shown to give an accurate representation of the effect of the droplet spectrum when 
computing the amount of ice accretion for an object passing through the cloud (Finstad et al., 1988).

The FAA, TC, and JAA regulations for icing certification require demonstration that all affected aircraft components and systems can operate safely in the vast majority of icing conditions that can occur in nature. This is to ensure that the aircraft can operate safely under almost all conditions that might be encountered. Testing in natural icing conditions would require many hours of flight time in efforts to find the appropriate conditions. This coupled with the added danger of flying an iced aircraft makes testing in natural icing conditions the last step in the certification process. During the aircraft design and development phases and in the early certification phase, ground test facilities, notably icing wind tunnels, are used to assess behaviour in icing conditions.

\subsection{DESCRIPTION OF THE ICING PROCESS}

The rate at which ice accretes on aircraft components and the shape of the ice accretions are important in determining the effect of the accretions on performance. Also, the majority of the instruments described in sections 2.5.1 and 2.5 .2 measure cloud properties by determining an ice accretion rate, i.e. the mass of ice to accrete per unit of time. The ice accretion rate is directly related to: the LWC and MVD of the spray cloud, the free stream velocity, the object's collision efficiency, and the type of ice to form on the object. The following two 
subsections will explain the physics of droplet collision efficiency and the mechanics that lead to the formation of different types of ice accretions.

\subsubsection{Droplet Collision Efficiency}

The amount of supercooled liquid water impinging onto the surface of an object is the key quantity that needs to be determined for computing the icing rate. The impingement rate of supercooled water is of particular interest because it dictates the type and volume of ice that will accumulate, as well as the amount of energy that is required to melt the ice, or to keep the surface ice-free (Lozowski et al., 1987 and Makkonen, 1984).

As an object is moving through a cloud, it is sweeping out an effective area of liquid water. Consider the force balance on a single droplet having a diameter that is equal to the MVD of the spray cloud. Assume that this droplet is traveling along a streamline heading towards a cylinder of infinite length. As the streamline bends around the object, the droplet's coefficient of drag $\left(C_{d}\right)$ tends to keep the droplet following the streamline, while the droplet's momentum (or inertia) tends to keep the droplet following its initial course towards the object (see Figure 2.1). Virtually all of the droplets traveling along the streamline that intersects the horizontal axis of the cylinder will strike it; but as the initial distance of the droplet above or below this streamline is increased it will eventually reach

a point where the droplets just graze the surface of the cylinder and do not 
actually impinge on it. The overall collision efficiency of the cylinder $(E)$ is defined (see Figure 2.1) by:

$$
E=y^{\prime} / R_{c y l}
$$

where $R_{c y l}$ is the radius of the cylinder and $y^{\prime}$ is the initial upstream height of the droplet that just grazes the cylinder's surface (Finstad, et al., 1988).

For a detailed presentation of the relations used to compute the collision efficiency for a cylinder in cross-flow see Appendix A. For a fixed set of atmospheric conditions the collision efficiency is inversely related to the radius of the cylinder (see Figure 2.2). The collision efficiency increases as the MVD increases.

\subsubsection{Types of Ice Accretion}

There are three different ice accretion regimes. They are: rime, mixed and glaze. The following section will outline the three types of accretion regimes. The type of ice that accretes on an object is mainly a function of the velocity and air temperature as well as the cloud LWC and MVD. If the temperature is cold enough, and the LWC and MVD are small enough, the droplets impinging on the surface of an object will completely freeze immediately upon contact. This corresponds to a freezing fraction of 1.0 , and the phenomenon is referred to as rime icing. 
When the droplets impinge on a surface and begin to freeze, the latent heat of fusion tends to warm the surface towards $0^{\circ} \mathrm{C}$ (Wagner et al., 1997). This effect is counteracted by the convective heat loss to the ambient atmosphere; hence the surface temperature of the accretion is closely tied to the LWC and the air temperature. Increasing the velocity of the air stream has the effect of increasing the collision efficiency, the rate of water impingement, and also the rate of convective heat loss. These effects tend to counteract one another to a certain extent. Figure 2.3 shows the variation of mean surface temperature (as computed by eq. B1.6) with respect to airspeed for five rotating cylinders with different diameters. In Figure 2.3 the LWC, MVD and static temperature are kept constant throughout all the runs and only the airspeed is changed. Although increasing the airspeed greatly increases the amount of water that impacts the cylinders, the extra convective cooling provided keeps the surface temperature relatively low.

If the rate of water impingement is relatively high, the rate of release of latent heat could exceed the rate of convective heat transfer. In such a case, not all the water would freeze on impact and glaze icing would occur. In glaze icing the freezing fraction is less than 1.0 and the surface temperature is $0^{\circ} \mathrm{C}$. For cases of rime icing, the surface temperature is always below $0^{\circ} \mathrm{C}$, and the ice that forms has a dry, white, opaque appearance. The milky appearance of the ice is often attributed to air bubbles trapped in the ice due to the rapid rate at which the droplets freeze (Wagner et al., 1997). In glaze icing conditions the ice 
accretion is clear and transparent and the surface of the accretion is wet since some of the impinging water remains liquid.

As mentioned above, as the LWC or air temperature is increased a point will be reached where not all of the impinging water freezes on contact. In this case the freezing fraction is less than one, and this marks the onset of mixed icing conditions; that is, some regions on the accretion are glaze icing while others are rime icing. During mixed and glaze icing conditions the droplets have a tendency to impact then run-back before completely freezing. The extent of the run back is a function of the air velocity and size of the droplets. This runback tends to freeze at a spot downstream of the stagnation point where convection to the atmosphere cools the water enough for it to freeze. Mixed ice accretions may have a region of clear glaze ice along the stagnation line surrounded by horns of mixed ice; the tips of the horns may be rime ice since the convective heat transfer is highest at that point (see Figure 2.4). The forward facing surface of the ice is covered with intricate crevasses that form as a result of the runback collecting into rivulets and freezing onto the rougher regions of the accretion (See Figure 2.5).

If the LWC or temperature is increased such that the freezing fraction falls below roughly 0.3 then the accretion is entirely composed of glaze ice. Glaze ice has a double-horned appearance just as mixed icing and tends to be clear and transparent (Macklin, 1962). Since the freezing fraction is so low, some of the 
water that impacts the object is likely to run back and may actually blow off the accretion. This phenomenon is present to a lesser extent in mixed icing. The impinging water lost to blow off is a problem for the methods described in the latter part of this chapter because the ice accretion rate is computed from the total amount of liquid water collected during the run. The missing water would clearly cause a source of error. For this reason, calculations were done to ensure that the test conditions were appropriate for rime icing conditions only (as per Makkonen, 1984). The computations will be described in detail in Appendix B.

\subsection{ICING WIND TUNNELS}

Icing wind tunnels are similar in operation and design to conventional wind tunnels, with the added complication of a spray system and refrigeration system. There are typically two types of icing tunnels; they are open-circuit and closedcircuit tunnels. The main components of an open circuit icing tunnel in order from inlet to outlet are: a bellmouth, settling chamber, heat exchanger, spray bar system, contraction, test section, diffuser, fan and outlet. Closed-circuit tunnels have a comparable configuration, only the settling chamber and outlet are linked by ducting. In the case of the Altitude Icing Wing Tunnel (AIWT) of the National Research Council of Canada (NRC), which is a closed circuit tunnel, the diffuser leads the flow directly into the turning vanes of the 1st corner, and the fan is located after the second set of turning vanes. The flow is then turned by the $3^{\text {rd }}$ 
corner and passes through the heat exchanger before turning one last time and passing through the spray bar system (See Fig 2.6) (Oleskiw et al., 2001).

The spray systems of icing tunnels vary from one facility to the next although there are several trends that are evident. The spray nozzles are usually arranged in some sort of repeating pattern in order to produce a uniform cloud downstream in the test section. The position of the nozzles may be variable by the use of spacers in order to achieve cloud uniformity. There are two different types of nozzles used to atomize the liquid water; they are internal mix and external mix nozzles. Internal mix nozzles contain a mixing chamber before the orifice from which the spray emerges; while in external mixing nozzles the fluid orifice and atomizing air meet at the exit of the plane of the nozzle (see Fig. 2.7). There is no real evidence to support the use of one particular type of nozzle over the other, but the calibration curves for each are considerably different so the choice of one type is necessary. The AlWT uses stainless steel commercial external mix nozzles from Spraying Systems Inc. The water nozzles are type PF2050S and the air caps are PA120 (see Fig. 2.8). The nozzles are typically set up on spray bars in order to compensate for head loss with as little control equipment as necessary. The AIWT has six horizontal spray bars with seven nozzles per bar placed in a symmetrical pattern about the tunnel's horizontal and vertical axis. The individual nozzles can be turned on and off depending on the cloud conditions and size required for a particular test. For example, every other nozzle could be turned off in order to create a very low LWC spray cloud, or a 
cluster of nozzles can be used to concentrate the cloud along the tunnel centerline. The water and air lines leading to each of the nozzles are the same length to minimize the flow difference from one nozzle to the next.

In order to vary the size of the MVD of the spray cloud generated the airflow rate through the nozzles is varied while keeping the water flow rate constant. The MVD is inversely proportional to the airflow rate.

The presence of impurities in the liquid water may act as nucleation sites or "motes" and facilitate the freezing of droplets (Schulz, 1997). As a result the water is typically filtered or distilled (or both) in order to prevent such droplet freeze-out. The atomizing air is filtered for the same reason. Freeze-out is also prevented by heating the water and atomizing air as described in Section 2.6 .

\subsection{INSTRUMENTATION FOR MEASURING CLOUD PROPERTIES}

The following section will describe several instruments that are used to measure cloud properties. Each following subsection will include a physical description of the instrument as well as some background on the theory behind its operation. 


\subsubsection{Instrumentation for Measuring LWC}

The following subsection gives background theory of several instruments used to measure the liquid water content of clouds. These instruments are the icing blade, the single rotating cylinder and the King probe. The icing blade and the single rotating cylinder measure the cloud LWC by determining the rate at which ice accretes, while the King probe functions by measuring the power required to keep a hot-wire at a constant temperature. The icing blade and single rotating cylinder must operate at conditions that would lead to rime ice accretion, while the King probe works best near $0^{\circ} \mathrm{C}$ to facilitate anti-icing of the instrument support structure.

\subsubsection{1 /cing Blade}

The icing blade is a conventional standard used for determining the LWC of a spray cloud. It is the accepted calibration method used at the NASA Glenn Icing Research tunnel, as well as at many other facilities. The icing blade is simply a flat rectangular plate two inches wide by six inches long by one-eighth inch thick (see Figure 2.9). The plane of the blade is aligned with the flow direction. The blade is usually placed inside a sheath of some sort so that it may be easily and quickly inserted and retracted to and from the test section centerline. The supports for the blade and sheath must be strong enough to 
prevent vibration throughout the range of velocities over which the blade is to be used.

The icing blade technique requires that the blade be exposed to the spray cloud for an amount of time sufficient to accrete between two and four millimeters of ice on the leading edge of the blade. Measuring the thickness of the ice and knowing the amount of time it took to accrete that amount, the LWC of the spray cloud can be determined as outlined below (appendix A.1 of SAE-ARP-5905):

$$
L W C_{\text {blade }}=\frac{\rho_{\text {ice }} \tau_{\text {ice }}}{E_{\text {blade }} U \cdot \tau}
$$

Where:

$\rho_{\text {ice }}=$ density of ice, $=880 \mathrm{~kg} / \mathrm{m}^{3}$

$\tau_{i c e}=$ thickness of ice accreted on blade as shown in fig 2.9

$E_{\text {blade }}=$ collision efficiency of the blade

$U \quad=$ freestream velocity

$\tau \quad=$ exposure time

The ice density of $880 \mathrm{~kg} / \mathrm{m}^{3}$ is recommended in SAE-ARP-5905. Many experiments have been carried out to assess the average density of ice accretions. The collision efficiency of the blade is determined as outlined by Stallabrass, (1978) in his interpretation of Langmuir et al., (1946).

Stallabrass first computes Stokes' parameter as defined in equation (A1.1) in Appendix A of this thesis. For small values of Stokes' parameter, i.e. if $K \leq 1.1$ 
he derives a working form of Langmuir's equation (40) using the droplet Reynolds number rather than the range. This has been presented as equation (A1.8) of this thesis.

If $(\mathrm{K} \leq 1.1)$

$$
K_{o}=0.125+\frac{(K-0.125)}{\left(1+0.1206 \operatorname{Re}_{d}^{0.59}\right)}
$$

Then the collection efficiency of the icing blade is given by Langmuir's equation (54):

$$
E_{\text {blade }}=1.35 \cdot\left(\log 8 K_{o}\right)^{2}
$$

However, for larger values of Stokes parameter, i.e. $K>1.1$ Stallabrass uses Langmuir's equation (57):

If $(K>1.1)$

$$
H_{E}=0.48+0.046 \cdot \operatorname{Re}_{d}{ }^{0.63}
$$

The collection efficiency is given by Langmuir's equation (56):

$$
E_{\text {blade }}=\frac{K}{\left(K+H_{E}\right)}
$$

Figure 2.10 of this thesis shows the collision efficiency of the icing blade for various airspeeds and MVDs. The calculations were done at standard atmospheric pressure with an ambient air temperature of $-20^{\circ} \mathrm{C}$. Stallabrass found that the collision efficiency varies negligibly (roughly $0.75 \%$ ) as the 
temperature is changed from $-10^{\circ} \mathrm{C}$ to $-20^{\circ} \mathrm{C}$. The majority of the testing described in section 3.2 of this thesis using the icing blade was performed at either $-18^{\circ} \mathrm{C}$ or $-23^{\circ} \mathrm{C}$. Consequently $-20^{\circ} \mathrm{C}$ seems a suitable temperature to use when computing the collision efficiency of the blade.

\subsubsection{Single Rotating Cylinder}

The single rotating cylinder is similar to the icing blade as it is used to determine an ice accretion rate that is then used to determine the LWC of the spray cloud. One advantage of the rotating cylinder is that the ice which accretes is also cylindrical, so the theory used to compute its collision efficiency remains true and accurate. The rotating cylinder also has the advantage that it may be easily inserted to the test section centerline via a small window in the wall of the tunnel. This makes it easy to perform multiple trials without having to stop the tunnel. For these reasons, the single rotating cylinder is the accepted LWC calibration method used by the NRC-AIWT.

The single rotating cylinder used at the NRC's AIWT is $50.4 \mathrm{~mm}$ long and has a diameter of $2.41 \mathrm{~mm}$. The cylinder fits snugly onto a shaft that attaches to a motor used to rotate it at approximately $1 \mathrm{~Hz}$. The shaft has a bushing whose position can be adjusted so that the cylinder is located on the tunnel centerline when the bushing touches the outside window of the tunnel (see Figure 4.6). 
The single rotating cylinder may be used to compute the LWC of the spray cloud using equation 4 of Stallabrass, (1978). That is

$$
L W C_{c y l}=\frac{\pi \rho_{i c e}}{E_{c y l} U \cdot \tau}\left(r_{c f}-r_{c i}\right)
$$

where:

$$
\begin{array}{ll}
\rho_{i c e} & =\text { density of ice, }=880 \mathrm{Kg} / \mathrm{m}^{3} \\
r_{c f} & =\text { final cylinder diameter (outside diameter of ice accretion) } \\
r_{c i} & =\text { initial cylinder diameter (before accretion) } \\
E_{c y l} & =\text { collision efficiency of the cylinder } \\
U & =\text { freestream velocity } \\
\tau & =\text { exposure time }
\end{array}
$$

The mass of the ice accretion can be expressed as a function of its inner and outer radius by:

$$
m_{i c e}=2 \pi \rho_{i c e} l_{c y l} \int_{c i c}^{c o} r \cdot d r=\pi \rho_{i c e} l_{c y l}\left(r_{c f}{ }^{2}-r_{c i}{ }^{2}\right)
$$

Where:

$l_{c y l} \quad=$ length of cylinder

So the final radius of the cylinder is given by:

$$
r_{c f}=\sqrt{\frac{m_{i c e}}{\pi \rho_{i c e} l_{c y l}}+r_{c i}^{2}}
$$

Now substituting (2.8) into (2.6), the LWC of the cloud can be determined without the need to measure the outside diameter of the ice: 


$$
L W C_{c y l}=\frac{\pi \rho_{i c e}}{E_{c y l} U \tau}\left(\sqrt{\frac{m_{i c e}}{\pi \rho_{i c e} l_{c y l}}+r_{c i}{ }^{2}}-r_{c i}\right)
$$

The use of equation (2.9) is preferred over (2.6) because accurately measuring the outside diameter of the ice accretion is far more difficult than accurately measuring its mass. This is mainly because the use of chilled micrometers introduces a source of error since the force used to take the measurement can greatly affect the result. The ice is extremely fragile and is easily crushed by the calipers. The calipers also have a tendency to melt the accretion even though they have been chilled and gloves are used.

The collision efficiency of the cylinder, $E_{c y l}$, is computed as presented in Appendix $A$ and the density of the ice is determined as outlined by Jones (1990).

Accurate assessment of the density of the ice accretion is necessary for accurately determining the collision efficiency of the cylinder. A lower ice density will result in a larger accretion thereby slightly reducing the collision efficiency. The density also has a first order effect on the LWC as shown in equation (2.9). Stallabrass, (1978) found that the average density of the ice accreted on the rotating cylinder was $880 \mathrm{~kg} / \mathrm{m}^{3}$ throughout his investigations at the NRC's ANT. Jones, (1990) presents a correlation for computing ice accretion density using non-dimensional parameters to collapse years of icing data from the Mt. Washington observatory onto a single curve. The details of determining the non- 
dimensional parameters by the Buckingham- $\mathrm{Pi}(\pi)$ theorem will be omitted here since they are presented clearly in Jones' paper. Ultimately, 12 non-dimensional parameters were found for analyzing the ice accretion density (Jones, 1990 , table 2). Of these, $3 \pi$ products are used in the correlation presented by Jones as equation ( $(9)$ of her paper:

$$
\pi_{C}=\frac{k_{a}\left(-T_{\text {air }}\right) / D_{\text {mean }}}{L W C \cdot U \cdot L_{f}}
$$

where:

$k_{\alpha} \quad=$ molecular conductivity of air

$T_{\text {air }} \quad=$ atmospheric temperature

$D_{\text {mean }}=$ mean diameter of accretion $=\left(r_{c f}+r_{c i}\right)$

$L_{f} \quad=$ latent heat of fusion of water

$\pi_{K}=$ Stokes parameter (as shown in equation 2.2)

and,

$\pi_{\phi}=$ Langmuir's parameter (as shown in equation 2.3)

The density of a rime ice accretion can be computed by:

$$
\begin{aligned}
& \rho_{\text {ice }}=0.249-0.0840 \ln \pi_{C}-0.00624\left(\ln \pi_{\phi}\right)^{2}+0.135 \ln \pi_{\mathrm{K}}+ \\
& +0.0185 \ln \pi_{\mathrm{K}} \ln \pi_{\phi}-0.0339\left(\ln \pi_{\mathrm{K}}\right)^{2}
\end{aligned}
$$




\subsubsection{King Probe}

The King probe is a type of hot wire anemometer used for measuring cloud LWC. The sensor head of the instrument is a two-pronged fork that holds the hot wire sensor (see Figure 2.11). The unit can accurately measure the LWC over a range of operating conditions. These conditions are: true airspeed from 60 to $100 \mathrm{~m} / \mathrm{s}$, altitude from 0 to $12 \mathrm{~km}$, air temperature from $-40^{\circ} \mathrm{C}$ to $+40^{\circ} \mathrm{C}$, and relative humidity from 0 to $100 \%$ (CSIRO-KING Operating Manual). The twopronged fork is used to hold the sensor element in the undisturbed free stream, and the sensor element itself is composed of three coils of 38 gauge copper wire wrapped around a stainless steel tube (see Figure 2.12). The central master coil is approximately $20 \mathrm{~mm}$ long and has a resistance of $2.1 \mathrm{ohms}$. The two slave coils on either side of the master are exactly half its length and resistance. The probe functions by keeping the master coil at a constant temperature. The slave coils are connected to each other in series and are placed in a parallel circuit with the master. As a result they are forced to the same temperature as the master and are used to minimize axial heat loss due to conduction. The amount of power required to maintain a constant temperature in the master coil is then proportional to the sum of the convective heat loss to the ambient atmosphere and the heat lost due to evaporating the impacting liquid water. The LWC of the spray cloud can be determined as presented in appendix A.3 of SAE-ARP-5905. That is

$$
L W C_{K}=\frac{\left(P_{K}-P_{d r y}\right)}{\left[\left(T_{e}-T_{a i r}\right) c_{w}+L_{v}\right] D_{K} l_{K} U \cdot E_{k}}
$$


where:

$P_{K} \quad=$ King probe total power

$P_{d r y}=\mathrm{dry}$ power term

$T_{e} \quad=$ absolute temperature at which water evaporates $\left(90^{\circ} \mathrm{C}-100^{\circ} \mathrm{C}\right)$

$T_{\text {air }}=$ absolute static temperature of air, equal to droplet impingement temperature

$c_{w} \quad=$ specific heat capacity of water

$L_{v} \quad=$ latent heat of vaporization of water

$D_{K} \quad=$ king probe wire diameter

$l_{K} \quad=$ king probe wire length

$U \quad=$ free stream velocity

$E_{K} \quad=$ collision efficiency of King probe wire

Theoretically, the dry power term $\left(P_{d r y}\right)$ can be computed as a function of the true airspeed and the temperature difference between the King probe wire and the static temperature. In practice however, it is simpler and more accurate to 'zero' the probe before the spray is turned on (if the probe is mounted to an aircraft, this can be accomplished by flying through dry air). The collision efficiency of the King probe wire $\left(E_{K}\right)$ is determined as shown in appendix $A$ of this thesis. 


\subsubsection{Instrumentation for Measuring MVD}

There are many methods available for measuring the median volumetric diameter (MVD) of a cloud. They range in complexity from physically catching the droplets using the momentary exposure of an oil slide to commercially available laser scattering equipment. Each method is faced with its own limitations and sources of error. This Section will briefly describe two light scattering instruments (the Malvern and the PDPA) and will give a detailed description of the multi-rotating cylinder method for determining LWC and MVD.

\subsubsection{Light-Scattering Instruments}

The Malvern Instruments Spraytec particle size analyzer is a laser based system capable of measuring droplet size distributions in aerosol sprays and jets. Depending on the focal length of the receiver lens the Spraytec can be used to measure particles from 0.5 to 1000 microns. The receiver lens configuration used for the tests described in this thesis had a focal length of $200 \mathrm{~mm}$ and is capable of measuring distributions with an MVD of 5-250 microns. The transmitter and receiver are set up on opposite sides of the test section with the transmitter pointed directly into the receiver. In order to aid in aligning the instrument, the transmitter and receiver were mounted on a bench rather than on two separate pedestals (see Figure 2.13). This had the added effect of keeping 
the transmitter and receiver aligned after the alignment procedure was completed.

The Spraytec system uses a detector which has 32 concentric rings in order to measure the scattering effect that the spray cloud has on the laser beam. When the instrument is initially set up and no spray is present, the laser is focused so that all of the beam, strikes ring zero in the center of the detector and no signal is picked up by the other rings. The case with no signal on rings 1-32 is an idealized case since background light, slight blemishes on the lenses, and electronic noise are present which make it next to impossible to achieve in practice. Consequently a tare of the time average electronic noise and background light can be taken that corrects the measured signal. The electronic noise reading is taken with the spray and laser turned off so that any fluctuations in the signal picked up by each of the rings are solely a function of the noise itself. The background reading is taken with the spray off and the laser on so that any scattering due to imperfections in the lenses or blotches on their surface would be removed. However, this is not intended to be used as a substitute for cleaning the lenses and keeping them free of debris.

Once the instrument has been correctly aligned and setup the spray can be turned on and particle size measurements can be taken. The spray cloud causes the laser beam to scatter and the intensity of the scatter is measured on the concentric rings. The data reduction software interprets the intensity 
measured on each of the rings and determines a droplet spectrum that would produce such a scatter pattern. Passing the beam through a highly concentrated spray causes the beam to experience multiple scattering; however the software contains an algorithm that corrects for this.

The setup of the Spraytec system can be checked with the use of the RS3 Reference Reticle. The reticle is an ASTM (American Society for Testing and Materials) standard for referencing laser diffraction equipment. The reticle is a clear glass block that contains a series of laser markings that are representative of a droplet spectrum. When the reticle is placed along the laser's path and perpendicular to it, the output from the data reduction software should match the known size distribution of the reticle. Although the reticle is not capable of fully calibrating the Spraytec, it does check a specific point of operation and gives a good indication of whether the instrument is properly configured.

While the Spraytec is operating it continuously records a time history of the particle size distribution in a data file. Many process control variables can be displayed; however, for the purpose of icing tunnel calibration only the MVD, the $10 \%$ and $90 \%$ cumulative particle size distribution, and the transmission are used. The $10 \%$ and $90 \%$ cumulative particle size distribution are displayed to give an idea of the droplet spectrum and to show the presence of tails with large droplets. The transmission is displayed because the percentage of beam intensity received at the detector is an important factor in deciding whether the 
data is acceptable. For example if the cloud is too dense or too sparse the quality of the measurements taken will be compromised. The data reduction can be controlled by the user with a series of parameters. These include the scattering limits (which detector rings are used in the computation), the size limits and resolution of the bins that define the droplet spectrum, the solution residual and several options to do with the multiple scattering algorithm. Tags can be inserted in real-time in order to mark the beginning of test points to aid post processing. After testing has been completed the time history is saved to the hard drive and the data can be reassessed. The reduction controls mentioned above are not retroactive so they only affect records taken after they are changed, however, time averages over a range of the history can be produced and used as test point data.

The Phase Doppler Particle Analyzer (PDPA) was invented in 1982 as a method to characterize the atomization and mixing of fuel sprays in gas turbine combustors. The device is able to accurately take measurements of particle size and velocity in hostile environments without disturbing the flow or the particles themselves. For these reasons the PDPA has become a worldwide standard for spray measurements (SAE RevisedPDI3-10-04). Since its inception the PDPA has been utilized for many different spray measuring applications including the characterization of icing clouds. A flight-worthy version of the instrument has been developed and the ground based unit has been used for the calibration of icing wind tunnels. 
The PDPA measures the size and velocity of one droplet at a time using a solid state laser (SAE RevisedPDI3-10-04). The beam is split into two parallel beams of equal intensity with a known phase shift between them. The beams are then focused using a lens to cross their paths and the receiver is set up on the opposite side of the test section at a $40^{\circ}$ incidence from the incoming laser beam, looking upstream. The receiver optics contain a small slit which is focused on the point where the beams cross and the sample volume is then defined as a cylindrical region with a diameter equal to the focused beam diameter and length equal to the aperture of the slit (see Fig 2.14).

When a particle passes through the sample volume a Doppler burst is generated as shown in figure 2.15. The Doppler burst is picked up by the receiver using three sensors that are a known distance apart which are located behind the aperture slit. The phase shift measured by the detectors is directly proportional to the size of the droplet that produced the burst. Using three receivers removes the uncertainty as to whether or not the phase difference measured between two detectors are from the same fringe or not. A fringe corresponds to a measured phase shift of $360^{\circ}$. As shown in Figure 2.16, detectors 1 and 2 are a known distance apart and measure a phase difference $\Phi_{12}$, and detectors 1 and 3 are a further distance apart and measure a phase shift of $\Phi_{13}$. Using a phase diagram such as that of Figure 2.16 , the droplet 
diameter is determined as a function of $\Phi_{12}$ and $\Phi_{13}$. A detailed description of the physics involved is available in section 7.1 of SAE RevisedPDI3-10-04.

Once the transmitter and receiver are aligned properly and the amplitude and phase shift of the beams have been correctly set several calibration and assessment routines must be run in order to ensure that all systems are functioning correctly. These routines are well documented in the operations manual. After all the checks are completed but before any measurements can be taken the user must set several data acquisition parameters in order to tailor the instrument's operation to a given operating condition. Setting these parameters is not essential, however it was found that fine tuning them improved the data collected using the instrument. (For example the number of valid samples and the percentage of valid samples increased). The two parameters found to most affect the data collected are the data sample rate and the low-pass filter. The sample rate is the frequency at which the real time signal analyzer (RSA) samples data. The sampling rate should be at least twice the Doppler frequency (as defined on page 3-6 of the PDPA operations manual) in order to ensure that the incoming signal is read with a high enough resolution. The lowpass filter (LPF) attenuates frequencies above its value, so correctly determining the LPF will aid in eliminating background noise from the signal. The LPF is a function of the sample frequency and is derived on page 3-8 of the PDPA operations manual. The Doppler frequency is a function of the estimated maximum particle velocity (in this case the true airspeed in the test section) and 
the beam properties. Thus when either of these values changes the sample frequency and the LPF must be recomputed.

\subsubsection{Rotating Multicylinder Method}

The rotating multicylinder method can be used to determine the liquid water content and the median volumetric diameter of a cloud. The apparatus for the method is simply a series of rotating cylinders of different diameters (see Figure 4.5). Because of this, it is an extremely cost effective method when compared to light scattering instruments. The technique works on the principle that cylinders of different diameters have different ice accretion rates due to their respective collision efficiencies. The ice accretion rate is also a function of airspeed, atmospheric pressure, atmospheric temperature, LWC and MVD. If all the cylinders are exposed to the same cloud conditions and their diameters are known the only remaining unknowns are the cloud LWC and MVD since the other parameters can be easily measured. A fairly straightforward computer code can be used to compute the LWC and MVD that would account for the ice accretion rate measured by the cylinders. Theoretically, only two cylinders of different diameters are required for the technique to function, but more cylinders are used to minimize error.

Although the multi-rotating cylinder method has not been routinely used in icing wind tunnel work, it has been used at the Mt. Washington observatory, 
Gorham, New Hampshire for many years as a tool for meteorological studies (Howe, 1991). Several graphical and computational methods have been developed for the data reduction of the multi-cylinder results, and the method employed herein is based on that of Makkonen, (1991). In order to compute the LWC and MVD of a cloud, several cylinders of known diameter, length and mass are used to accrete ice for a measured amount of time. The cylinders are then weighed in order to determine the mass of the ice accretion. The exposure duration is denoted $\tau$. Additionally, the atmospheric temperature $T_{\text {air }}$, atmospheric pressure $P_{a t m}$, and airspeed $U$ must be known so that a time dependent model can be used to compute the theoretical mass of ice that should accrete on the cylinders during the exposure time. A modified version of Makkonen's, (1984) time dependent model is used in the present work for computing the theoretical mass of ice to accrete. This model is presented in Appendix $B$ of this thesis.

Since the dimensions of the cylinders and the atmospheric conditions are known, the theoretical mass can be computed for each cylinder (Makkonen, 1991). Various values of LWC and MVD are methodically tried in order to find the values which give the best fit to the measured accreted ice masses. For the purpose of systematically converging on the LWC and MVD that produced the measured ice accretion it is best to begin with small values of both parameters (for example LWC $=0.1 \mathrm{~g} / \mathrm{m}^{3}$ and MVD $=0.1 \mu \mathrm{m}$ ). The measured masses are then plotted versus the theoretically accreted masses and a weighted least- 
squares linear regression is performed to determine the slope of the line through the origin as well as the correlation coefficient. The scaling parameter used as a weighting factor for the linear regression is the actual measured mass itself. Several other weighting functions were tested but the mass was determined to return the best results. The weighted least-squares linear regression method is presented in Appendix C. Once the correlation coefficient is determined, the hypothetical MVD is incremented by 0.1 , without changing the hypothetical LWC, and a new set of theoretically accreted masses is computed. The new theoretically computed masses are again plotted against the measured accreted masses and a new slope through the origin and correlation coefficient are determined. This process continues until the correlation coefficient reaches a maximum value and then the LWC is corrected by multiplication with the slope of the best fit line. Once the LWC has been adjusted the computation begins again using the new LWC and a small MVD (again assume MVD $=0.1 \mu \mathrm{m}$ ). The cycle continues until the change in LWC becomes insignificant or the slope of the line at the maximum correlation coefficient becomes 1.00 . A tolerance of $0.01 \mathrm{~g} / \mathrm{m}^{3}$ on LWC is used for a convergence criterion, although this value may need to be adjusted for some cases where convergence to this tolerance cannot be achieved.

A complete LabView ${ }^{\mathrm{TM}}$ version of the data-reduction code is available on the $C D$ that accompanies this thesis. 


\subsection{CALBRATION OF ICING MIND TUNNELS}

Since icing wind tunnels are to be used to simulate natural conditions in controlled environments for the purpose of aircraft certification, much labor and care must be used in their calibration and maintenance. A comprehensive guideline has been produced by the Society of Automotive Engineers (SAE) for the calibration and maintenance of icing wind tunnels. The document: Aerospace Recommended Practices 5905 (SAE-ARP 5905, 2002) outlines the procedures for the calibration of tunnel instrumentation, aero/thermal calibration, and spray cloud calibration.

The calibration of the tunnel instrumentation is essential to proper operation. Instruments such as temperature sensors (thermocouples or resistance temperature devices (RTDs)), pressure transducers, and flow meters must be kept well calibrated to ensure that test conditions can be met with repeatability. Data acquisition systems and signal conditioners require similar attention. The calibration of all instrumentation should be traceable to a national standards setting agency.

According to ARP-5905, MVD calibrations should be conducted along the tunnel's centerline inside the test section using one of the accepted instruments described in SAE AR4906. These instruments are an FSSP (Forward Scattering Spectrometer Probe), OAP (Optical Array Probe), PDPA (Phase Doppler Particle 
Analyzer), or a Malvern Particle Size Analyzer (SAE-ARP 5905 Sect. 6.2.5). There are several possible ways to go about MVD calibration, but one of the most accepted approaches is to choose an operating airspeed, then select a given spray water flow rate and vary the air flow rate to the spray nozzles and record its effect on the MVD. The MVD tends to be inversely proportional to the airflow rate, so a high flow rate of air tends to break the water stream into smaller droplets (atomization). MVDs occurring in natural icing conditions are typically on the order of 15-25 microns (Jeck, 1997). Depending on the airspeed and LWC requirement of the test, the flow rates of water and air through the nozzles can get quite high. The danger in this is that the atomizing air pressure will have to be very high, and when the air undergoes isentropic expansion to atmospheric pressure its temperature will drop to very low values, possibly causing droplet freeze-out and crystallization (Marek, 1988). To avoid this, the air and water flowing to the spray bars must be heated. Heating the air and water also has the benefit of keeping the lines from freezing when testing at extremely low temperatures. In order to meet accepted calibration standards, the MVD along the centerline of the test section must be measured to an accuracy of $\pm 10 \%$ with a temporal stability of the same value (SAE-ARP 5905 sect. 5).

The LWC calibration must also be performed on the geometric centerline of the tunnel test section. Accepted instruments for carrying out the LWC calibration are the icing blade, the single rotating cylinder, or a hot-wire type probe such as the King probe for example. Each of these instruments has been 
discussed in greater detail in previous sections of this thesis. The uniformity of the LWC throughout the test section must be verified to be within $\pm 20 \%$ of the centerline value. The uniformity of the spray cloud is confirmed with either a traverser sweep of a hot-wire probe or by the use of an icing grid that covers the entire test section. The temporal stability (LWC fluctuations with time) on the test section centerline must also be within $\pm 20 \%$ of the desired value (SAE-ARP 5905 sect. 5).

An important part of the present thesis work consisted of an assessment of the suitability of the rotating multicylinder technique for measurement of LWC and MVD in icing wind tunnels for calibration purposes. This work is reported in chapters 4 and 5 . 


\section{DESCRIPTION OF INITIAL AIWT EXPERIMENTS}

This chapter describes the initial experiments which were carried out at the NRC's AIWT in order to investigate the potential causes of the discrepancies between the AIWT results and those of other facilities, found in an inter-facility comparison study. These experiments involved a replication study of several of the inter-facility test cases and a comparison of icing blade, single rotating cylinder and King probe measurements.

Six icing wind tunnels, including the AIWT, were involved in an inter-facility comparison study where three standard models were passed between the facilities and nominally identical test conditions were used at each facility to accrete ice on the models. This study was facilitated by the SAE. The three models were a cylinder with a diameter of 1.5 inches, and two NACA 0012 airfoils with a chord length of 12 and 36 inches. A series of test points were examined that covered a range of conditions from glaze to rime icing at two different operating speeds. The cross-sectional profile of the ice accretions was taken at the centerline of the tunnel and 2 inches to either side in each facility. All the tracings were digitized and subsequently compared. The results of the inter-comparison study showed that although the spanwise uniformity was acceptable, a number of the facilities were consistently producing either larger or smaller ice shapes than the others. These results will be presented at a later date in a report that is being prepared by the SAE AC-9C (the Icing Technology 
Sub-Committee). In general certain scatter is to be expected in the ice shapes generated, but some of the ice shapes being produced differed by as much as $100 \%$ in cross-sectional area from one facility to another.

It was reasoned by the facility operators that the discrepancies in the generated ice shapes was likely not caused by standard tunnel operating instrumentation such as thermocouples (air temperature) or pressure transducers (operating airspeed). The source of the disagreement in the results from one facility to another was considered to be most probably due to errors in the calibration of the spray system resulting in errors in either the LWC or the MVD, or both. An internal memo of the SAE AC-9C suggested that the discrepancy in the volume of ice generated by the facility with the largest accretions could be caused by an error in the LWC or MVD of roughly 30\% (Anderson, 2003). This hypothesized overestimation of cloud parameters was arrived at by comparing the experimentally measured thickness of the ice accretions along the stagnation line with the expected analytically determined stagnation line thickness. The analytic stagnation line thickness was computed using the stagnation line collision efficiency and the freezing fraction as determined using Messinger's (1953) energy balance. As a result of these conclusions it was reasoned that an investigation into the instrumentation used to measure the cloud properties in icing wind tunnels during calibration and operation might yield some explanation as to why the volume of ice generated varied by large amounts from facility to 
facility. The AIWT experiments outlined in this chapter were motivated by these considerations.

Many physical changes had been made to the spray bar system at the AlWT between the time that the inter-comparison tests were completed and the present work began. The positions of the spray bars were changed as well as the number of nozzles and water and air lines that lead to each of them. This meant that replicating the conditions generated during the inter-comparison tests (and thus the ice shapes generated) could not be accomplished by simply running the same water and air flow rates through the nozzles. Consequently, tests were undertaken to attempt to replicate the ice shapes generated during the inter-comparison study. The motivation for this testing was that once the ice shapes were replicated the LWC and MVD could be varied to determine their effect on the cross-sectional profile of the ice.

After the test results were successfully replicated and the effects of a potential calibration error on the cross-sectional profile of the ice generated were understood, additional tests were carried out comparing several instruments outlined in ARP-5905 for measuring cloud properties. In particular, tests which focused on the measurement of the LWC were conducted, comparing the single rotating cylinder with the icing blade, and the single rotating cylinder with the King probe. The results of these experiments are presented and discussed in Chapter 5. 


\subsection{REPLICATION OF INTER-FACILITY COMPARISON STUDY RESULTS FOR THE $1.5^{\prime \prime}$ DIAMETER CYLINDER}

As mentioned previously, these tests were performed because the spray bar system at the AIWT had been modified since the time that the original interfacility comparison tests had been done. Another motivation for the investigation is to attempt to confirm the hypothesis that a $30 \%$ error in either the LWC or MVD could be responsible for the large volumes of ice produced at the AIWT. Due to limitations in tunnel availability for the tests it was decided that only three of the cylinder test cases would be used in the replication study. These test conditions are listed in Table 3.1; SAE Case 1, 3, and 9 refer to the designations used during the SAE inter-facility comparison study. The tests were carried out with a replica of the original inter-facility comparison polished stainless steel cylinder having a diameter of 1.5 inches. The cylinder was mounted in the second test section bay along the centerline of the AWT, and was secured to the Plexiglas side windows using bolts. The items used in the replication study are shown in Figure 3.1. The normal AIWT procedures were used in the testing and to make and process the ice tracings. These procedures are outlined in Appendix D.

The results of the inter-facility comparison replication study are presented in section 5.1. The replication of the results generated by the AIWT during the inter-facility comparison was successful for the 3 cases considered. Trends 
relating the MVD to ice accretion geometry and volume are also discussed in section 5.1

\subsection{PROCEDURES FOR ICING BLADE LWC VS. SINGLE ROTATING CYLINDER LWC MEASUREMENTS}

The icing blade and the single rotating cylinder have become the standard benchmark methods for measuring the liquid water content of a spray cloud in icing wind tunnel facilities. Both methods are considered accepted methods for calibration by the ARP-5905. It is rare however that both methods are used simultaneously in the calibration procedures of a particular facility. Although the two techniques are considered interchangeable, limited published data exists comparing the icing blade with the single rotating cylinder (Ide, 1999). The purpose of this set of experiments was to determine if any limitations could be found for one of the methods over the other over the range of test conditions used in the inter-facility comparison study. That is to test whether or not the techniques are comparable at airspeeds of $67 \mathrm{~m} / \mathrm{s}$ and $90 \mathrm{~m} / \mathrm{s}$ since these were used in the original inter-facility comparison study.

The icing blade was manufactured as specified by the ARP-5905; a flat plate, six inches long, 2 inches wide, by one-eighth of an inch think. The blade was mounted so that it could be quickly be extended and retracted from an aerodynamic sheath using two rods and a handle. The use of the aerodynamic 
sheath reduced errors associated with timing and flow stabilization that would have occurred if the blade were simply mounted in the tunnel and the spray was turned on. The icing blade apparatus is shown in Figure 3.2. The single rotating cylinder is $50.4 \mathrm{~mm}$ long, has a diameter of $2.41 \mathrm{~mm}$, and fits snuggly onto a shaft that attaches to the handheld gun used to rotate the cylinder at 60 revolutions per minute. An aerodynamic sheath is used for the single rotating cylinder for the same reason that one is used for the icing blade. The apparatus for the single rotating cylinder is similar to what is shown in Figure 4.6. Figure 4.6 shows cylinder \#2 of the rotating multicylinder set which has a diameter that is larger that that of the single rotating cylinder.

The sheaths for the icing blade and the single rotating cylinder were set up so that they faced each other across the tunnel's test section. With the sheaths mounted in this fashion, both techniques could be run in succession and were exposed to virtually identical cloud conditions. This procedure is feasible with a single operator, however the help of a second person considerably reduces the amount of time required to measure a test point. In either case, the operators should wear insulated gloves throughout the procedure. Once the tunnel was sealed and the test conditions had been selected the length of time that ice was allowed to accrete on each of the instruments needed to be determined. The approximate length of each run was determined by the length of time that it would take the single rotating cylinder to accrete between $0.3 \mathrm{~g}$ and $0.6 \mathrm{~g}$ of ice. The ice accretion code described in Appendix B was used to predict the 
approximate length of the test for the icing cylinder. The blade was allowed to accrete ice for approximately the same amount of time. While ice was accreting on the blade, the operators ensured that the ice thickness $(\tau)$ did not grow past $1 / 8$ " or that the accretion become anvil shaped over the leading edge of the blade. If this began to occur, the blade was retracted immediately and timing was stopped. This was done during the present tests to ensure that the theory used to compute the collision efficiency for the blade remained applicable. The electronic balance was zeroed with the specimen box containing the single rotating cylinder. The specimen box was centered on the balance plate to ensure consistency when the sample mass was taken later. The calipers that were used for measuring the ice thickness on the blade were chilled by resting their tips in a small glass of ice water.

Once all the pre-run preparations were completed the tunnel fan was turned on and the airspeed and temperature were allowed to stabilize. The blade was fully extended from the sheath and given some time to cool to the temperature of the tunnel. It was then retracted. The single rotating cylinder was then inserted into the funnel test section and allowed to cool. The rotating cylinder was then removed from the test section and a dry, clean rag was used to remove any condensation that formed on it while the spray was turned on and allowed to stabilize. Once the flow rates through the nozzles became constant the cylinder was reinserted into the tunnel for the predetermined amount of time and ice was allowed to accrete. The length of the run was dictated by the time 
between when the cylinder was first exposed to the air stream as it was extended from the sheath to the time when it left the air stream as it was being retracted. Once the cylinder was fully covered by the sheath great care was taken when completely removing the cylinder from the test section so as to not damage the accretion by striking the sides of the sheath. Quick motions were used when extending and retracting the cylinder from the sheath so that it spent as much time as possible collecting ice along the tunnel's centerline. Once the cylinder was carefully removed the specimen box was closed around the accretion and used to remove the cylinder from the shaft. The box was then placed on in the center of the balance plate and the sample mass was recorded. The sample mass was used in the data reduction as described in Section 2.5.2.2 to determine the LWC of the spray cloud.

The icing blade was then extended into the flow and ice was allowed to accrete on its leading edge for approximately the same amount of time as the rotating cylinder. Again, if the accretion grew too think or became anvil shaped the run was terminated immediately to avoid collecting erroneous data. Just as for the rotating cylinder, the length of the trial was measured as the time from when the blade first became exposed to the air flow to the time when it was fully hidden inside the sheath. The blade was also extended and retracted quickly to ensure that as much time as possible was spent collecting ice along the tunnel's centerline. When the blade was retracted however, care was taken not to slam 
the blade against the window. This was found to loosen the ice accretion and the sample was lost down the tunnel on a number of occasions.

After both samples had been collected the spray water was turned off and the tunnel was stopped. The spray air and the heat exchanger (refrigeration system) were left on in order to maintain a sub zero temperature in the test section. The tunnel door that holds the single rotating cylinder sheath was removed to give access to the icing blade so that the ice sample thickness could be measured. The blade was extended into the test section and the chilled calipers were used to measure the accretion thickness. In order to simplify the measurement process the thickness was measured by recording the distance from the trailing edge of the blade to the leading edge of the accretion and the width of the blade was then subtracted. A video camera mounted on top of the test section looking down onto the blade was used to make sure that the calipers were aligned perpendicular to the trailing edge of the blade. When taking the measurements care was taken not to crush the ice accretion with the calipers. This was done by taking the measurement just as the calipers touched the accretion. Even though the calipers were chilled they still had a tendency to melt or damage the accretion so each measurement could only be taken once. The blade was marked with three dark lines on its topside, one that marks the centerline of the tunnel when the blade is fully extended and two lines that are offset 1 inch to either side of it. One measurement was taken along each of the lines and the average of the three was used as $\tau$ in the data reduction as 
described in Section 2.5.2.1. The test point conditions used for this investigation are listed in Tables $5.4 a$ and $5.4 b$. The results of the tests are presented in Section 5.2 .

\subsection{PROCEDURES FOR SINGLE ROTATING CYLINDER VS. KING PROBE LWC MEASUREMENTS}

The test points that were selected for this investigation were chosen as part of a calibration fix of the AIWT spray bar system so they covered the applicable operating range of the tunnel. The tests were done in order to determine if the value of the MVD of the spray cloud had an effect on the LWC measured in the test section. The hypothesis was that the contraction in the wind tunnel upstream of the test section may have the effect of concentrating larger droplets towards the centerline of the tunnel. Consequently, an investigation was performed to determine if keeping the water flow per nozzle constant and varying the atomizing air pressure would have an effect on the LWC measured along the centerline of the test section. The effect of velocity was also investigated since if the phenomenon did occur the effect would be altered by increasing the airspeed. The single rotating cylinder was used in the same fashion as described in Section 3.2 and the King probe was mounted on a traverser and positioned along the test section's centerline. Unlike the investigation described in Section 3.2, the single rotating cylinder and the King probe could not be run simultaneously. The rotating cylinder requires that the 
tunnel temperature be cold enough to ensure rime ice accretes on the cylinder. The King probe however performs better at higher temperatures where the antiicing mechanism is more effective at preventing ice accretion on the forks of the probe. The King probe can be used for a short time at very cold temperatures so the effect of operating temperature was investigated with a single test point. This was done to determine whether or not freeze-out may have an effect on the cloud LWC at cold temperatures and to verify that the dry term in the King probe LWC computation was accurately removed. This investigation was by no means a conclusive study however it would hopefully highlight any cause for concern by measuring a different LWC for a given water flow rate per nozzle as the temperature of the air in the tunnel was changed.

The King probe was positioned along the centerline of the test section and the tunnel was sealed. The tunnel fan was started and the temperature was set to $-2^{\circ} \mathrm{C}$ which is considered a typical operating temperature for the King probe. The water flow rate was set to achieve a reasonable LWC (approximately 1.0 $\mathrm{g} / \mathrm{m}^{3}$ ) so as to not over saturate the hot wire probe and a relatively small MVD was selected since a higher atomizing air pressure would increase the chance of freeze out occurring. Once the temperature and air speed stabilized the dry term was zeroed out so that the King probe measured a value of zero $\mathrm{g} / \mathrm{m}^{3}$. The spray was then turned on and the probe measured a time averaged value of 0.92 $\mathrm{g} / \mathrm{m}^{3}$. The spray was then turned off and the tunnel operating temperature was set to $-25^{\circ} \mathrm{C}$. After the temperature stabilized the dry term was zeroed out for a 
second time so that the King probe once again read zero. The spray was turned on again with the same flow settings used previously and although the temperature was 23 degrees colder the King probe read virtually the same LWC as before. This led to the conclusion that the water and atomizing air temperatures were warm enough to ensure that freeze-out would not be a problem when the same water flow rates were used at the colder temperature to compare the single cylinder with the King Probe.

The comparison of the King probe and the single rotating cylinder was performed across the operating envelope of the AIWT. The test point conditions used for the investigation are presented in Tables $5.5 \mathrm{a}$ through $5.5 \mathrm{~d}$. All of the test points were first examined using the King probe mounted along the tunnel's centerline at a temperature of $-2^{\circ} \mathrm{C}$ and the data reduction was performed as summarized in section $2 \cdot 5 \cdot 1.3$. The points were then repeated at $-25^{\circ} \mathrm{C}$ using the single rotating cylinder and the procedure outlined in Section 3.2. The results of the tests are examined in Section 5.3. 


\section{DESIGN, CONSTRUCTION AND USE OF THE ROTATING MULTICYLINDER APPARATUS}

The rotating multicylinder technique has been used for droplet sizing and liquid water content measurement of natural spray clouds for years (Brun et al, (1955) and Howe, (1991)). To date however little published data exists comparing the results of the technique to those collected using the instrumentation endorsed by ARP-5905 for icing tunnel work. Thus it was one of the goals of this thesis work to adapt and assess the rotating multicylinder method for use in the NRC's AIWT for LWC and MVD measurement. This work was carried out with the hope that the rotating multicylinder technique might be suitable for use as a simple and inexpensive method for spot checking tunnel MVD calibrations. The repeatability and robustness of the technique was investigated as discussed later in this chapter.

The present chapter focuses on the design, fabrication and implementation of the multicylinder apparatus for use in an icing wind tunnel environment. The chapter begins with a brief history of the multicylinder technique followed by an explanation of the rationale for its use in droplet sizing of icing clouds. The modified apparatus is then described followed by an investigation of the robustness of the data reduction technique of Makkonen, (1991). The experimental procedure is then outlined along with a description of the rotating multicylinder experiments conducted in the AIWT. 
The rotating multicylinder has been in use at the Mt. Washington meteorological observatory for many years (Howe, 1991). The technique has been used for the measurement of cloud LWC and MVD as well as to investigate the density of ice accretions on cylinders of different diameters (Jones, 1990). The apparatus used at Mt. Washington is a stepped object with five cylindrical sections of different diameters and tapered spacers making a smooth transition between them (see Figure 4.1). The device is easily disassembled into its separate components; however, great care must be taken not to damage the ice at the junction of the cylindrical sections and the tapered spacers. The benefit of having all the cylinders connected in one piece during an experimental trial is that all the cylinders are exposed to virtually the same icing cloud conditions with the same rate of rotation for the same length of time. This is important in the context of Mt. Washington since the natural cloud conditions are typically quite unsteady.

\subsection{RATIONALE}

The traditionally accepted methods for the determination of droplet size in icing wind tunnels are typically light scattering instruments such as those described in Section 2.5.2.1. These instruments are very efficient for use in the calibration of icing tunnels since time averaged test points can be taken as quickly as the tunnel spray conditions can be changed and stabilized. However, these techniques are plagued with alignment issues and tend to yield erroneous results should the lenses become soiled with debris or smudges. These 
instruments are also very expensive, on the order of $\$ 100,000$. Consequently, the development of a simple inexpensive technique for the determination of droplet size using accepted and relatively simple physics would be advantageous for benchmarking these instruments. The data reduction for the rotating multicylinder method relies on theoretical models for collision efficiency of circular cylinders (Finstad et al., 1988) and for the accretion rate of rime ice (Makkonen, 1984). Both processes are relatively simple and the theoretical models are accepted throughout the in-flight icing community. Thus the rotating multicylinder could be an excellent candidate for use as a calibration standard.

Before a rotating multicylinder apparatus could be designed for use in the NRC's AIWT, a potential design operating envelope had to be decided upon in order to choose the cylinder diameters. The typical airspeeds over which the AIWT normally operates are $20 \mathrm{~m} / \mathrm{s}$ to $120 \mathrm{~m} / \mathrm{s}$ without the high speed insert and up to $165 \mathrm{~m} / \mathrm{s}$ with the insert installed (Oleskiw et. al, 2001). It would be ideal to be able to use the rotating multicylinder over the entire range of air speeds. However, it would be virtually impossible to hold a large cylinder of an acceptable aspect ratio steady and without vibration at the tunnel's centerline when it is operating at high speeds without the use of a heavy support structure. Such a support structure would likely mean that the cylinder could not be removed from the tunnel with the tunnel running and this would significantly increase the length of time required between successive runs of the multicylinder technique. Consequently it was decided that the operating range of the new rotating 
multicylinder apparatus would be limited to $50 \mathrm{~m} / \mathrm{s}$ or less so that a relatively large cylinder could be held in place by hand without the use of a support strut. The other parameters that were used to size the cylinder diameters were the ambient air temperature, the LWC and the MVD of the spray cloud. The minimum tunnel operating temperature is $-30^{\circ} \mathrm{C}$ due to the mechanical limitations of the heat exchanger. In order not to over tax the cooling system of the AlWT, $25^{\circ} \mathrm{C}$ was selected as the coldest operating temperature at which the rotating multicylinder would be used. The AIWT is required to accurately produce clouds with MVDs within the range of $10 \mu \mathrm{m}$ to $50 \mu \mathrm{m}$ so this is the droplet size range used to size the cylinders. The maximum LWC to be measured with the rotating multicylinder technique is dictated by the Ludlum limit of the individual cylinders. The Ludlum limit is the boundary at which certain combinations of LWC, MVD and air temperature cause the temperature of the icing surface to remain at $0^{\circ} \mathrm{C}$, (that is glaze icing occurs). At this point, there is the possibility that some of the liquid water does not freeze on impact and some of the water may be blown off the cylinder. The Ludlum limit should not be exceeded for any of the cylinders during a particular run.

\subsection{DESIGN AND DESCRIPTION OF THE APPARATUS}

The test section of the NRC's AIWT has a cross-section with the dimensions of $56 \mathrm{~cm}$ by $56 \mathrm{~cm}$. The cross-sectional dimension of the spray cloud is normally considerable smaller than this. As a result, using a one piece 
cylinder such as that used at the Mt. Washington observatory would be impossible without seriously compromising the aspect ratio of the cylindrical sections. Consequently it was decided that the cylindrical sections would be inserted into the test section individually, that is one at a time, each for approximately the same length of time. This would be problematic if the apparatus were used in natural conditions where the cloud conditions fluctuate frequently, but the AIWT has been shown to provide very consistent spray clouds with little time variation as seen in Figures 4.2 and 4.3. Figure 4.2 shows the time variation of LWC along the AlWT centerline measured with the King probe. The sharp spike in LWC at the end of the trial is caused by the atomizing air as it purges the rest of the water out of the line as the water flow being switched to flow to drain. This was the main reason that it was decided to remove the cylinders from the tunnel completely before switching the water flow. Figure 4.3 shows the time variation of MVD along the centerline of the test section as measured by the Malvern Spraytec. Both Figures 4.2 and 4.3 show the cloud parameters are very stable with time, so that each of the cylinders will be exposed to virtually the same cloud conditions.

The initial intent was to use five cylinders of different diameters, following the example of the Mt. Washington observatory. It was decided to make the cylinders out of stock stainless steel pipe to reduce manufacturing time and cost. The diameters of stock pipe considered for use in the multicylinder set are shown in Table 4.1. Furthermore the smallest cylinder in the set would be the current 
NRC single rotating cylinder so that the single-cylinder LWC could be computed and compared to the multicylinder LWC. The diameter of the current NRC single rotating cylinder is $2.41 \mathrm{~mm}$. In order to determine what the diameter each of the other four cylinders should be the collision efficiency of the stock pipe diameters was computed over the estimated operating range. The objective was that the cylinders should have as wide a range of collision efficiency as possible without having the largest cylinder be too big. The computations of the collision efficiency were done using the equations given in Appendix A. Figure 4.4 shows the results of this investigation. The independent axis shows the true airspeed for which the collision efficiency was computed and the dependent axis shows the difference in collision efficiency between the $2.41 \mathrm{~mm}$ cylinder and either a $40 \mathrm{~mm}$ or $50 \mathrm{~mm}$ diameter cylinder. When an MVD of $10 \mu \mathrm{m}$ is used for the computation a large difference in collision efficiency exists between the smallest and largest cylinder regardless of the airspeed. However when the upper region of the MVD envelope is examined only a relatively small difference in collision efficiency is seen between the smallest and largest cylinder. Since the overall range in collision efficiency is small, the difference in collision efficiency between the individual cylinders in the set would be small as well. This may cause potential problems since the technique relies on the difference in collision efficiency to determine MVD. As a result it was decided to manufacture a cylinder with a diameter of $50.8 \mathrm{~mm}$ first in order to run several trials to determine whether there would be any vibration or fastening issues at an airspeed of 50 $\mathrm{m} / \mathrm{s}$. To reduce the potential impact of three dimensional flow over the span of 
the cylinder, it was decided to keep the aspect ratio of the largest cylinder above 2. The data reduction code assumes that the ice diameter is uniform over the span of the cylinder so any deviation from this would obviously cause errors in the MVD and LWC computed for the cylinder set. Ideally the aspect ratio of the cylinders should be as large as possible, but again the problem of adequately supporting the cylinder at higher speeds limits the overall size that can be used. Thus a diameter of $50.08 \mathrm{~mm}$ and a length of $127 \mathrm{~mm}$ were selected as the dimensions for the prototype largest cylinder.

The preliminary tests on the prototype largest cylinder showed that although it was difficult at times to insert and retract the cylinder without striking the circular cutout in the test section window, only minor vibration was experienced on the cylinder. The prototype was tested at $20 \mathrm{~m} / \mathrm{s}$ and $50 \mathrm{~m} / \mathrm{s}$ as well as at both extremes of the MVD operational envelope. Careful visual examination of the ice accreted on the cylinder showed little if any three dimensional icing effects across the span of the cylinder (the worst case being at $20 \mathrm{~m} / \mathrm{s}$ with a MVD of $10 \mu \mathrm{m}$ where there was a slight drop off of the ice thickness $3 \mathrm{~mm}$ from both ends of the cylinder). Consequently it was decided that the $50.8 \mathrm{~mm}$ prototype cylinder would be used as the largest cylinder in the set and the other three cylinders would be chosen to evenly cover the range of sizes from $2.41 \mathrm{~mm}$ to $50.8 \mathrm{~mm}$ using the stock pipe diameters. The diameters selected are highlighted in Table 4.1. The new rotating multicylinder apparatus is shown in Fig 4.5. 
The cylinders are numbered 1 through 5 from smallest to largest. The two smallest cylinders are mounted on the mounting shaft of the current NRC single rotating cylinder apparatus (shown above the ruler in Fig. 4.5), and have a length of $50.8 \mathrm{~mm}$. The mounting shaft attaches to the shaft of a motorized gun by means of a set screw. The gun drives the shaft at $60 \mathrm{rpm}$. The mounting shaft is also fitted with a bushing whose position is adjustable by means of a set screw in order that the lateral position of the cylinder can be adjusted to fall onto the tunnel centerline when the bushing is in contact with the outside of the tunnel sidewall. The two smaller cylinders are inserted though a small hole in the test section sidewall window that has been fitted with an aerodynamic sheath as shown in Fig 4.6. The three larger cylinders (\# $3, \# 4$ and \#5) have a length of $127 \mathrm{~mm}$ and are mounted on a $12.7 \mathrm{~mm}$ shaft using two PVC (polyvinyl chloride) bushings and set screws. Cylinders \# 4 and \# 5 use nylon bushings to keep them concentric with the $12.7 \mathrm{~mm}$ shaft, while cylinder \# 3 fits somewhat snugly on the shaft. The $12.7 \mathrm{~mm}$ shaft attaches to the same gun as the single rotating cylinder mounting shaft. In order to easily insert and retract the largest cylinder without striking the glass an $88.9 \mathrm{~mm}$ hole was cut into a test section sidewall window to allow plenty of clearance. Since the hole is so large, a Plexiglas plate is secured to the $12.7 \mathrm{~mm}$ shaft with the use of two more PVC bushings and positioned so that when the plate sits flush against the tunnel window, the cylinders fall onto the tunnel centerline and the plate effectively closes the hole in the window. The Plexiglas plate is fitted with two screws in diagonally opposite corners and with a sturdy metal handle to help keep the apparatus steady when 
the tunnel is operating at higher speeds. The apparatus configuration for the largest cylinder is shown in Fig 4.7. The surfaces of all the cylinders were lightly sanded and polished by hand to remove any roughness.

To measure the mass of the ice that accretes on a given cylinder a container is required so that any water that forms from the ice melting is caught. It is imperative for the success of the technique that none of the mass is lost throughout the trial. For the smallest two cylinders a specimen box was built out of stainless steel. The box is just long enough to fit the $50.8 \mathrm{~mm}$ long cylinders inside. When the lid of the box is closed around the cylinder, the cylinder and the entire ice accretion can easily be pulled off the shaft. For the three larger cylinders a large specimen box could not be used since the sensitive electronic balance that was available at the AIWT can only support a maximum of $120 \mathrm{~g}$. The combined mass of the largest cylinder and a large specimen box would be greater than the maximum mass supportable by the balance. Rather than substituting a far less sensitive balance that could support more mass an alternative solution was devised. A specimen plate was manufactured out of stainless steel and the three largest cylinders could be rested on their ends on the plate when their masses were taken. 


\subsection{SIMULATION STUDIES FOR THE DESIGN AND DEVELOPMENT OF DATA REDUCTION METHODS}

In order to check the robustness of the data reduction method several investigations were attempted. The first investigation was very straight forward and was performed in order to check the solution algorithm presented by Makkonen, (1991) as outlined in Section 2.5.2.2 of this thesis. The ice accretion code presented in Appendix B of this thesis was used to compute the theoretical amount of ice that would accrete on the five cylinders for a given set of atmospheric and cloud conditions. The solution algorithm of Section 2.5.2.2 was then used to back solve for the LWC and MVD. The inputs used in this investigation are presented in Table 4.4. The results are displayed in the "No Error" column in Table 4.4, as well as in Figure 4.8. In all cases tested the solution algorithm returned the original LWC and MVD used to generate the theoretical ice accretions within a miniscule margin of error. This shows that the solution algorithm functions correctly as expected. A second investigation was performed in order to determine the effect of a potential measurement error on one of the cylinders of the set. The theoretical masses generated for the first study were used once again but the value for one of the cylinders was perturbed by minus $10 \%$ to simulate a measurement error or inaccuracy. The mass was perturbed on either the smallest or the largest cylinder in the set since this would test the outer limits of the technique (it is reasoned that the effect of perturbing cylinder \#3 would have an effect somewhere between what is found for cylinder 
\#1 and cylinder \#5). The results of this study are shown in Table 4.4 and Figure 4.9. Perturbing the mass accreted on the cylinder \#1 has only minor effects on the MVD returned. The error ranged from 0.2 microns to 3.6 microns for the cases examined. The largest error was seen at the largest MVDs examined; assessing the inaccuracy as a percent error yields a discrepancy of less $1.3 \%$. The errors associated with a $10 \%$ measurement error on cylinder $\# 5$ are potentially of some concern as shown in Figure 4.9. The worse case found showed a potential $30 \%$ error in the MVD returned if there was a $10 \%$ error in the mass collected on the cylinder \#5. Comfort can be found in the knowledge that the $10 \%$ error is equivalent to a mass of approximately 0.76 grams of ice. If such an error were due to striking cylinder and loosing a chunk of ice, or due to melting of the accretion before the mass could be measured, the operator should be able to observe by visual inspection that there is a problem with the trial and the test could be repeated.

A third and final computational assessment of the method focused on the effect of droplet size spectrum on the solution returned. This was performed since it was hypothesized that relatively large droplets may be present in the AIWT spray clouds for any particular MVD. If such droplets did indeed exist an assessment of their potential effect on the MVD returned by the solution algorithm would be beneficial for analyzing the results. The droplet spectra used in the study are the same as those used at the Mt. Washington observatory since 1973; they are presented as Table 4.2. In order to perform this investigation both 
the accretion code of Appendix B and the solution algorithm of Section 2.5.2.2 were modified to incorporate a droplet spectrum as yet another input. The droplet spectrum is included by dividing each time step into a series of sub-steps, each sub-step corresponding to one of the size bins in the droplet spectrum histogram. For example if distribution $B$ was being used to theoretically determine the amount of ice that would accrete on a cylinder when the LWC was $1 \mathrm{~g} / \mathrm{m}^{3}$ and the MVD was $10 \mu \mathrm{m}$, the first step of the accretion would be computed using an LWC of $0.05 \mathrm{~g} / \mathrm{m}^{3}$ and an MVD of $7.3 \mu \mathrm{m}$. The second step of the accretion would be computed using an LWC of $0.10 \mathrm{~g} / \mathrm{m}^{3}$ and an MVD of $9.2 \mu \mathrm{m}$. The computation carries on until all 7 bins of the distribution have been used to accrete ice on the cylinder. The sub-step values for LWC and MVD are used in all the computations requiring these parameters except for the ice density. The ice density of each sub-step is always computed as a function of the spectrum MVD (in the above example an MVD of $10 \mu \mathrm{m}$ would be used to determine the ice density throughout all the sub-steps).

The droplet spectra presented in Table 4.2 are shown graphically in Figure 4.10. The spectra progress from the mono-disperse spectrum $A$ (not shown in Fig. 4.10) to spectrum $J$ which has a rather long 'tail' of large droplets. The objective of this study was to determine the sensitivity of the solution algorithm to the spectra used. For example, if spectrum A was used to theoretically compute the amount of ice that would accrete for a given set of conditions, what would happen if spectrum $B$, or $\mathcal{J}$ were used to back solve? Conversely, what would 
happen if spectrum $J$ were used to theoretically compute the amount of ice that would accrete on the cylinders and then spectrum B were used to back solve? The second case is of particular concern since it investigates the effect that distributions with tails of large droplets would have on the solution algorithm. Table 4.3 shows the complete results of the above investigation and Figures 4.11a to $4.11 \mathrm{~d}$ illustrate the results for MVD returned by the solution algorithm. Examination of the results demonstrates that if a similar spectrum is used in the solution algorithm as that which was used to compute the theoretical mass of ice that would accrete, then the MVD and LWC returned by the solution algorithm is almost identical to that initially used (Fig. 4.11a and 4.11d). However, if a wide distribution was used to determine the theoretical amount of ice that would accrete and a narrow distribution was used in the solution algorithm there was a considerable effect of the MVD and LWC returned (see Fig. 4.11c). This is especially evident at small MVDs and large LWCs. The same is true for the case where of a narrow distribution used to determine the theoretical amount of ice that would accrete and a wide distribution used in the solution algorithm (see Fig. 4.11b). This investigation suggests that the data reduction technique may be sensitive to droplet specirum. If the droplet distributions produced by the AWT spray system do in fact contain large droplets the rotating multicylinder technique may yield inaccurate results especially at small MVDs and large LWCs. 


\subsection{EXPERIMENTAL PROCEDURES AND DATA REDUCTION METHODS}

The experimental procedure of the rotating multicylinder technique requires that all the cylinders in the set be exposed to identical icing conditions. The time variation of LWC and MVD measured in the AlWT test section show minimal fluctuations as measured by the King probe and the Malvern Spraytec (Fig. 4.2 and 4.3). Consequently all of the cylinders in the set can be tested in succession with the assurance that each of the cylinders is exposed to identical airflow and spray conditions. Prior to beginning a test run the tunnel operating speed and temperature are allowed to stabilize. The operating temperature must be set to a value cold enough to ensure that all of the cylinders will accrete rime ice (i.e. below the Ludlum limit) in order to make certain that all the liquid water that strikes the cylinder freezes on contact. This ensures that no water is blown off the cylinder. Figure 4.12 shows the maximum MVD and LWC that can be measured using the rotating multicylinder for a given operating speed when the static temperature in the test section is $-25^{\circ} \mathrm{C}$. The operating threshold was determined by computing the freezing fraction and average surface temperature for all 5 cylinders using equations $\mathrm{B} 1.2$ and B1.6 respectively. The threshold presented in Figure 4.12 maintains a freezing fraction of 1.00 and an average surface temperature colder than $-2^{\circ} \mathrm{C}$ on all the cylinders in the set. To ensure that rime ice is grown, it is advisable to stay below the operating threshold of Figure 4.12. The accretions were visually inspected immediately after the 
cylinders were removed from the tunnel to ensure that they exhibited properties indicative of rim ice.

The procedure could be carried out by a single operator, however, a second operator considerably reduces the length of time required to complete a run of all the cylinders since many of the tasks could be completed simultaneously. The aid of a second operator was significantly helpful for operating the stopwatch used for timing the length of exposure of each cylinder since two hands were required to carefully insert and retract the cylinder. Insulated gloves were worn by both operators throughout the procedure in order to prevent heat transfer to the cylinders that would increase the rate at which the ice melts. Regardless of this, the cylinders were touched as little as possible once ice had been accreted and they had been removed from the tunnel. Before any measurements were taken, all the cylinders, the specimen box, and the specimen plate were cleaned and dried with a clean cloth and compressed shop air. When taking measurements with cylinders \#1 and \#2, the specimen box was used to remove the cylinders from the shaft so that they were not touched by hand at all (see Fig. 4.13). Consequently prior to accreting ice on the cylinders a tare reading of the combined mass of the box and the cylinder must be taken.

Once the tunnel operating speed, air temperature, spray water flow, and spray air flow had been set and allowed to stabilize, the rotating cylinder was inserted into the test section so that it could be cooled to the operating 
temperature. The cylinder was then removed from the test section while the spray system was switched from flowing-to-drain to flowing-through-nozzles. During this time a clean dry cloth was used to remove any frost that formed on the cylinder due to the humidity of the air. Once the spray settings had stabilized the cylinder was reinserted to the centerline of the test section so that ice could be accreted. The length of the exposure was determined by attempting to accrete between 0.3 and 0.6 grams of ice on cylinder \#1. (This is typical of what is used when performing LWC tests with the single rotating cylinder). The ice accretion theory presented in Appendix B was used to estimate what the length of the run should be given the tunnel operating conditions. The typical length of the exposure ranged from 15 seconds to 2 minutes depending on the operating airspeed, LWC and MVD. Once the cylinder had been allowed to accrete ice for the correct amount of time, it was removed from the test section, being careful not to damage the accretion by striking it against the streamlined sheath or the cutout in the Plexiglas window. At this time the spray system was switched to flow to the drain in order to save water and most importantly to minimize the amount of ice that collected on the tunnel turning vanes downstream of the test section. Time was of the essence here since the mass of the sample needed to be measured before the ice began to melt. The ice was visually inspected to confirm that the accretion exhibited the characteristics of rime ice. If the accretion looked shiny or wet, the sample was melted, the cylinder was dried and the trial was repeated at a colder temperature. The specimen box was used to 
remove the cylinder from the shaft and the electronic balance was used to take the sample mass.

While the sample mass was being taken, the second operator used a heat gun to melt the ice that had accreted on the shaft which holds the cylinder. The shaft was dried using a clean dry cloth. This was important since if the cylinder was placed on a wet shaft it had a tendency to freeze and it became difficult to remove after ice had been collected. After the sample mass was recorded, the cylinder was removed from the specimen box and the box was dried using compressed shop air. Cylinder \#2 was placed in the box and a new tare of the mass and cylinder \#2 was taken. Cylinder \#2 was then placed on the shaft and it was ready to be cooled to the tunnel operating temperature. The same procedure was used for icing cylinder \#2 as what was used for cylinder \#1. All the cylinders were also iced for approximately the same amount of time. (The effect of icing the cylinders for different lengths of time was investigated and the results are discussed in Section 5.4). The test procedures for cylinders \#3, \#4, and $\# 5$ were also similar to that of cylinders $\# 1$ and $\# 2$ except that the shaft on the gun was switched to the thicker $12.7 \mathrm{~mm}$ one, and the specimen plate was used to weigh the cylinders rather than the specimen box. Care was taken to dry the PVC bushings as well as the shaft and cylinders since the bushings also had a tendency to freeze to the cylinders and shaft. 
The electronic balance used to measure the sample mass is an OHAUS Analytical Plus, model number AP210S. The balance is capable of measuring a maximum mass of 120 grams to an accuracy of \pm 0.0001 grams. The fact that the balance could only measure a maximum mass of 120 grams is notable since the combined mass of cylinder $\# 5$ and the specimen plate is roughly 80 grams. This means that the maximum amount of ice that could accurately be measured on cylinder \#5 is less than approximately 40 grams. When testing in conditions with a relatively high true airspeed, LWC and MVD, this was taken into consideration along with the theoretical mass that would collect on cylinder \#1 when determining the length of time to permit the cylinders to accrete ice. In other words, the length of accretion time was determined by attempting to collect between 0.3 and 0.6 grams of ice on cylinder \#1 while collecting less than 40 grams on cylinder \#5.

Several suggestions can be made that may help improve the quality of the data collected. When the tare of the cylinder and the specimen container is taken the container should be placed on the center of the plate of the electronic balance. The container should be placed in the same spot with the same orientation when the mass of the ice sample is taken. Care should also be taken when handling the larger cylinders since they can easily fall off the specimen plate. The ice accretions should not be touched by hand and the cylinders should only be handled by their sides or by the nylon bushings if necessary. 
The data reduction was carried out using the solution algorithm outlined in Section 2.5.2.2. The computations were carried out twice for each data point, first using the ARP-5905 recommended ice density of $880 \mathrm{~kg} / \mathrm{m}^{3}$, and second, using the density computed using Jones' correlation (eq. 2.11).

\subsection{DESCRIPTION OF ROTATING MULTICYLINDER EXPERIMENTS IN THE AIWT}

Each complete run of the rotating multicylinder technique takes approximately 15 minutes to complete from the time the test conditions are determined to the time when the data reduction is completed. As a result it would be far too time consuming to map the entire operating range of the AIWT using this technique. Test points representative of the AIWT's operating range were selected. The test points were selected to cover 3 ranges of MVDs, 10-15 microns, approximately 25 microns and a final range of larger MVDs (30-50 microns). Within each of the MVD ranges several LWCs from approximately 0.5 $\mathrm{g} / \mathrm{m}^{3}$ to $2.5 \mathrm{~g} / \mathrm{m}^{3}$ were selected. Tests were conducted at operating speeds of 30 $\mathrm{m} / \mathrm{s}$ and $50 \mathrm{~m} / \mathrm{s}$ and at a temperature of $-25^{\circ} \mathrm{C}$ unless otherwise specified. Several trials were attempted at $70 \mathrm{~m} / \mathrm{s}$ using only cylinders vibration of the larger two cylinders led to erroneous results. In order to produce the spray cloud for the rotating multicylinder tests the two centermost bars with 5 nozzles on each bar were used. The 5 nozzles were used in a wide pattern so that the spray cloud would extend horizontally across the tunnel from nearly wall 
to wall. The results of the rotating multicylinder experiments are presented in Section 5.4 of this thesis.

After all the test points using the rotating multicylinder were completed, AlWT runs using the same sets of test conditions were done with the Malvern Spraytec and the PDPA mounted in the tunnel simultaneously. The instruments were mounted so that both transmitters were located on the same side of the tunnel. This meant that it was relatively safe to work on that side of the tunnel without having to worry about looking directly into a laser beam (several areas did exist where the beams were reflected so care was still necessary). The operating manuals of both instruments were strictly followed in preparing for the tests. In order to reduce the multiple scattering effect on the results of the Malvern, the spray cloud was concentrated on the side of the tunnel where the receiver was located by shutting off the nozzles on the transmitter side of the tunnel. In turn the beams of the PDPA were focused to converge half way between the centerline and the receiver side of the tunnel. The results of the comparison between the MVD measured by all three techniques is also presented in Section 5.4 


\section{RESULTS AND DISCUSSION}

This chapter presents and discusses the results of the experiments outlined in chapters three and four.

\subsection{COMPARISON OF ICE PROFILE TRACINGS WITH RESULTS OF THE INTER-FACILITY COMPARISON STUDY}

This study was undertaken after an internal memo of the SAE AC-9C committee suggested that an error in the LWC or MVD calibration of about $+30 \%$ may have been responsible for the larger than average ice volumes generated by one of the facilities. Since the time of the original inter-facility comparison tests many changes had been made to the spray bar system of the AIWT, hence it was deemed necessary to re-evaluate the nozzle calibration that was then in use. The testing involved in this re-evaluation was part of the present thesis work. The test conditions used in this replication study are shown in Tables 5.1 to 5.3 for SAE Cases 1,3 , and $9^{1}$ respectively. Prior to each test run, the LWC in the AWT was measured using the single rotating cylinder method, and the MVD was determined using an existing calibration curve which relates the MVD to the water flow rate per nozzle and the airflow rate per nozzle. During this investigation the repeatability of the AIWT was verified by repeating test runs on different days. Once the study began it was found that producing the ice

\footnotetext{
${ }^{1}$ The term SAE Case \# is used in this thesis to refer to the test cases specified for the SAE interfacility comparison test program. There are 12 such test cases.
} 
accretions and then tracing them took considerable time. Because of constraints on available AIWT time, the scope of the replication study was limited to examining the effects of a $30 \%$ increase in MVD. It was not possible to examine the effect of a $30 \%$ increase in LWC. This was not considered a serious shortcoming, however, because the LWC calibration of the AIWT is most probably quite reliable, at least at airspeeds below about $90 \mathrm{~m} / \mathrm{s}$, because it is ultimately based on a reliable primary instrument, the single rotating cylinder.

The test point labels referred to in Tables 5.1 to $5.3 \log$ the date of the run with their first eight digits. The numbers after the hyphen refer to the run number that day ( 01 being the first run of the morning and so on). The ice profile tracings corresponding to these test points are shown in Figures 5.1 to 5.3. In the legend of Figs 5.1 to 5.3 , the first six tracings listed refer to the tests made at the six different icing wind tunnel facilities which were involved in the original inter-facility comparison study. These tracings are taken at the mid span of the 1.5 inch cylinder, which corresponds to the test section centerline. The facilities were each designated with a letter to maintain anonymity during the study. Facility ' $H$ ' consistently produced accretions with cross sectional areas substantially larger than the average produced by the other facilities. The tracings listed after the six original ones refer to the replication study tests run with the conditions shown in Tables 5.1 to 5.3. The first three digits of the tracing label refer to the SAE Case number (i.e. c01 corresponds to SAE Case 1). The next two digits refer to the span-wise position where the tracing was made. Oc corresponds to the 
centerline of the test section while $5 p$ and $5 s$ correspond to the port and starboard tracings. The starboard and port tracings are not shown in Figures 5.1 to 5.3 to minimize clutter, however the Tecplot layouts included on the CD attached to the Appendix of this thesis contain all the tracings made during the course of the study. The final 10 digits of the tracing label refers to the tunnel operating conditions used to create the accretion and correspond to the test point labels used in Tables 5.1 to 5.3 .

From Figure 5.1, it is evident that there is a considerable spread in the results of the original inter-facility comparison tests shown in tracings ' $A$ ' through ' $P$ '. The stagnation line thickness of the accretion varies by roughly $10 \%$ from the thinnest to thickest profile. The horn angles are approximately the same from one facility to the next but, the size of the horns varies considerably. The first two bold tracings in Fig. 5.1 represent profiles of ice accretions generated in the AIWT replication study tests with the tunnel operating conditions defined by SAE Case 1 of the inter-facility comparison study. The last bold tracing represents a profile generated using all the same tunnel operating conditions as the first two except the MVD setting was increased by $10 \mu \mathrm{m}$, from $20 \mu \mathrm{m}$ to 30 um. The first two bold tracings were made four days apart and show excellent repeatability. The stagnation thickness seems to be on the large side when compared to the tracings of the original inter-comparison study but the horn shapes and size seem to fall within the spread of the other facilities. The third bold tracing seems to overlay quite nicely with the largest original tracing from 
facility $H$. This would suggest that a $33 \%$ error in MVD may have been responsible for the oversize accretion at facility $H$. That is, the true MVD may have been about $33 \%$ greater than the targeted value, due to an error in the MVD calibration used by facility $H$ during the original SAE inter-facility comparison tests runs.

Figure 5.2 shows the results for the replication of SAE Case 3 of the interfacility comparison study. The layout of the legend is similar to that of Figure 5.1 where the results of the original study are displayed first and the results of the replication study are shown below as bold tracings. As before, the results of the original study show a significant variation in accretion thickness along the stagnation line. There is also considerable variation in the horn angle and their size from one facility to the next (for example from facility ' $E$ ' to facility ' $H$ '). The bold tracings shown in Figure 5.2 refer to two repeat runs with the test conditions defined by SAE Case 3, followed by a run where the set MVD was increased by $33 \%$, followed by two more repeat runs with the original test conditions. As in SAE Case 1, facility ' $H$ ' produced the accretion with the largest cross sectional area. Replication Trials 01 and 03 performed on August $26^{\text {th }}$ are almost identical to one another and seem to exhibit horn angles and horn sizes that are comparable to the average generated by all the other facilities. The horns are perhaps slightly larger and sharper, but this will be discussed shortly. During the fourth trial of the $26^{\text {th }}$ of August the spray airflow rate per nozzle was modified so that the MVD would be $33 \%$ larger than that defined for SAE Case 3 . The ice 
accretion tracing generated using this larger MVD overlays agreeably with that produced by facility ' $\mathrm{H}$ ' during the original inter-facility comparison study. This again suggests that a potential MVD calibration error may have been to blame for the large cross sectional profiles generated at facility ' $H$ ' during the original interfacility comparison study.

An important note to make here is that the LWC values shown in Tables 5.1 to 5.3 were not measured by the single rotating cylinder and are values that were computed from the tunnel LWC calibration. The then-current tunnel calibration was used to determine the water flow rate that would produce the appropriate LWC in the test section. The tests conducted on the $26^{\text {th }}$ of August 2003 were intended to yield a preliminary assessment of the effect of the MVD on the ice accretion geometry, but limited tunnel availability eventually dictated that they would have to serve as final results. At a later date, two trials were performed in order to re-evaluate the results of August $26^{\text {th }}$. These tests were performed on the $18^{\text {th }}$ and $22^{\text {nd }}$ of September. Prior to the September tests the LWC was measured using the single rotating cylinder and the water flow rate per nozzle was adjusted to achieve a value close to 1.0. This is evident in the water flow rates shown in Table 5.2 since a lower flow rate was used for the last two runs as compared to that used for the first two. For example, cross referencing with run 27 in Table $5.4 b$ shows that a water flow rate of $42.5 \mathrm{~g} / \mathrm{min} / \mathrm{nozzle}$ and an air flow rate of $92 \mathrm{~g} / \mathrm{min} /$ nozzle produces a test section LWC of 1.08 and 1.05 $\mathrm{g} / \mathrm{m}^{3}$ as measured by the single rotating cylinder and the icing blade respectively. 
Regardless of the fact that the nozzle flow rates were slightly modified, the trials of September $18^{\text {th }}$ and $22^{\text {nd }}$ agree well with the trials on August $26^{\text {th }}$ in that they have roughly the same stagnation line thickness and horn angles. The only obvious difference being that the horns are more rounded. But this only causes them to agree better with the average profile of the original inter-facility comparison. Another point to note here is that the LWC used to generate the accretions on September $18^{\text {th }}$ and $22^{\text {nd }}$ is still at least $5 \%$ higher than the value that is defined in the test parameters for SAE Case 3 as measured by the single rotating cylinder. Thus slightly reducing the water flow rate per nozzle to achieve an LWC of $1.0 \mathrm{~g} / \mathrm{m}^{3}$ as measured by the single rotating cylinder would further reduce the cross sectional profile of the ice accretion as seen from the first 2 profiles shown in Figure 5.2 from August 26 to the profiles produced in September in (keeping in mind that the water flow rate was reduced by $6 \%$ from August 26 to September 18).

Figure 5.3 shows the results of the replication runs for SAE Case 9. Case 9 is clearly a case of rime icing and so no horns form. The key parameters to note here are the stagnation line thickness and the width of the accretion from top to bottom. As in the previous two figures the original study results are presented first in the legend followed by the replication results. Once again there is a spread in the results produced at the various facilities but as before facility ' $H$ ' was responsible for the accretion with the largest cross sectional profile. Two tests were performed on the $18^{\text {th }}$ and $22^{\text {nd }}$ of September using the test conditions 
defined by SAE Case 9. Runs 23 through $24 b$ of Table $5.4 b$ show that the LWC for the given nozzle flow rates as measured by the single rotating cylinder and icing blade are $0.5 \mathrm{~g} / \mathrm{m}^{3}$ and $0.45 \mathrm{~g} / \mathrm{m}^{3}$ respectively, and Case 9 requires an LWC of $0.5 \mathrm{~g} / \mathrm{m}^{3}$. The profile tracings of these runs agree well with the profiles of the original results as the accretion width is similar and the stagnation line thickness is comparable. The trial of September $29^{\text {th }}$ represents a case where the air flow rate per nozzle was intentionally set to produce an MVD that was $33 \%$ larger than what was defined by the requirements for SAE Case 9 . The agreement of the profile generated using the new air flow rate with the profile generated by facility ' $\mathrm{H}$ ' is undeniable. This example presents the strongest support for the suggestion that errors in calibration of cloud parameters are mainly responsible for the discrepancies between the original results for facility ' $H$ ' and the other facilities.

An interesting observation can be made looking at Figures 5.1, 5.2, and 5.3 with regards to the stagnation line thickness of the accretions. For the rime icing case (SAE Case 9, Fig 5.3) the effect of the 30\% increase in MVD evidently increases the stagnation line thickness of the accretion since the collision efficiency at the stagnation line (as well as everywhere else) increases. For the glaze/mixed icing cases (SAE Cases 1 and 3, Figs. 5.1 and 5.2) the stagnation line thickness appears to be virtually insensitive to the increase in MVD. Although the collision efficiency at the stagnation line still increases with increasing MVD the freezing rate at the stagnation line is already at its maximum. 
That is, it is at the upper limit enabled by the convective cooling provided by the air flow over the ice accretion. The 'extra' water striking the accretion runs back and freezes downstream of the stagnation region where the convective cooling is sufficient to cause it to freeze. This leads to larger horns that can be more swept back.

The results of the replication study show that accretions generated at the AIWT are readily repeatable if the same operating conditions are set (i.e. the same operating airspeed, temperatures, and nozzle flow rates are used). Tests conducted on different days using the same conditions produce very similar accretions. The surfaces of mixed and glaze ice accretions are very irregular and so individual crevasses are obviously not identical, but their cross sectional profiles overlay one another nicely. The irregular crevasses can be seen in Figure 2.5 .

\subsection{ICING BLADE LWC VS. SINGLE ROTATING CYLINDER LWC RESULTS}

The icing blade and the single rotating cylinder were compared in an investigation as described in section 3.2. The data recorded during the study was the thickness of ice to accrete on the blade as well as the mass of ice to accrete on the cylinder. These results were used in the data reduction as summarized Sections 2.5.1.1 and 2.5.1.2 to determine the LWC of the spray 
cloud for the given set test point operating conditions. The MVD used in the computation is that which was interpolated from the AIWT nozzle calibration. The test point operating conditions, data recorded and results for LWC are presented in Tables 5.4a and 5.4b, as well as Figure 5.4.

Table $5.4 a$ shows the results for the first 22 test points. These trials were performed with the high speed insert installed in the AIWT. Although the tunnel was capable of operating at high airspeeds with the insert, the trials were limited to the operating airspeeds defined as the test points for the inter-facility comparison study discussed in the previous subsection. Table $5.4 \mathrm{~b}$ shows the results of trials performed sometime later with the high speed insert removed from the AlWT. For the most part the results of Tables $5.4 \mathrm{a}$ and $5.4 \mathrm{~b}$ conclusively show that the icing blade and the single rotating cylinder methods are equivalent for measuring the LWC of a spray cloud. One considerable discrepancy found was during runs 6 through 9 in Table 5.4a. The blade measured a considerably lower LWC than the single rotating cylinder. A likely explanation for this might be that the icing blade reaches its Ludlum limit before the rotating cylinder does. During this comparison study the single rotating cylinder's Ludlum limit was interpolated from Figure 7 of Stallabrass, 1978. Appropriate test temperatures were selected in order to remain below the Ludlum limit assuming that the limit for the icing blade would be similar to that of the cylinder. Cases 6 through 9 show that this assumption may be incorrect since the icing blade read much lower LWCs than the single rotating cylinder as the 
test section LWC was increased to values of approximately $1.5 \mathrm{~g} / \mathrm{m}^{3}$ at a static temperature of $-18^{\circ} \mathrm{C}$. The problem seems to disappear in runs 12 through 16 where a static temperature of $-23^{\circ} \mathrm{C}$ is used and the icing blade and single rotating cylinder agree well up to an LWC of approximately $1.5 \mathrm{~g} / \mathrm{m}^{3}$.

Several spray-nozzle configurations were used in generating the results of Tables $5.4 \mathrm{a}$ and $5.4 \mathrm{~b}$. The configurations were selected so that the spray cloud would adequately cover the centerline region of the test section. Both tight and wide patterns were used in the results of Table 5.4a. The tight pattern with ten nozzles used the innermost five nozzles on two bars in order to generate the spray cloud. The wide pattern was similar except that the five nozzles per bar extended outwards to the walls of the tunnel. The only difference that can be seen in the results is that the tight pattern uses less water flow per nozzle in order to create a spray cloud with a given tunnel centerline LWC when compared to the wide pattern (for example run 4 versus run 19).

In generating Figure 5.4 the test points which potentially exceeded the Ludlum limit of the icing blade have been removed. For the most part the results for the single rotating cylinder fall within $\pm 5 \%$ of the icing blade. During the tests performed with the insert several LWC values measured by the cylinder are between 5 and 10 percent higher than the blade. A potential explanation for this is that the measurements of the ice thickness accreted on the icing blade may have been made with too much force. As mentioned previously, the ice accreted 
is rather fragile and sensitive to the touch of the calipers. Even though the calipers are chilled, they seem to sink into the accretion either by melting it or crushing the surface. Attempts were made to take the measurements without crushing the surface of the ice by visually determining when the calipers were touching the leading edge of the accretion rather than by relying on touch. Although this does not seem complicated, it is actually rather difficult to accomplish while attempting to keep the calipers perpendicular to the trailing edge of the blade. After several days of testing, however, it was easier to successfully take thickness measurements from the icing blade and this is perhaps why the results generated in the later tests are in better agreement.

Another potential explanation for the discrepancy between the LWC measured by the icing blade and the LWC measured by the single rotating cylinder is the manner in which the collision efficiency of the blade is computed. The collision efficiency of the blade is computed by assuming that the cross sectional profile of the accretion maintains sharp corners top and bottom and a flat leading edge just as the original blade cross section. In reality however, the accretion can become somewhat rounded at times, depending on the test conditions. If the computation of the collision efficiency was modified during each time step to incorporate the change in leading edge profile, the LWC computed by the data reduction software would yield a slightly higher LWC for the icing blade. This would put the icing blade in better agreement with the single rotating cylinder. 
A linear correlation through the origin of all the data points presented in Figure 5.4 generates line of best fit with the equation $y=1.023 x$ having an $R^{2}$ value of 0.9717

\subsection{SINGLE ROTATING CYLINDER LWC VS. KING PROBE LWC RESULTS}

This subsection contains the results of the comparison tests outlined in Section 3.3. As previously discussed, the test conditions used in this investigation were selected in order to examine the potential effect of MVD on the LWC measured in the test section. The nozzle water flow rates were selected so that in conjunction with the tunnel operating airspeed, they would cover the operating range of the AIWT for LWC. At each of the water flow rates the nozzle atomizing air pressure was varied in order to create a set of MVDs that ranged from roughly $15 \mu \mathrm{m}$ to $80 \mu \mathrm{m}$. For each LWC and MVD combination the liquid water content was measured using both the single rotating cylinder method and the King probe with the procedure outlined in Section 3.3. The test point conditions as well as the results for LWC from the single rotating cylinder and the King probe are shown in Tables $5.5 \mathrm{a}$ through $5.5 \mathrm{~d}$ for operating airspeeds of 30 $\mathrm{m} / \mathrm{s}, 50 \mathrm{~m} / \mathrm{s}, 70 \mathrm{~m} / \mathrm{s}$, and $90 \mathrm{~m} / \mathrm{s}$ respectively.

The results for the King probe are computed using the collision efficiency for the MVD corresponding to the tunnel calibration for the nozzle flow rates used 
in order to create the spray cloud. The MVD for the three blocks of data in each section of the table separated by the grey rows are $15 \mu \mathrm{m}, 30 \mu \mathrm{m}$, and $50 \mu \mathrm{m}$ $( \pm 0.9 \mu \mathrm{m}$ averaged over time). The single rotating cylinder results are computed using the new Malvern MVD correlation that is listed in the table. Overall this has a negligible effect on the results presented except at the lowest airspeed and smallest MVD where the difference in collision efficiency is of the order of $8 \%$. For example, the first test point of Table 5.5 a would have an LWC $0.42 \mathrm{~g} / \mathrm{m}^{3}$ measured by the single rotating cylinder if the nozzle calibration MVD of $15.9 \mu \mathrm{m}$ was used in its computation, rather than the $0.47 \mathrm{~g} / \mathrm{m}^{3}$ obtained using the Malvern value of $12.2 \mu \mathrm{m}$. The effect becomes less pronounced at higher MVDs and airspeeds, for example at an airspeed of $30 \mathrm{~m} / \mathrm{s}$ and an MVD of $50 \mu \mathrm{m}$ the difference in collision efficiency is of the order of $1 \%$, and at an airspeed of 70 $\mathrm{m} / \mathrm{s}$ and an MVD of $15 \mu \mathrm{m}$ the effect is reduced to only $3 \%$ down from $7 \%$. Overall the effect would help improve the agreement between the LWC measured by the two techniques, but the improvement would be small.

Figures $5.5 \mathrm{a}$ to $5.5 \mathrm{~d}$ show the results discussed above for tunnel operating airspeeds of $30 \mathrm{~m} / \mathrm{s}, 50 \mathrm{~m} / \mathrm{s}, 70 \mathrm{~m} / \mathrm{s}$, and $90 \mathrm{~m} / \mathrm{s}$ respectively. The equation of a linear correlation through the origin as well as the correlation coefficient is displayed on each of the figures. The King probe seems to be functioning correctly yet the LWC it measures is always somewhat less than that measured by the single rotating cylinder method. The disagreement in measured LWC between the two techniques becomes worse as the airspeed increases. 
This leads to the hypothesis that the King probe might not have been operating at a temperature hot enough to evaporate all the water striking the hotwire on contact and that some of the water was being stripped off. The operating manual of the King probe suggests that the hotwire should operate at a temperature of $190^{\circ} \mathrm{C}$. The AlWT's King probe has been modified so that the current flow through the hotwire and the voltage across it can be measured by the data acquisition system. Knowing the resistance of the wire at room temperature and its temperature coefficient of resistance the operating temperature of the wire can be determined from the resistance computed using the voltage and current. Using this method the operating temperature of the hotwire has been calculated to be between $135^{\circ} \mathrm{C}$ and $140^{\circ} \mathrm{C}$ for all the trials of this study. Looking through the history of data collected with the King probe at the AIWT revealed that the hotwire operating temperature has always been within the range found by this investigation. Previous comparisons of the single rotating cylinder and the King probe performed at the AWIT have shown the two instruments to be in good agreement. This suggests that a hotwire operating temperature of $135^{\circ} \mathrm{C}$ is adequate for evaporating the liquid water on contact, or that the wire temperature was actually hotter than what was computed from its resistivity.

Further investigation into the discrepancy in LWC measured by the two techniques should be undertaken when time permits. A faulty connection or short in the King probe may be responsible for its under prediction of cloud LWC. Another potential error may come from the fact that the hotwire was replaced by 
a new element numerous times and the new resistance of the replacement wires was not measured. The hot wires seem to be manufactured to strict tolerances, so differences from one wire to the next should be minimal, but without actually measuring the resistance of the wire it is impossible to draw a conclusion.

Figures 5.6 a through $5.6 \mathrm{~d}$ show the results of the investigation into the effect of MVD on the LWC measured in the test section. Figures 5.6a through $5.6 \mathrm{~d}$ show the results for LWC as measured by the single rotating cylinder method with the collision efficiency computed using the new Malvern correlation for MVD. As explained above the nozzle atomizing air pressure was varied at each water flow rate in order to produce a range of MVDs. The MVDs shown in the legend of the figures are the target MVDs determined by the old nozzle calibration. Cross referencing with Tables $5.5 \mathrm{a}$ through $5.5 \mathrm{~d}$ shows that the actual MVDs are of the order of $13 \mu \mathrm{m}, 23 \mu \mathrm{m}$, and $45 \mu \mathrm{m}$. A definite effect of MVD on measured LWC is evident. This effect is thought to be due to a 'focusing' effect that occurs as the air and the spray cloud pass through the tunnel contraction. With larger MVD, the larger droplet inertia results in a spray cloud having a smaller cross-sectional area in the test section and thus a higher centerline LWC value. In Figures 5.6a to $5.6 \mathrm{~d}$ the effect of the MVD on LWC measured in the test section appears to be more prominent at $30 \mathrm{~m} / \mathrm{s}$. This is likely because at higher speeds the increased drag on a given droplet tends to keep it closer to its original airflow streamline. An interesting observation is that the slopes of the lines of best fit are nearly the same for the three MVDs at 50 
$\mathrm{m} / \mathrm{s}, 70 \mathrm{~m} / \mathrm{s}$, and $90 \mathrm{~m} / \mathrm{s}$ and these are more typical of the airspeeds used during aircraft testing. The fact that the slopes are nearly the same implies that the focusing effect is relatively the same at each of these speeds. Thus a nozzle MVD calibration performed at one of these airspeeds should be applicable at all of them. Aside from this fact, it would be interesting to verify that the droplet spectrum is not affected by the operating airspeed of the tunnel by measuring the MVD along the centerline of the test section using the PDPA. The Malvern correlation referred to in Tables 5.5 a through $5.5 \mathrm{~d}$ was preformed at $50 \mathrm{~m} / \mathrm{s}$.

\subsection{RESULTS OF ROTATING MULTICYLINDER EXPERIMENTS TO DETERMINE SPRAY CLOUD LWC AND MVD}

This subsection presents the results of the investigation outlined in Section 4.5. The results are subdivided into two sections based on the tunnel operating airspeed. The nozzle flow rates as well as the results for the rotating multicylinder, Malvern Spraytec and the PDPA are shown in Table 5.6a for a tunnel operating airspeed of $30 \mathrm{~m} / \mathrm{s}$. Table $5.6 \mathrm{~b}$ shows a similar table for test points taken at an operating airspeed of $50 \mathrm{~m} / \mathrm{s}$. Both Tables $5.6 \mathrm{a}$ and $5.6 \mathrm{~b}$ contain the rotating multicylinder results for two data reduction approaches. The only difference between the two methods is the ice density that is assumed when each consecutive time step grows a layer of ice on the cylinders. The first

method uses the SAE-ARP-5905 recommended $880 \mathrm{~kg} / \mathrm{m}^{3}$ while the second method uses the Jones, 1990, Buckingham Pi correlation for the density. The 
choice of density is found to have a negligible effect on the MVD and LWC that is returned from the multicylinder data reduction code. This is as expected since the density has only a small effect on the outside radius of the ice accretion and this in turn has only a small effect on the collision efficiency computed for the accretion in the following time step. The Buckingham Pi density correlation was used in the data reduction for generating the rotating multicylinder cylinder results presented in this chapter.

As part of the data reduction software a component was added that would take the final multicylinder MVD and the mass of ice accreted on cylinder \#1 (the $2.41 \mathrm{~mm}$ diameter cylinder) to compute the LWC by the single-rotating-cylinder method (outlined in Section 2.5.2.2). This LWC was compared to that which is returned from the multicylinder method as a check on the consistency of the results returned by the multicylinder technique. This was done because the MVD calibration of the nozzles was in question at the time that the tests were completed and the Malvern and PDPA had not yet arrived at the AIWT lab. After the first days of testing with the multicylinder, it was established that a reasonable correlation between the multicylinder LWC and the single rotating cylinder LWC could not be found. Careful inspection of the data reduction software and assessment of the multicylinder procedure led to the conclusion that a design flaw in the multicylinder apparatus was the likely source of error. There are two bushings that are used to hold cylinders \#3, $\# 4$, and $\# 5$ to the 12.7 $\mathrm{mm}$ shaft. It was recognized that the outside diameter of the bushings is larger 
than the outside diameter of cylinder $\# 3$, thus they were having an effect on accretion of ice near the ends of the cylinder. Removing cylinder \#3 from the data reduction altogether solved the problem. Because of the time associated with the redesign and manufacturing of a new cylinder \#3 it was decided that the remainder of the tests would be conducted using only cylinders \#1, \#2, \#4, and \#5.

Figures $5.7 \mathrm{a}$ and $5.7 \mathrm{~b}$ show the correlation of the single cylinder LWC and the multicylinder LWC as discussed above. Figure $5.7 \mathrm{a}$ represents data collected at a tunnel operating speed of $30 \mathrm{~m} / \mathrm{s}$ while Figure $5.7 \mathrm{~b}$ shows data collected at $50 \mathrm{~m} / \mathrm{s}$. A linear correlation through the origin of all the data points presented in Figure $5.7 a$ yields a line of best fit with the equation $y=1.064 x$ with an $R^{2}$ value of 0.996 , the same exercise performed for Figure $5.7 \mathrm{~b}$ generates a line of best fit with the equation $y=1.053 x$ with an $R^{2}$ value of 0.995 . Therefore both figures show a linear offset of roughly $6 \%$ in the LWC between one method and the other. The variation is independent of tunnel operating speed and this suggests that the discrepancy is rooted in the data reduction itself. A series of temperature dependant variables are used in the data reduction such as the density of air or its dynamic viscosity. Different correlations were used in each of the methods, and although the differences between them are minute, they may be partially responsible for the difference. A more likely explanation is that the offset in LWC is inherent in the solution algorithm for the rotating multicylinder method. In particular, the relations between cylinder diameter, MVD and collision 
efficiency may be responsible. Another possibility is that the end effects play a role, particularly for the larger cylinders. Regardless of the source of the discrepancy in LWC determined by the single rotating cylinder and the rotating multicylinder, the difference is within the relative error of the comparison between the single rotating cylinder and the icing blade. In fact the results of Section 5.2, Figure 5.4 suggest that if the icing blade were used to measure the LWC along side the rotating multicylinder, and the single rotating cylinder, that all three methods would agree within about $5 \%$.

When the data reduction code of the rotating multicylinder converges on a MVD and LWC it does so by systematically converging on a set of theoretical masses that would accrete on each of the four cylinders. These four masses are of a magnitude that best relates to the experimentally measured masses by linear regression (i.e. they have an $R^{2}$ value closest to 1.0 and a slope through the origin of 1.00 ). As a testament to the accuracy of the theory underlying the code and to the care with which the data was collected, the theoretical masses from the last time step of the data reduction are plotted against the experimentally measured masses in Figures $5.8 \mathrm{a}$ and $5.8 \mathrm{~b}$. Figures $5.8 \mathrm{a}$ and $5.8 \mathrm{~b}$ show data collected from test points at $30 \mathrm{~m} / \mathrm{s}$ and $50 \mathrm{~m} / \mathrm{s}$ respectively. Both figures show an excellent correlation between the experimentally observed masses and those theoretically generated by the data reduction code. This inspires additional confidence to the results for MVD and LWC returned from the data reduction software for the rotating multicylinder measurements. 
Figures $5.9 \mathrm{a}$ and $5.9 \mathrm{~b}$ show the results of the comparison between the MVD values obtained from the rotating multicylinder and from the Malvern Spraytec for test points taken at $30 \mathrm{~m} / \mathrm{s}$ and $50 \mathrm{~m} / \mathrm{s}$ respectively. For the most part the results of the rotating multicylinder agree well with those of the Malvern and the majority of the results agree within $\pm 10 \%$. The only major discrepancy occurs at the large MVDs measured at $30 \mathrm{~m} / \mathrm{s}$. For some unexplained reason the Malvern was measuring distributions with tails of large droplets during the day when the MVD data was collected. In fact all of the distributions measured by the Malvern over the course of the day looked questionable when compared to what had been measured the previous day for the recalibration of the AIWT nozzles. Despite the difficulties experienced with the Malvern on the day of testing the results are favorable and, with one localized exception, show consistent agreement with the rotating multicylinder technique.

Figures $5.10 \mathrm{a}$ and $5.10 \mathrm{~b}$ show the results of the comparison between the rotating multicylinder and the PDPA for test points taken at $30 \mathrm{~m} / \mathrm{s}$ and $50 \mathrm{~m} / \mathrm{s}$ respectively. As with the Malvern, the rotating multicylinder MVD values compare well with the PDPA values for MVD at both speeds. The only inconsistency in the results occurs at $50 \mathrm{~m} / \mathrm{s}$ when attempting to measure clouds with MVDs of roughly $23 \mu \mathrm{m}$. At these test conditions the PDPA seems to measure larger MVD than both the rotating multicylinder and the Malvern (see Fig. 5.11). This inconsistency is rather odd since the test points were ordered by water flow rate first rather than airflow rate since the water flow rate was more 
difficult to set and stabilize. This means that the test points measured at roughly $23 \mu \mathrm{m}$ were not measured consecutively, so the odds of a consistent error in flow rate for all of the points would be slim. Also, the Malvern and rotating multicylinder show excellent agreement at these points and the Malvern and PDPA were run simultaneously.

Figure 5.11 shows the MVD measurements taken with the PDPA plotted versus those taken with the Malvern. As mentioned previously the measurements were taken simultaneously so differences in the nozzle flow conditions were not responsible for the inconsistencies seen. The lens configuration used for the Malvern has a focal length that allows it to measure droplet spectra with MVDs larger than the PDPA. This is likely why the PDPA measurements tend to drop off at the larger MVDs. Figures 5.12 and 5.13 show droplet distributions simultaneously measured by the Malvern and PDPA. The dependent axis of both figures has been normalized by the size of the individual bins in microns. This was done because the sizes of the bins for the PDPA are much smaller than those of the Malvern. Figure 5.12 shows the droplet spectra measured by the two instruments for test point 26 of Table 5.6b. Test point 26 had a relatively large difference in MVD measure by the two instruments (roughly $3 \mu \mathrm{m})$ yet the droplet spectra are very comparable. Figure 5.13 shows the droplet spectra for test point 5 of Table 5.6a. The MVDs measured by both instruments for this test condition are virtually identical and the droplet spectra are quite comparable except for the tail of large droplets measured by the 
Malvern. Despite this difference the area under both curves is roughly the same due to the sharp spikes in the distribution measured by the PDPA as it measures the diameter of one droplet at a time. Figures 5.12 and 5.13 show that both of the light scattering instruments measure similar droplet distributions even though they might measure a slightly different MVD. For the most part, the largest error in MVD found between the two instruments was on the order of 5 microns (see results of Table 5.6).

The results presented above indicate a reasonably consistent agreement between the rotating multicylinder and the two light scattering instruments that were tested. The Malvern and PDPA also seem to agree well with one another. There were several instances encountered, however, where one of the light scattering instruments measured values of MVD that slightly differed from the rotating multicylinder and the other light scattering instrument. These discrepancies may have occurred due to alignment issues with the instrument itself or perhaps debris obstructing the receiver of the device. If the instrument were not run in conjunction with the two other instruments there is little chance that the small discrepancy would have been noticed. For this reason it is recommended that whenever light scattering instrumentation is used for measuring MVD, it should be benchmarked versus some other instrument. The rotating multicylinder is a low cost, relatively simple instrument to use for such a purpose, and although measurements may take considerable time the benefits of assuring that a calibration is sound is invaluable. 


\subsection{FURTHER DISCUSSION OF RESULTS}

The replication study of the SAE inter-facility comparison study results presented in Section 5.1 showed that a 30\% increase in the MVD creates a significant effect on the ice shapes produced at a given set of conditions. The effects are obvious in both the rime and glaze cases tested. Prior to both the original tests and the replication study the liquid water content of the spray cloud was measured prior to the tests using the single rotating cylinder method and the water flow rates used were shown to produce spray clouds with the LWC dictated by the SAE test requirements. During the original study, if in fact the MVD was $30 \%$ larger than what it should have been, the larger MVD would only have changed the collision efficiency of the single rotating cylinder by roughly $5 \%$. This would have had only have a minute effect on the LWC measured by the single rotating cylinder and the discrepancy could easily have gone unnoticed since the MVD was not measured prior to the tests. The results presented in Section 5.3 show the effect of increasing the MVD on the LWC measured on the centerline the test section of the AlWT. This may also occur in other icing facilities where the spray nozzles are located upstream of the contraction. The results of Section 5.3 suggest that increasing the MVD may increase the concentration of large droplets near the centerline of the test section due to the inertia of the larger droplets carrying them away from their original streamlines. This effect was determined to be dependent on tunnel operating airspeed. The 
higher concentration of larger droplets along the centerline would skew the droplet spectrum to the right and thereby increase the MVD. The nozzle MVD calibration was only performed at $50 \mathrm{~m} / \mathrm{s}$ and although the slopes of the lines in Figures $5.6 \mathrm{~b}$ through $5.6 \mathrm{~d}$ show negligible change in LWC with increasing the airspeed from $50 \mathrm{~m} / \mathrm{s}$, the droplet spectrum may be affected significantly. The results for LWC presented in Figures $5.6 \mathrm{~b}$ to $5.6 \mathrm{~d}$ are measured using the single rotating cylinder method, which is relatively insensitive to MVD. (Recall that the MVD affects the results of the single rotating cylinder by its collision efficiency; at $67 \mathrm{~m} / \mathrm{s}$ increasing the MVD from $20 \mu \mathrm{m}$ to $30 \mu \mathrm{m}$ would only shift the collision efficiency by $5 \%$. As the airspeed increased, the effect on collision efficiency would become smaller and smaller). Thus it would be worthwhile to investigate the effect of the MVD on the droplet spectrum and to quantify its effect in relation to airspeed.

The recalibration of the AIWT nozzles was performed using both the Malvern and the PDPA at $50 \mathrm{~m} / \mathrm{s}$ with the spray cloud concentrated on the side of the tunnel where the receivers of both instruments were located. This was done in order to minimize the effect of multiple scattering on the results of the Malvern. The beams of the PDPA were focused to cross half way between the centerline of the tunnel and the side where the receivers were located in order to attempt to measure the center of the spray cloud. This technique would not be ideal for attempting to measure the focusing of large droplets on the tunnel centerline. Instead, the sample volume of the PDPA should be set onto the 
centerline of the tunnel and the nozzles should be set to a configuration which is symmetrical about it. Having an equal number of nozzles spraying on both sides and top and bottom of the sample volume would ensure that if in fact the contraction is responsible for focusing the spray cloud that it would be picked up by the PDPA. 


\section{CONCLUSIONS}

Overall the instrumentation comparisons performed as part of this thesis were successful. They showed that regardless of the instrumentation used in the baseline calibration that the results from one icing wind tunnel facility to the next should be comparable.

The comparison of the icing blade with the single rotating cylinder for measuring LWC was successful in showing agreement between the two methods. A line of best fit passing through the origin relating all the data points showed that on average the single rotating cylinder reads an LWC that is $2.3 \%$ higher than the icing blade.

The comparison of the instrumentation used for measuring the MVD of spray clouds was also successful in showing agreement between the various techniques. The rotating multicylinder technique, as modified for use in the AlWT, proved to be successful in measuring the MVD of a variety of spray clouds. The results for MVD from the rotating multicylinder compared well with both the Malvern Spraytec and the PDPA. The cross comparison of the all three techniques showed only relatively minor discrepancies of the order of $5 \mu \mathrm{m}$. Typical SAE recommended practices (ARP-5905) require that icing tunnels produce clouds within $\pm 10 \%$ of the desired MVD and for the most part the results are comparable within that degree of accuracy. The discrepancies in the results 
can be ascribed to anomalies encountered when collecting data with the laser instruments. The erroneous data occurred at only certain MVDs and airspeeds where the other light scattering instrument compared well with the rotating multicylinder. Thus the rotating multicylinder is shown to be an excellent benchmarking technique that can be employed whenever light scattering instrumentation is used to measure MVD. The rotating multicylinder's relative simplicity and low cost make it a viable technique for this purpose. However experimentation for a complete test point takes approximately 10 minutes to complete, making the technique suitable mainly for 'spot checking' or benchmarking of facility calibrations and/or of light scattering instrumentation. Picking check points that adequately cover the range that is to be measured is crucial. The multicylinder apparatus used in this thesis work is limited by vibration considerations to airspeeds at or below about $50 \mathrm{~m} / \mathrm{s}$. In order for the method to be used at higher airspeeds the support shaft that secures the larger cylinders must be reinforced in order to stop vibration. This modification would make it possible to use the rotating multicylinder over a range of airspeeds more typical of aircraft icing conditions.

The rotating multicylinder returns an LWC as well as an MVD as part of its results. A cross comparison of the LWC returned by the multicylinder with that of the single rotating cylinder and the icing blade showed that the three methods give consistent results. Examination of all the LWC data collected as part of this thesis reveals a trend relating the three instruments. The single rotating cylinder 
method measures the largest LWC for a given set of spray conditions. The icing blade measures a slightly lower LWC than the single rotating cylinder (about $2.3 \%$ smaller on average). The rotating multicylinder measures an LWC that is roughly $5.6 \%$ smaller that the single rotating cylinder. For the most part the difference in observed trends lies within the uncertainty of the measurements, and the methods are basically in agreement in measuring LWC.

The sole exception to instrument consistency was the comparison of the King probe LWC results with those of the single rotating cylinder. During this investigation it was found that the rotating cylinder consistently measured a higher liquid water content than the King probe and that the discrepancy increased with increasing airspeed. Because previous results obtained from these two methods have been comparable it is highly likely that the King probe used for the tests conducted as part of this thesis was malfunctioning. Further investigation into the source of the malfunction is necessary if the King probe is to be used for calibration and mapping purposes.

The replication study of the SAE inter-facility comparison study results presented in Section 5.1 determined that a $30 \%$ increase in the MVD has a significant impact on the ice shapes produced for given set of conditions. The effects are obvious in both the rime and glaze cases tested. 


\section{RECOMMENDATIONS}

As mentioned in Section 5.5, the effect of the concentration of large droplets towards the centerline of the test section on the droplet spectrum should be investigated at different airspeeds.

The single rotating cylinder, icing blade, and rotating multicylinder have been shown to be accurate instruments for measuring the properties of spray clouds. Because they rely on simple physics and the predicable accretion of rime ice, their results are repeatable and there is relatively little chance for error as compared with light scattering instrumentation. It is suggested that these instruments be used in validating the results of more complex instrumentation. Hot wire probes and light scattering instrumentation are efficient since many data points can be collected in a relatively short amount of time. However, their results are more prone to errors as shown in Sections 5.3 and 5.4 of this thesis. 


\section{REFERENCES}

Achenbach, E., 1977, 'The Effect of Surface Roughness on the Heat Transfer from a Circular Cylinder in Cross Flow of Air', Int. J. of Heat Mass Transf., Vol. 20, pp 359-369.

Anderson, D., 2003, "Private communication"

Anonymous, 'CSIRO-KING Liquid Water Content Probe PMS Model KLWC-5 Operating and Servicing Manual'

Anonymous, 2004, 'SAERevisedPDI3-10-04 Draft.doc', revised subsection for upcoming ARP document.

Brun, R., Lewis, W., Perkins, P. and Sacrafini, J., 1955, 'Impingement of Cloud Droplets on a Cylinder and Procedure for Measuring Liquid Water Content and Droplet Sizes in Supercooled Clouds by Rotating Cylinder Method', NACA Report 1215.

Finstad, R.J., Lozowski, E.P., Gates, E.M., 1988, 'A Computational Investigation of Water Droplet Trajectories', J. Atmospheric and Oceanic Technology, Vol. 5.

Finstad, R.J., Lozowski, E.P., Makkonen, L., 1988, 'On the Median Volume Diameter Approximation for Droplet Collision Efficiency', J. Atmospheric Sciences, Vol. 45 , No. 24.

Howe, J.B., 1991, 'Rotating Multicylinder Method for the Measurement of Cloud Liquid-Water Content and Droplet Size', CRREL Report 91-2.

Ide, R.F., 1999, 'Comparison of Liquid Water Content Measurement Techniques in an Icing Wind Tunnel', National Aeronautics and Space Administration, Cleveland Oh. Glenn Research Center, AD-a371 598 NASA-E-11975.

Jeck, R., 1997, 'Meteorological Data for Use in Simulating Icing Conditions', Chapter 2 AGARD-AR-344 Ice Accretion Simulation.

Jones, K.F., 1990, 'The Density of Natural Ice Accretions Related to NonDimensional Icing Paramters', Q. J. R. Meteorological Society, Vol. 116, pp 477496.

Langmuir, I., Blodgett, K., 1946, 'A Mathematical Investigation of Water Droplet Trajectories', Collected Works of Irving Langmuir, Vol. 10, Pergamon Press, pp. 348-393. 
Lozowski, E.P., Gates, E.M., Makkonen, L., 1987, 'Recent Progress in the Incorporation of Convective Heat Transfer Into Ice Accretion Models', ASME International Symposium on Cold Regions Heat Transfer.

Macklin, W. C., 1962, 'The Density and Structure of Ice Formed by Accretion', Quarterly Journal of the Royal Meteorological Society, Vol. 88, pp. 30-50.

Makkonen, L., 1984, 'Modeling of Ice Accretion on Wires', J. Climate and Applied Meteorology, 23.

Makkonen, L., 1991, 'Analysis of Rotating Multicylinder Data in Measuring CloudDroplet Size and Liquid Water Content', J. of Atmospheric and Oceanic Technology, Vol. 9, pp 258-263.

Marek, C. J., 1988, 'Stability Relationship for Water Droplet Crystallization with the NASA Lewis Icing Spray Nozzle', $26^{\text {th }}$ AIAA Aerospace Sciences Meeting.

Messinger, B.L., 1953, 'Equilibrium Temperature of an Un-heated Icing Surface as a Function of Airspeed', Journal of Aeronautical Sciences, vol. 20, pp. 29-41.

Oleskiw, M.M., Hyde, F.H., Penna, P.J., 2001, 'In-Flight Icing Simulation Capabilities of NRC's Altitude Icing Wind Tunnel', $39^{\text {th }}$ AIAA Aerospace Sciences Meeting \& Exhibit, AIAA-2001-0094.

SAE, 2002, 'Calibration and Acceptance of Icing Wind Tunnels', SAE Aerospace Recommended Practices (ARP)-5905, Society of Automotive Engineers, Warrendale, PA, draft.

Schulz, R.J. 1997, 'Modeling of Water Particle Freezing for Simulation of Adverse Weather Conditions', XIII International Symposium on Air Breathing Engines, September.

Stallabrass, J.R., 1978: An Appraisal of the Single Rotating Cylinder Method of Liquid Water Content Measurement. National research Council of Canada, Division of Mechanical Engineering, Ottawa, Ontario, K1A OR6, Canada, Tech. Rep. LTR-LT-92, 26 pp.

van Hengst, J., Gent, R., Hammond, D., Seubert, R., Wagner, B., 1997, 'Ice Accretion and lits Effects on Aircraft', Chapter 3 in AGARD-AR-344.

Wagner, B., Hammond, D., van Hengst, J., Gent, R., Kind, R., 1997, 'Introduction', Chapter 1 in AGARD-AR-344 Ice Accretion Simulation. 


\begin{tabular}{|c|c|c|c|c|c|c|c|}
\hline $\begin{array}{l}\operatorname{Re} \\
\text { drop }\end{array}$ & $\begin{array}{c}\text { lamda/lamdas } \\
\text { Langmuir } \\
\text { (eq. 2.5) }\end{array}$ & $\begin{array}{l}\text { larnda/lamdas } \\
\text { Stallabrass } \\
\text { Aproximation } \\
\text { (eq. 2.6) }\end{array}$ & $\begin{array}{c}\% \text { error } \\
\text { Langmuir } \\
\text { vs } \\
\text { Stallabrass }\end{array}$ & Re drop & $\begin{array}{c}\text { lamda/lamdas } \\
\text { Langmuir } \\
\text { (eq. 2.5) }\end{array}$ & $\begin{array}{l}\text { lamda/lamdas } \\
\text { Stallabrass } \\
\text { Aproximation } \\
\text { (eq. 2.6) }\end{array}$ & $\begin{array}{c}\% \text { error } \\
\text { Langmuir } \\
\text { vs } \\
\text { Stallabrass }\end{array}$ \\
\hline 0.00 & 1.0000 & 1.0000 & 0.0000 & \multirow{14}{*}{\multicolumn{2}{|c|}{ 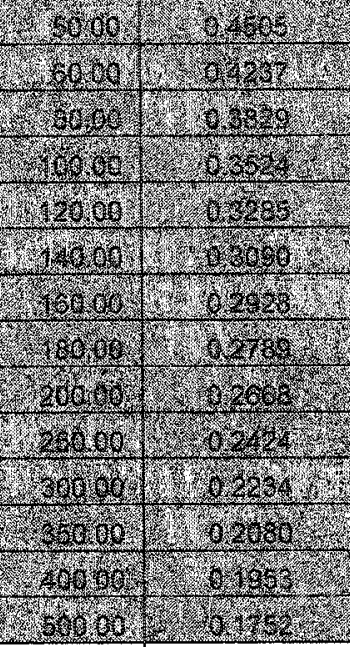 }} & \multirow{4}{*}{\multicolumn{2}{|c|}{ 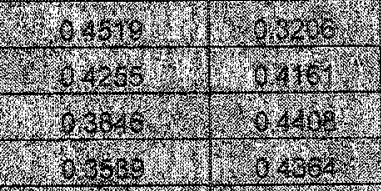 }} \\
\hline 0.05 & 0.9956 & 0.9798 & -1.5848 & & & & \\
\hline 0.10 & 0.9911 & 0.9699 & -2.1357 & & & & \\
\hline 0.20 & 0.9832 & 0.9554 & -2.8256 & & & & \\
\hline 0.40 & 0.9652 & 0.9344 & -3.1939 & & & & 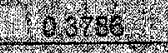 \\
\hline 0.60 & 0.9493 & 0.9181 & -3.2878 & & & & $176,1+6$ \\
\hline 0.80 & 0.9342 & 0.9044 & -3.1915 & & & & 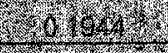 \\
\hline 1.00 & 0.9200 & 0.8924 & -3.0023 & & & 2 & Togras \\
\hline 1.20 & 0.9068 & 0.8816 & -2.7786 & & & 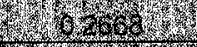 & (x) \\
\hline 1.40 & 0.8950 & 0.8718 & -2.5948 & & & $18+4$ & \multirow{2}{*}{ 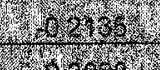 } \\
\hline 1.60 & 0.8842 & 0.8627 & -2.4306 & & & & \\
\hline 1.80 & 0.8744 & 0.8543 & -2.3023 & & & & \multirow{3}{*}{ 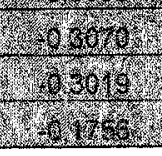 } \\
\hline 2.00 & 0.8653 & 0.8464 & -2.1890 & & & & \\
\hline 2.50 & 0.8452 & 0.8284 & -1.9821 & & & Why & \\
\hline 3.00 & 0.8273 & 0.8126 & -1.7750 & 600.00 & 0.1597 & 0.1599 & 0.1303 \\
\hline 3.50 & 0.8120 & 0.7984 & -1.6784 & 800.00 & 0.1373 & 0.1384 & 0.8010 \\
\hline 4.00 & 0.7978 & 0.7854 & -1.5554 & 1000.00 & 0.1215 & 0.1234 & 1.5923 \\
\hline \multirow{6}{*}{ 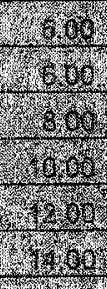 } & $1+6 x^{3}$ & \multirow{2}{*}{ r } & \multirow{2}{*}{ 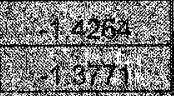 } & 1200.00 & 0.1097 & 0.1123 & 2.3329 \\
\hline & $\sqrt{3}$ & & & 1400.00 & 0.1003 & 0.1035 & 3.2005 \\
\hline & W & 8086 & 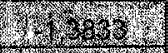 & 1600.00 & 0.0927 & 0.0964 & 4.0176 \\
\hline & & 66 & (x) $14 x<5$ & 1800.00 & 0.0863 & 0.0905 & 4.9098 \\
\hline & 668 & (1) & $4(3), 4$ & 2000.00 & 0.0809 & 0.0855 & 5.7445 \\
\hline & 10 & 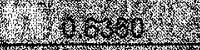 & r. & 2500.00 & 0.0703 & 0.0758 & 7.8155 \\
\hline \multirow{3}{*}{ m } & 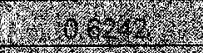 & 618 & 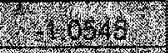 & 3000.00 & 0.0624 & 0.0686 & \multirow{2}{*}{$\begin{array}{c}9.9272 \\
12.1121 \\
\end{array}$} \\
\hline & & & (3) & 3500.00 & 0.0562 & 0.0630 & \\
\hline & 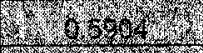 & 4 & (2) & 4000.00 & 0.0513 & 0.0585 & \multirow{2}{*}{$\begin{array}{l}14.0602 \\
17.6945\end{array}$} \\
\hline \multirow{2}{*}{$x^{2}+2 \times 1,0$} & & (f 658 & 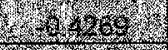 & 5000.00 & 0.0439 & 0.0517 & \\
\hline & . & (6. 62 & 46 & 6000.00 & 0.0385 & 0.0466 & 21.1540 \\
\hline \multirow{2}{*}{ Prats } & & 政 & 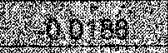 & 8000.00 & 0.0311 & 0.0397 & 27.4965 \\
\hline & & & (3) & 10000.00 & 0.0262 & 0.0349 & 33.3244 \\
\hline
\end{tabular}

Table 2.1: Computed values of $\lambda / \lambda_{s}$ as determined by equations (2.5) and (2.6). The range of applicable of Reynolds numbers has been shaded in grey. 


\begin{tabular}{|c|c|c|r|r|c|}
\hline & $\begin{array}{c}\text { True } \\
\text { Airspeed } \\
(\mathrm{m} / \mathrm{s})\end{array}$ & $\begin{array}{c}\text { Static } \\
\text { Temp } \\
(\mathrm{C})\end{array}$ & $\begin{array}{c}\text { Calculated } \\
\text { MVD (um) }\end{array}$ & $\begin{array}{c}\text { Calculated } \\
\text { LWC } \\
(\mathrm{g} / \mathrm{m} 3)\end{array}$ & $\begin{array}{c}\text { Run } \\
\text { Time } \\
(\mathrm{sec})\end{array}$ \\
\hline SAE Case 1 & 67.0 & -7.0 & 20.0 & 0.50 & 900 \\
\hline & & & & & \\
\hline SAE Case 3 & 67.0 & -7.0 & 20.0 & 1.00 & 600 \\
\hline & & & & & \\
\hline SAE Case 9 & 67.0 & -23.0 & 20.0 & 0.50 & 900 \\
\hline
\end{tabular}

Table 3.1: Test Point Conditions Replicated from the SAE Facility InterComparison Study.

\begin{tabular}{|c|c|}
\hline Inches & $\mathrm{mm}$ \\
\hline 5.0000 & 127.000 \\
\hline 20000 & 6roor \\
\hline 1.7500 & 44.450 \\
\hline Wh t ror & 860 \\
\hline 0.8750 & 22.225 \\
\hline 0.7500 & 19.050 \\
\hline ro 626 & 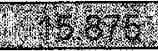 \\
\hline 0.5000 & 12.700 \\
\hline 0.3750 & 9.525 \\
\hline 0.3125 & 7.938 \\
\hline 0.2569 & 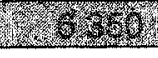 \\
\hline 0.1969 & 5.000 \\
\hline
\end{tabular}

Table 4.1: Diameters of stock pipe considered for use in the multicylinder set.

\begin{tabular}{|l|rrrrrrr|}
\hline & \multicolumn{7}{|c|}{ Percent of Total Liquid Water } \\
\cline { 2 - 9 } Distribution & 5 & 10 & 20 & 30 & 20 & 10 & 5 \\
\hline A & 1.00 & 1.00 & 1.00 & 1.00 & 1.00 & 1.00 & 1.00 \\
B & 0.73 & 0.92 & 0.96 & 1.00 & 1.06 & 1.16 & 1.26 \\
C & 0.63 & 0.88 & 0.94 & 1.00 & 1.09 & 1.25 & 1.41 \\
D & 0.53 & 0.85 & 0.92 & 1.00 & 1.12 & 1.35 & 1.59 \\
E & 0.46 & 0.81 & 0.90 & 1.00 & 1.16 & 1.45 & 1.78 \\
F & 0.39 & 0.78 & 0.88 & 1.00 & 1.19 & 1.56 & 2.00 \\
G & 0.33 & 0.75 & 0.87 & 1.00 & 1.23 & 1.68 & 2.25 \\
H & 0.28 & 0.72 & 0.85 & 1.00 & 1.26 & 1.81 & 2.52 \\
J & 0.21 & 0.66 & 0.82 & 1.00 & 1.34 & 2.10 & 3.18 \\
\hline
\end{tabular}

Table 4.2: Droplet Size Spectra Used at the Mt. Washington Observatory (as presented by Jones, 1989) 


\begin{tabular}{|c|c|c|c|c|c|c|c|c|c|c|c|c|c|c|c|c|}
\hline$\frac{\overrightarrow{0}}{0}$ & $\stackrel{8}{8}$ & 8 & : & 8 & 5 & 8 & $\Phi$ & $\div$ & 8 & 8 & 818 & 8 & $\stackrel{8}{-}$ & 8 & 8 & $\stackrel{8}{-}$ \\
\hline$\frac{8}{6}$ & 8 & 8 & 8 & 8 & {$[5$} & 8 & 5 & 8 & 8 & 8 & 8 & $\stackrel{8}{-}$ & 8 & 8 & $\stackrel{8}{-}$ & 8 \\
\hline 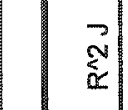 & $\left|\begin{array}{l}0 \\
8 \\
8 \\
0\end{array}\right|$ & $\begin{array}{l}9 \\
8 \\
g \\
0 \\
0\end{array}$ & $\begin{array}{l}2 \\
8 \\
0 \\
0 \\
0\end{array}$ & 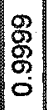 & $\begin{array}{l}0 \\
0 \\
0 \\
0 \\
0\end{array}$ & $\mid \begin{array}{l}1 \\
8 \\
0 \\
0 \\
0\end{array}$ & $\begin{array}{l}\infty \\
8 \\
8 \\
0 \\
0\end{array}$ & $\begin{array}{l}\mathcal{N} \\
8 \\
0 \\
0\end{array}$ & $\begin{array}{l}0 \\
\\
5 \\
0 \\
\end{array}$ & $\begin{array}{l}1 \\
\overline{8} \\
\% \\
0 \\
0\end{array}$ & \begin{tabular}{l|l}
2 \\
2 \\
8 \\
0 \\
0
\end{tabular} \mid & $\begin{array}{l}0 \\
: \\
: \\
o \\
0\end{array}$ & $\begin{array}{l}\infty \\
8 \\
8 \\
0 \\
0\end{array}$ & $\begin{array}{l}\hat{8} \\
8 \\
8 \\
0\end{array}$ & $\mid \begin{array}{l}\infty \\
: \\
8 \\
0 \\
0\end{array}$ & \begin{tabular}{l}
8 \\
8 \\
\hdashline
\end{tabular} \\
\hline 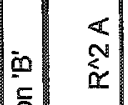 & 8 & 8 & $\begin{array}{l}8 \\
8 \\
8 \\
0\end{array}$ & 8 & 8 & 8 & 8 & $\begin{array}{l}8 \\
8 \\
0 \\
-1\end{array}$ & 8 & 8 & $\begin{array}{l}\mathscr{8} \\
8 \\
8 \\
0 \\
0\end{array}$ & $\begin{array}{l}8 \\
8 \\
\\
-1\end{array}$ & \begin{tabular}{l}
8 \\
8 \\
\hdashline \\
\end{tabular} & $\begin{array}{l}8 \\
8 \\
-8\end{array}$ & $\frac{8}{8}$ & $\begin{array}{l}8 \\
8 \\
8 \\
0 \\
0\end{array}$ \\
\hline 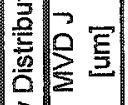 & 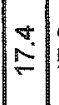 & $\mid \frac{\infty}{\nabla}$ & $\frac{9}{\circ}$ & $\begin{array}{l}q \\
\sigma \\
\sigma\end{array}$ & $F$ & $\begin{array}{l}5 \\
g\end{array}$ & $\infty$ & {$\left[\begin{array}{l}\Omega \\
0 \\
0\end{array}\right.$} & $\stackrel{\infty}{\infty}$ & $\log$ & $\infty$ & $\frac{\nabla}{8}$ & $\stackrel{\sim}{\sim}$ & $\begin{array}{l}8 \\
\dot{8}\end{array}$ & 운 & is \\
\hline 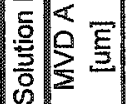 & 웅 & 10 & 10 & : & $\begin{array}{l}0 \\
0 \\
16\end{array}$ & : & 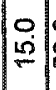 & 웅 & $\begin{array}{l}0 \\
10 \\
2\end{array}$ & : & 息 & $\begin{array}{l}0 \\
8 \\
8\end{array}$ & 10 & $\begin{array}{l}0 \\
0 \\
0\end{array}$ & 10 & 家 \\
\hline$\underline{3}:$ & $\begin{array}{l}8 \\
8 \\
0\end{array}$ & $\mid \begin{array}{l}8 \\
8 \\
0\end{array}$ & $\begin{array}{l}1 \\
0 \\
\infty \\
0 \\
0\end{array}$ & $\begin{array}{l}m \\
\infty \\
0 \\
0\end{array}$ & Sू: & I: & $\begin{array}{l}\overline{8} \\
0 \\
0\end{array}$ & $\frac{1}{8}$ & $\mid \begin{array}{c}0 \\
0 \\
0 \\
0 \\
0\end{array}$ & 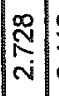 & $\left.\frac{N}{d}\right]^{2}$ & م. & हึ่ & $\begin{array}{c}\mathbb{R} \\
N \\
N\end{array}$ & เึ: & $\frac{n}{i n}$ \\
\hline$\sum_{3}^{<}=$ & 兽 & $\frac{5}{8}$ & $\frac{\mathscr{B}}{8}$ & 8 & 号 & - & 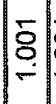 & $\overline{8}$ & $\frac{\pi}{x}$ & $\frac{N}{2}$ & $\left(\begin{array}{l}\infty \\
N \\
n\end{array}\right.$ & $\mid \begin{array}{c}i \\
⿱ 乛 \\
i\end{array}$ & $\mid \begin{array}{l}\bar{n} \\
\frac{1}{n}\end{array}$ & No & $\stackrel{m}{n}$ & W \\
\hline $\begin{array}{l}\overrightarrow{0} \\
\frac{0}{0} \\
0\end{array}$ & 8 & 8 & 8 & 8 & 임 & $|8|$ & 8 & $\stackrel{5}{\circ}$ & $\stackrel{8}{8}$ & 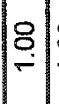 & $\stackrel{8}{\circ}$ & 8 & 8 & 8 & 8 & 8 \\
\hline $\begin{array}{l}\alpha \\
0 \\
\frac{0}{0} \\
\frac{0}{6}\end{array}$ & 8 & 8 & 8 & 8 & 原 & 8 & 5 & $\mid \begin{array}{l}\mathscr{O} \\
0 \\
0\end{array}$ & 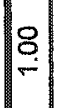 & 8 & 8 & $\stackrel{8}{\circ}$ & 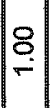 & 8 & $\mid \frac{8}{8}$ & 8 \\
\hline$\vec{\sim}$ & $\begin{array}{l}8 \\
8 \\
8\end{array}$ & 8 & 8 & 8 & $\begin{array}{l}8 \\
8 \\
8 \\
0 \\
0\end{array}$ & 8 & 8 & 8 & 18 & 8 & 8 & 8 & 8 & 8 & 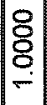 & 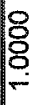 \\
\hline $\begin{array}{l}\varangle \\
\mathbb{q} \\
\ltimes\end{array}$ & 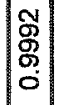 & $\begin{array}{l}\infty \\
\beta \\
8 \\
0 \\
0\end{array}$ & $\begin{array}{l}0 \\
5 \\
8 \\
0 \\
0\end{array}$ & \& & 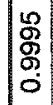 & $\begin{array}{l}2 \\
2 \\
8 \\
0 \\
0\end{array}$ & $\mid \begin{array}{l}5 \\
\stackrel{8}{8} \\
0 \\
0\end{array}$ & 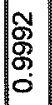 & $\begin{array}{l} \\
\\
5 \\
0\end{array}$ & 存 & {$\left[\begin{array}{l}\dot{2} \\
0 \\
0 \\
0\end{array}\right]$} & 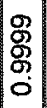 & $\mid \begin{array}{l}\mid \\
\overline{8} \\
0 \\
0 \\
0\end{array}$ & $\mid \begin{array}{l}\hat{\infty} \\
0 \\
0 \\
0 \\
0\end{array}$ & $\begin{array}{l}\infty \\
8 \\
8 \\
0 \\
0\end{array}$ & 贻 \\
\hline 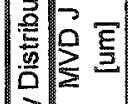 & in & 5 & ș & lo & 20 & $\mid \begin{array}{l}0 \\
0 \\
0\end{array}$ & $\frac{4}{8}$ & $\mid \begin{array}{l}0 \\
g \\
\end{array}$ & 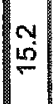 & $5:$ & $\infty$ & 10 & $\mid \begin{array}{c}2 \\
1 \\
12\end{array}$ & $\left(\begin{array}{l}3 \\
8\end{array}\right.$ & $\begin{array}{l}y \\
10\end{array}$ & 10: \\
\hline$\frac{5}{8} \sum_{i} \Xi$ & $\stackrel{a}{-a}$ & $\begin{array}{l}8 \\
8 \\
8\end{array}$ & $\stackrel{\Omega}{\stackrel{3}{2}}$ & 10 & $\mid \stackrel{g}{\dot{m}}$ & $\mid \begin{array}{l}\infty \\
0 \\
9 \\
q\end{array}$ & $\underset{\infty}{\infty}$ & $\begin{array}{l}8 \\
0\end{array}$ & $\stackrel{\leftrightarrow}{\stackrel{2}{2}}$ & $\mid \begin{array}{l}0 \\
8 \\
0\end{array}$ & $\stackrel{i}{\sim}$ & $\begin{array}{l}0 \\
0 \\
0\end{array}$ & $\stackrel{a}{\sim}$ & 8 & $\stackrel{m}{m}$ & 象 \\
\hline ड़ & $\mid$ & 18 & \% & 18 & $\begin{array}{l}5 \\
8 \\
0 \\
0\end{array}$ & $\left|\begin{array}{l}\infty \\
8 \\
0 \\
0\end{array}\right|$ & S. & 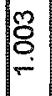 & $\stackrel{R}{R}$ & $\frac{5}{\mathrm{~L}}$ & $\left(\frac{0}{N}\right.$ & $\frac{1}{n}$ & लि & 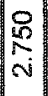 & $\operatorname{lid}^{+}$ & riv \\
\hline 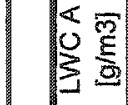 & $\stackrel{\infty}{=}$ & $\check{L}^{\infty}$ & $\frac{1}{5}$ & $\int_{0}^{\infty}$ & 足 & $\mid \begin{array}{l}0 \\
0 \\
口\end{array}$ & $\mid \begin{array}{l}0 \\
0 \\
0 \\
-1\end{array}$ & $\stackrel{N}{O}$ & $\frac{\infty}{2}$ & $\left|\begin{array}{c}3 \\
0 \\
N \\
N\end{array}\right|$ & {$\left[\begin{array}{c}0 \\
0 \\
m\end{array}\right]$} & D & $\left|\begin{array}{c}\infty \\
0 \\
0 \\
m\end{array}\right|$ & $\stackrel{m}{\infty}$ & $\stackrel{8}{\infty}$ & No \\
\hline$\frac{1}{\frac{\pi}{\omega}}$ & i⿱宀 & $\stackrel{\overbrace{}}{2}$ & $\infty 8$ & ชิ & 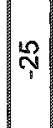 & m & พั & $\underset{⿴ 囗 十)}{\stackrel{2}{*}}$ & No & $\stackrel{2}{\leftrightarrow}$ & จึ & $\mathscr{N}$ & $|\stackrel{\leftrightarrow}{*}|$ & $\stackrel{\leftrightarrow}{\sim}$ & $\stackrel{\circ}{\gamma}$ & $\stackrel{W}{\sim}$ \\
\hline$\sum_{3}^{0}$ & - & - & - & - & - & -1 & -1 & $F$ & $\frac{2}{2}$ & $\begin{array}{l}\mathscr{L} \\
\mathrm{N}\end{array}$ & {$\left[\begin{array}{l}N \\
\mathrm{~N}\end{array}\right.$} & $\stackrel{R}{N}$ & ro & $\frac{10}{2}$ & $\frac{N}{\sim}$ & in \\
\hline$\sum_{\Sigma}$ & 12 & 品 & 12 & in & $\stackrel{12}{\div}$ & 18 & 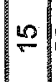 & 18 & 12 & 18 & 12 & 8 & $\because 2$ & 18 & 10 & 오 \\
\hline$\frac{\bar{n}}{\varepsilon}$ & 8 & 足 & 옥 & 8 & 움 & 유 & 8 & 18 & Pי & m & IR & Iㅁ & I요 & 8 & 18 & R \\
\hline
\end{tabular}

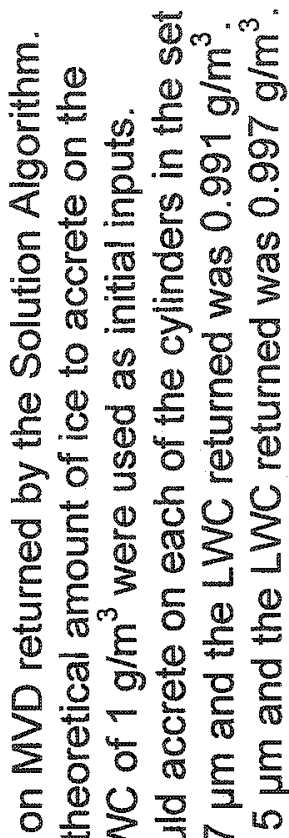

ह乌 $5 \div 5+\infty$ Q ब N $8 \equiv .2 E 5$ क 20 눙 ॠ.

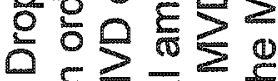
$\square \leq \sum \frac{0}{\sigma} \sum$

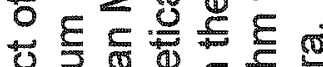
Q (11) 0 윤 8 0 응

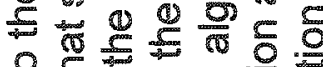

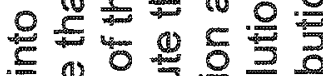

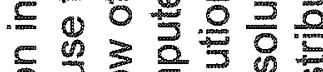
59323 은 $=0$ (1) 8 क

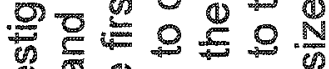

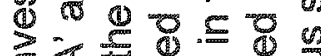
$\geq< \pm 0=0$ $\leq \pm 9 \mathscr{0}$. \& $\overrightarrow{0} 0 \mathrm{c}$ क ल $\div$ 을 3 क एँ $\pm 00$ \% लं 0 하 m * $\frac{0}{0}$ 응 $\frac{5}{0} \frac{1}{0}$

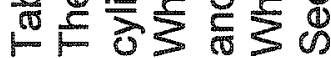



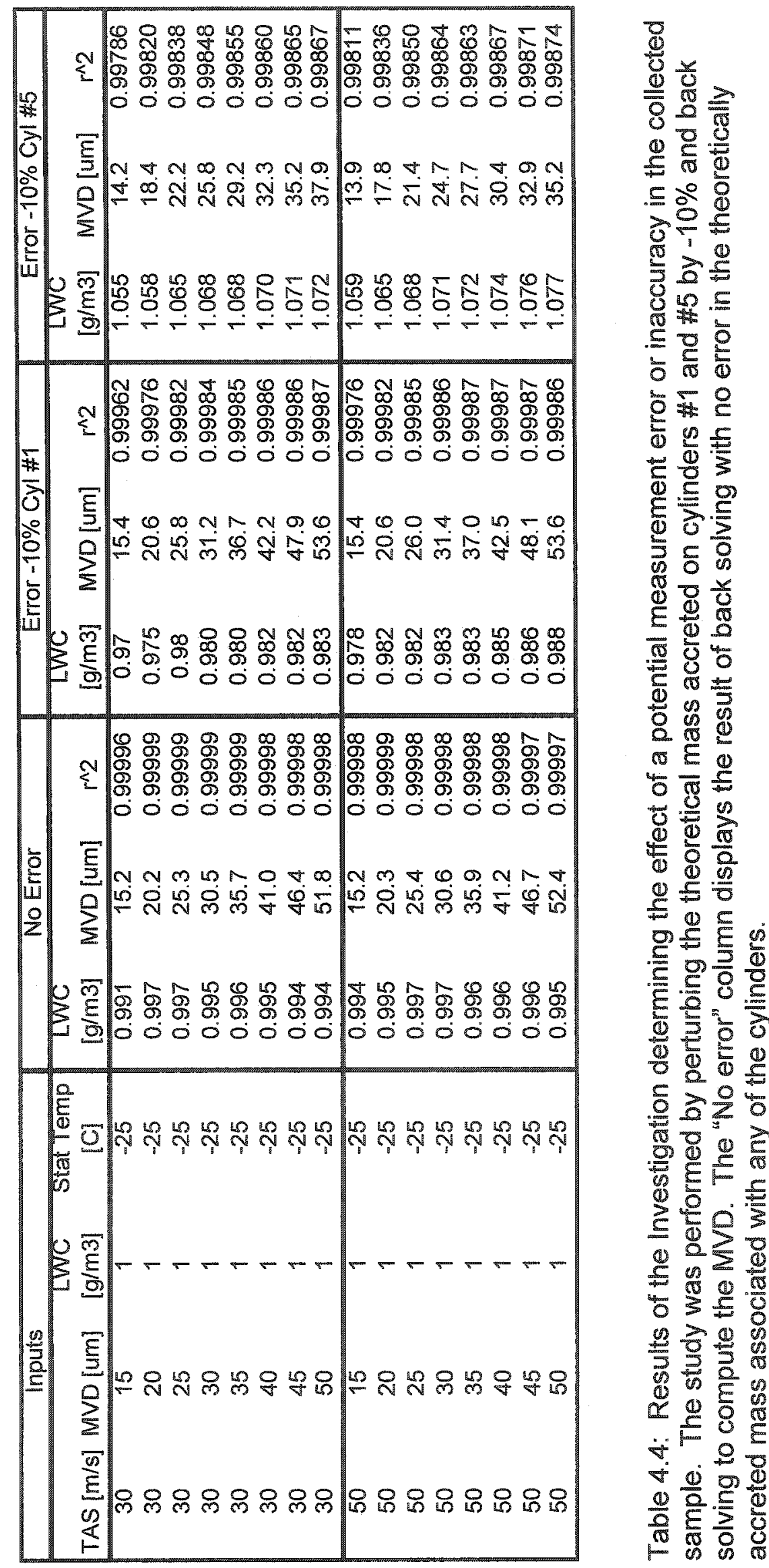


\begin{tabular}{|c|c|c|c|c|c|c|c|c|c|}
\hline & $\begin{array}{l}\text { True } \\
\text { Airspeed } \\
(\mathrm{m} / \mathrm{s})\end{array}$ & $\begin{array}{l}\text { Static } \\
\text { Temp } \\
\text { (C) }\end{array}$ & $\begin{array}{c}\text { Spray Air } \\
\text { Pressure } \\
(\mathrm{kPa})\end{array}$ & $\begin{array}{c}\text { Spray Air } \\
\text { Flow } \\
(\mathrm{g} / \mathrm{min} / \mathrm{noz})\end{array}$ & $\begin{array}{l}\text { Calculated } \\
\text { MVD (um) }\end{array}$ & $\begin{array}{c}\text { Spray } \\
\text { Water } \\
\text { Pressure } \\
(\mathrm{kPa})\end{array}$ & $\begin{array}{c}\text { Spray Water } \\
\text { Flow } \\
\text { (g/min/noz) }\end{array}$ & $\begin{array}{c}\text { Calculated } \\
\text { LWC }(\mathrm{g} / \mathrm{m} 3)\end{array}$ & $\begin{array}{l}\text { Run } \\
\text { Time } \\
(\mathrm{sec})\end{array}$ \\
\hline Nominal & 67.0 & -7.0 & - & - & 20.0 & - & - & 0.50 & 900 \\
\hline 20030918-02 & 67.0 & -7.0 & 79.0 & 105.8 & 20.2 & 200.0 & 21.3 & 0.48 & 900 \\
\hline 20030922-02 & 67.0 & -7.0 & 80.0 & 106.0 & 20.0 & 200.0 & 21.0 & 0.47 & 900 \\
\hline 20030929-01 & 67.0 & -7.0 & 47.9 & 80.3 & 30.0 & 200.0 & 21.3 & 0.48 & 900 \\
\hline
\end{tabular}

Table 5.1: Test Points Used in the Replication of SAE Case 1 of the Inter-Facility Comparison.

\begin{tabular}{|c|c|c|c|c|c|c|c|c|c|}
\hline & $\begin{array}{c}\text { True } \\
\text { Airspeed } \\
(\mathrm{m} / \mathrm{s})\end{array}$ & $\begin{array}{c}\text { Static } \\
\text { Temp } \\
\text { (C) }\end{array}$ & $\begin{array}{c}\text { Spray Air } \\
\text { Pressure } \\
(\mathrm{kPa})\end{array}$ & $\begin{array}{c}\text { Spray Air } \\
\text { Flow } \\
\text { (g/min } / \text { noz) }\end{array}$ & $\begin{array}{l}\text { Calculated } \\
\text { MVD (um) }\end{array}$ & $\begin{array}{c}\text { Spray } \\
\text { Water } \\
\text { Pressure } \\
(\mathrm{kPa})\end{array}$ & $\begin{array}{c}\text { Spray Water } \\
\text { Flow } \\
\text { (g/min/noz) }\end{array}$ & $\begin{array}{c}\text { Calculated } \\
\text { LWC }(\mathrm{g} / \mathrm{m} 3)\end{array}$ & $\begin{array}{l}\text { Run } \\
\text { Time } \\
\text { (sec) }\end{array}$ \\
\hline Nominal & 67.0 & -7.0 & - & - & 20.0 & - & - & 1.00 & 600 \\
\hline $20030826-01$ & 66.9 & -7.0 & 106.0 & 124.4 & 20.2 & 315.7 & 45.0 & 1.01 & 600 \\
\hline $20030826-02$ & 66.9 & -6.9 & 106.1 & 124.8 & 20.2 & 361.7 & 45.0 & 1.01 & 600 \\
\hline $20030826-03$ & 67.0 & -7.0 & 106.0 & 126.1 & 20.1 & 351.9 & 45.0 & 1.01 & 600 \\
\hline $20030826-04$ & 66.9 & -7.0 & 66.0 & 95.5 & 29.7 & 375.6 & 45.0 & 1.01 & 600 \\
\hline $20030918-03$ & 67.0 & -7.0 & 103.0 & 124.9 & 19.9 & 219.9 & 42.3 & 0.95 & 600 \\
\hline $20030922-03$ & 67.0 & -7.0 & 106.0 & 124.4 & 19.7 & 200.0 & 42.5 & 0.95 & 600 \\
\hline $20030922-04$ & 67.0 & -7.0 & 106.1 & 124.6 & 19.6 & 200.0 & 42.2 & 0.94 & 600 \\
\hline
\end{tabular}

Table 5.2: Test Points Used in the Replication of SAE Case 3 of the Inter-Facility Comparison.

\begin{tabular}{|c|c|c|c|c|c|c|c|c|c|}
\hline & $\begin{array}{c}\text { True } \\
\text { Airspeed } \\
(\mathrm{m} / \mathrm{s})\end{array}$ & $\begin{array}{l}\text { Static } \\
\text { Ternp } \\
\text { (C) }\end{array}$ & $\begin{array}{c}\text { Spray Air } \\
\text { Pressure } \\
(\mathrm{KPa})\end{array}$ & $\begin{array}{l}\text { Spray Air } \\
\text { Flow } \\
\text { (g/min/noz) }\end{array}$ & $\begin{array}{l}\text { Calculated } \\
\text { MVD (um) }\end{array}$ & $\begin{array}{c}\text { Spray } \\
\text { Water } \\
\text { Pressure } \\
\text { (kPa) }\end{array}$ & $\begin{array}{c}\text { Spray Water } \\
\text { Flow } \\
\text { (g/min/noz) }\end{array}$ & $\begin{array}{c}\text { Calculated } \\
\text { LWC }(g / \mathrm{m} 3)\end{array}$ & $\begin{array}{l}\text { Run } \\
\text { Time } \\
\text { (sec) }\end{array}$ \\
\hline Nominal & 67.0 & -23.0 & - & - & 20.0 & - & - & 0.50 & 900 \\
\hline 20030918-01 & 67.0 & -23.0 & 81.0 & 108.0 & 19.8 & 200.0 & 21.1 & 0.47 & 900 \\
\hline $20030922-01$ & 67.0 & -23.0 & 80.0 & 106.5 & 20.11 & 200.0 & 21.0 & 0.47 & 900 \\
\hline $20030929-02$ & 67.0 & -23.0 & 49.0 & 81.4 & 29.5 & 200.0 & 21.1 & 0.47 & 900 \\
\hline
\end{tabular}

Table 5.3: Test Points Used in the Replication of SAE Case 9 of the Inter-Facility Comparison. 


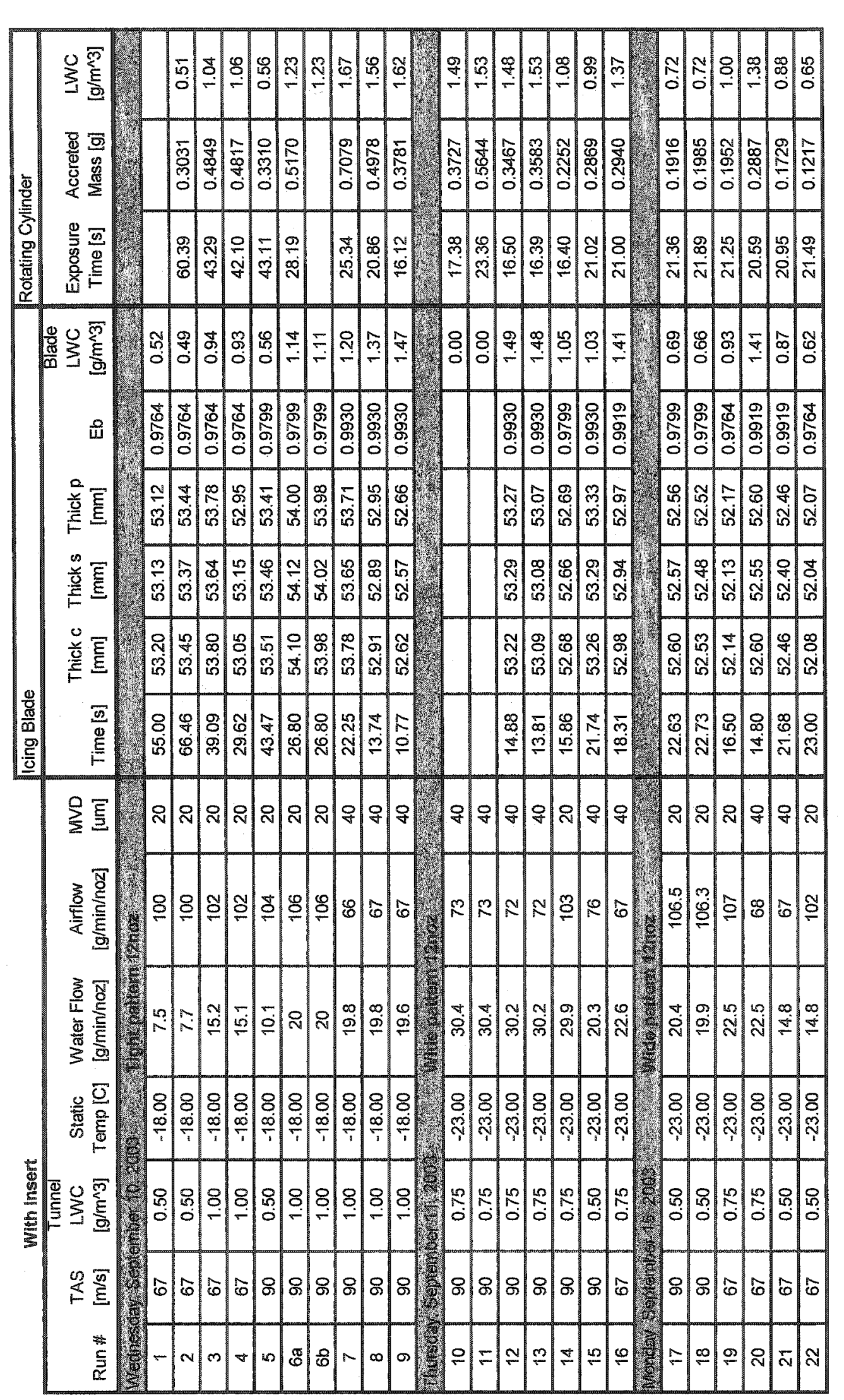

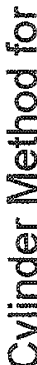

돈

8

$\propto \frac{\pi}{\pi}$

을

क $\frac{5}{0}$

(2)

5

${ }_{0}$

(1)

똥

용

돌

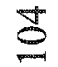

잉

ᄃ 틀

60

\%

ह

(2)

홍

os

5

a)

$\alpha$

눈

올 옥

00

帘

$10 \frac{2}{0}$

ष

แ०

(1) त्व

$\frac{10}{0}$ 


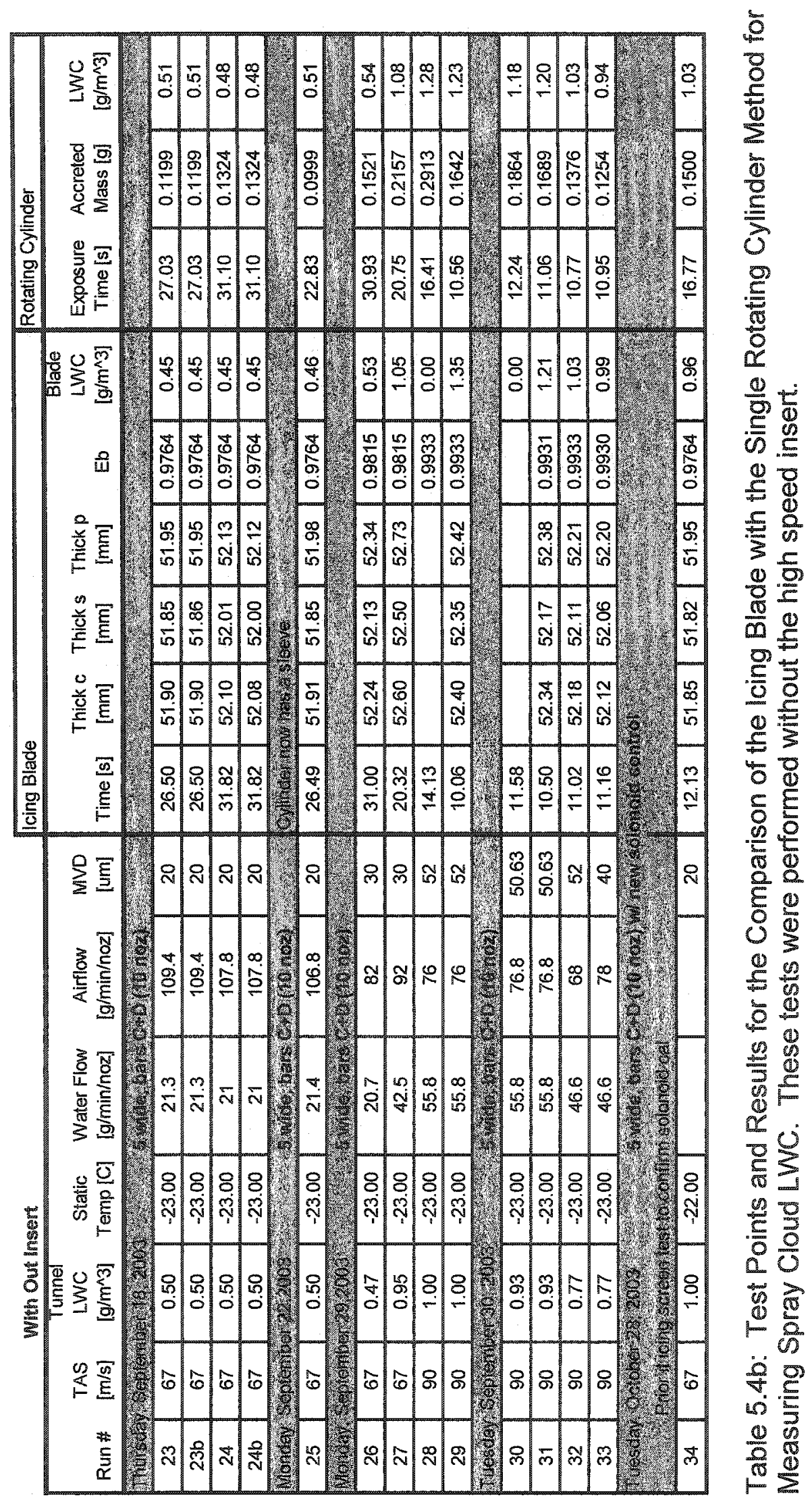




\begin{tabular}{|c|c|c|c|c|c|c|c|c|c|c|}
\hline $\begin{array}{l}\text { True } \\
\text { Air } \\
\text { Speed } \\
(\mathrm{m} / \mathrm{s})\end{array}$ & $\begin{array}{c}\text { Spray Air } \\
\text { Pressure } \\
(\mathrm{kPa})\end{array}$ & $\begin{array}{l}\text { Spray Air } \\
\text { Flow } \\
\text { (g/min/noz) }\end{array}$ & $\begin{array}{l}\text { Cal } \\
\text { MVD } \\
\text { (um) }\end{array}$ & $\begin{array}{c}\text { Spray Water } \\
\text { Pressure } \\
\text { (kPa) }\end{array}$ & $\begin{array}{c}\text { Spray Water } \\
\text { Flow } \\
\text { (g/min/noz) }\end{array}$ & $\begin{array}{l}\text { King } \\
\text { LWC } \\
\text { (g/m3) }\end{array}$ & $\begin{array}{c}\text { Icing } \\
\text { Time }[\mathrm{s}]\end{array} \mid$ & $\begin{array}{l}\text { Accreted } \\
\text { mass [g] }\end{array}$ & $\begin{array}{l}\text { New } \\
\text { Malvern } \\
\text { MVD } \\
\text { correlation } \\
\text { [um] }\end{array}$ & $\begin{array}{l}\text { RotCyl } \\
\text { LWC } \\
{[\mathrm{g} / \mathrm{m} 3]}\end{array}$ \\
\hline 30.0 & 103.6 & 121.8 & 15.9 & 239.1 & 10.8 & 0.43 & 120.31 & 0.2067 & 12.2 & 0.47 \\
\hline 30.0 & 116.9 & 131.8 & 15.3 & 240.0 & 20.2 & 0.81 & 69.63 & 0.2076 & 12.6 & 0.81 \\
\hline 30.0 & 129.4 & 139.9 & 14.9 & 239.2 & 26.4 & 1.07 & 50.04 & 0.2131 & 12.7 & 1.16 \\
\hline 30.0 & 130.0 & 139.0 & 15.2 & 240.4 & 29.2 & 1.16 & 50.30 & 0.2458 & 13.0 & 1.30 \\
\hline \multicolumn{11}{|l|}{ W28 } \\
\hline 30.0 & 44.5 & 75.4 & 30.0 & 240.0 & 11.2 & 0.58 & 119.72 & 0.3825 & 21.9 & 0.71 \\
\hline 30.0 & 49.8 & 79.9 & 29.0 & 239.9 & 20.1 & 1.08 & 59.99 & 0.3081 & 23.2 & 1.18 \\
\hline 30.0 & 50.7 & 80.8 & 29.6 & 240.0 & 24.1 & 1.36 & 60.34 & 0.3941 & 24.4 & 1.42 \\
\hline 29.9 & 54.0 & 83.6 & 29.4 & 239.8 & 28.7 & 1.60 & 50.19 & 0.3840 & 24.6 & 1.67 \\
\hline \multicolumn{11}{|l|}{ Try } \\
\hline 30.0 & 26.2 & 56.9 & 47.2 & 239.7 & 11.2 & 0.64 & 120.46 & 0.4615 & 37.7 & 0.78 \\
\hline 30.0 & 25.7 & 56.8 & 51.4 & 239.9 & 20.1 & 1.32 & 50.13 & 0.3367 & 45.1 & 1.44 \\
\hline 30.0 & 28.1 & 59.1 & 49.5 & 240.0 & 24.2 & 1.60 & 50.42 & 0.4466 & 44.4 & 1.79 \\
\hline 30.0 & 29.5 & 60.0 & 50.3 & 240.0 & 28.9 & 1.89 & 40.22 & 0.3990 & 45.5 & 2.05 \\
\hline
\end{tabular}

Table 5.5a: Test Point Conditions and Results for the Comparison of the Single Rotating Cylinder with the King Probe. Test points taken at $30 \mathrm{~m} / \mathrm{s}$.

\begin{tabular}{|c|c|c|c|c|c|c|c|c|c|c|}
\hline $\begin{array}{c}\text { True } \\
\text { Air } \\
\text { Speed } \\
(\mathrm{m} / \mathrm{s})\end{array}$ & $\begin{array}{c}\text { Spray Air } \\
\text { Pressure } \\
(\mathrm{kPa})\end{array}$ & $\begin{array}{l}\text { Spray Air } \\
\text { Flow } \\
\text { (g/min/noz) }\end{array}$ & $\begin{array}{l}\text { Cal } \\
\text { MVD } \\
\text { (um) }\end{array}$ & $\begin{array}{c}\text { Spray Water } \\
\text { Pressure } \\
\text { (kPa) }\end{array}$ & $\begin{array}{c}\text { Spray Water } \\
\text { Flow } \\
\text { (g/min/noz) }\end{array}$ & $\begin{array}{l}\text { King } \\
\text { LWC } \\
(g / m 3)\end{array}$ & $\begin{array}{c}\text { loing } \\
\text { Time [s] }\end{array}$ & $\begin{array}{l}\text { Accreted } \\
\text { mass [g] }\end{array}$ & $\begin{array}{c}\text { New } \\
\text { Malvern } \\
\text { MVD } \\
\text { correlation } \\
\text { [um] }\end{array}$ & $\begin{array}{l}\text { RotCyl } \\
\text { LWC } \\
{[\mathrm{g} / \mathrm{m} 3]}\end{array}$ \\
\hline 50.0 & 122.1 & 135.3 & 14.7 & 240.0 & 17.3 & 0.48 & 90.64 & 0.3251 & 12.1 & 0.53 \\
\hline 50.0 & 135.8 & 144.1 & 15.2 & 239.9 & 33.8 & 0.99 & 50.13 & 0.3797 & 13.2 & 1.07 \\
\hline 50.0 & 144.4 & 149.6 & 15.4 & 240.1 & 40.0 & 1.17 & 39.91 & 0.3751 & 13.4 & 1.33 \\
\hline 50.0 & 163.5 & 162.2 & 15.4 & 239.9 & 49.9 & 1.45 & 40.08 & 0.4712 & 13.5 & 1.59 \\
\hline 17x & 8 & $y_{3} y^{2}$ & 4 & 3.try & Ses & (r) & 8 & XIX & R. & 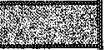 \\
\hline 50.0 & 47.5 & 78.8 & 29.5 & 240.0 & 17,3 & 0.53 & 80.41 & 0.4086 & 23.0 & 0.65 \\
\hline 50.0 & 56.0 & 86.2 & 30.1 & 239.9 & 34.0 & 1.10 & 39.58 & 0.3800 & 25.7 & 1.24 \\
\hline 50.0 & 62.2 & 91.5 & 29.5 & 240.0 & 40.0 & 1.30 & 36.65 & 0.4256 & 25.1 & 1.46 \\
\hline 50.0 & 70.0 & 97.1 & 30.4 & 239.8 & 49.8 & 1.74 & 35.79 & 0.6001 & 25.4 & 1.96 \\
\hline$x$ & & Wh & 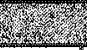 & 4 & 2 & 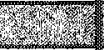 & & & 8 & 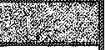 \\
\hline 50.0 & 25.8 & 57.8 & 49.7 & 240.0 & 17.3 & 0.63 & 59.74 & 0.3588 & 42.8 & 0.76 \\
\hline 50.0 & 32.2 & 64.0 & 49.1 & 240.0 & 34.0 & 1.18 & 29.93 & 0.3355 & 44.7 & 1.43 \\
\hline 50.0 & 34.3 & 65.8 & 50.4 & 239.9 & 40.0 & 1.37 & 30.38 & 0.3926 & 45.4 & 1.60 \\
\hline 50.0 & 40.3 & 72.4 & 49.8 & 240.1 & 50.0 & 1.80 & 25.87 & 0.4479 & 43.7 & 2.09 \\
\hline
\end{tabular}

Table 5.5b: Test Point Conditions and Results for the Comparison of the Single Rotating Cylinder with the King Probe. Test points taken at $60 \mathrm{~m} / \mathrm{s}$. 


\begin{tabular}{|c|c|c|c|c|c|c|c|c|c|c|}
\hline $\begin{array}{c}\text { True } \\
\text { Air } \\
\text { Speed } \\
(\mathrm{m} / \mathrm{s})\end{array}$ & $\begin{array}{l}\text { Spray Air } \\
\text { Pressure } \\
(\mathrm{kPa})\end{array}$ & $\begin{array}{c}\text { Spray Air } \\
\text { Flow } \\
\text { (g/min/noz) }\end{array}$ & $\begin{array}{c}\text { Cal } \\
\text { MVD } \\
\text { (um) }\end{array}$ & $\begin{array}{c}\text { Spray Water } \\
\text { Pressure } \\
\text { (kPa) }\end{array}$ & $\begin{array}{l}\text { Spray Water } \\
\text { Flow } \\
(\mathrm{g} / \mathrm{min} / \mathrm{moz})\end{array}$ & $\begin{array}{c}\text { King } \\
\text { LWC } \\
(\mathrm{g} / \mathrm{m} 3)\end{array}$ & $\begin{array}{c}\text { Icing } \\
\text { Time [s] }\end{array}$ & $\begin{array}{l}\text { Accreted } \\
\text { mass [g] }\end{array}$ & $\begin{array}{c}\text { New } \\
\text { Malvern } \\
\text { MVD } \\
\text { correlation } \\
\text { [um] }\end{array}$ & $\begin{array}{l}\text { RotCyl } \\
\text { LWC } \\
{[\mathrm{g} / \mathrm{m} 3]}\end{array}$ \\
\hline 70.0 & 125.5 & 138.4 & 15.0 & 240.0 & 24.1 & 0.46 & 43.62 & 0.2196 & 12.6 & 0.53 \\
\hline 70.0 & 159.6 & 160.6 & 15.2 & 239.9 & 47.2 & 0.96 & 23.48 & 0.2551 & 13.4 & 1.12 \\
\hline 70.0 & 177.6 & 171.7 & 15.3 & 240.2 & 56.0 & 1.18 & 22.24 & 0.2928 & 13.5 & 1.33 \\
\hline 70.0 & 213.9 & 194.4 & 15.1 & 239.9 & 69.8 & 1.47 & 18.31 & 0.2915 & 13.3 & 1.61 \\
\hline & trats & in & $\frac{34}{45}$ & 8 & ris & 1) & R & S2 & & $3 x$ \\
\hline 70.0 & 48.9 & 80.9 & 30.4 & 240.0 & 24.1 & 0.54 & 32.21 & 0.1916 & 25.1 & 0.60 \\
\hline 70.0 & 66.2 & 94.9 & 30.6 & 240.0 & 47.1 & 1.01 & 25.10 & 0.3180 & 25.8 & 1.18 \\
\hline 70.0 & 78.2 & 104.5 & 29.6 & 240.0 & 56.0 & 1.18 & 0.19 & 0.2769 & 24.4 & 1.38 \\
\hline 70.0 & 94.2 & 116.5 & 30.0 & 240.0 & 69.8 & 1.50 & 19.34 & 0.3609 & 23.6 & 1.70 \\
\hline x & Xxix & ry & 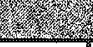 & H & $y$ & 24r & 36) & 19x & $3^{2}$ & $5+2 x$ \\
\hline 70.0 & 27.7 & 59.5 & 49.8 & 239.9 & 24.1 & 0.63 & 24.99 & 0.1792 & 44.7 & 0.72 \\
\hline 70.0 & 37.7 & 70.3 & 50.6 & 239.8 & 47.1 & 1.15 & 26.14 & 0.4081 & 44.8 & 1.36 \\
\hline 70.0 & 44.0 & 76.0 & 49.9 & 239.8 & 55.8 & 1.30 & 19.83 & 0.3425 & 42.7 & 1.56 \\
\hline 70.0 & 53.8 & 85.0 & 50.5 & 240.1 & 69.8 & 1.56 & 15.13 & 0.3232 & 40.4 & 1.95 \\
\hline
\end{tabular}

Table 5.5c: Test Point Conditions and Results for the Comparison of the Single Rotating Cylinder with the King Probe. Test points taken at $70 \mathrm{~m} / \mathrm{s}$.

\begin{tabular}{|c|c|c|c|c|c|c|c|c|c|c|}
\hline $\begin{array}{l}\text { True } \\
\text { Air } \\
\text { Speed } \\
(\mathrm{m} / \mathrm{s})\end{array}$ & $\begin{array}{c}\text { Spray Air } \\
\text { Pressure } \\
(\mathrm{kPa})\end{array}$ & $\begin{array}{c}\text { Spray Air } \\
\text { Flow } \\
\text { (g/min/noz) }\end{array}$ & $\begin{array}{c}\text { Cal } \\
\text { MVD } \\
\text { (um) }\end{array}$ & $\begin{array}{c}\text { Spray Water } \\
\text { Pressure } \\
\text { (kPa) }\end{array}$ & $\begin{array}{c}\text { Spray Water } \\
\text { Flow } \\
\text { (g/min/noz) }\end{array}$ & $\begin{array}{c}\text { King } \\
\text { LWC } \\
(\mathrm{g} / \mathrm{m} 3)\end{array}$ & $\begin{array}{c}\text { Icing } \\
\text { Time [s] }\end{array}$ & $\begin{array}{l}\text { Accreted } \\
\text { mass [g] }\end{array}$ & $\begin{array}{c}\text { New } \\
\text { Malvern } \\
\text { MVD } \\
\text { correlation } \\
\text { [um] }\end{array}$ & $\begin{array}{l}\text { RotCyl } \\
\text { LWC } \\
{[\mathrm{g} / \mathrm{m} 3]}\end{array}$ \\
\hline 90.0 & 134.9 & 146.9 & 14.9 & 239.7 & 31.2 & 0.43 & 21.50 & 0.1369 & 12.9 & 0.56 \\
\hline 90.0 & 195.1 & 183.8 & 14.9 & 240.1 & 61.0 & 0.91 & 30.20 & 0.4371 & 13.3 & 1.06 \\
\hline 90.0 & 226.4 & 203.2 & 14.7 & 239.8 & 71.8 & 1.11 & 18.59 & 0.3096 & 13.1 & 1.30 \\
\hline \multicolumn{11}{|c|}{ 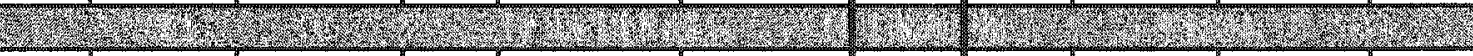 } \\
\hline 90.0 & 54.9 & 86.6 & 29.6 & 240.0 & 31.4 & 0.54 & 27.34 & 0.2313 & 25.0 & 0.65 \\
\hline 90.0 & 86.7 & 111.4 & 28.8 & 239.9 & 60.9 & 0.95 & 28.57 & 0.5265 & 23.3 & 1.22 \\
\hline 90.0 & 93.4 & 116.5 & 30.9 & 240.1 & 71.8 & 1.14 & 18.62 & 0.3468 & 24.1 & 1.34 \\
\hline 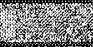 & 4 & 8 & 73 & 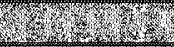 & $2 x^{2}$ & (1) & r. & & t) & ry \\
\hline 90.0 & 29.6 & 62.7 & 50.7 & 240.1 & 31.3 & 0.58 & 27.09 & 0.2726 & 46.1 & 0.74 \\
\hline 90.0 & 47.2 & 79.6 & 50.3 & 240.2 & 61.0 & 1.11 & 14.82 & 0.2656 & 41.9 & 1.32 \\
\hline 90.0 & 57.8 & 88.6 & 48.4 & 240.1 & 71.8 & 1.26 & 15.66 & 0.3598 & 38.4 & 1.61 \\
\hline
\end{tabular}

Table 5.5d: Test Point Conditions and Results for the Comparison of the Single Rotating Cylinder with the King Probe. Test points taken at $90 \mathrm{~m} / \mathrm{s}$. 


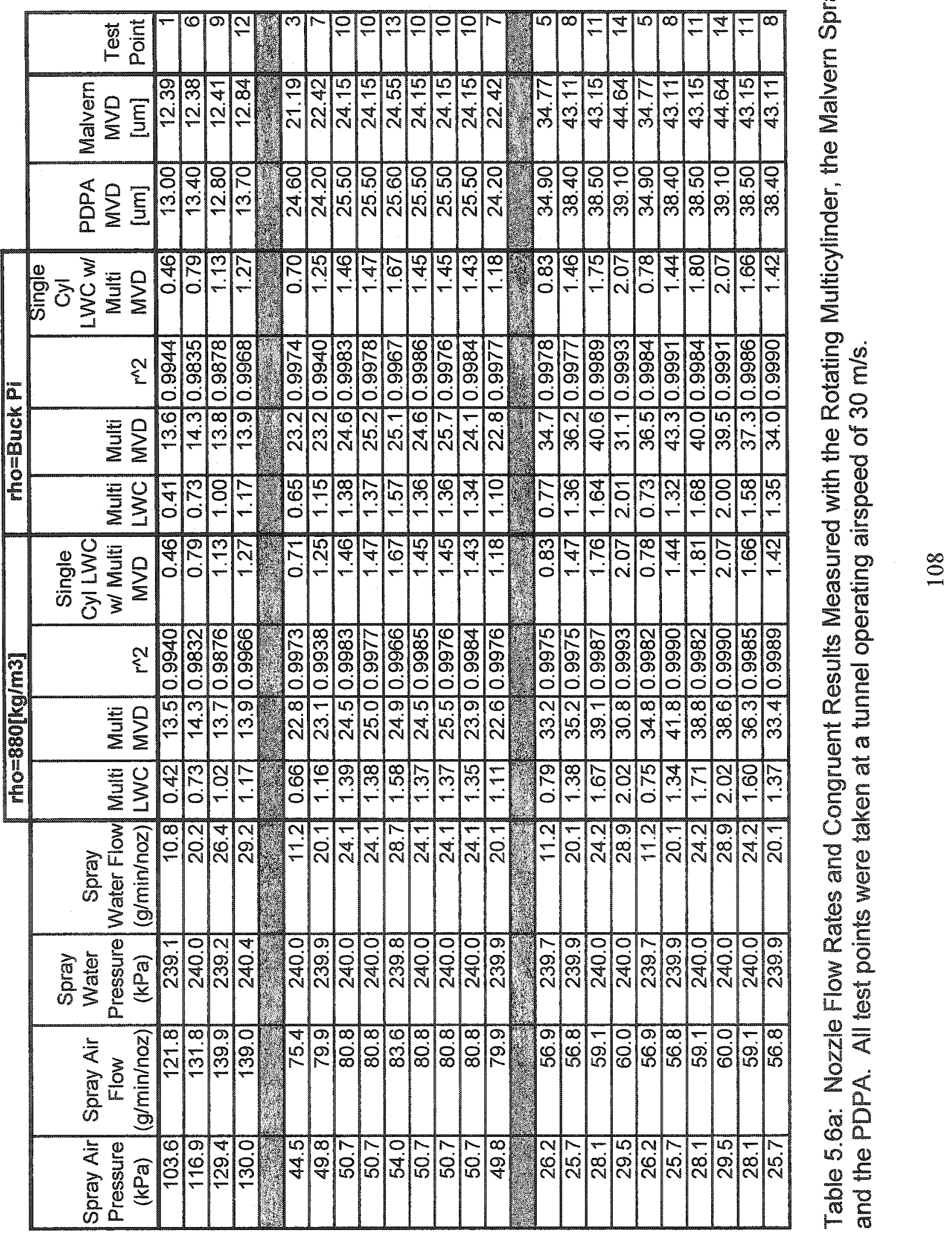




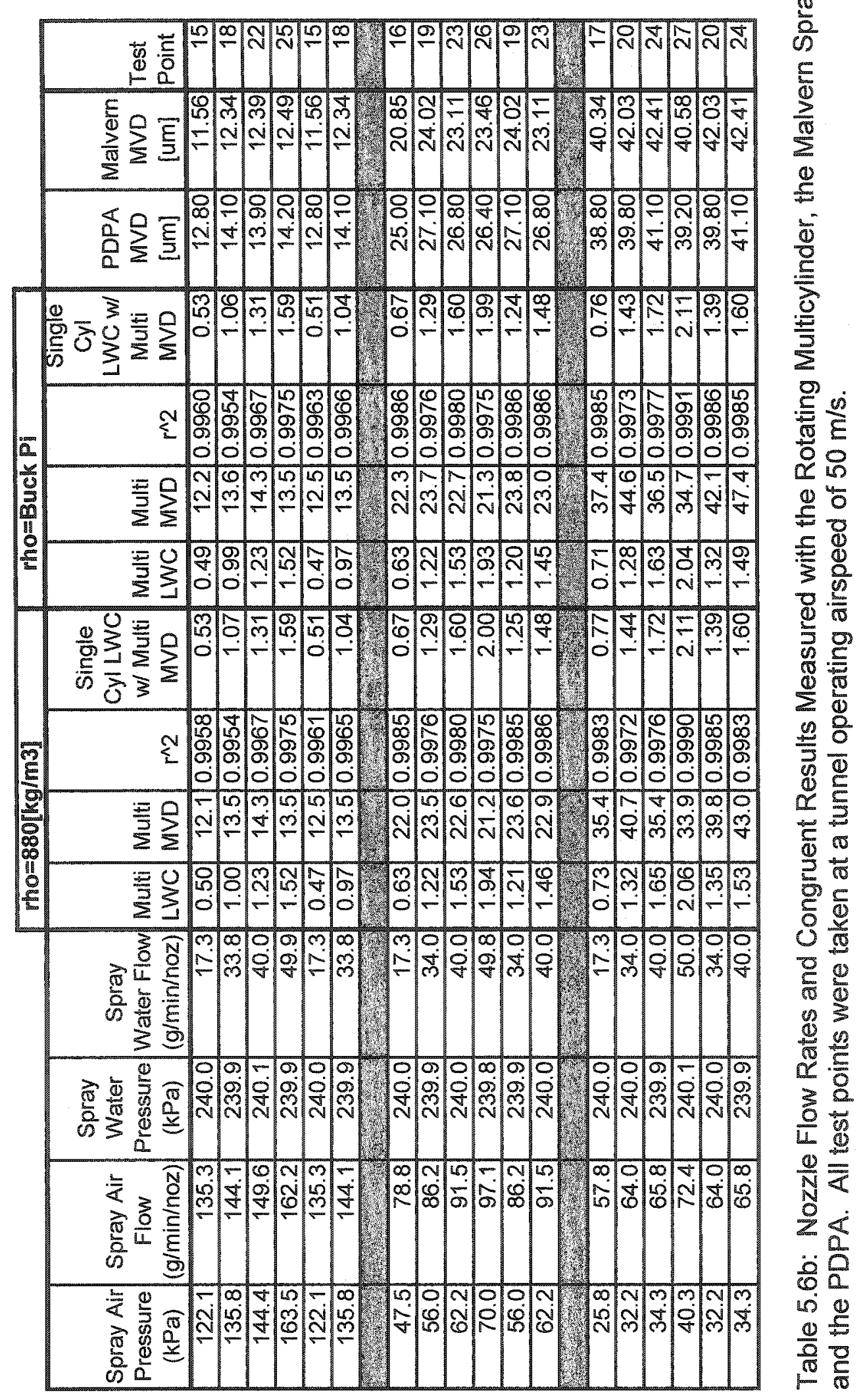




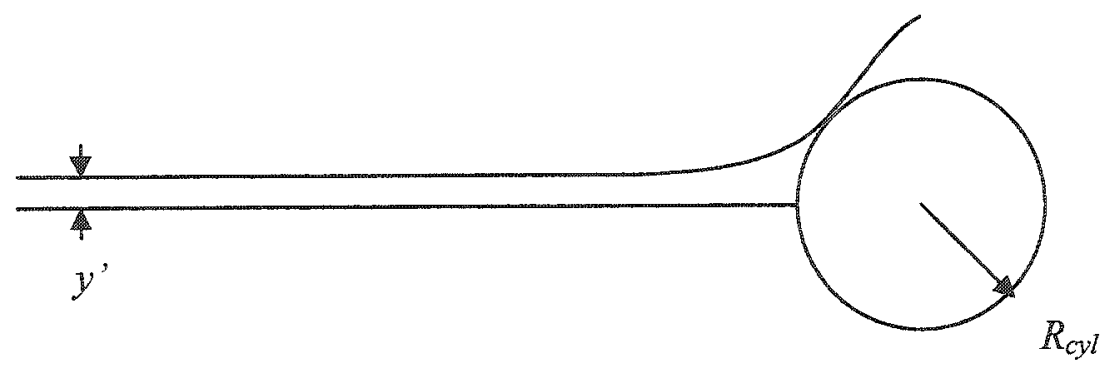

Figure 2.1: Droplet Trajectory Approaching a Cylinder in Cross-Flow

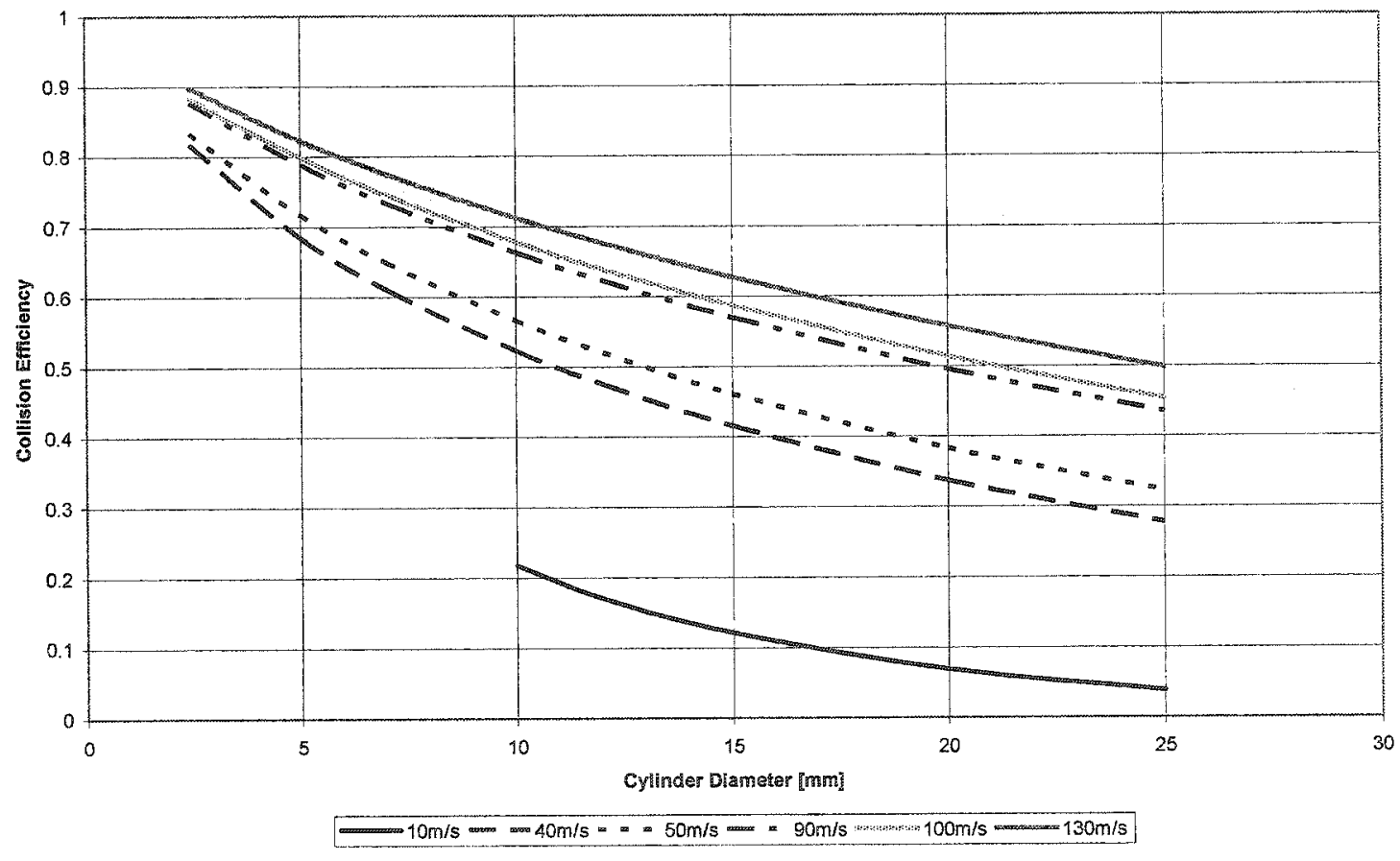

Figure 2.2: Collision Efficiency vs. Cylinder Radius as Computed by Finstad et al., (1988). Temp $=-18^{\circ} \mathrm{C}, M V D=10 \mu m$. Computation method is shown in Appendix A. 


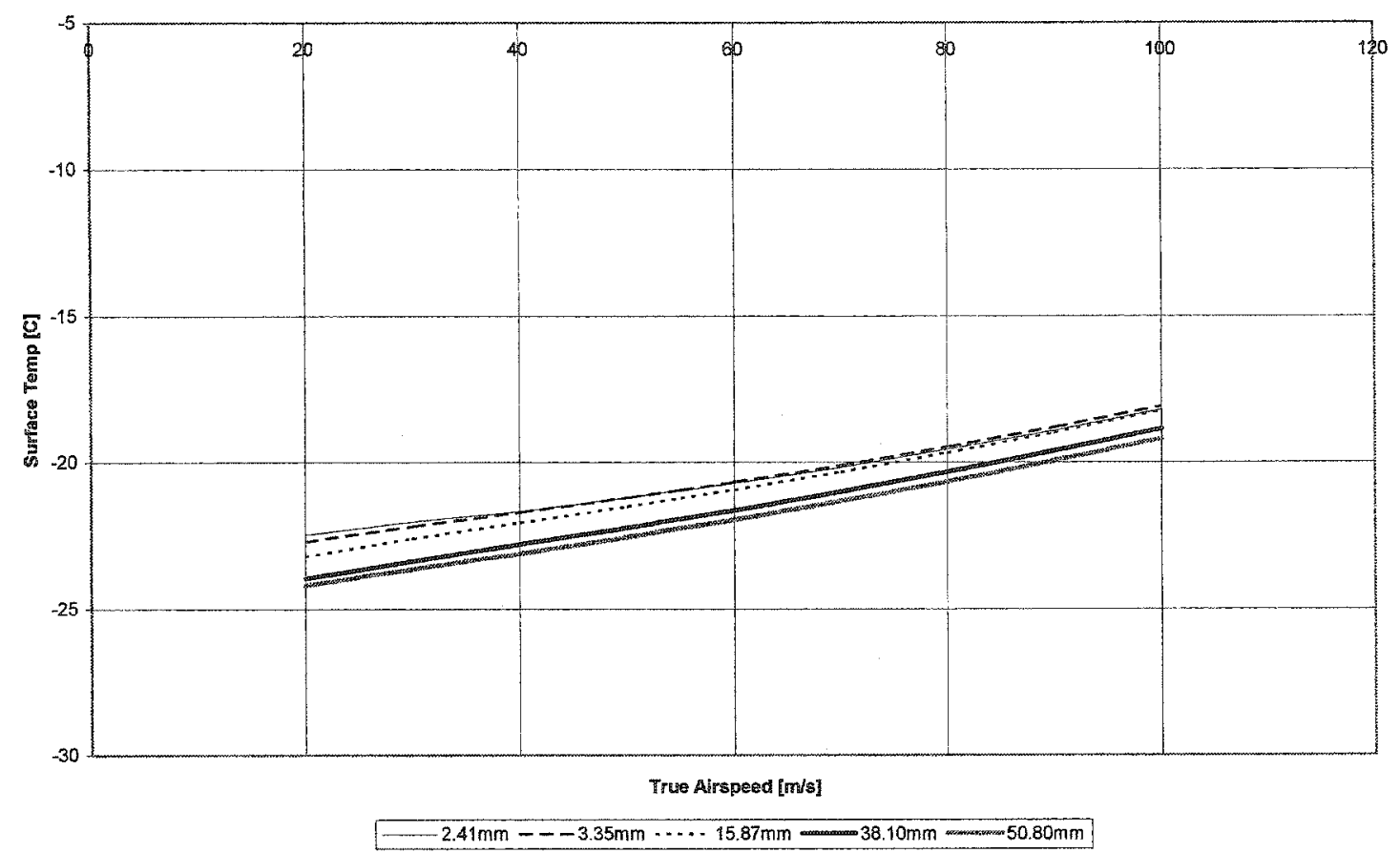

Figure 2.3: Mean Surface Temp vs. Velocity for Fixed LWC $\left(0.5 \mathrm{~g} / \mathrm{m}^{3}\right)$ and MVD $(15 \mu \mathrm{m})$. Static temperature of air is $-25^{\circ} \mathrm{C}$, and the simulation was allowed to run for 30 seconds.

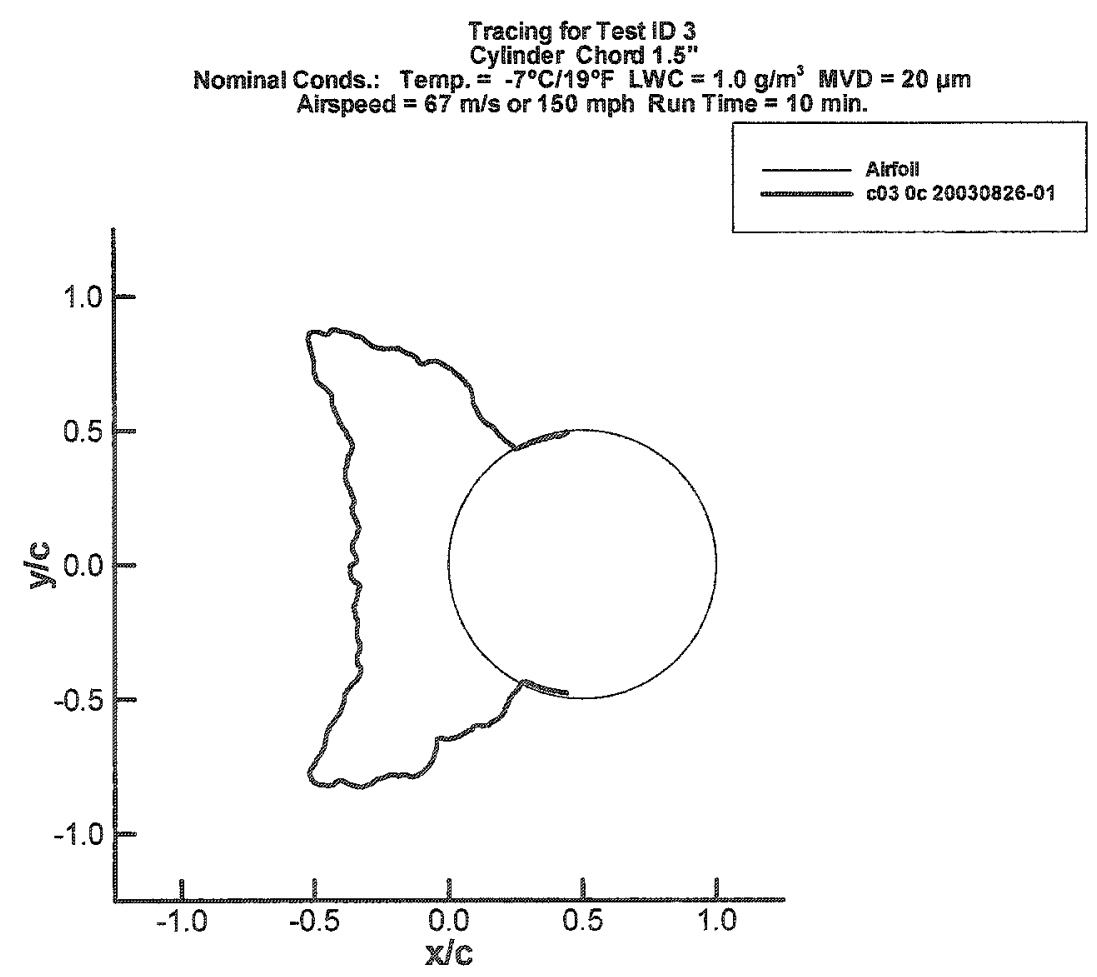

Figure 2.4: Cross Sectional Tracing of a Mixed Ice Accretion Grown on a Cylinder with a Diameter of 1.5 ". 


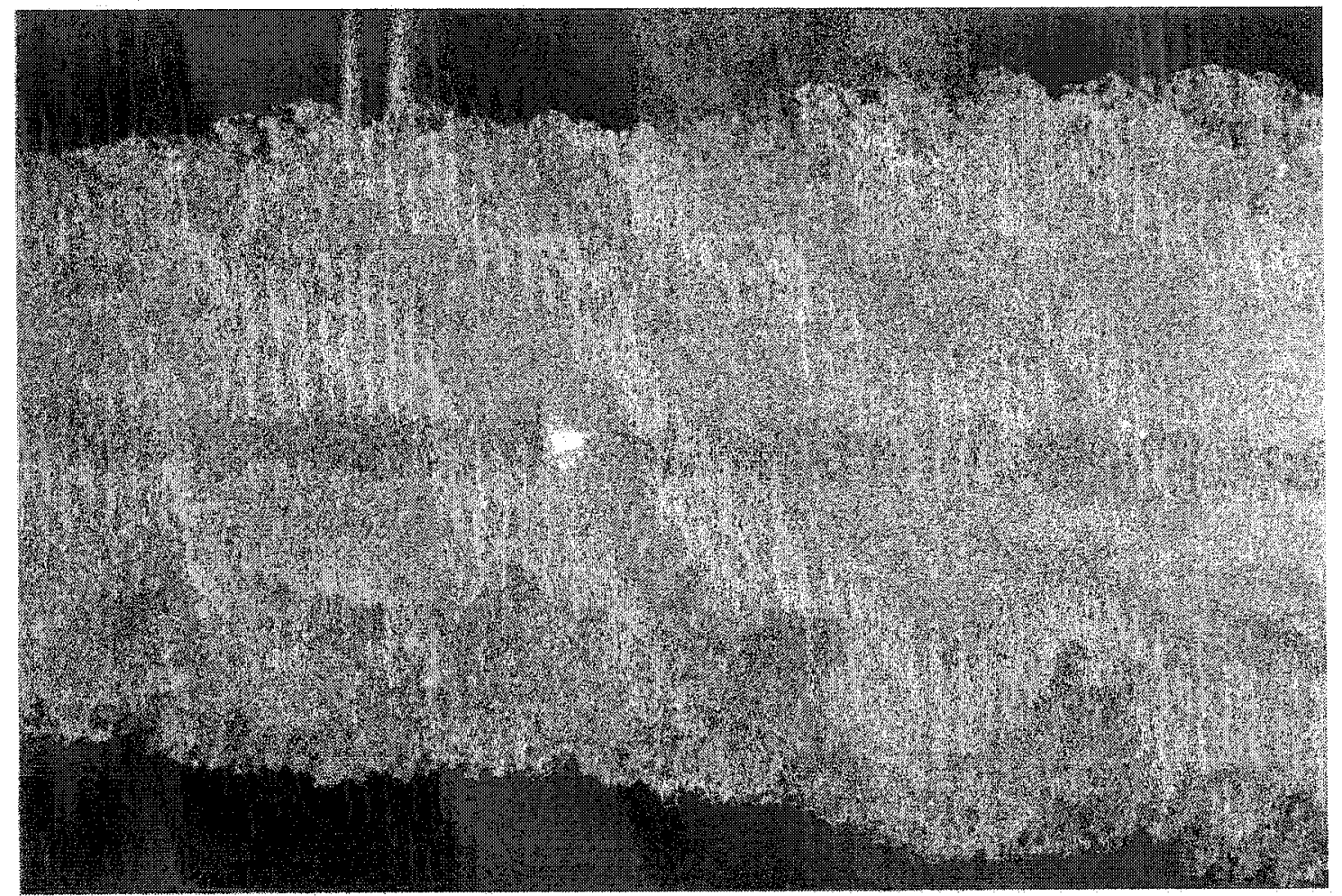

Figure 2.5: Photograph of Ice Accretion on a Cylinder with a Diameter of 1.5". Modified SAE Case 3 (MVD=30 $\mu \mathrm{m}$ ).

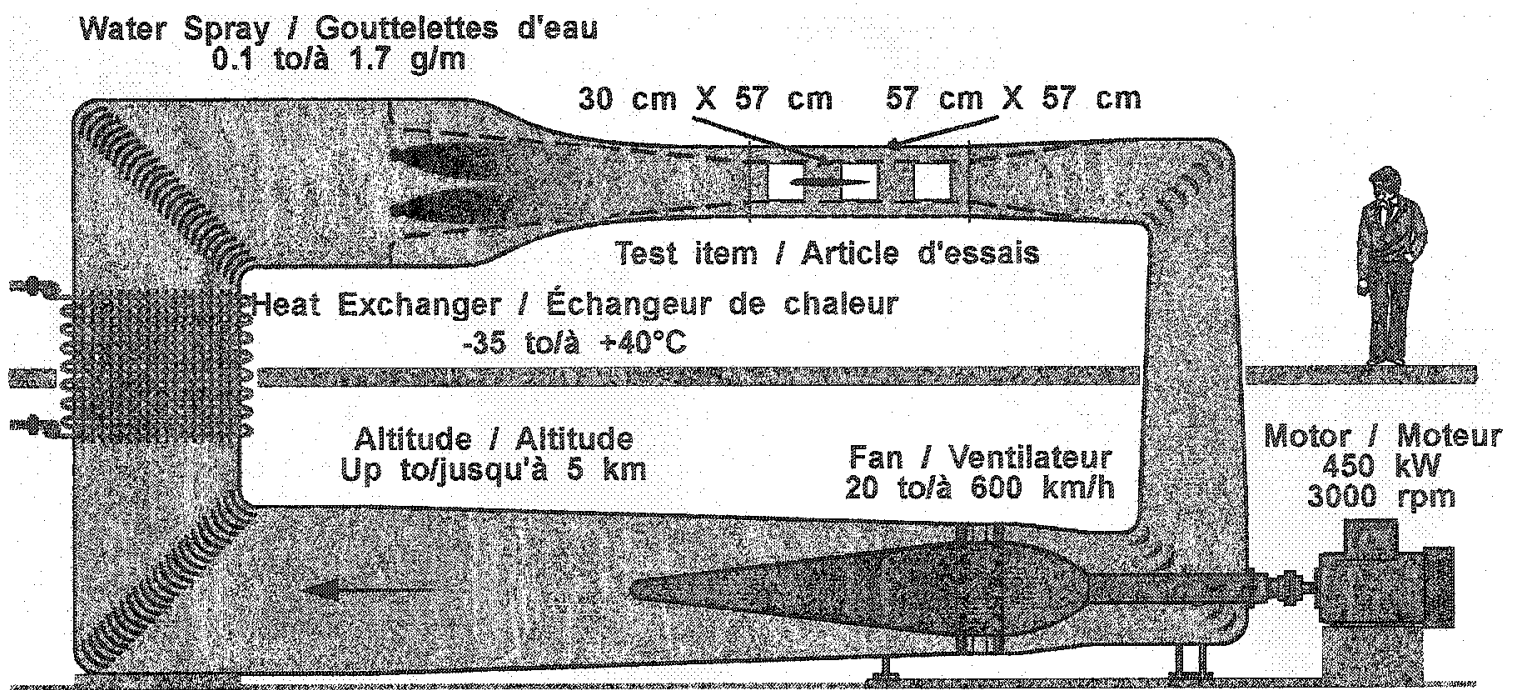

Figure 2.6: Schematic of the NRC-AIWT as shown in Oleskiw et al., (2001). 

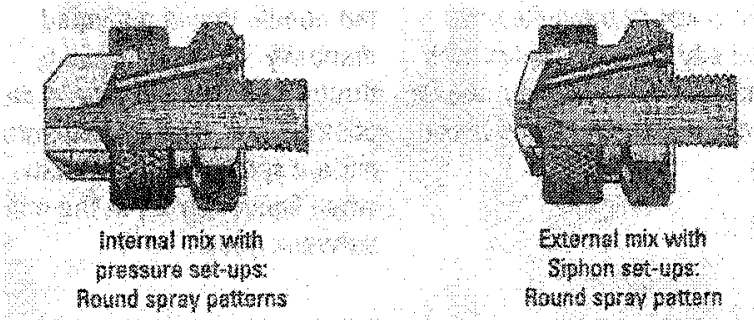

Figure 2.7: Internal Mixing Nozzle and External Mixing Nozzle.

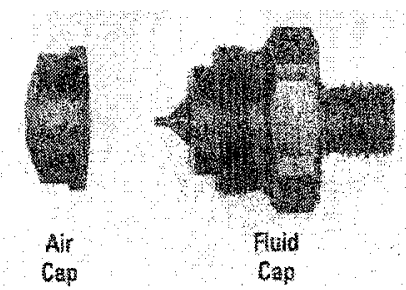

Figure 2.8: AIWT External Mixing Nozzle

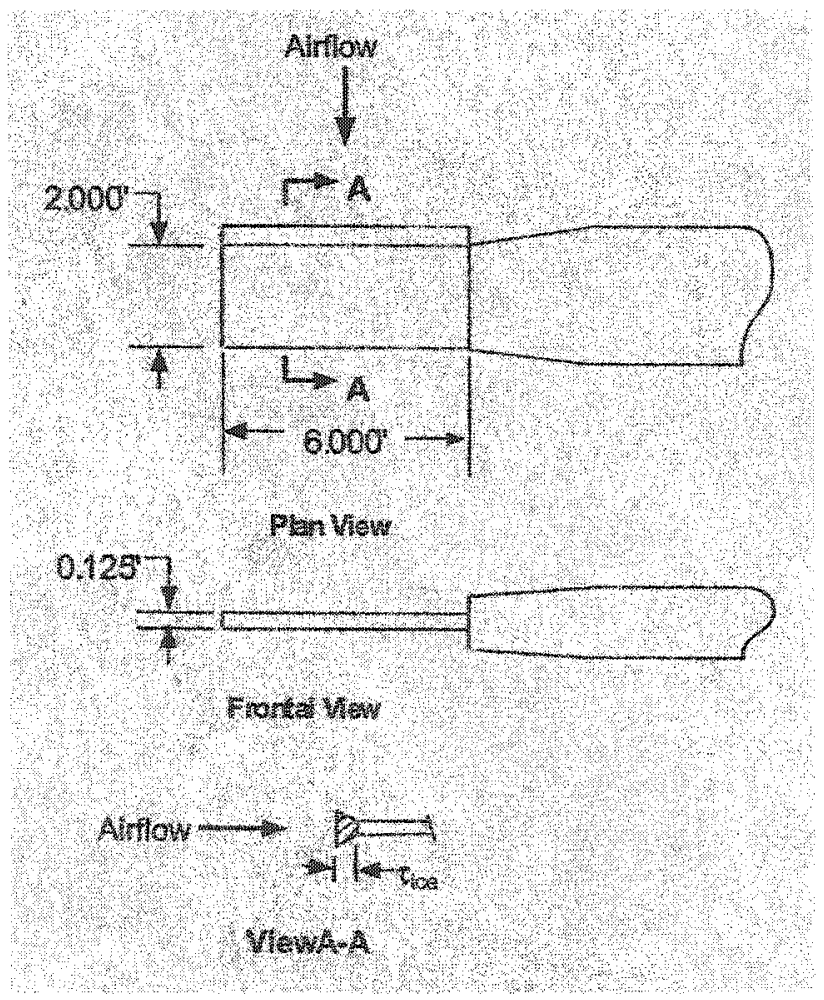

Figure 2.9: Working Drawing of the NASA Icing Blade. (From Appendix A.1 of ARP-5905) 
Icing Bade Collision Efhilelency

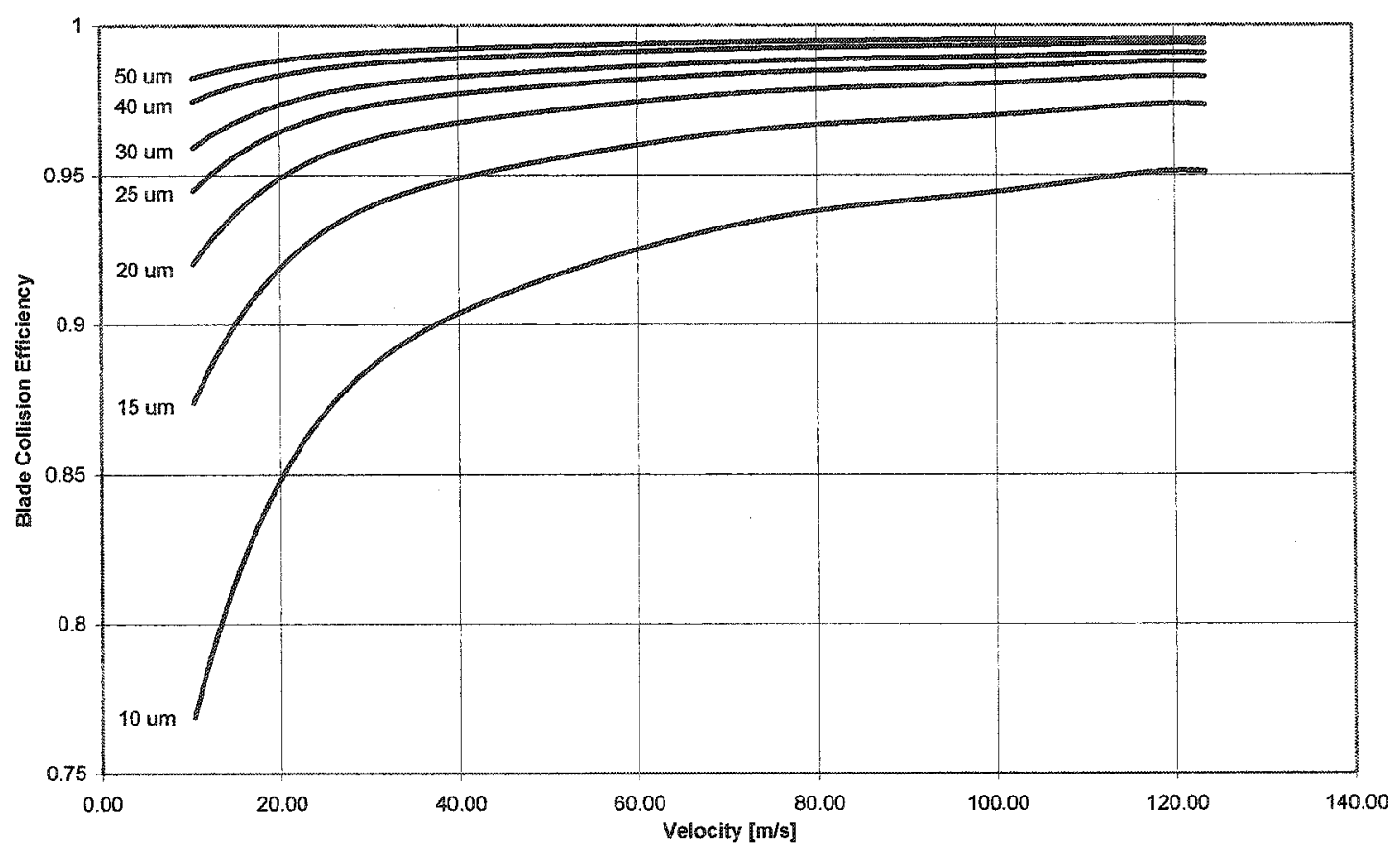

Figure 2.10: Collision Efficiency of a $1 / 8$ " thick icing blade for various MVDs.

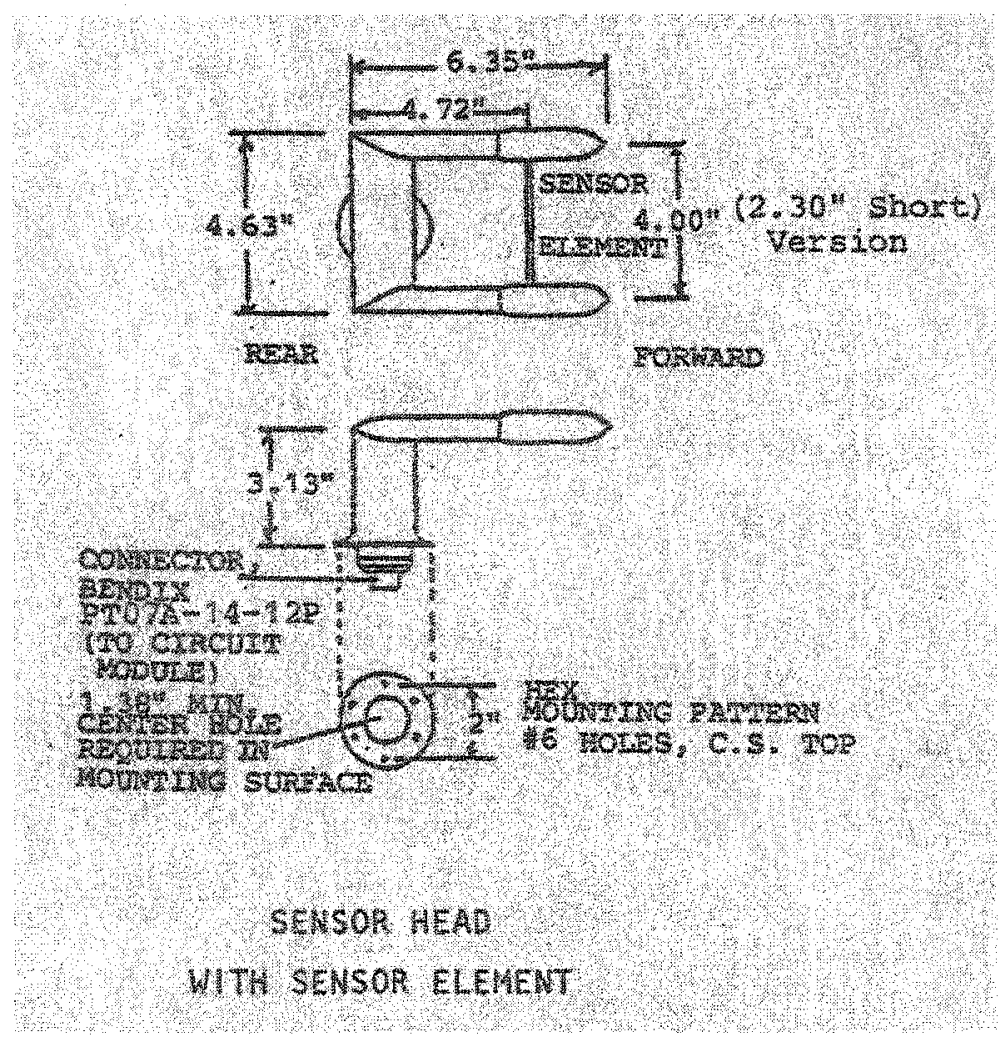

Figure 2.11: Working Drawing of the King Probe (Fig. 4-1 King probe manual) 


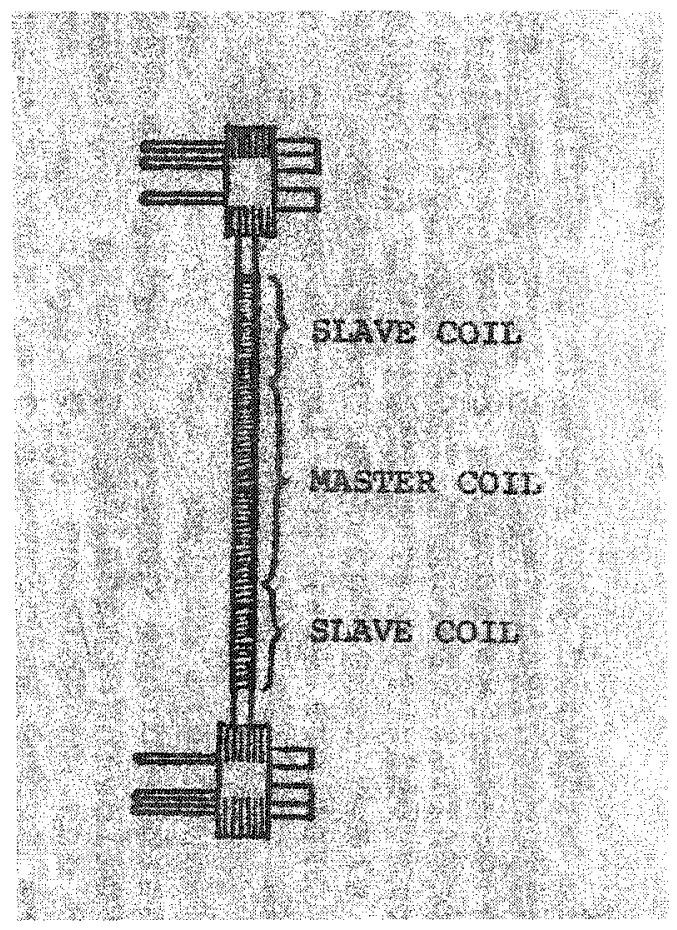

Figure 2.12: Working Drawing of the King Probe Hot-Wire (Fig. 6-1 King probe manual)

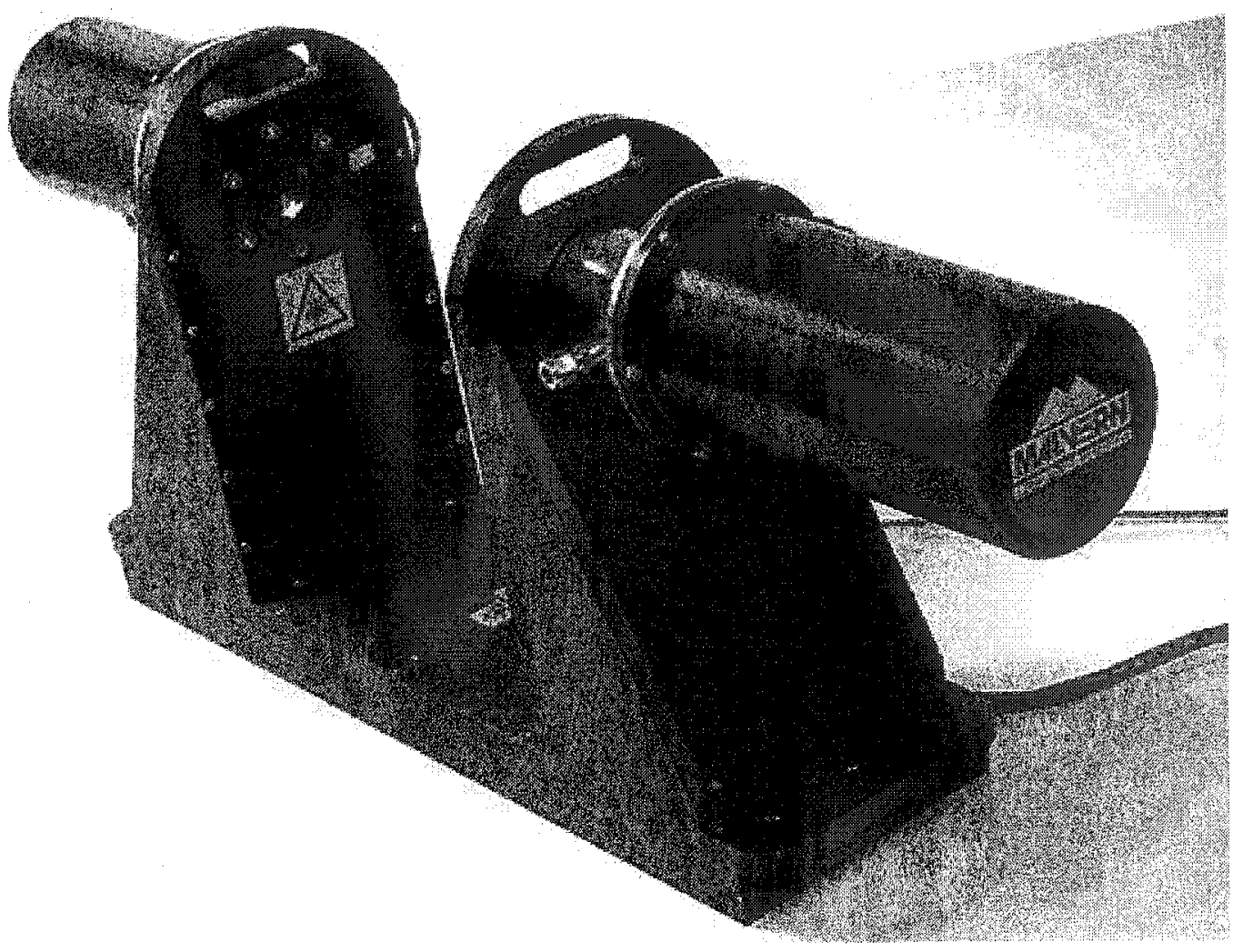

Figure 2.13: Photograph of the Malvern Spraytec Apparatus 


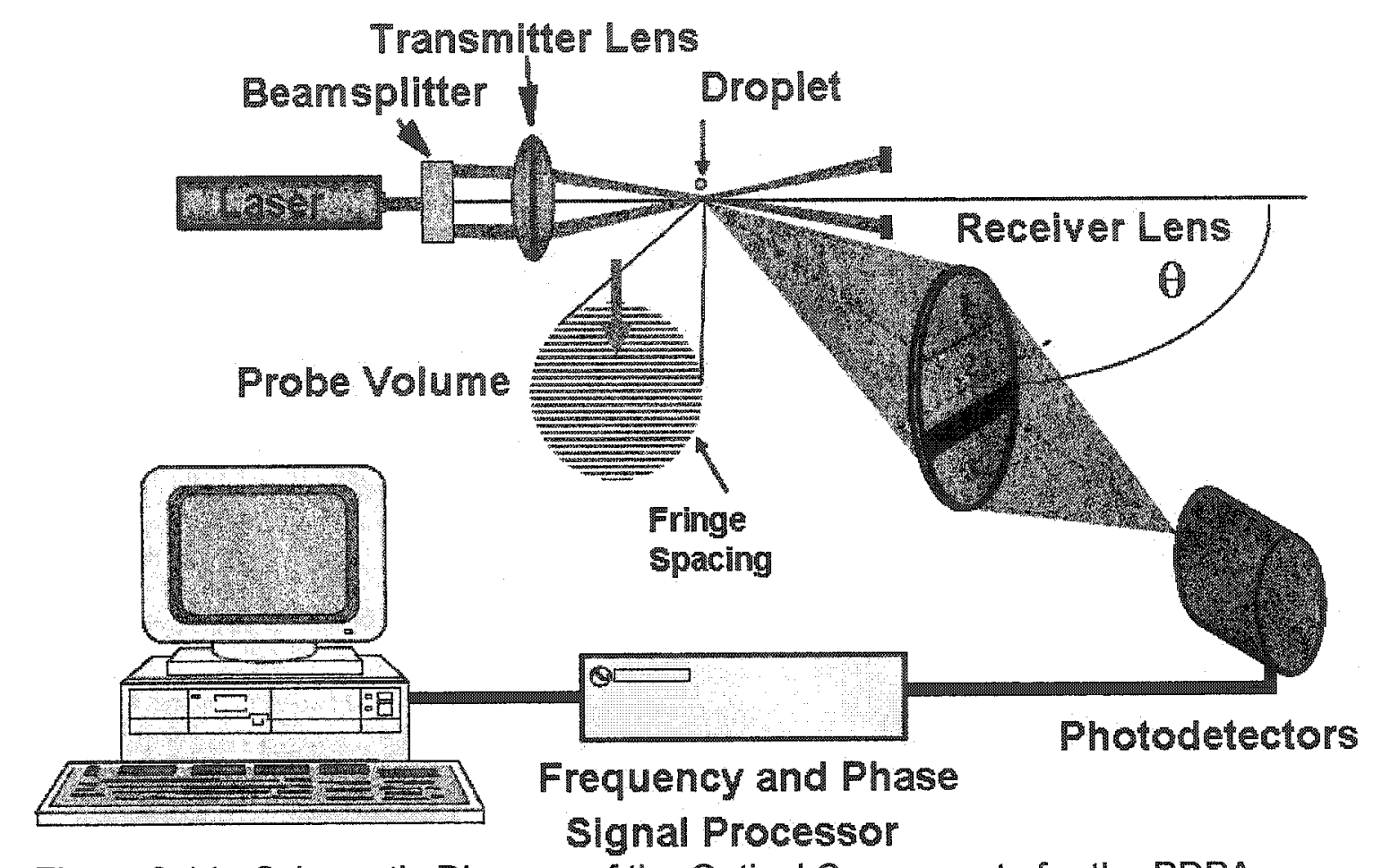

Figure 2.14: Schematic Diagram of the Optical Components for the PDPA Instrument (taken from SAERevisedPDI3-10-04)

Figure 2.15: Doppler Burst Signal (taken from SAERevisedPDI3-10-04)

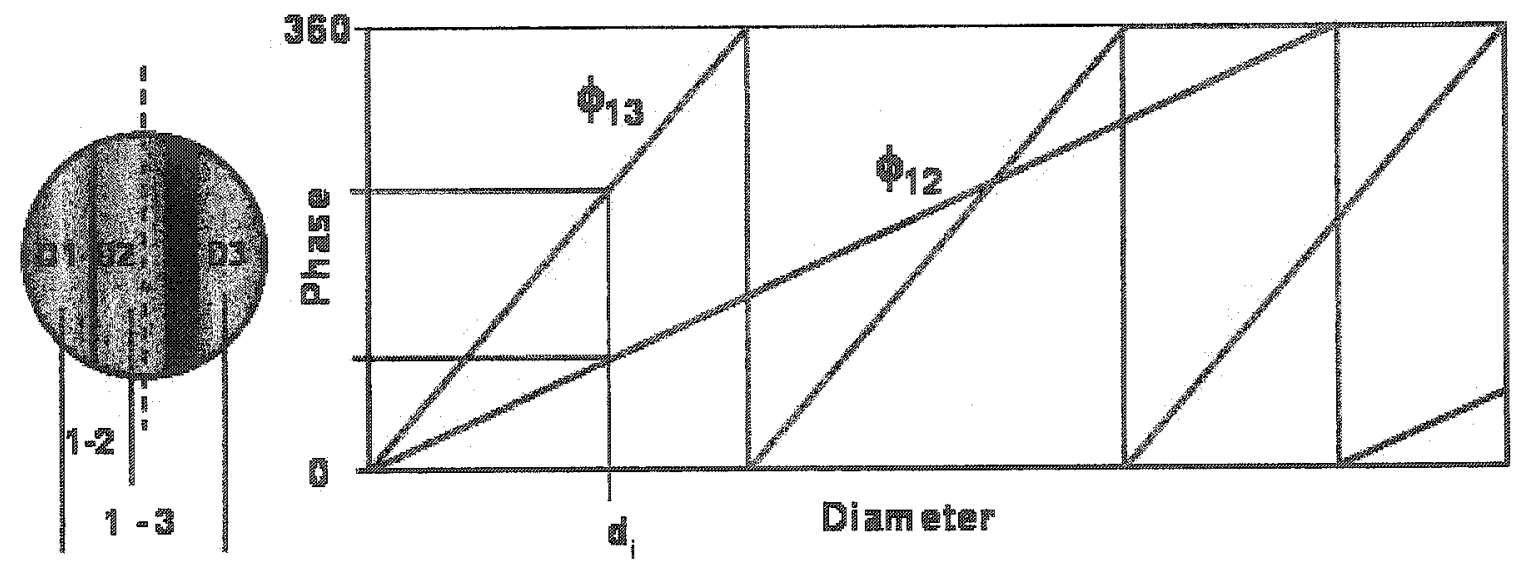

Figure 2.16: Effect of Droplet Diameter on the Phase Shift Measured by the PDPA Detectors (taken from SAERevisedPDI3-10-04) 


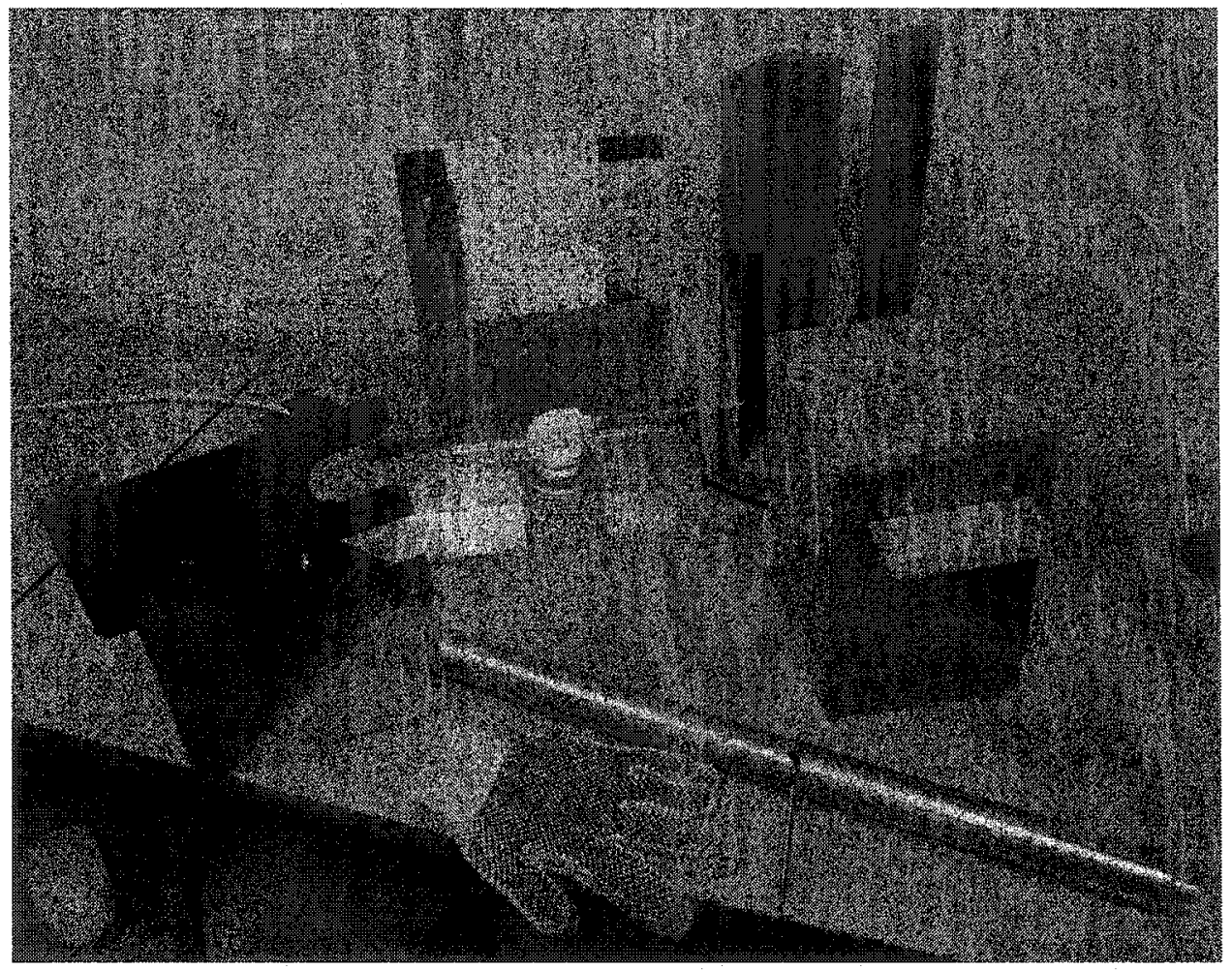

Figure 3.1: Items Used in the Replication Study. (Copper hot plate and hot plate holder, data cards, spacers, heater, compressed air canister, 1.5" diameter cylinder, insulating gloves, $90^{\circ}$ pencil)

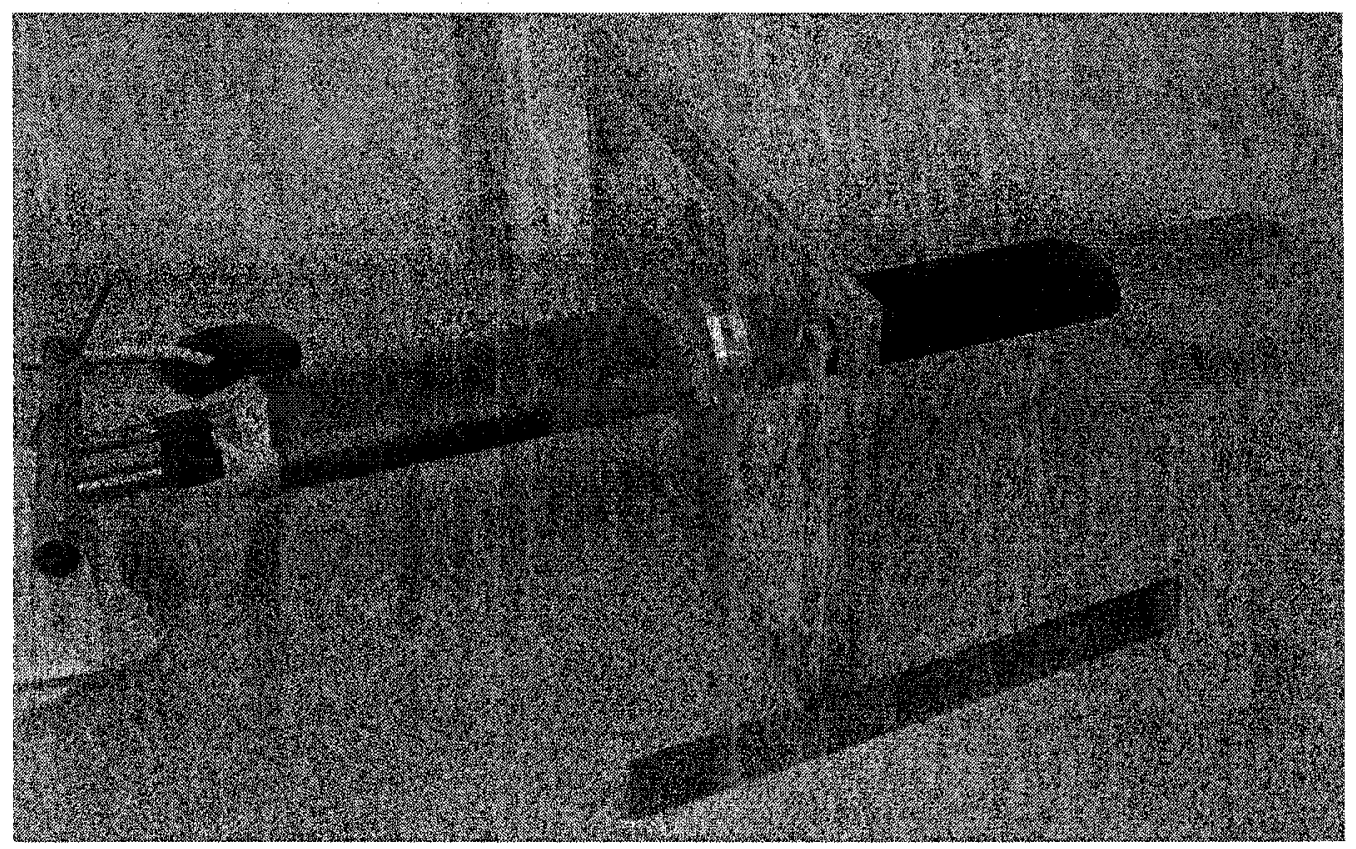

Figure 3.2: Icing Blade Apparatus 


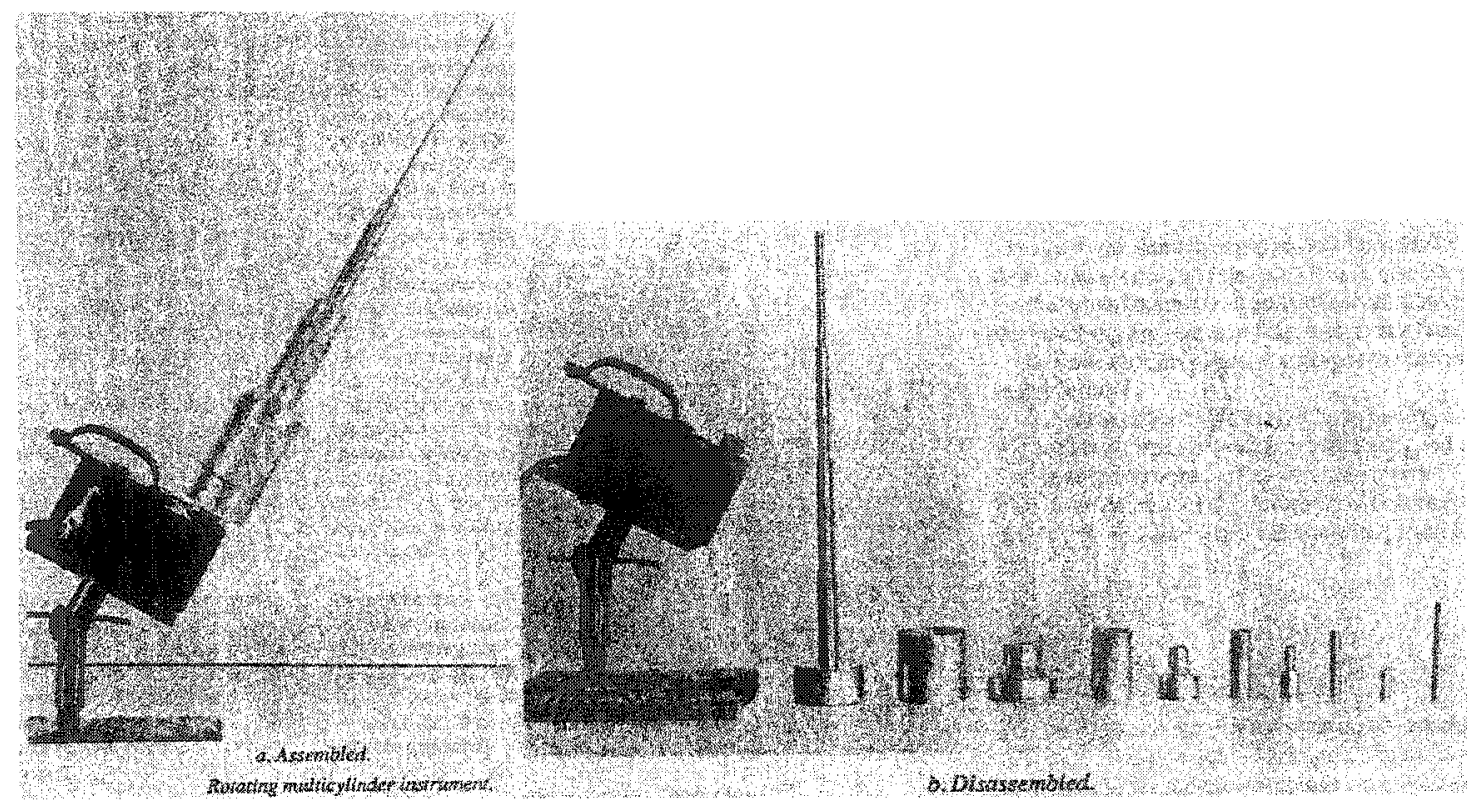

Figure 4.1: Mt. Washington Rotating Multicylinder Apparatus. (Howe, 1991)

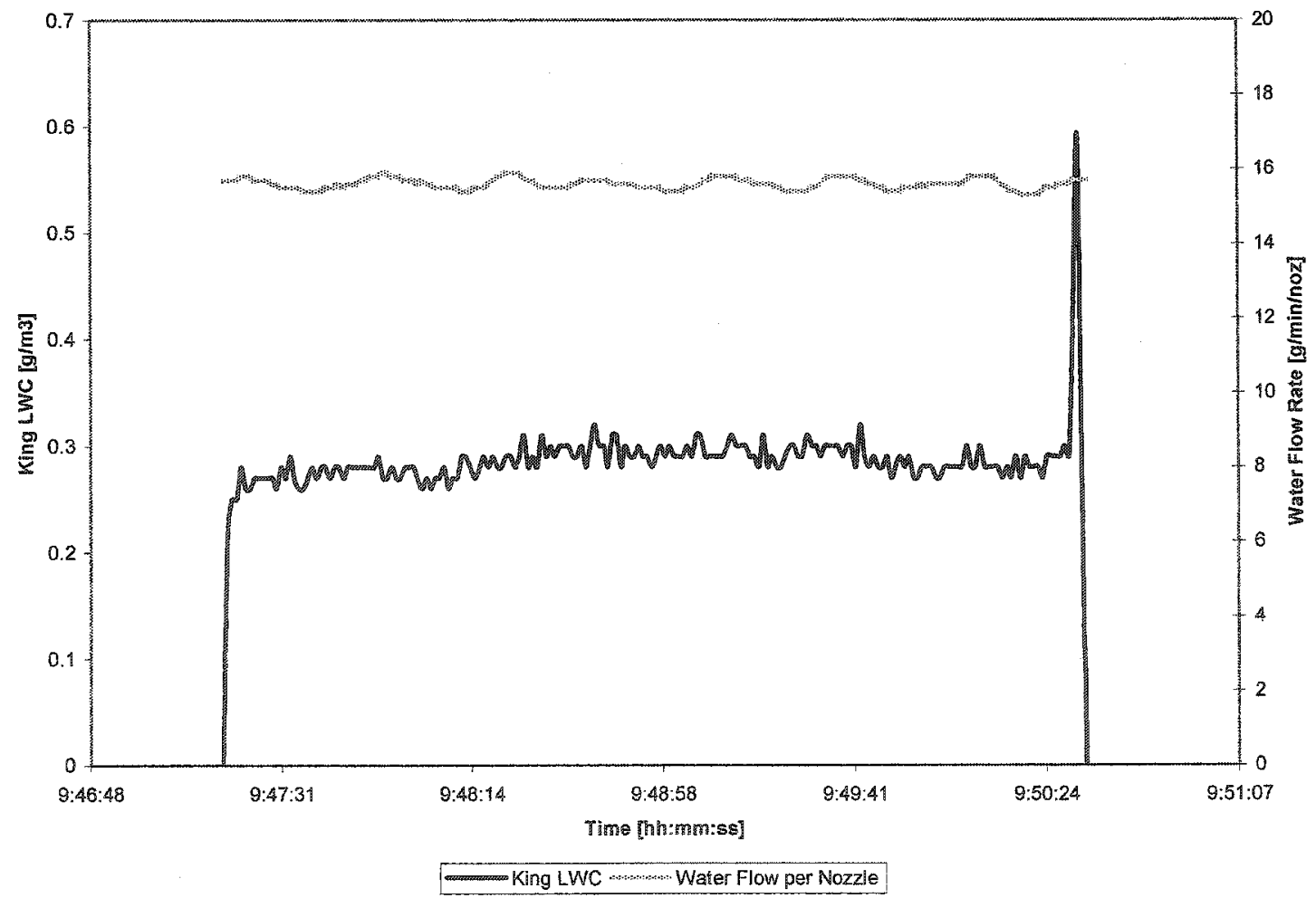

Figure 4.2: Time variation of LWC along the AIWT Centerline Measured with the King Probe. 


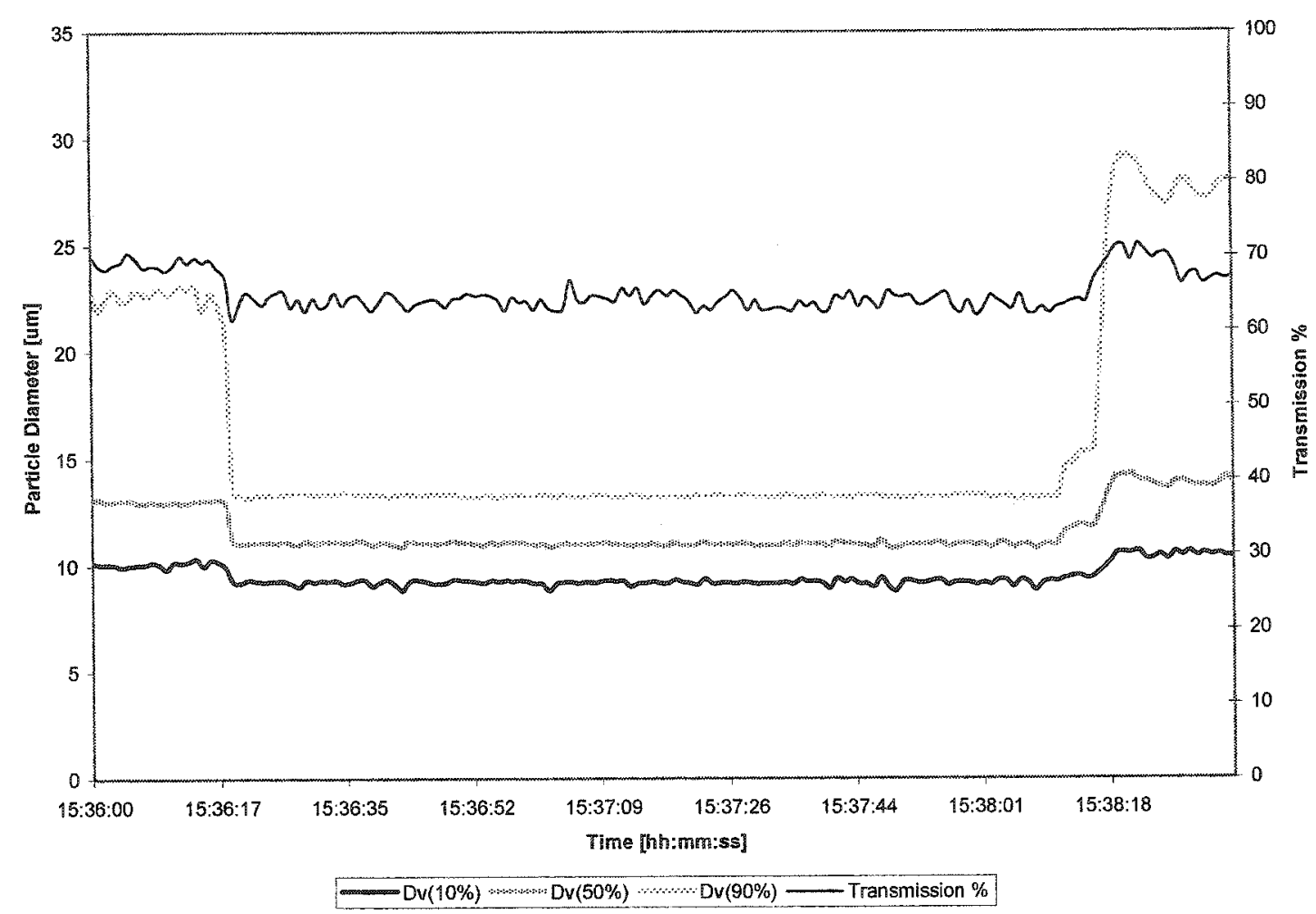

Figure 4.3: Time variation of MVD in the AIWT Test Section Measured with the Malvern Spraytec.

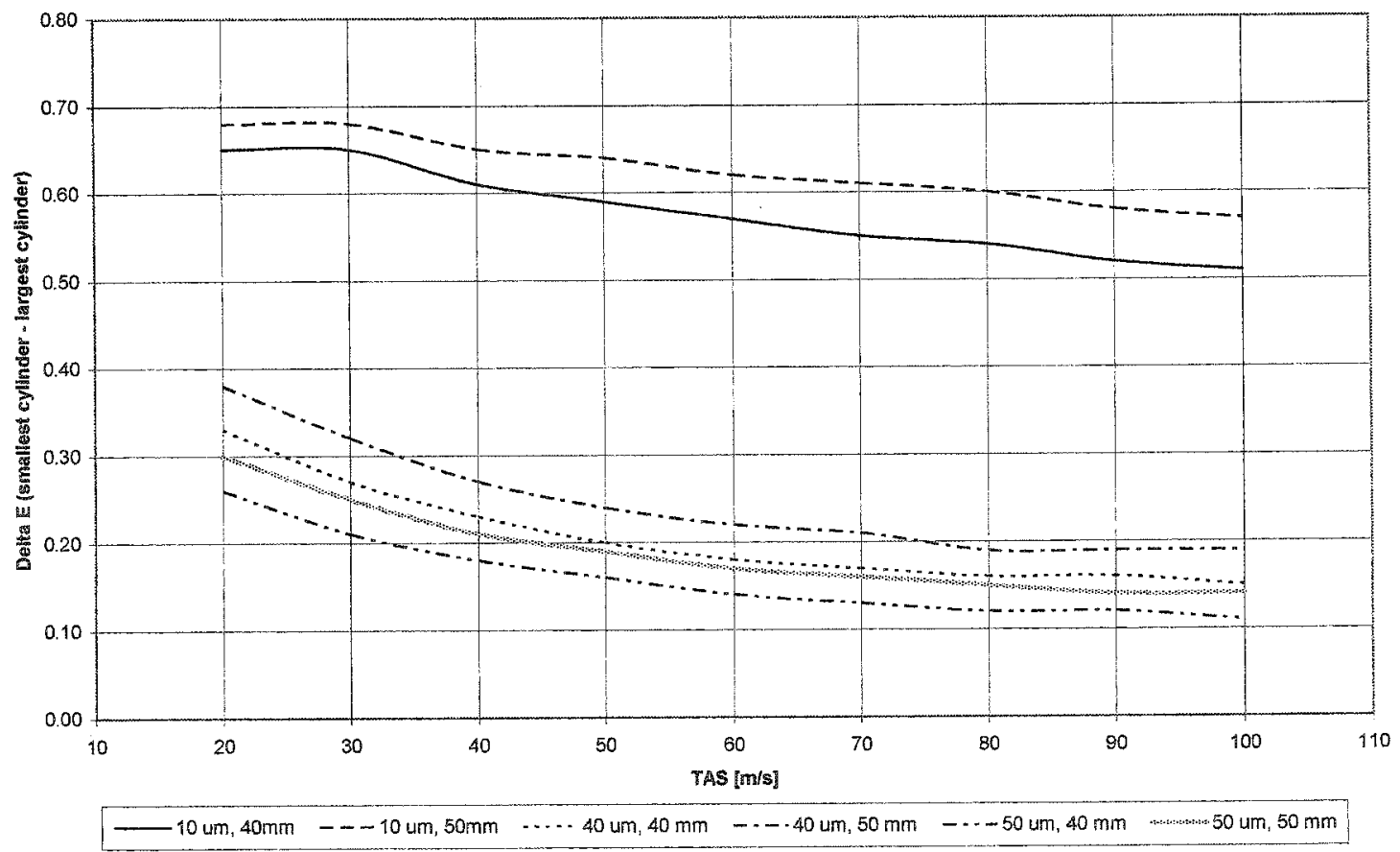

Figure 4.4: Difference in Collision Efficiency Between Smallest and Largest Cylinder. The values quoted in the legend are the MVD and largest cylinder diameter used in the trial respectively. (Smallest Cylinder Diameter $=2.41 \mathrm{~mm}$ ) 


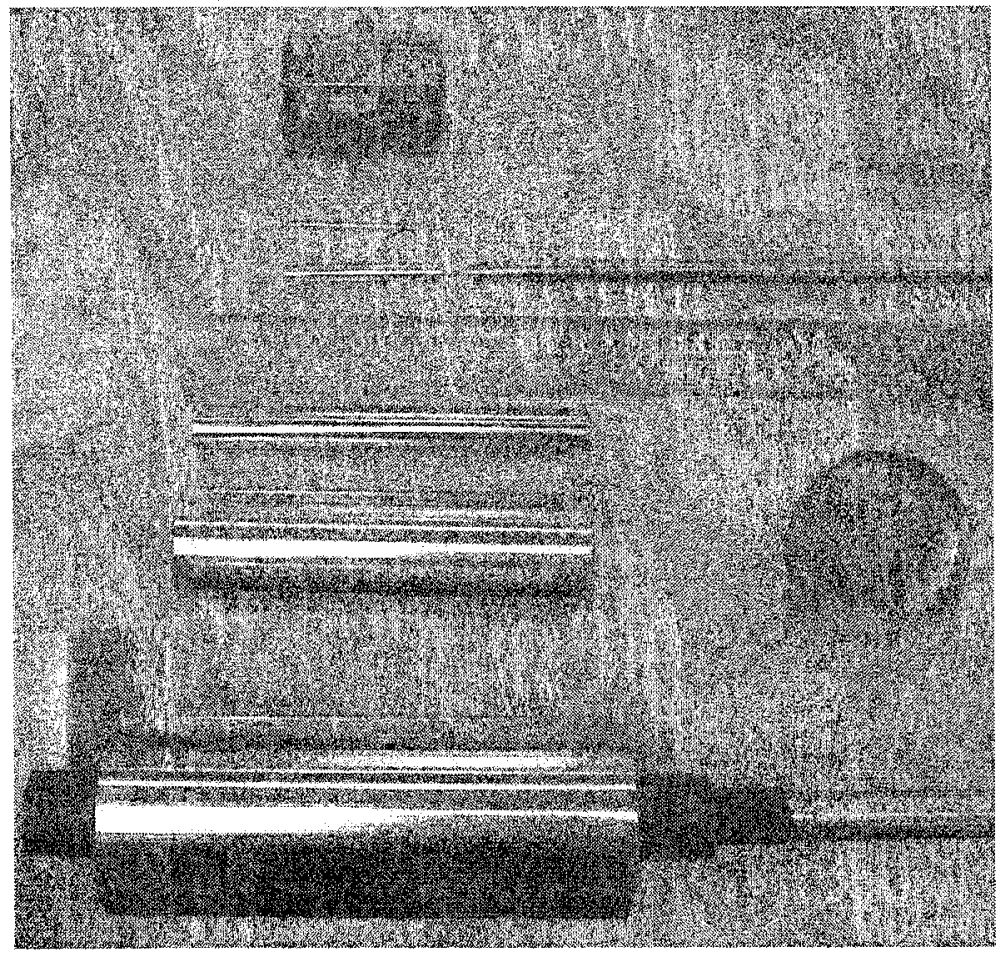

Figure 4.5: Rotating Multicylinder Apparatus

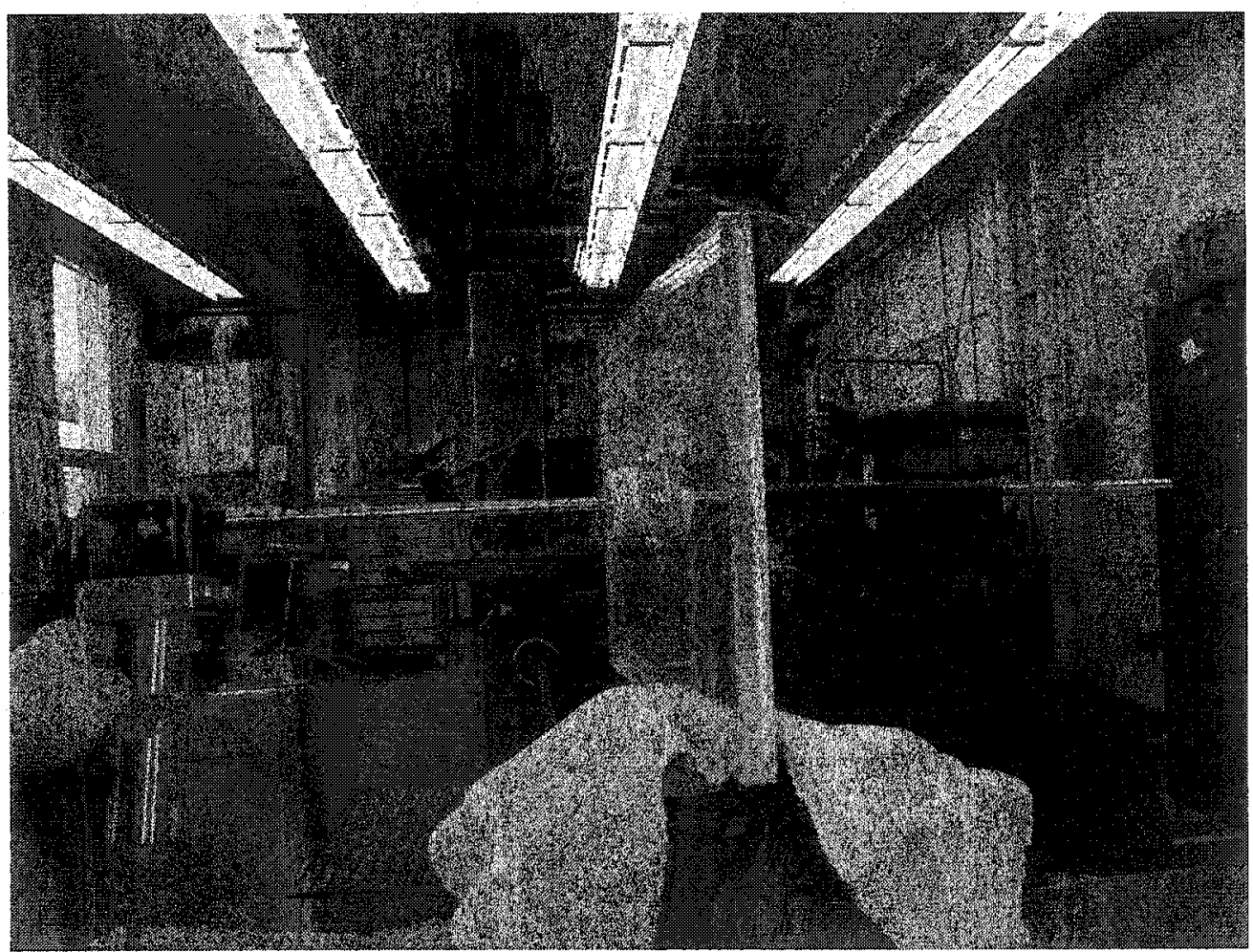

Figure 4.6: Apparatus Configuration for Cylinder \# 2 


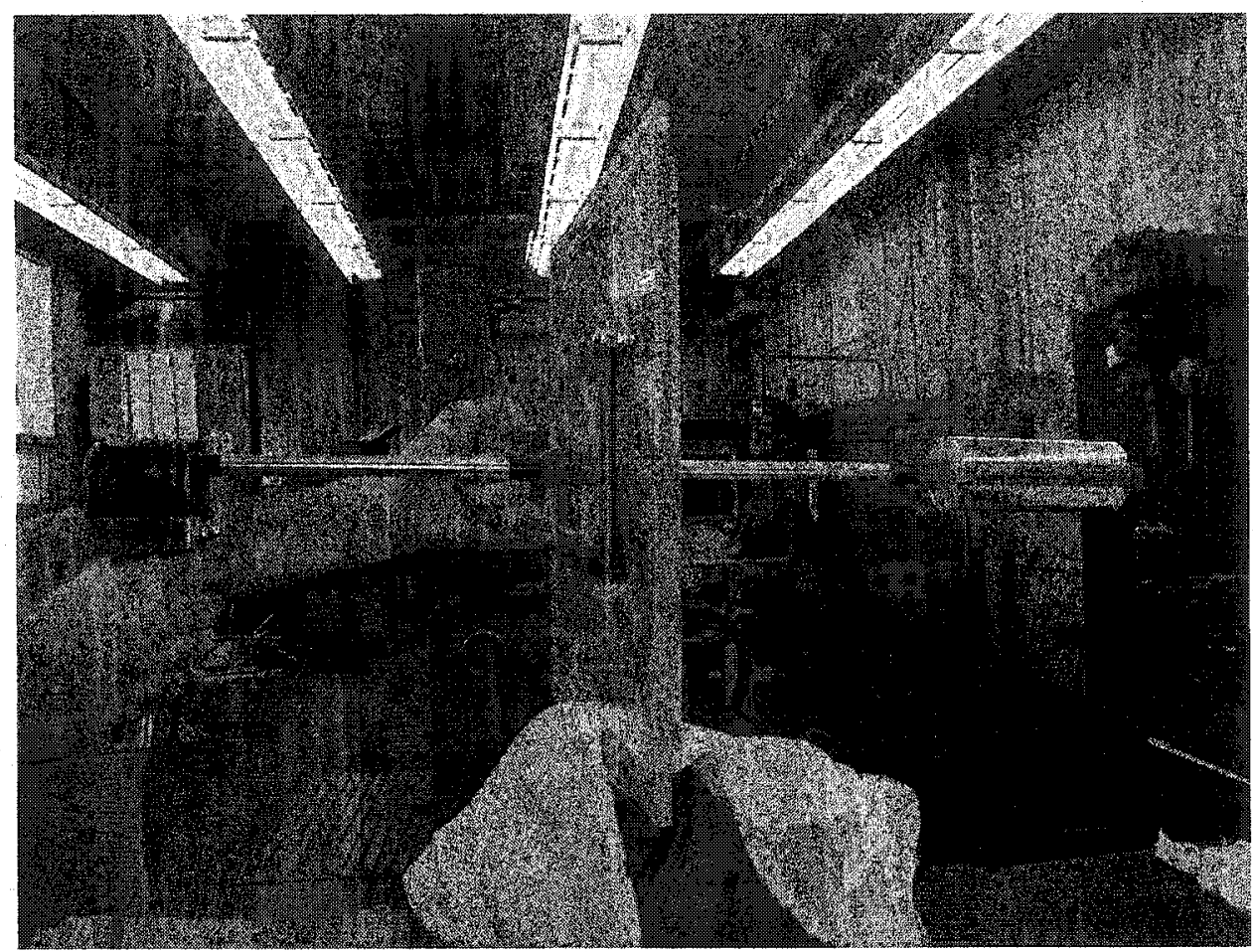

Figure 4.7: Apparatus Configuration for Cylinder \# 5

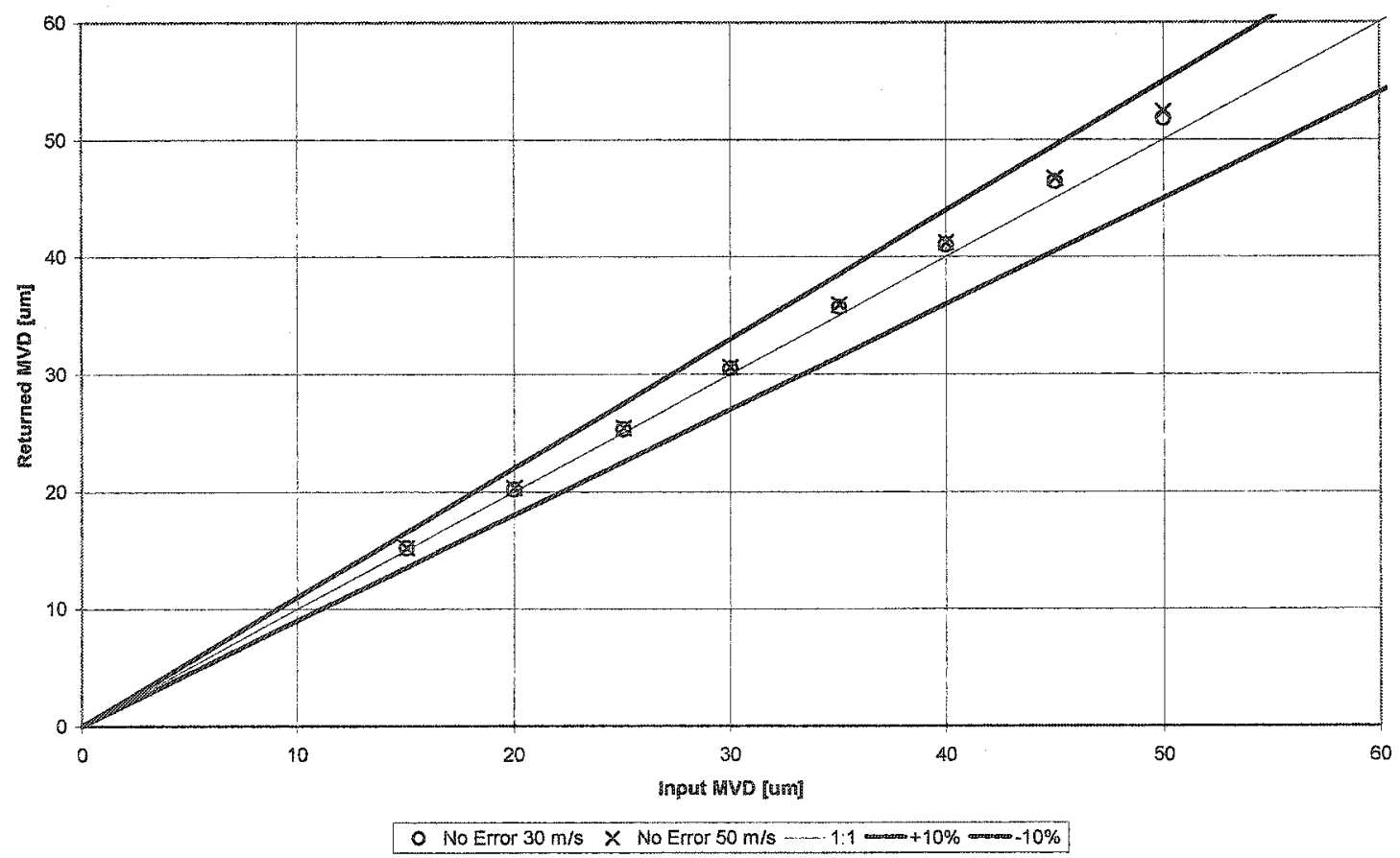

Figure 4.8: Results of Simulation Study Investigating the Accuracy of the Solution Algorithm Presented in Section 2.5.2.2. The independent axis displays the value of MVD used as the input to determine the mass of ice that would theoretically accrete on the five cylinders using the algorithm presented in Appendix B. These masses are then used in the solution algorithm of Section 2.5.2.2 and the value of MVD returned is shown on the dependent axis. 


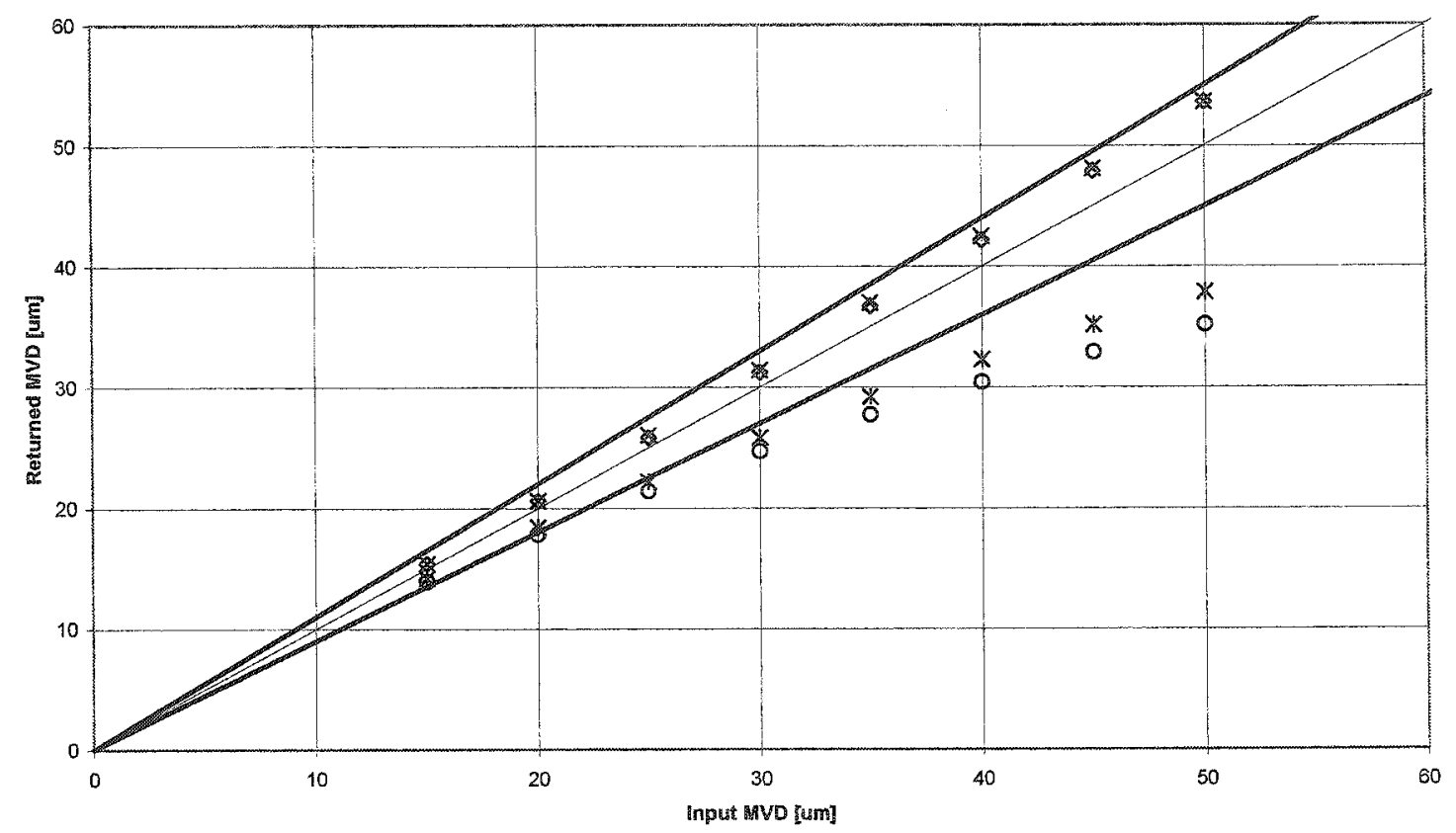

- Error $-10 \%$ Cyl $\# 1,30 \mathrm{~m} / \mathrm{s} \times$ Error $-10 \%$ Cyl $\# 1,50 \mathrm{~m} / \mathrm{s} \times$ Error $-10 \%$ Cyl $\# 5,30 \mathrm{~m} / \mathrm{s}$ O Error $-10 \%$ Cyl $\# 5,50 \mathrm{~m} / \mathrm{s}-111-+10 \%-10 \%$

Figure 4.9: Results of Simulation Study Investigating the Effect of a Potential Measurement Error on Cylinders \#1 and \#5.

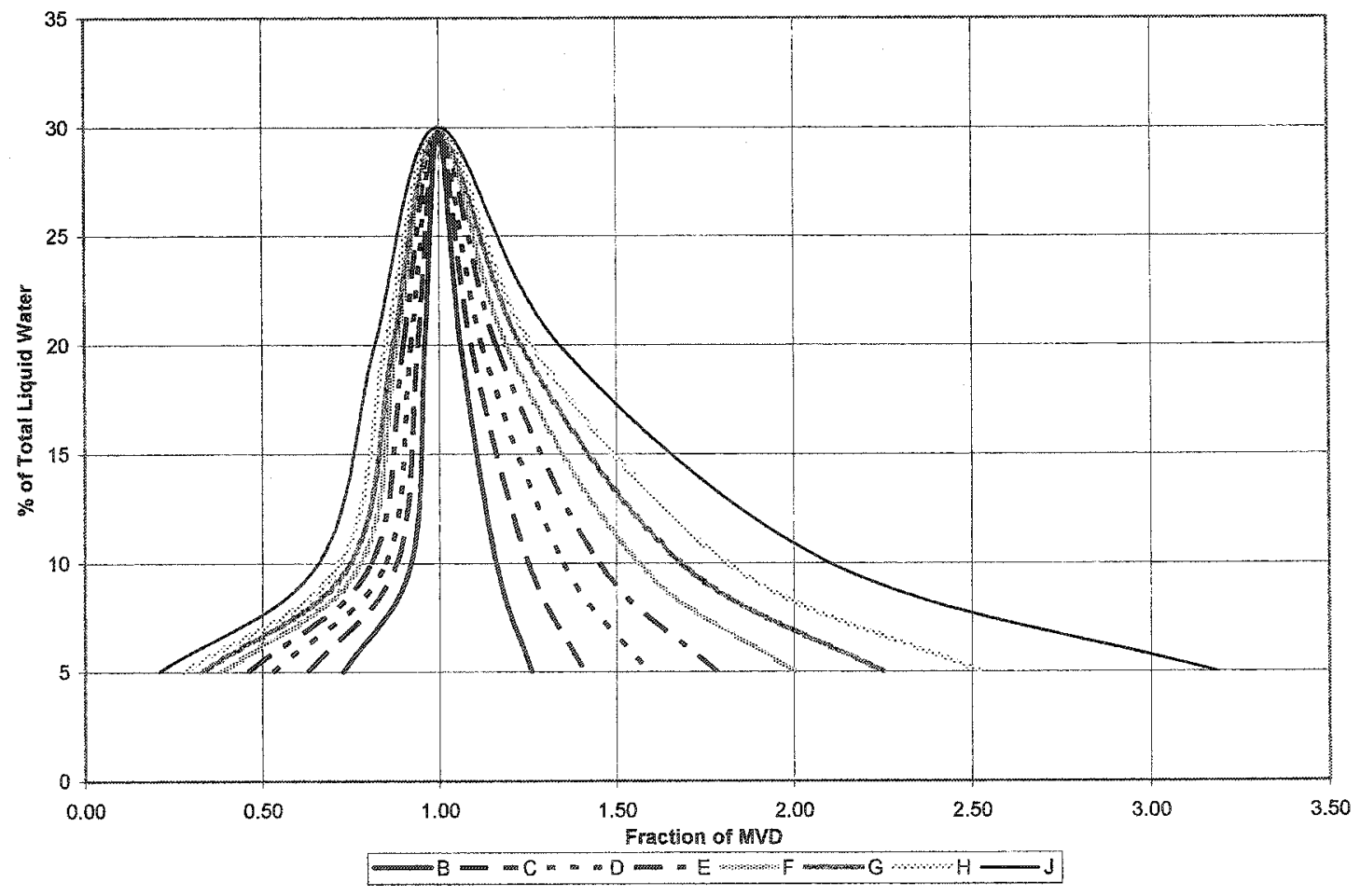

Figure 4.10: Graphical Representation of Droplet Spectra Shown in Table 4.2 


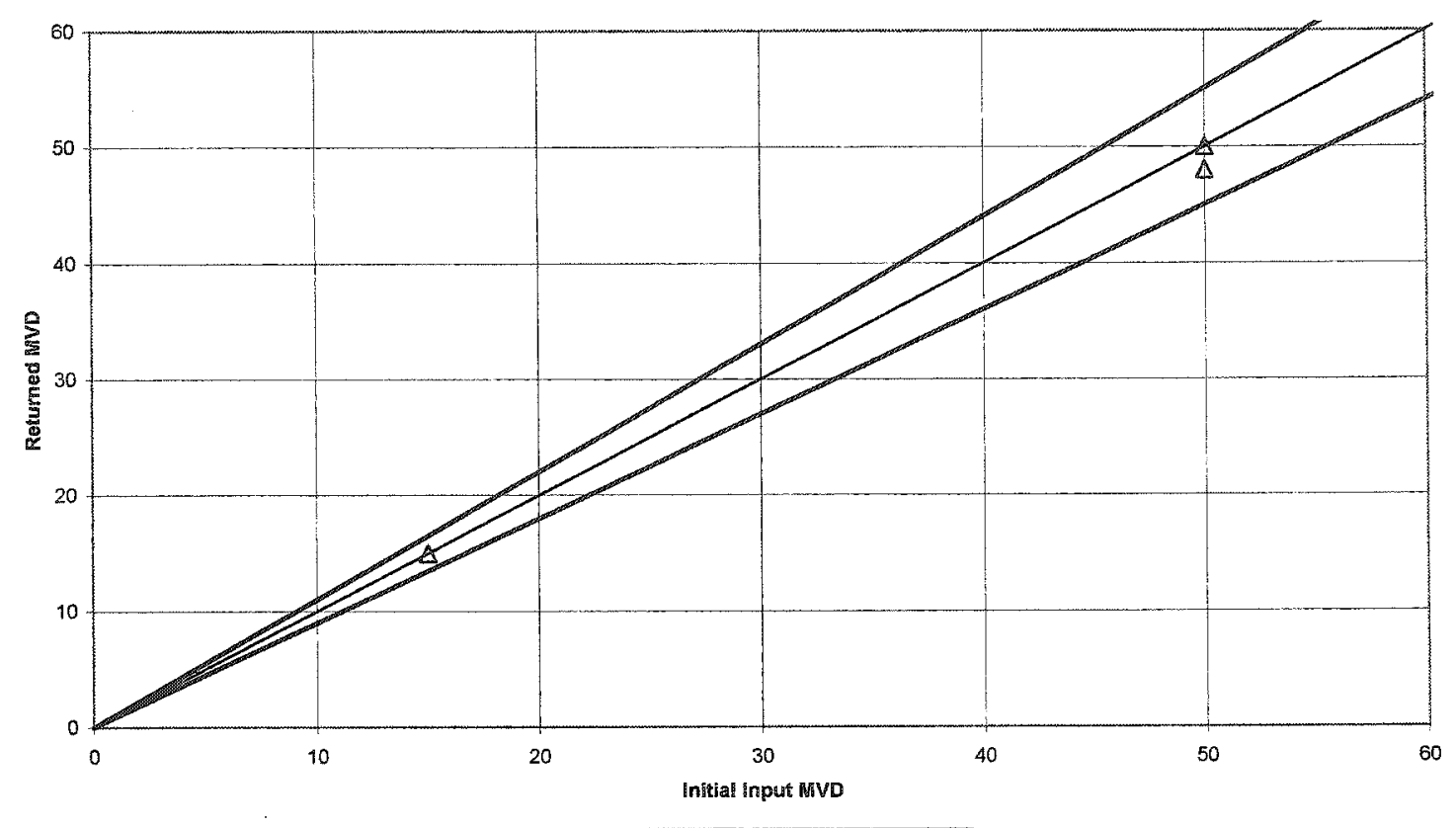

$\triangle A \cdot B-11=+10 \%-10 \%$

Figure 4.11a: Results of the Investigation into the Effect of Droplet Size Spectrum on MVD returned by the Solution Algorithm. (Theoretical mass accreted using spectrum $A$ and solution algorithm using spectrum $B$ ).

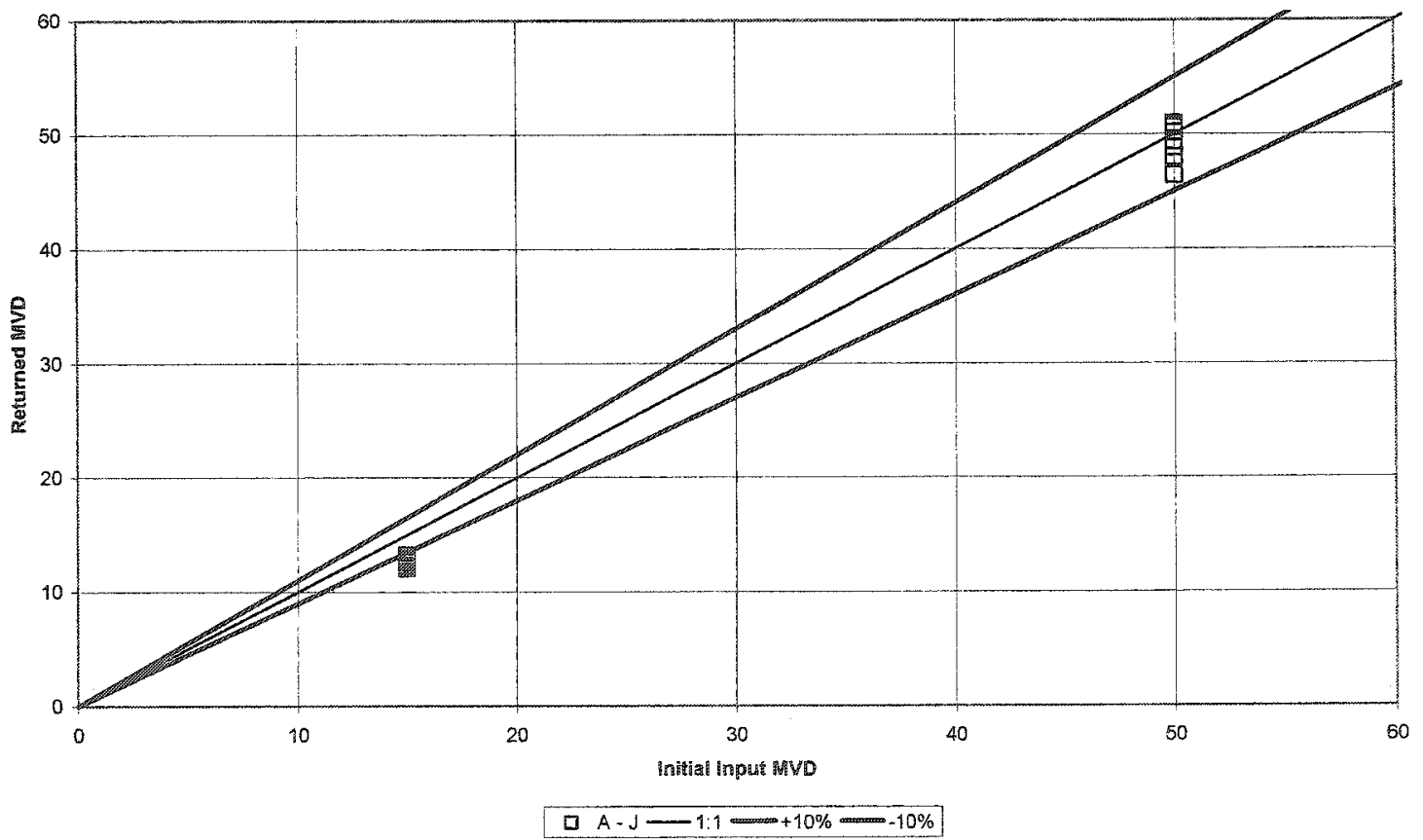

Figure 4.11b: Results of the Investigation into the Effect of Droplet Size Spectrum on MVD returned by the Solution Algorithm. (Theoretical mass accreted using spectrum $A$ and solution algorithm using spectrum J) 


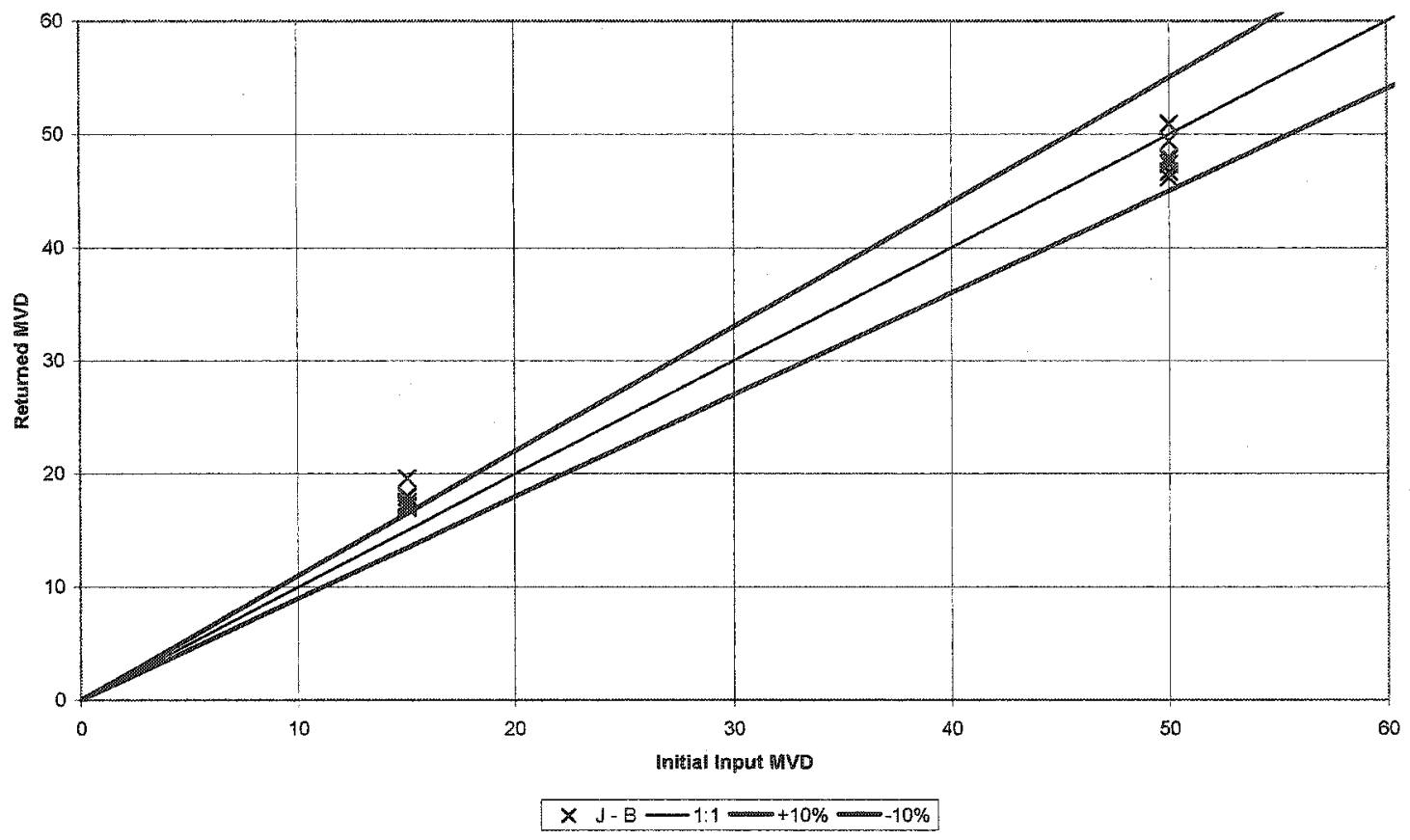

Figure 4.11c: Results of the Investigation into the Effect of Droplet Size Spectrum on MVD returned by the Solution Algorithm. (Theoretical mass accreted using spectrum $J$ and solution algorithm using spectrum B)

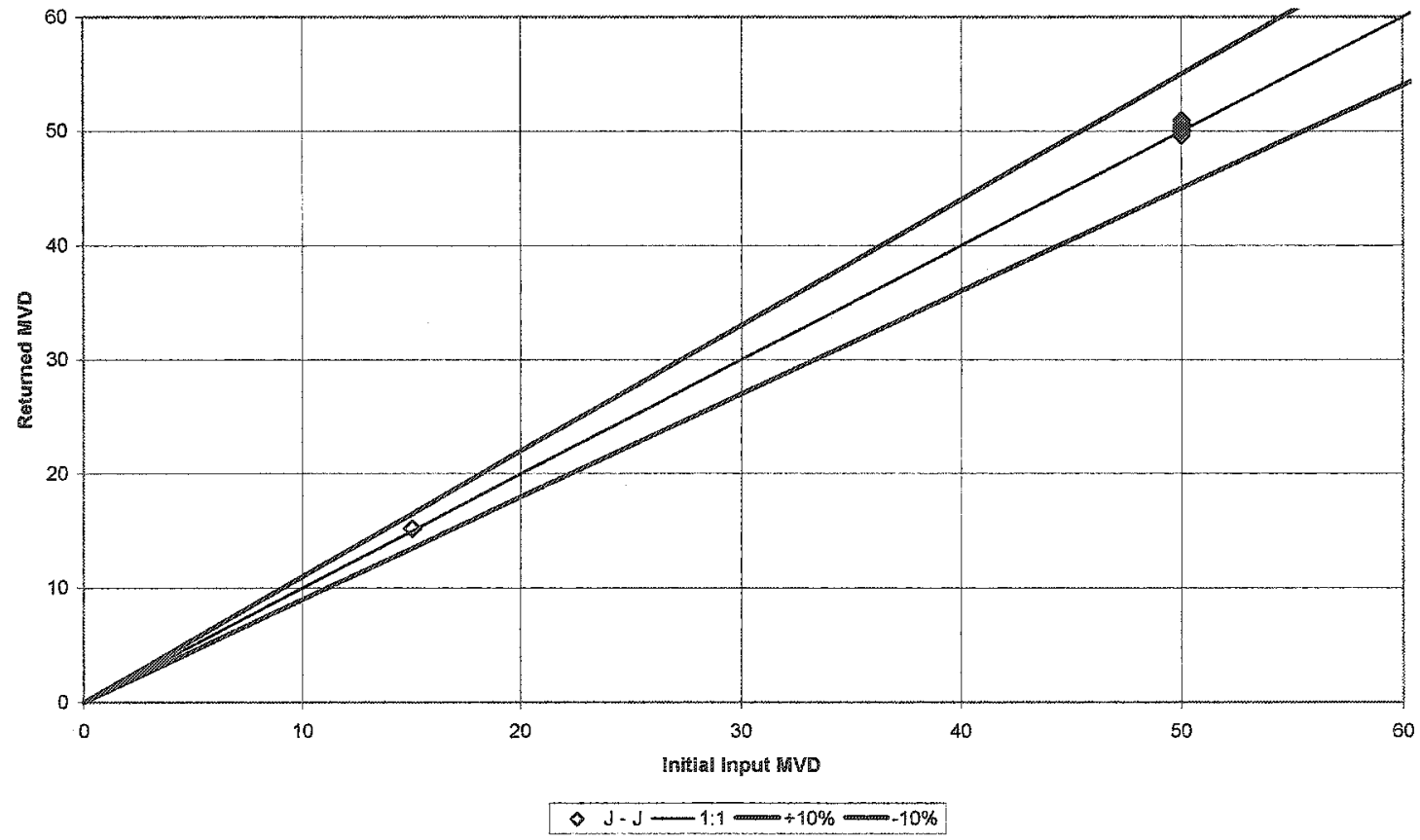

Figure 4.11d: Results of the Investigation into the Effect of Droplet Size Spectrum on MVD returned by the Solution Algorithm. (Theoretical mass accreted using spectrum $J$ and solution algorithm using spectrum $J$ ) 


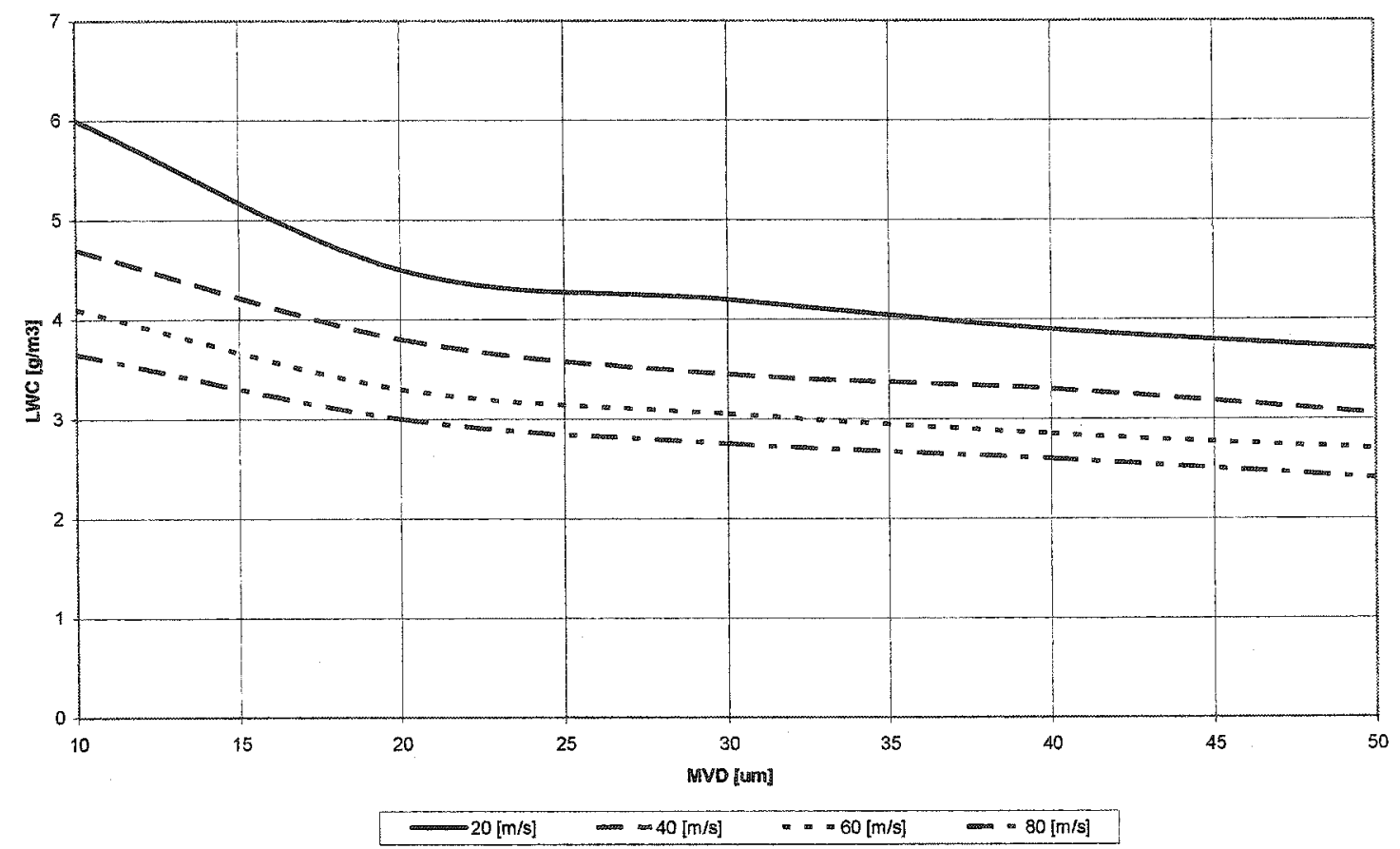

Figure 4.12: Threshold to Ensure Rime Icing on the Rotating Multicylinder Set as Determined by Computing the Average Surface Temperature and Freezing Fraction for Each Cylinder. Results are shown for a static temperature of $-25^{\circ} \mathrm{C}$.

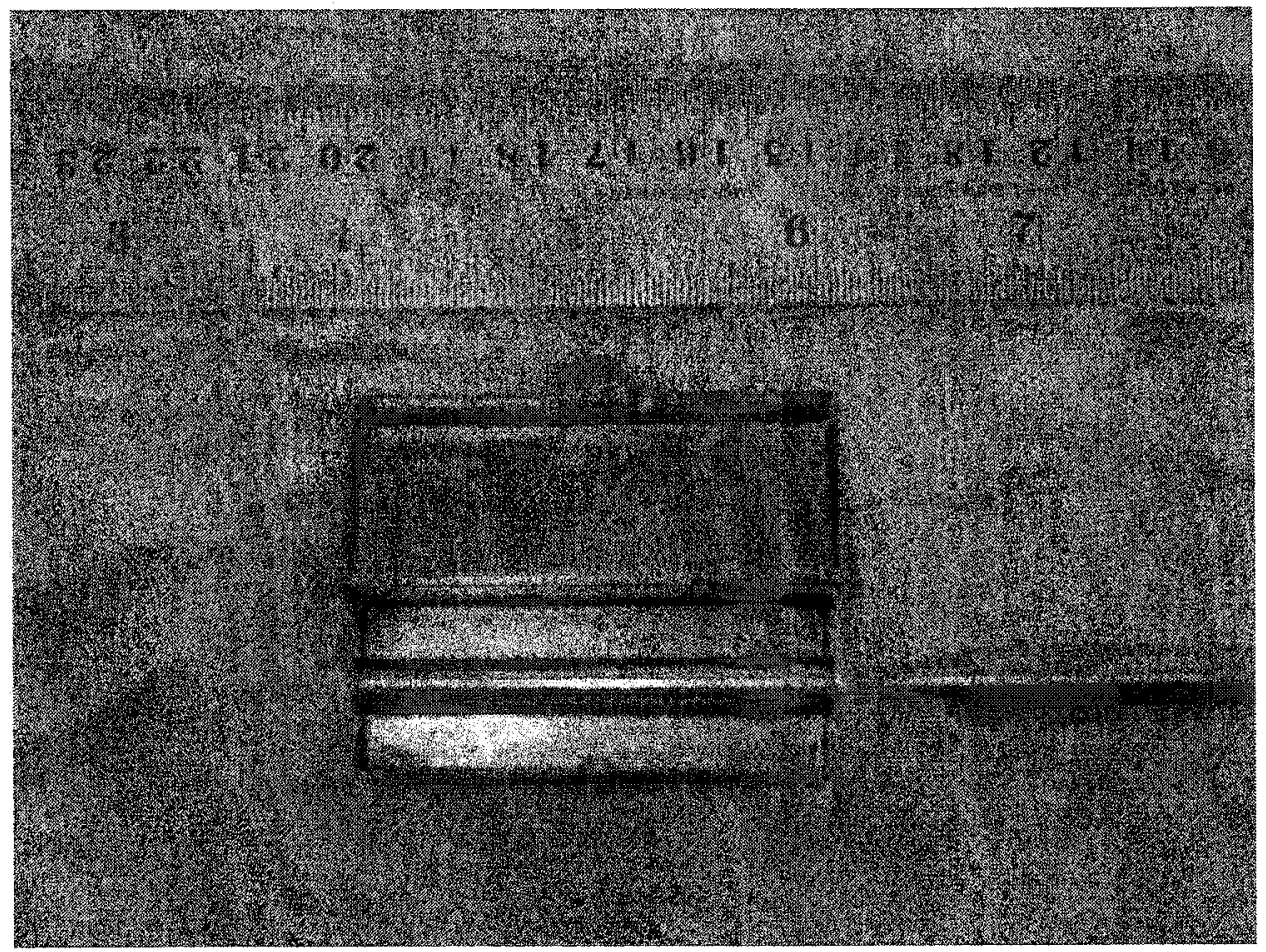

Figure 4.13: Specimen Box used to Remove Cylinders \#1 and \#2 from the Shaft of the Gun. (Cylinder \#2 shown) 


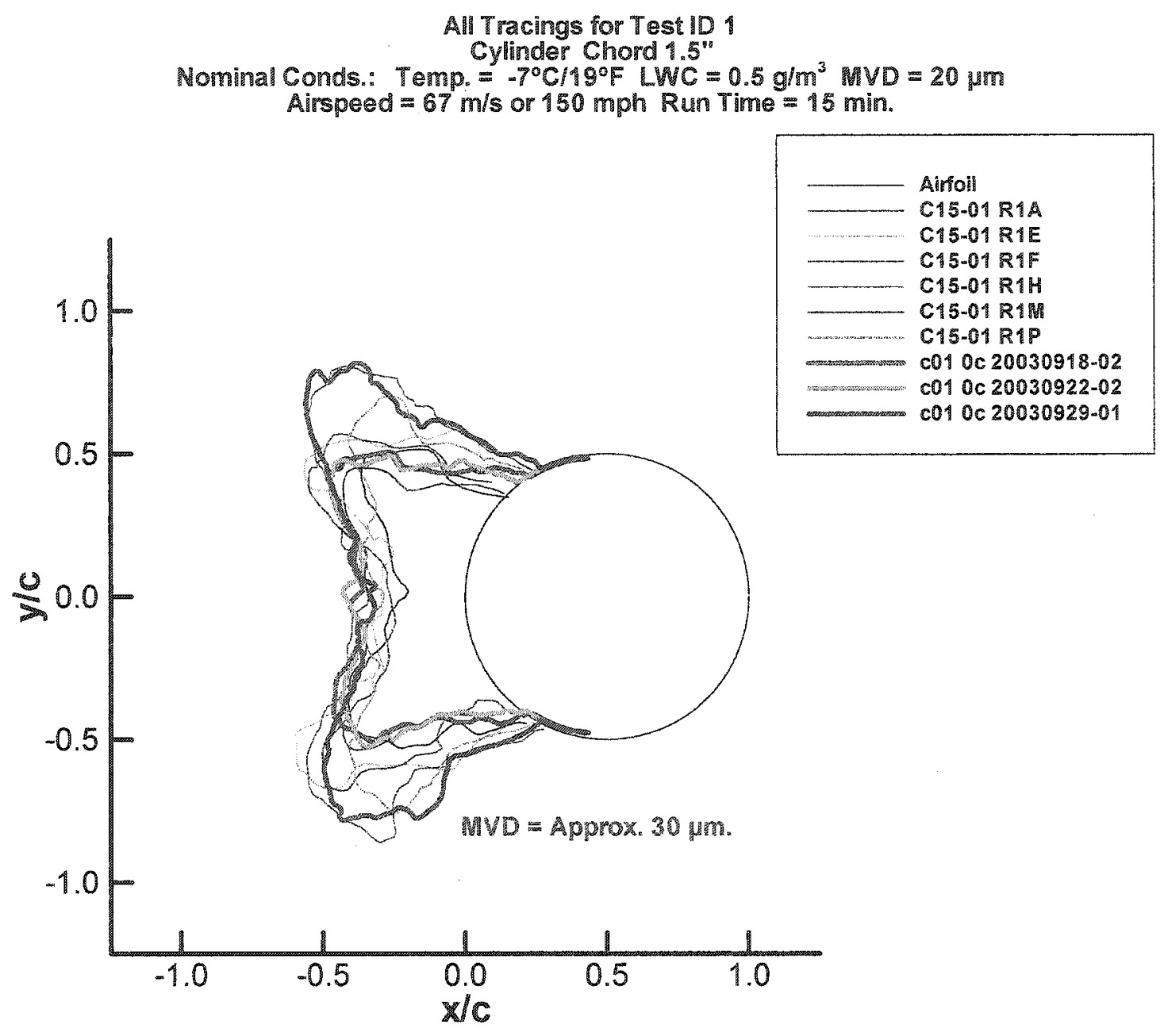

Figure 5.1: Tracings of Ice Profiles Generated by the Various Facilities for SAE Case 1. The bold tracings shown are for the present replication study. 


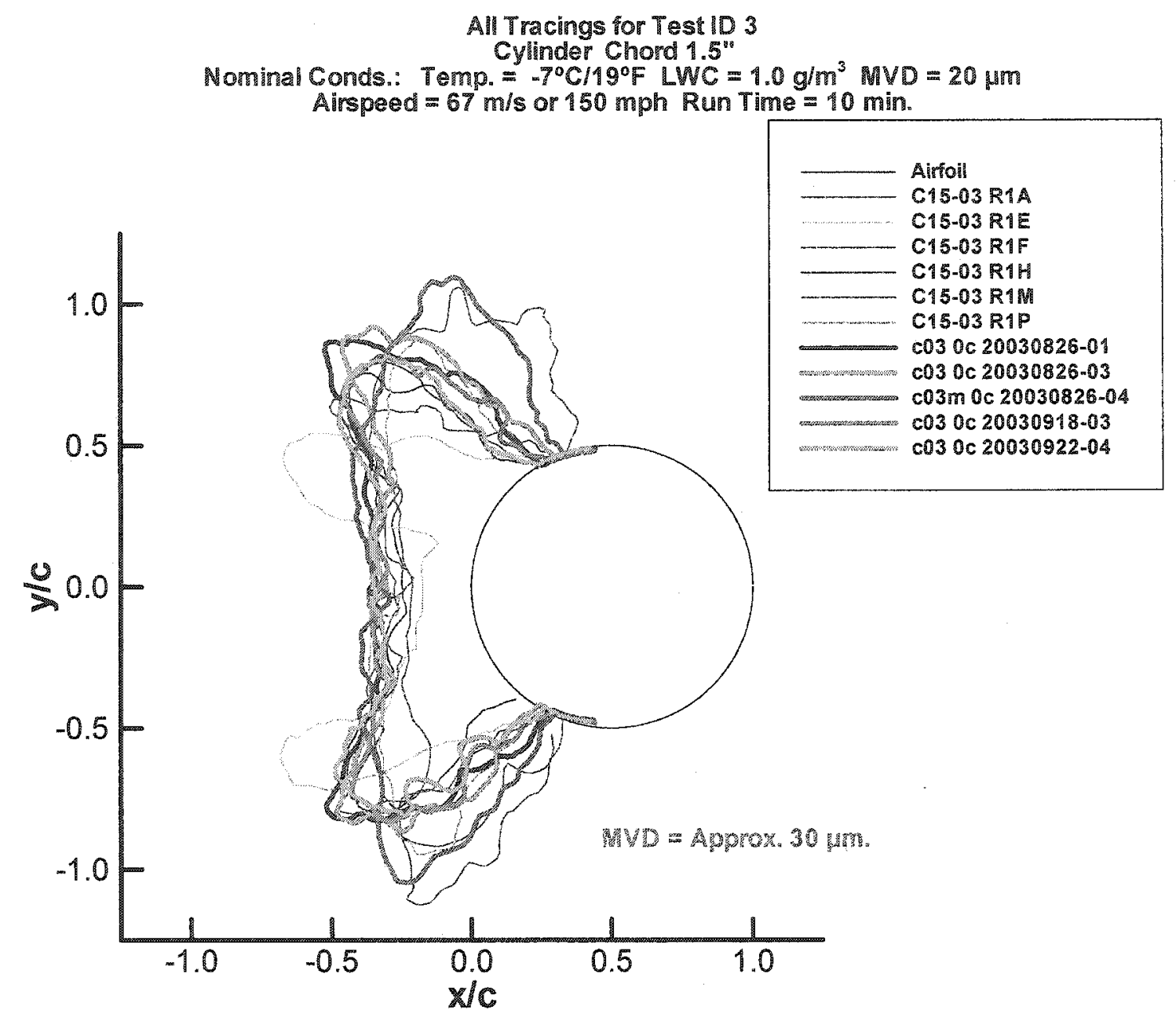

Figure 5.2: Tracings of Ice Profiles Generated by the Various Facilities for SAE Case 3. The bold tracings shown are for the present replication study. 


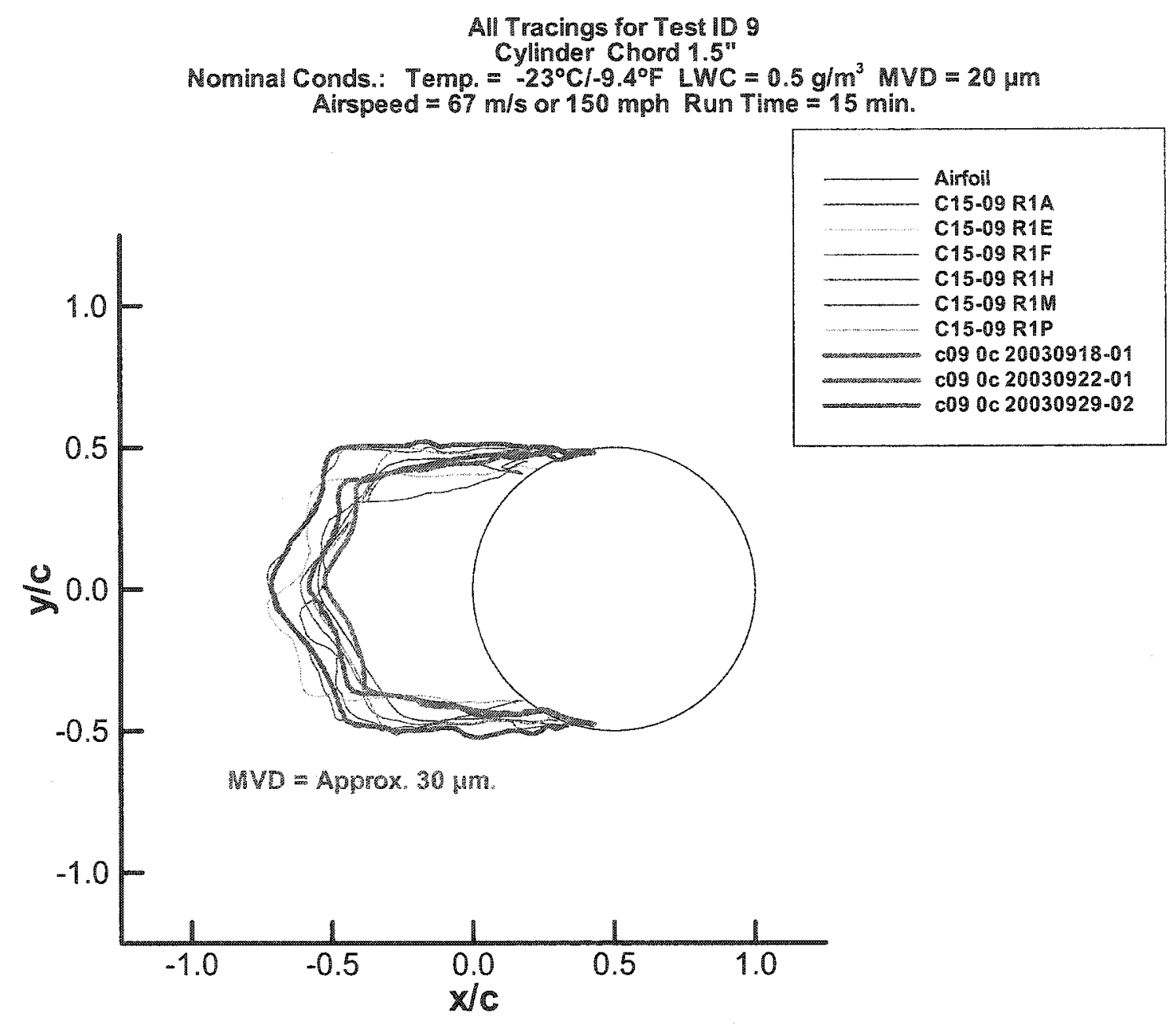

Figure 5.3: Tracings of Ice Profiles Generated by the Various Facilities for SAE Case 9. The bold tracings shown are for the present replication study. 


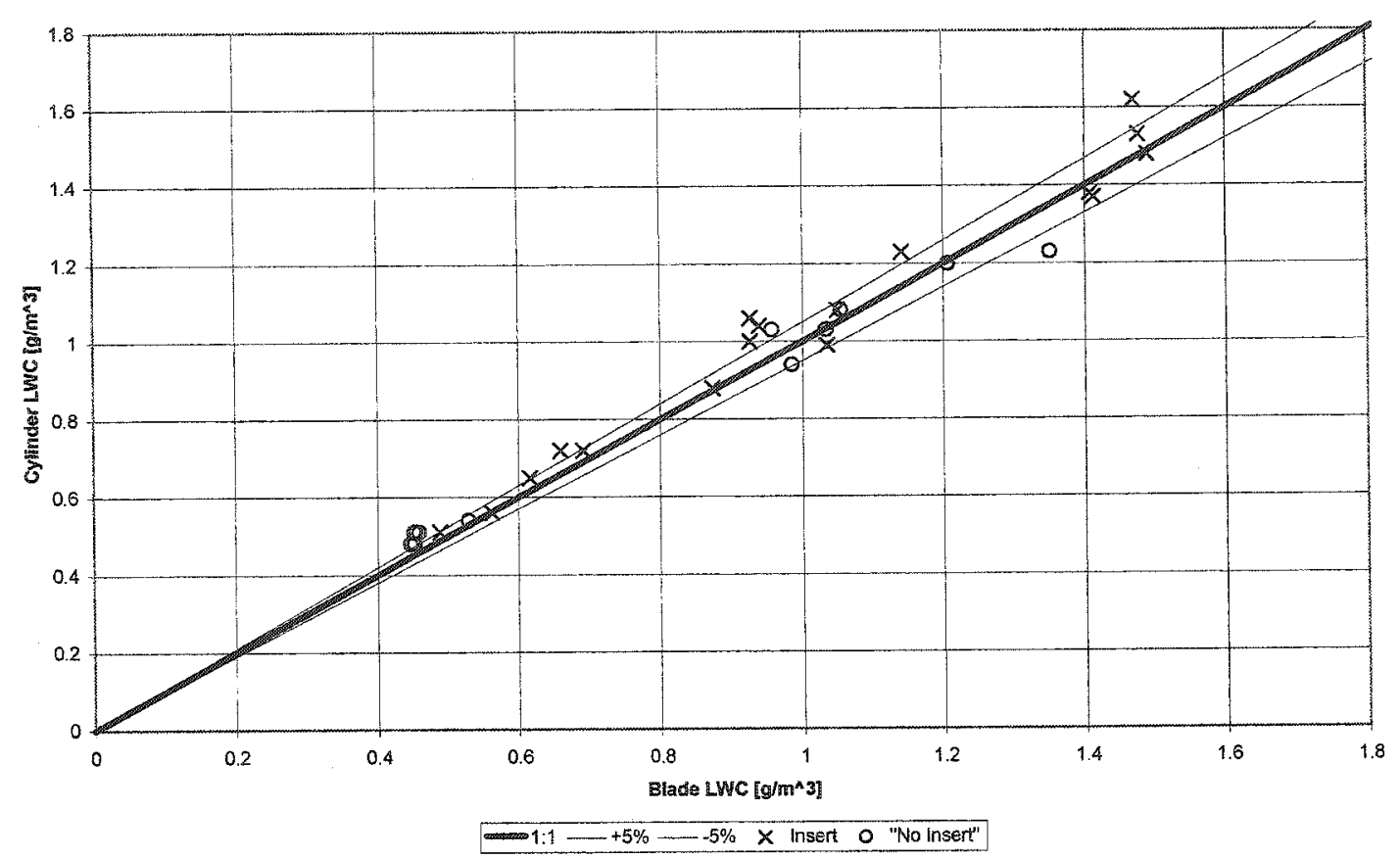

Figure 5.4: Results of the Comparison between the Icing Blade and the Single Rotating Cylinder.

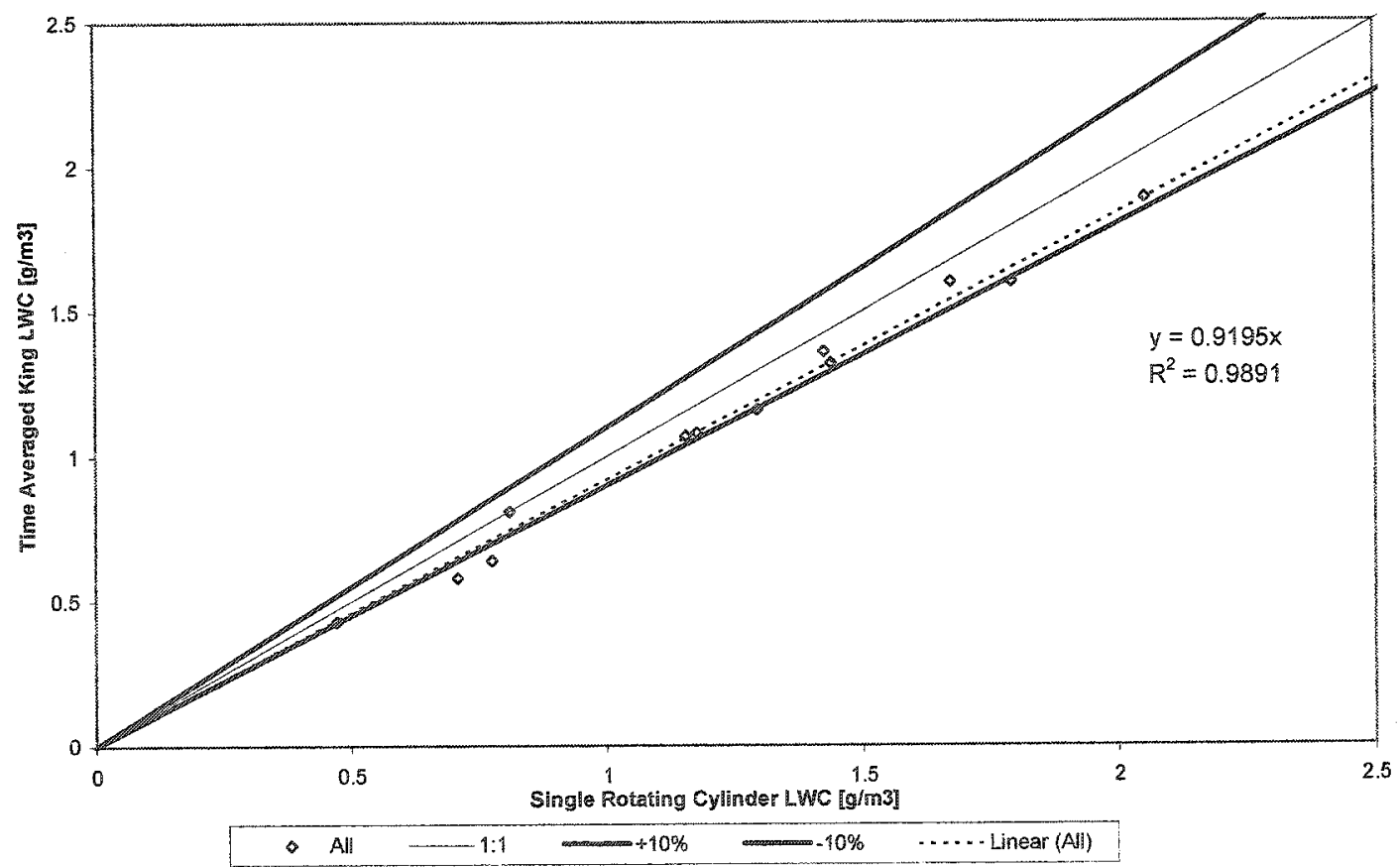

Figure 5.5a: Time Averaged King Probe LWC vs. Single Rotating Cylinder LWC. Test points at $30 \mathrm{~m} / \mathrm{s}$ 


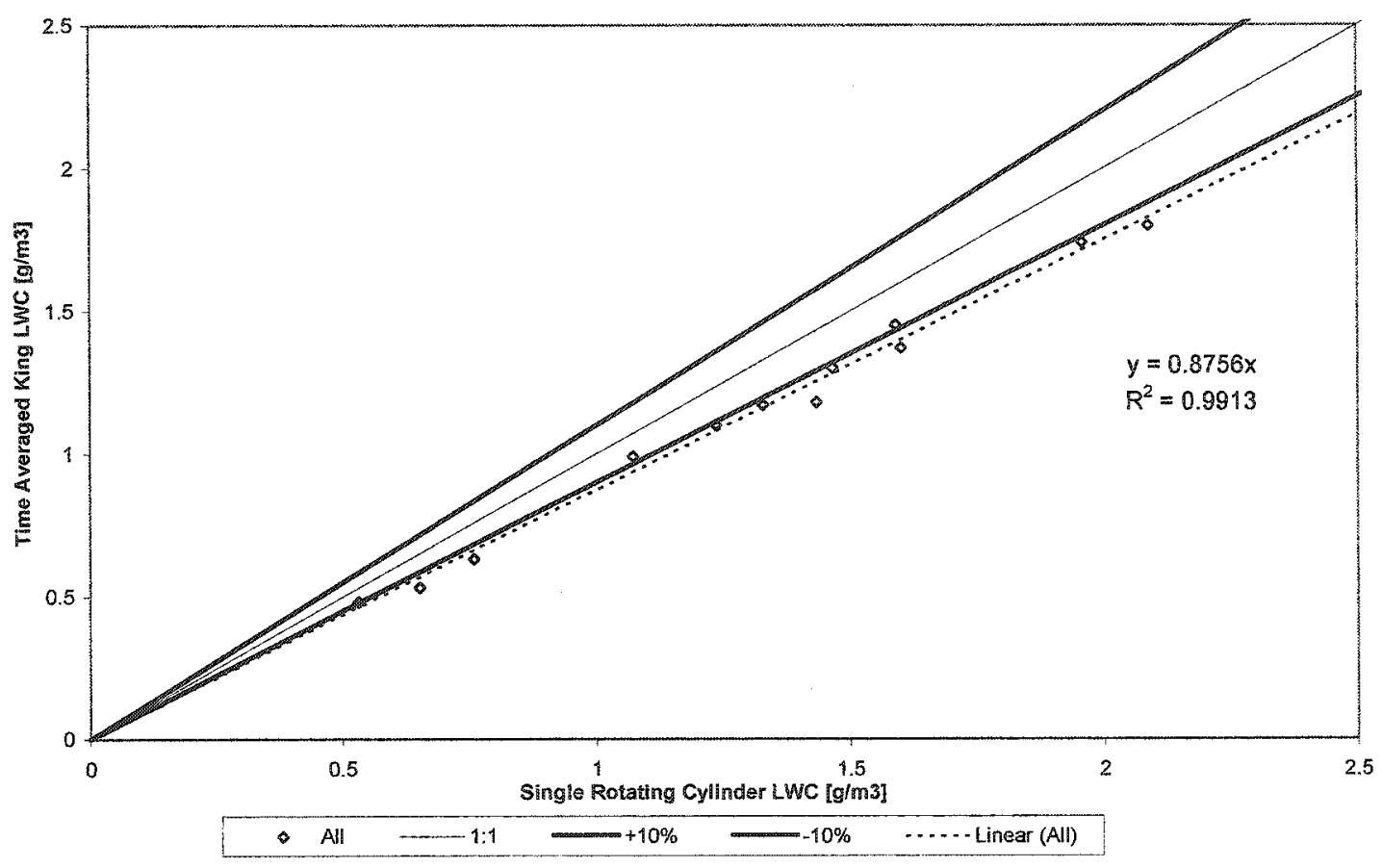

Figure 5.5b: Time Averaged King Probe LWC vs. Single Rotating Cylinder LWC. Test points at $50 \mathrm{~m} / \mathrm{s}$

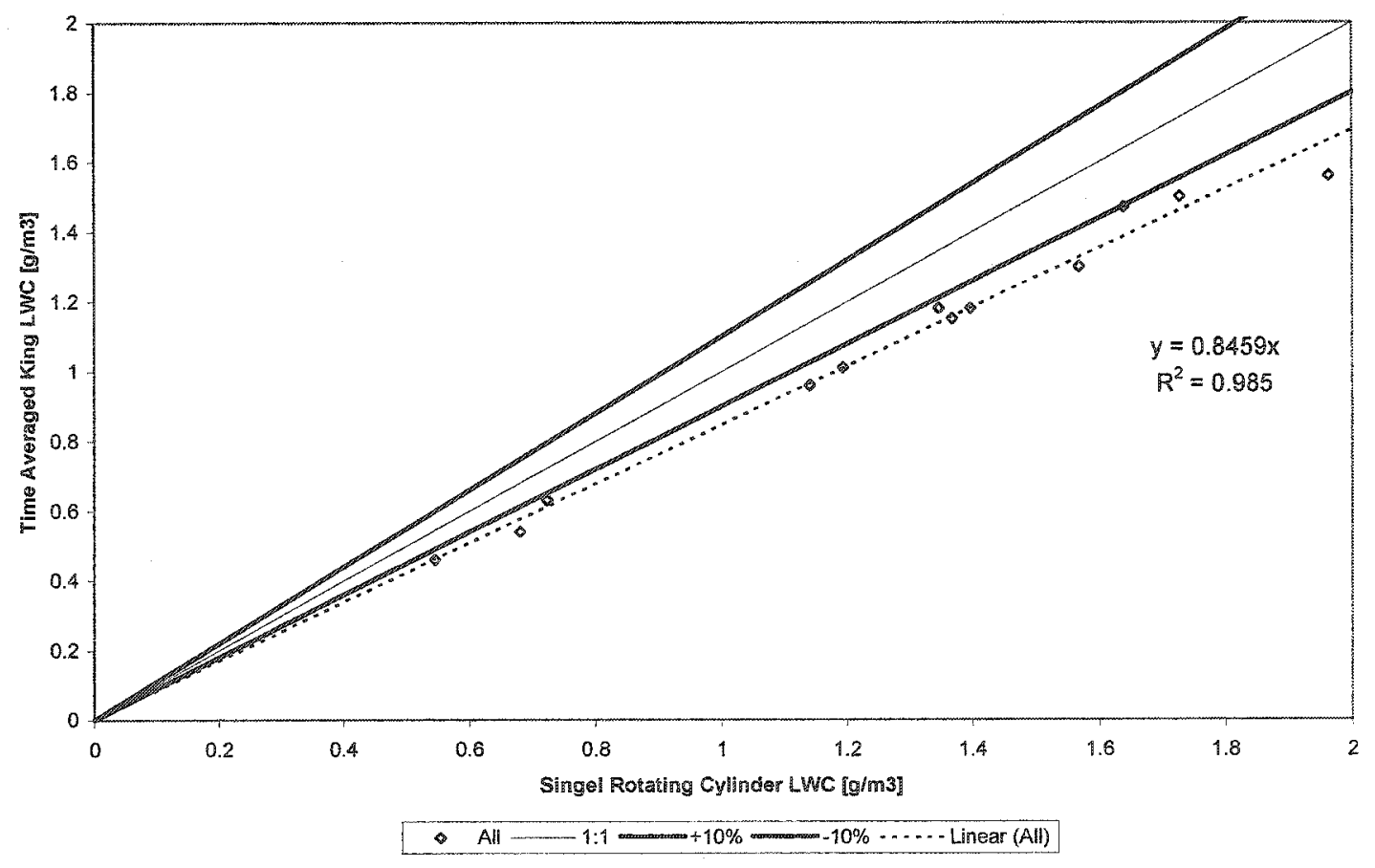

Figure 5.5c: Time Averaged King Probe LWC vs. Single Rotating Cylinder LWC. Test points at $70 \mathrm{~m} / \mathrm{s}$ 


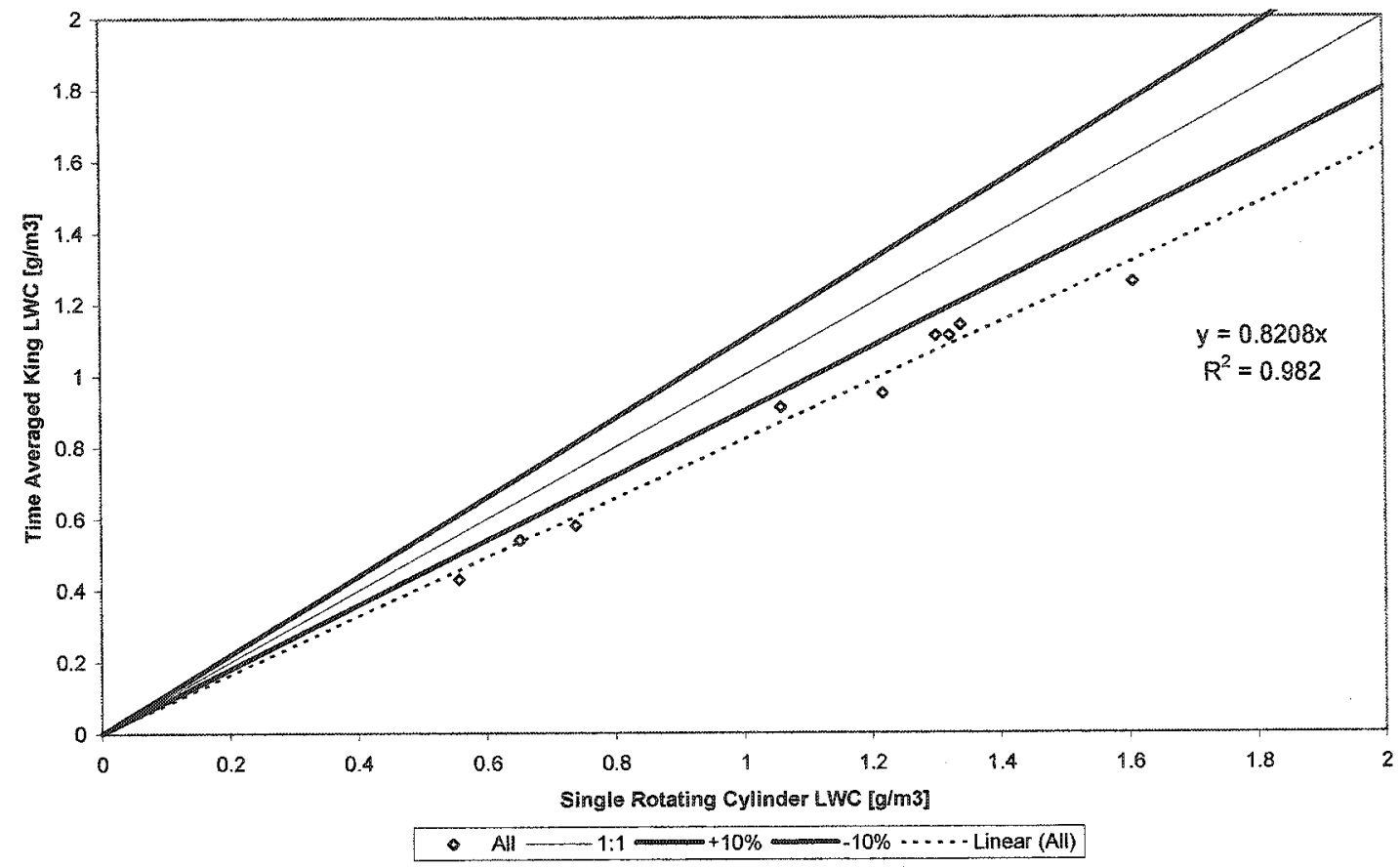

Figure 5.5d: Time Averaged King Probe LWC vs. Single Rotating Cylinder LWC. Test points at $90 \mathrm{~m} / \mathrm{s}$

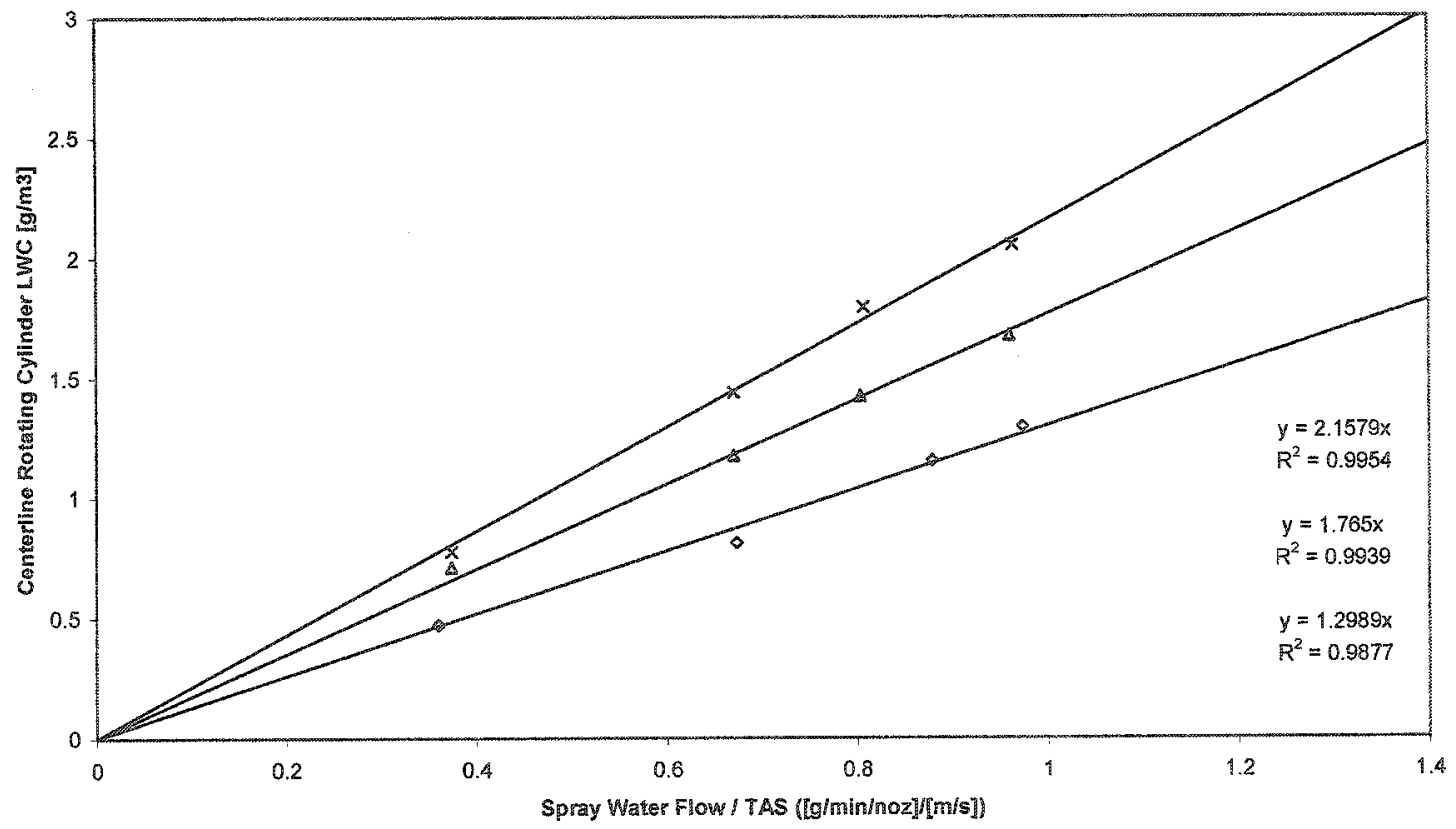

- MVD $=15[\mathrm{um}] \triangle \mathrm{MVD}=30$ [um] $\times \mathrm{MVD}=50$ [um] Linear (MVD $=15[\mathrm{um}])-$ Linear (MVD $=30$ [um]) - Linear (MVD $=50$ [um])

Figure 5.6a: Effect of MVD on the Test Section LWC as Measured by the Single Rotating Cylinder Method. Test Points at $30 \mathrm{~m} / \mathrm{s}$. 


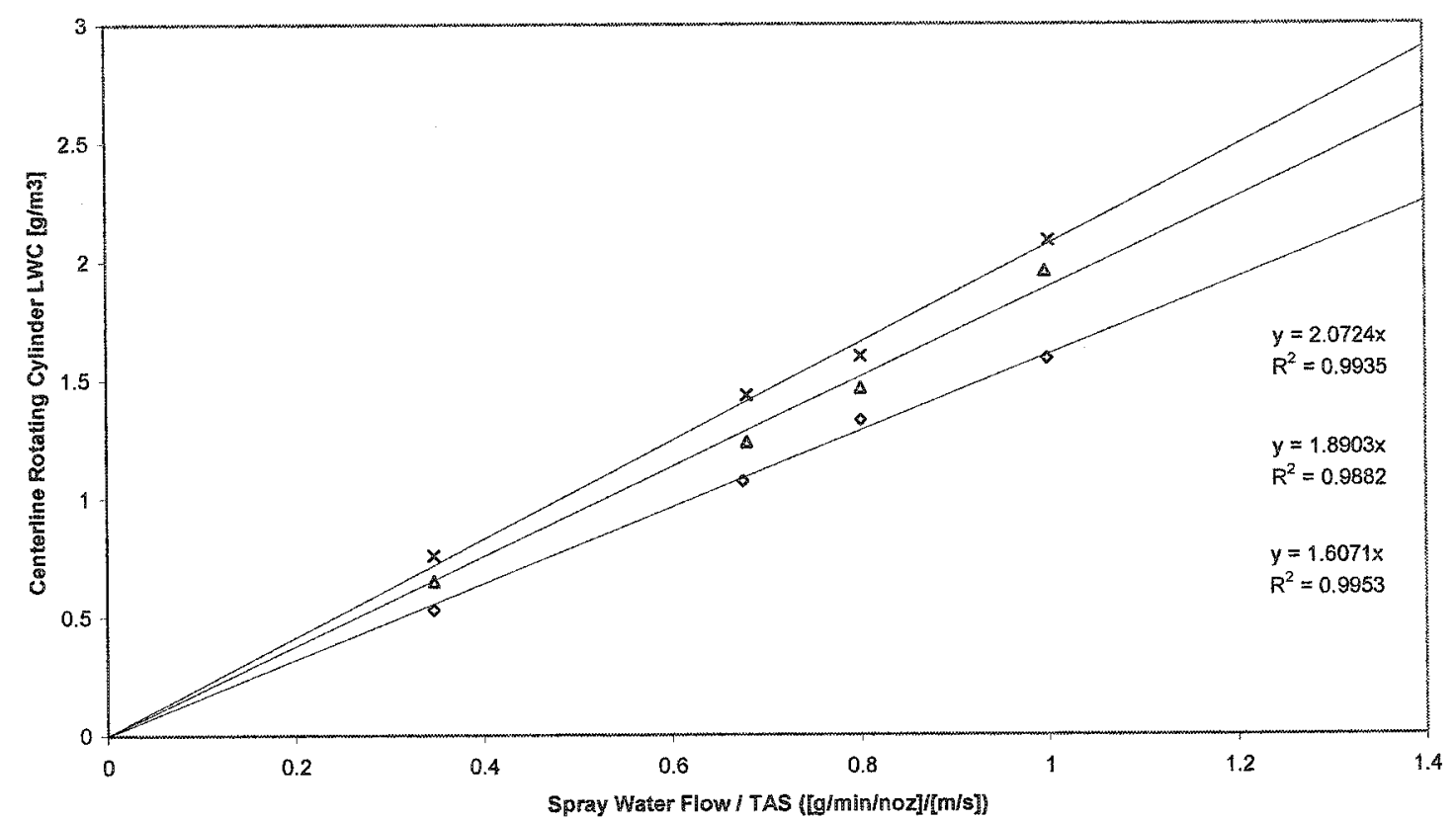

- MVD $=15[\mathrm{um}] \triangle \mathrm{MVD}=30$ [um] $\times \mathrm{MVD}=50[\mathrm{um}]-\operatorname{Linear}(\mathrm{MVD}=15[\mathrm{um}])-$ Linear (MVD $=30$ [um]) - Linear (MVD $=50$ [um])

Figure 5.6b: Effect of MVD on the Test Section LWC as Measured by the Single Rotating Cylinder Method. Test Points at $50 \mathrm{~m} / \mathrm{s}$.

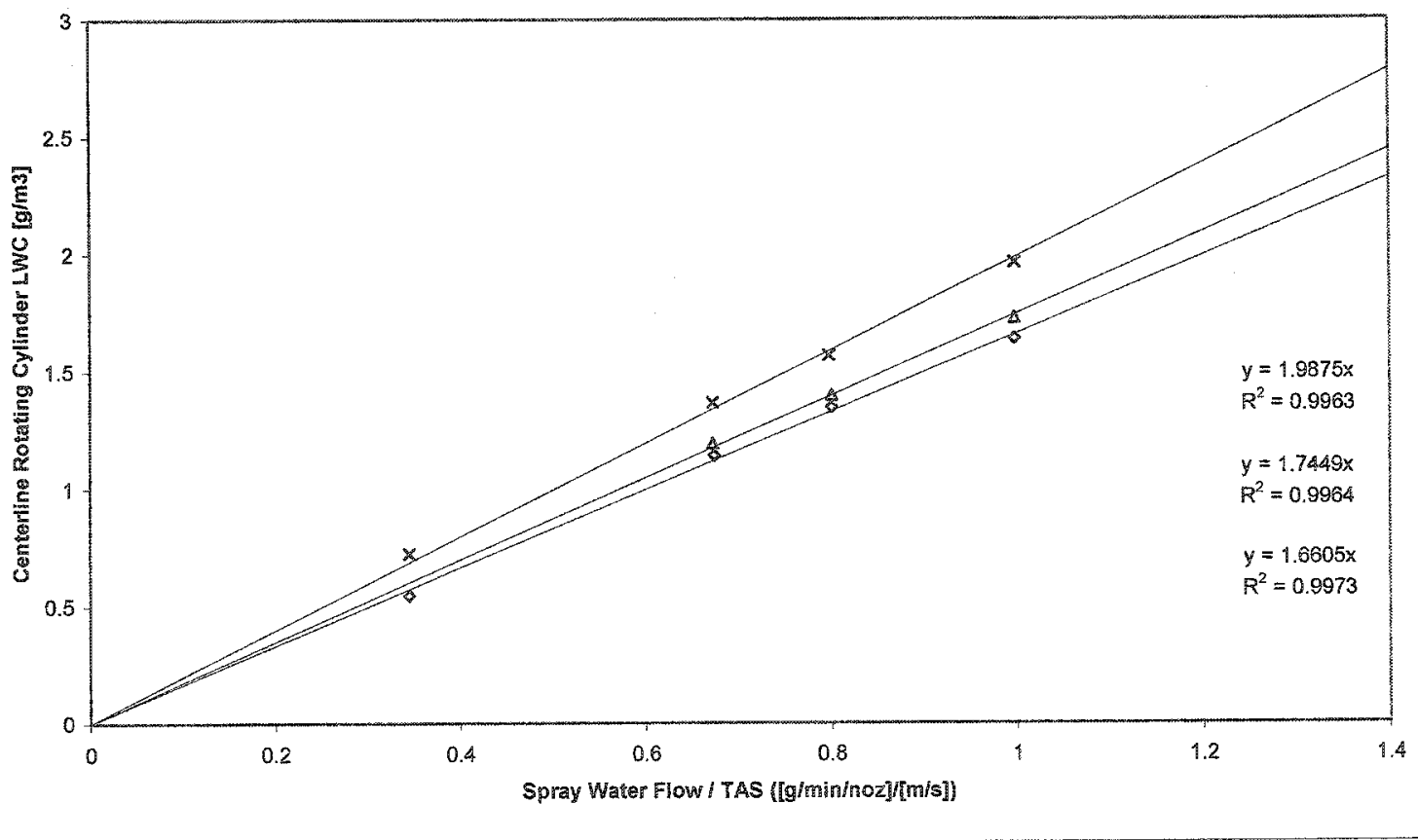

- MVD $=15[\mathrm{um}] \triangle \mathrm{MVD}=30$ [um] $\times \mathrm{MVD}=50$ [um] - Linear (MVD $=15$ [um]) - Linear (MVD $=30$ [um]) - Linear (MVD $=50$ [um])

Figure 5.6c: Effect of MVD on the Test Section LWC as Measured by the Single Rotating Cylinder Method. Test Points at $70 \mathrm{~m} / \mathrm{s}$. 


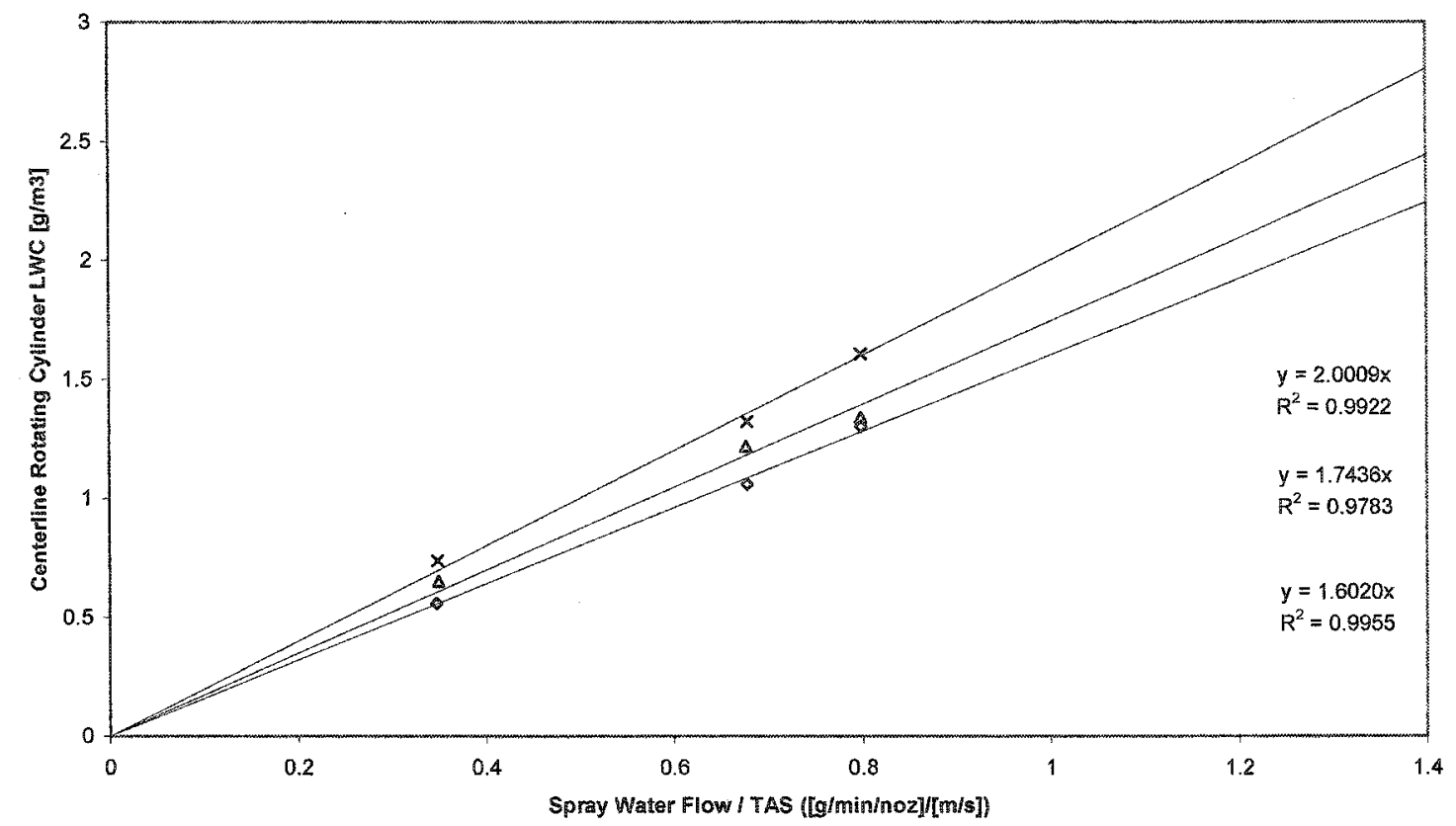

- MVD $=15[\mathrm{um}] \triangle \mathrm{MVD}=30[\mathrm{um}] \times \mathrm{MVD}=50[\mathrm{um}] \quad$ Linear $(\mathrm{MVD}=15$ [uml) Linear $(\mathrm{MVD}=30[\mathrm{um}])-$ Linear $(\mathrm{MVD}=50[\mathrm{um}])$

Figure 5.6d: Effect of MVD on the Test Section LWC as Measured by the Single Rotating Cylinder Method. Test Points at $90 \mathrm{~m} / \mathrm{s}$.

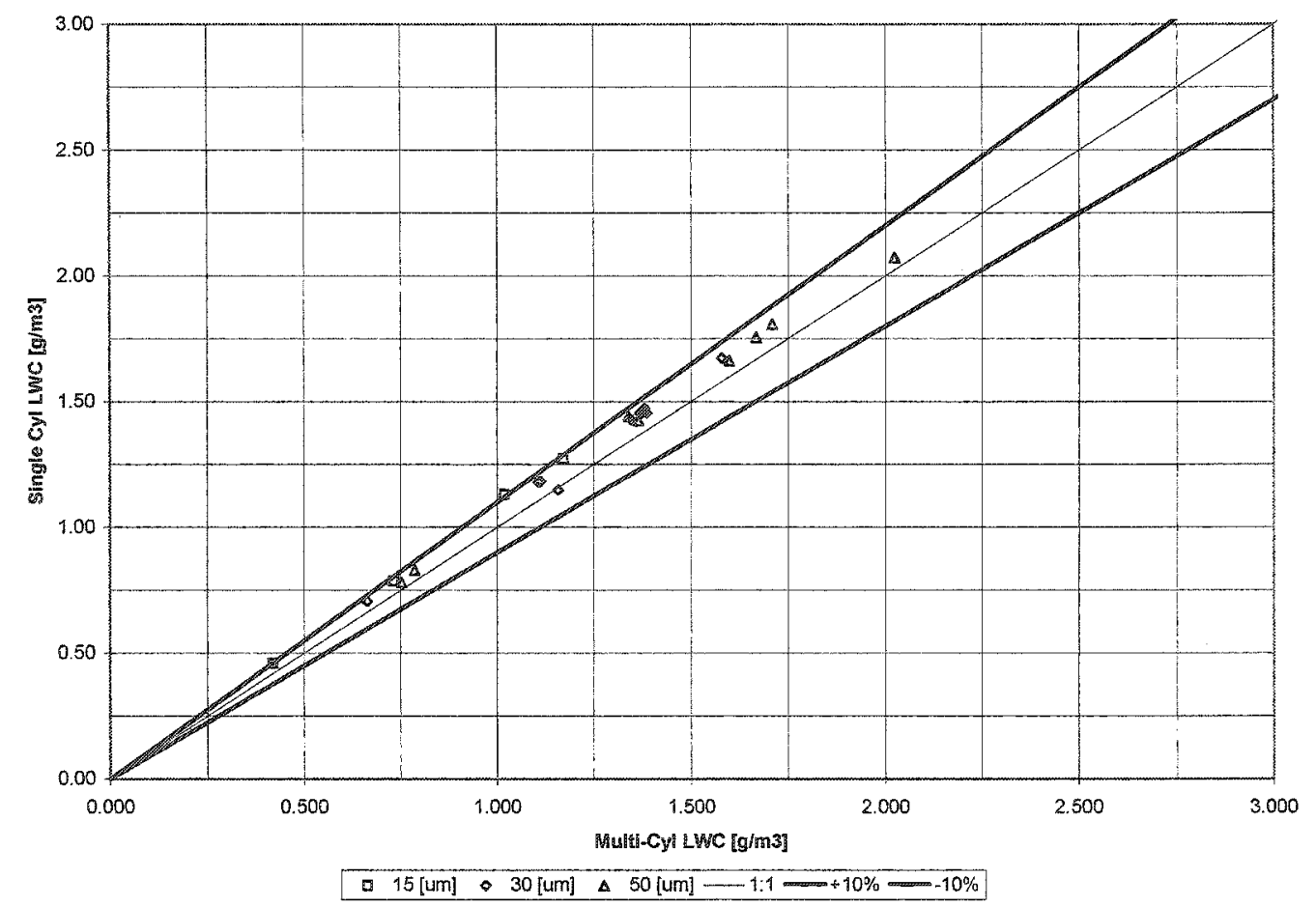

Figure 5.7a: Single Cylinder LWC vs. Rotating Multicylinder LWC for Test Points Conducted at $30 \mathrm{~m} / \mathrm{s}$. 


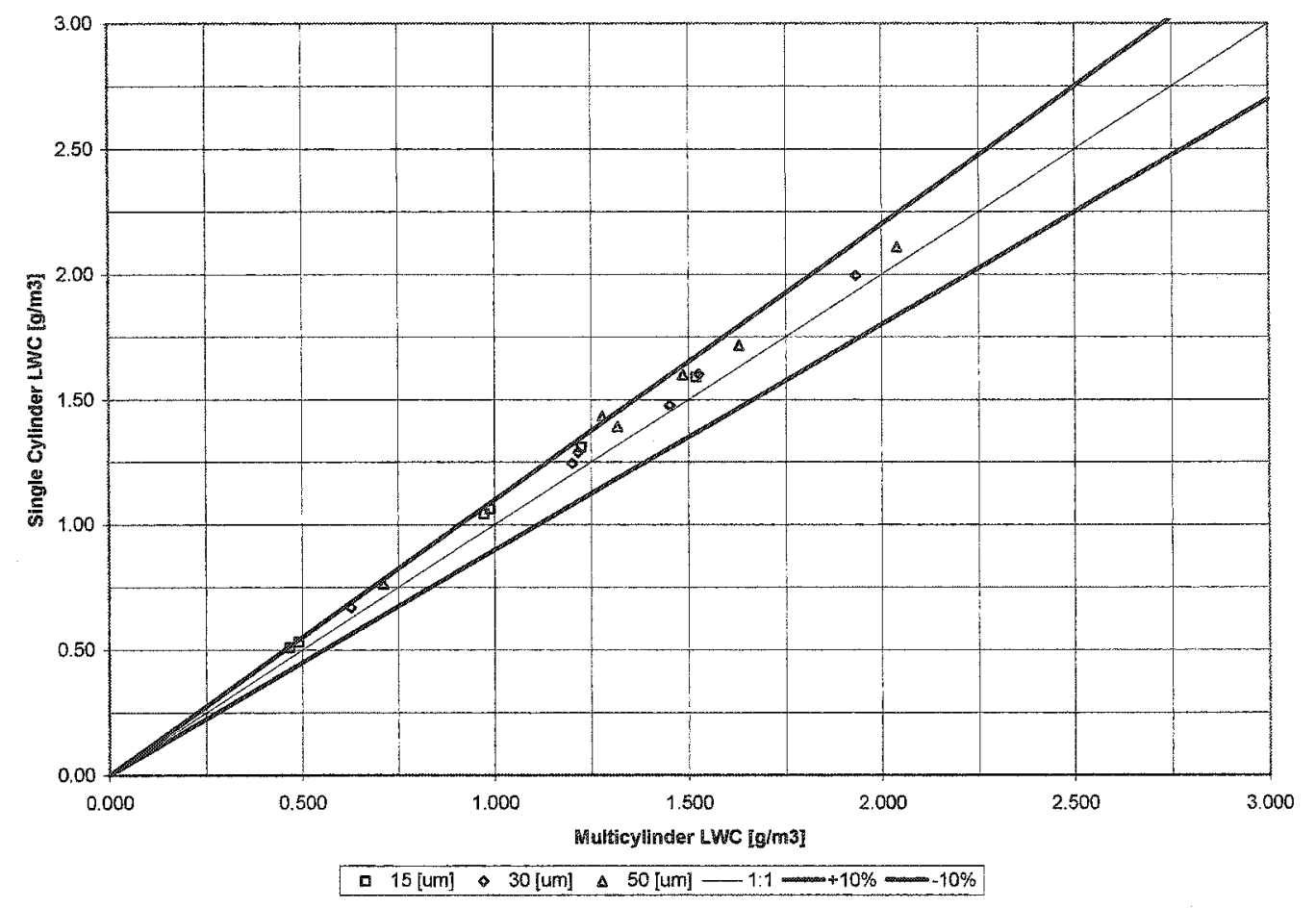

Figure 5.7b: Single Cylinder LWC vs. Rotating Multicylinder LWC for Test Points Conducted at $50 \mathrm{~m} / \mathrm{s}$.

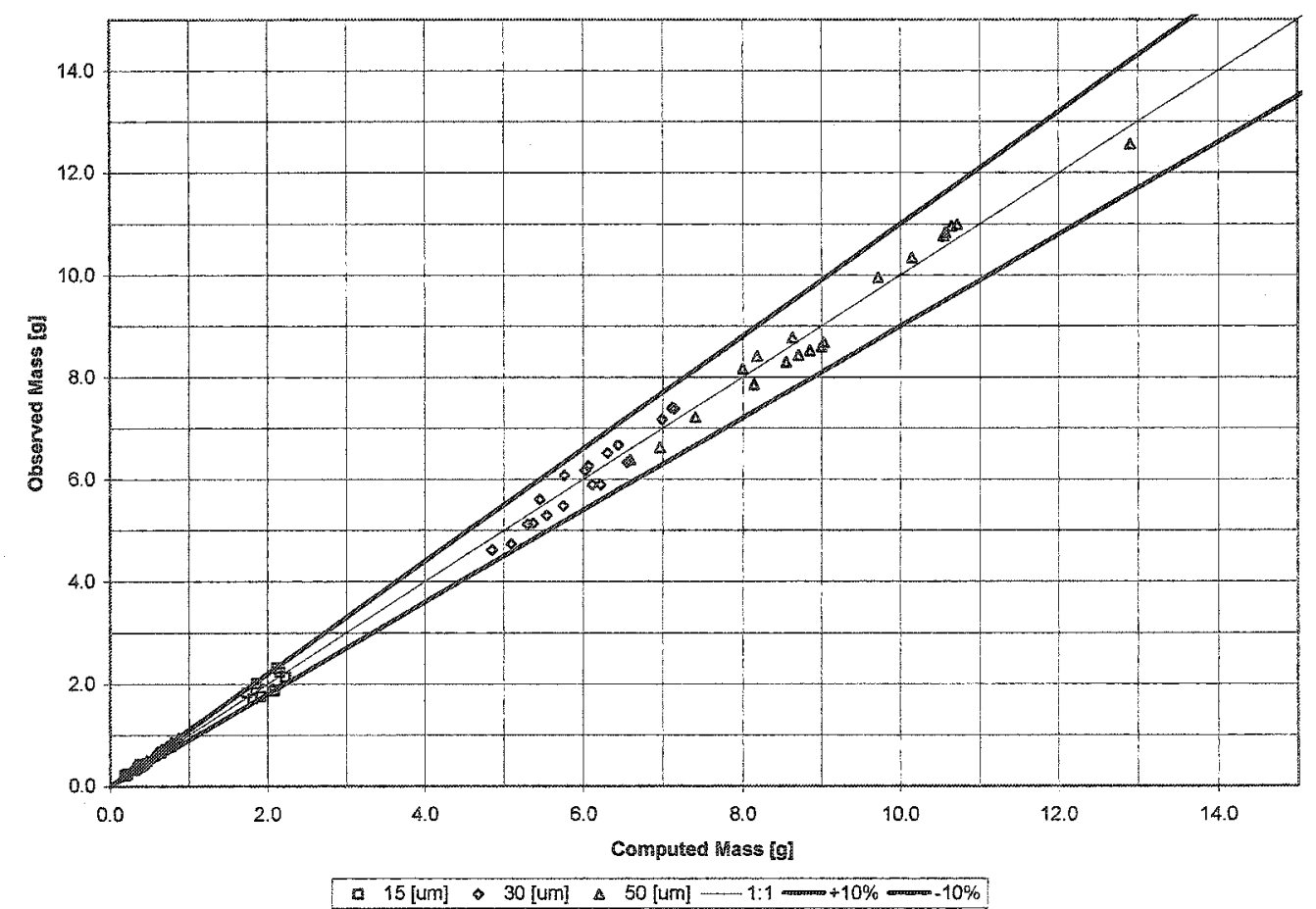

Figure 5.8a: Experimental Observed Mass vs. Theoretically Computed Mass on the Four Cylinders in the Rotating Multicylinder Set. Test points at $30 \mathrm{~m} / \mathrm{s}$. 


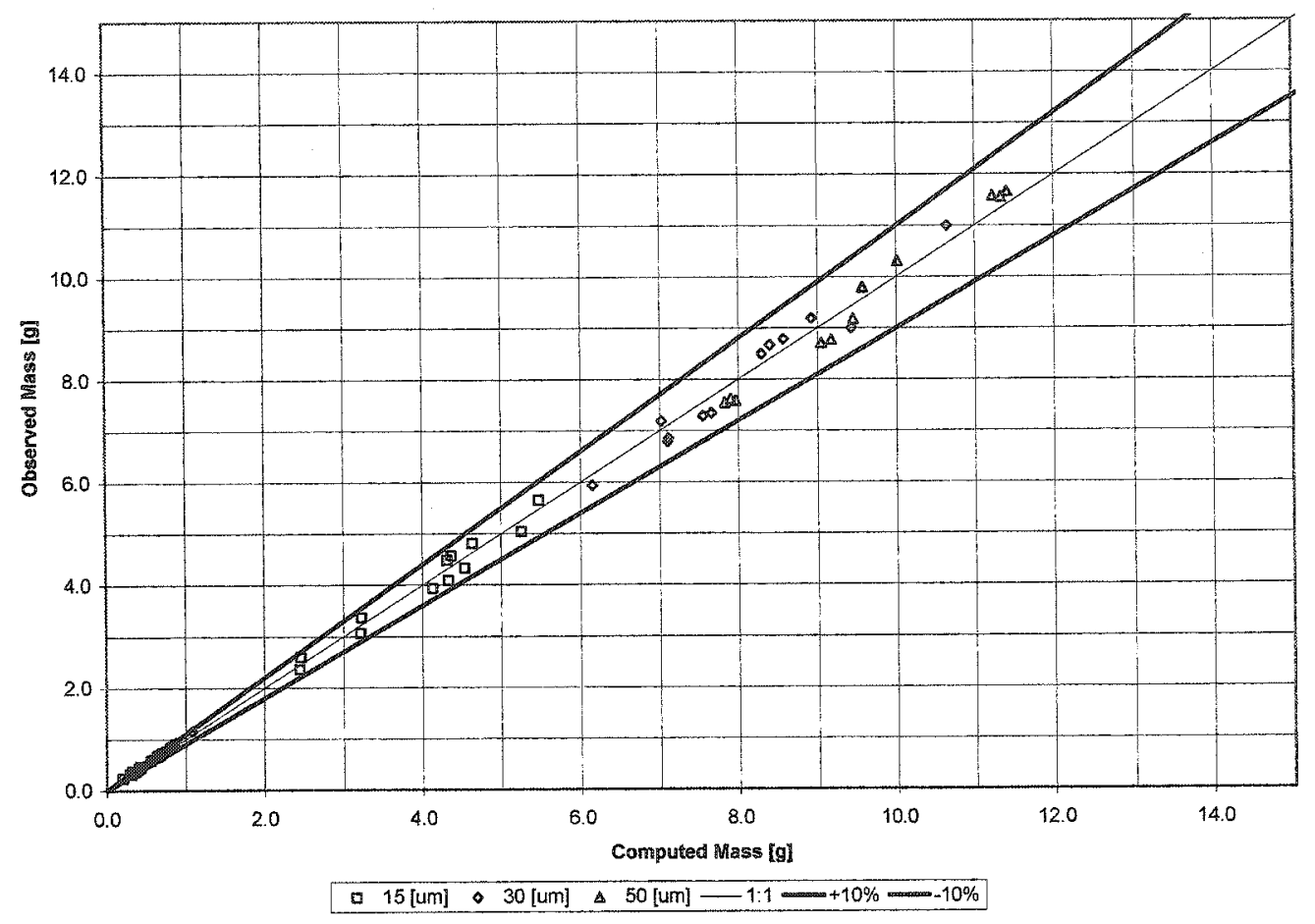

Figure 5.8b: Experimental Observed Mass vs. Theoretically Computed Mass on the Four Cylinders in the Rotating Multicylinder Set. Test points at $50 \mathrm{~m} / \mathrm{s}$.

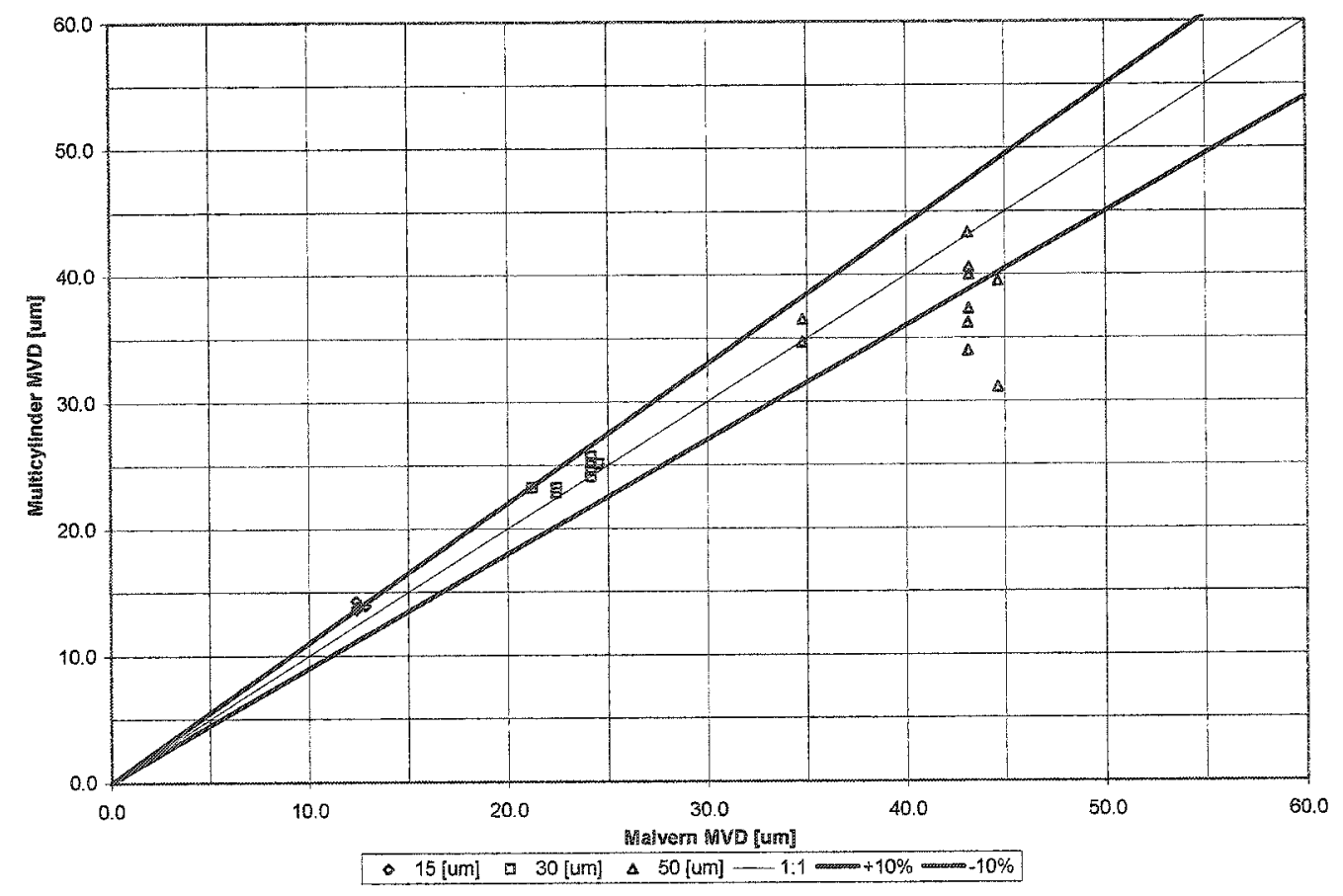

Figure 5.9a: Computed Rotating Multicylinder MVD vs. Measured Malvern Spraytec MVD. Test points at $30 \mathrm{~m} / \mathrm{s}$. 


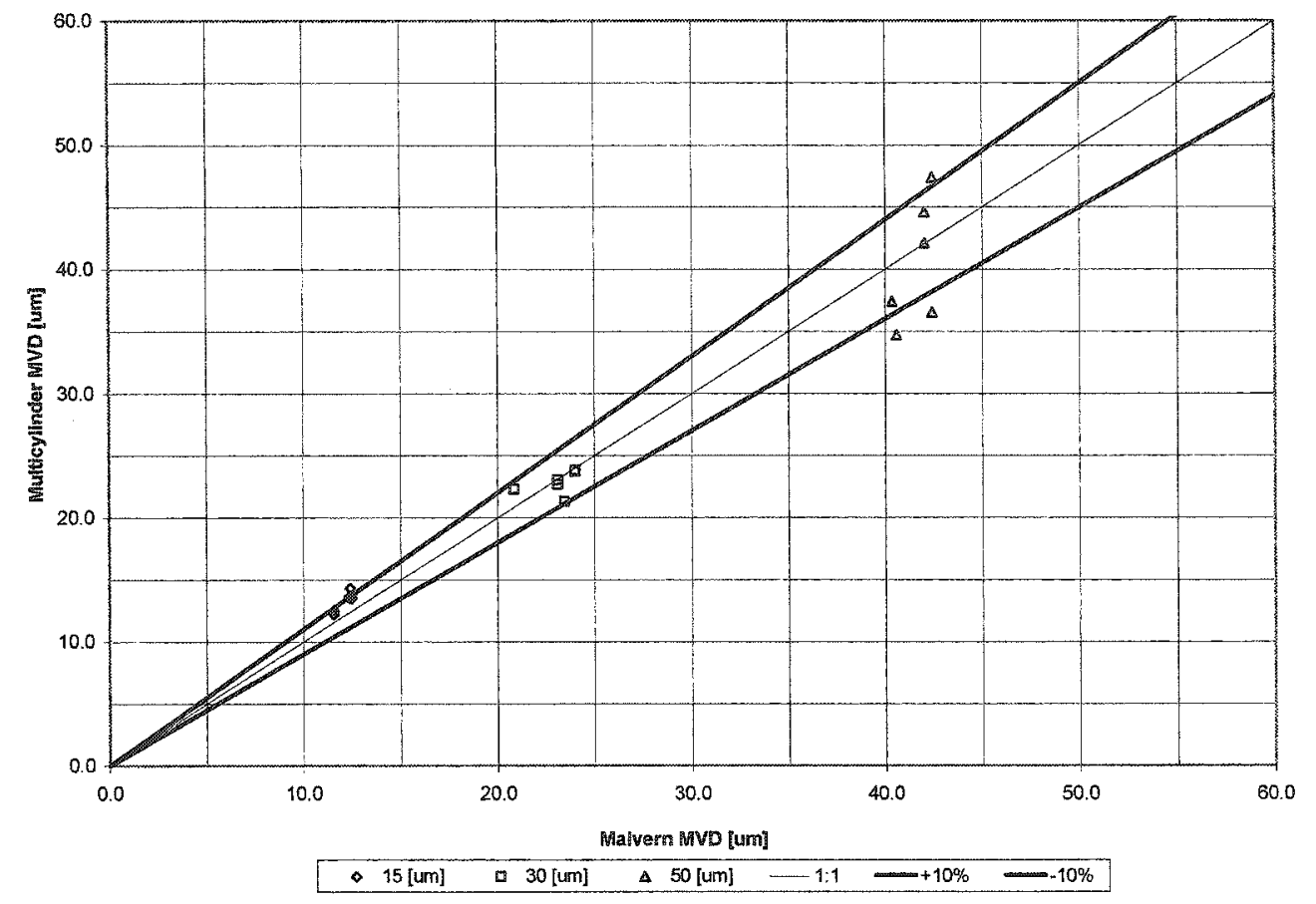

Figure 5.9b: Computed Rotating Multicylinder MVD vs. Measured Malvern Spraytec MVD. Test points at $50 \mathrm{~m} / \mathrm{s}$.

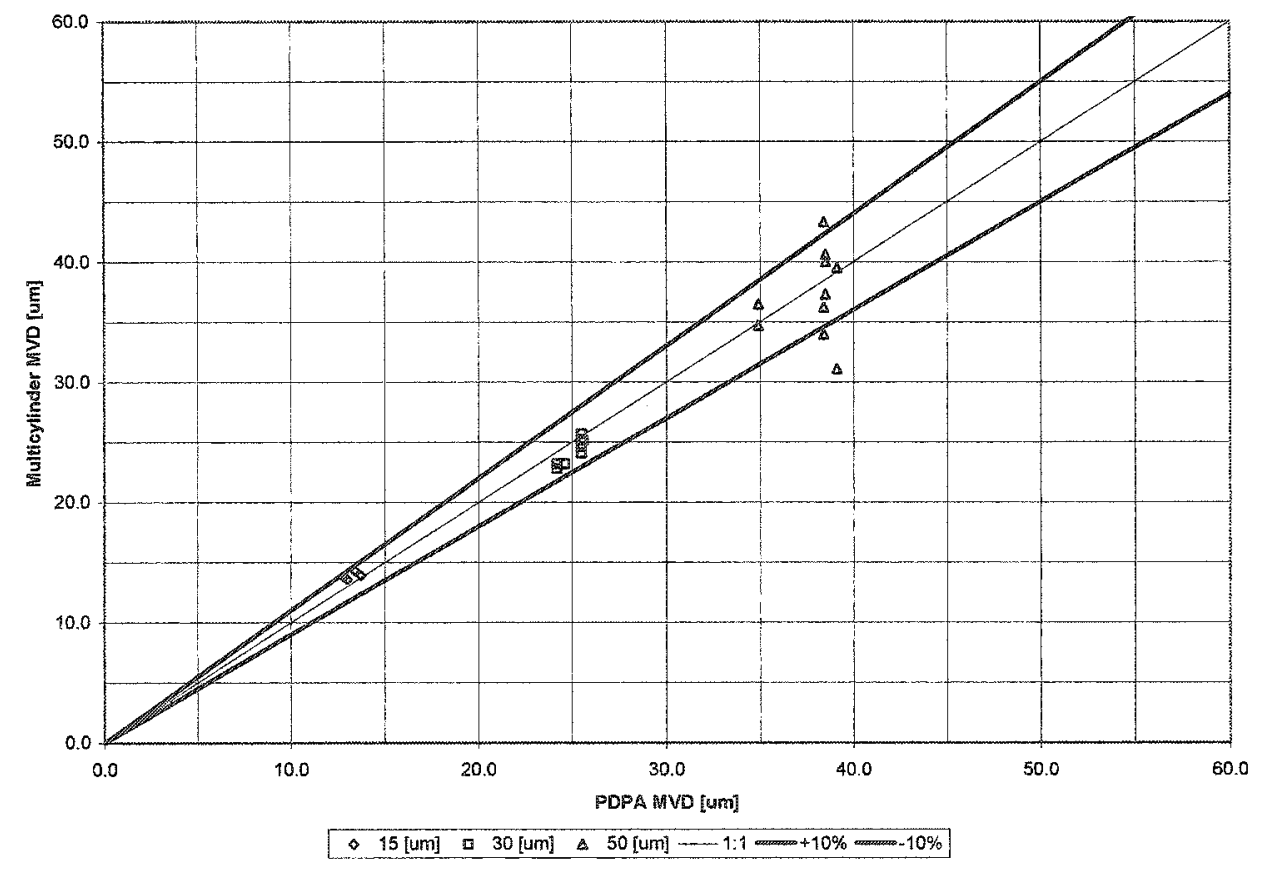

Figure 5.10a: Computed Rotating Multicylinder MVD vs. Measured PDPA MVD. Test points at $30 \mathrm{~m} / \mathrm{s}$. 


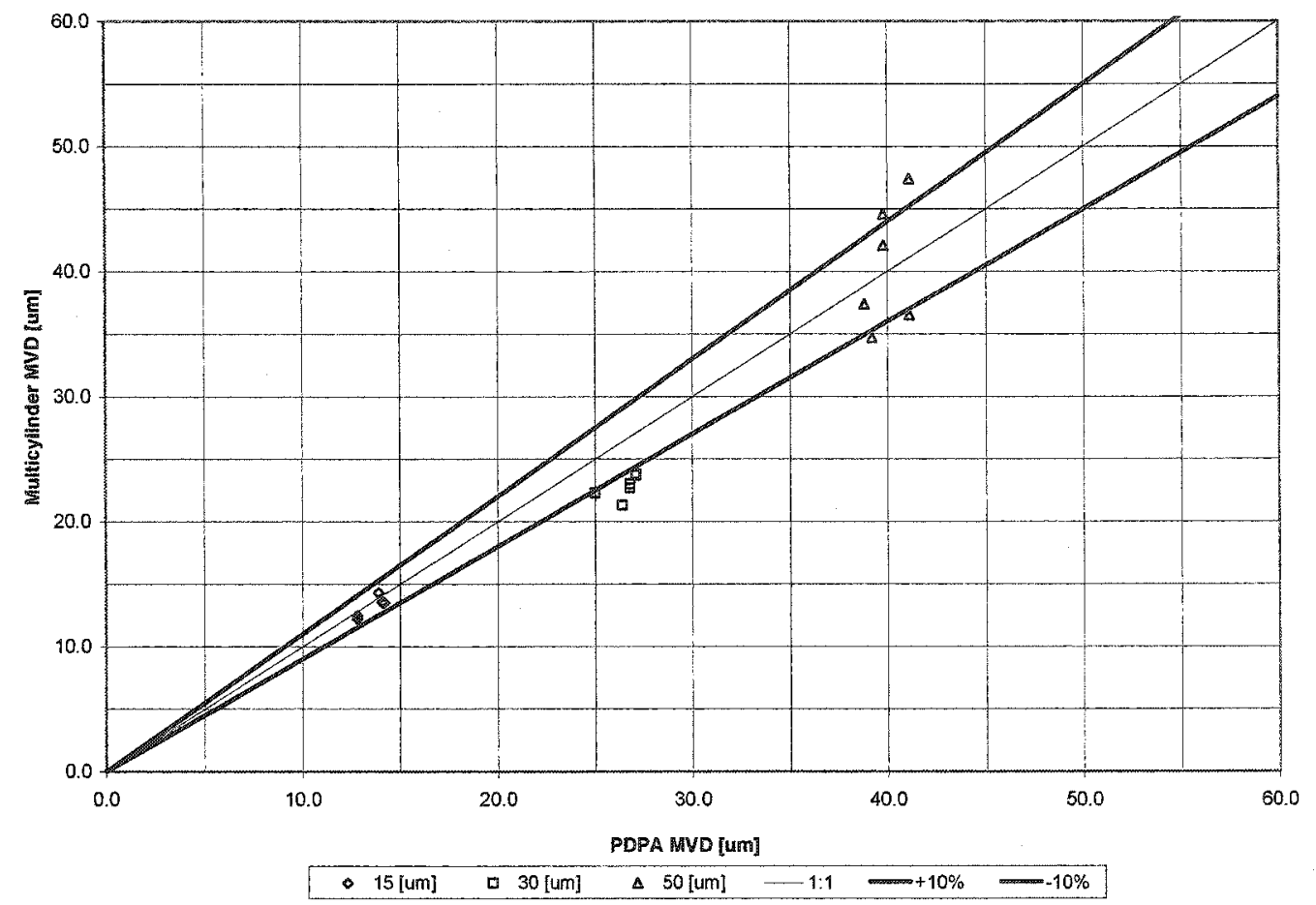

Figure 5.10b: Computed Rotating Multicylinder MVD vs. Measured PDPA MVD. Test points at $50 \mathrm{~m} / \mathrm{s}$.

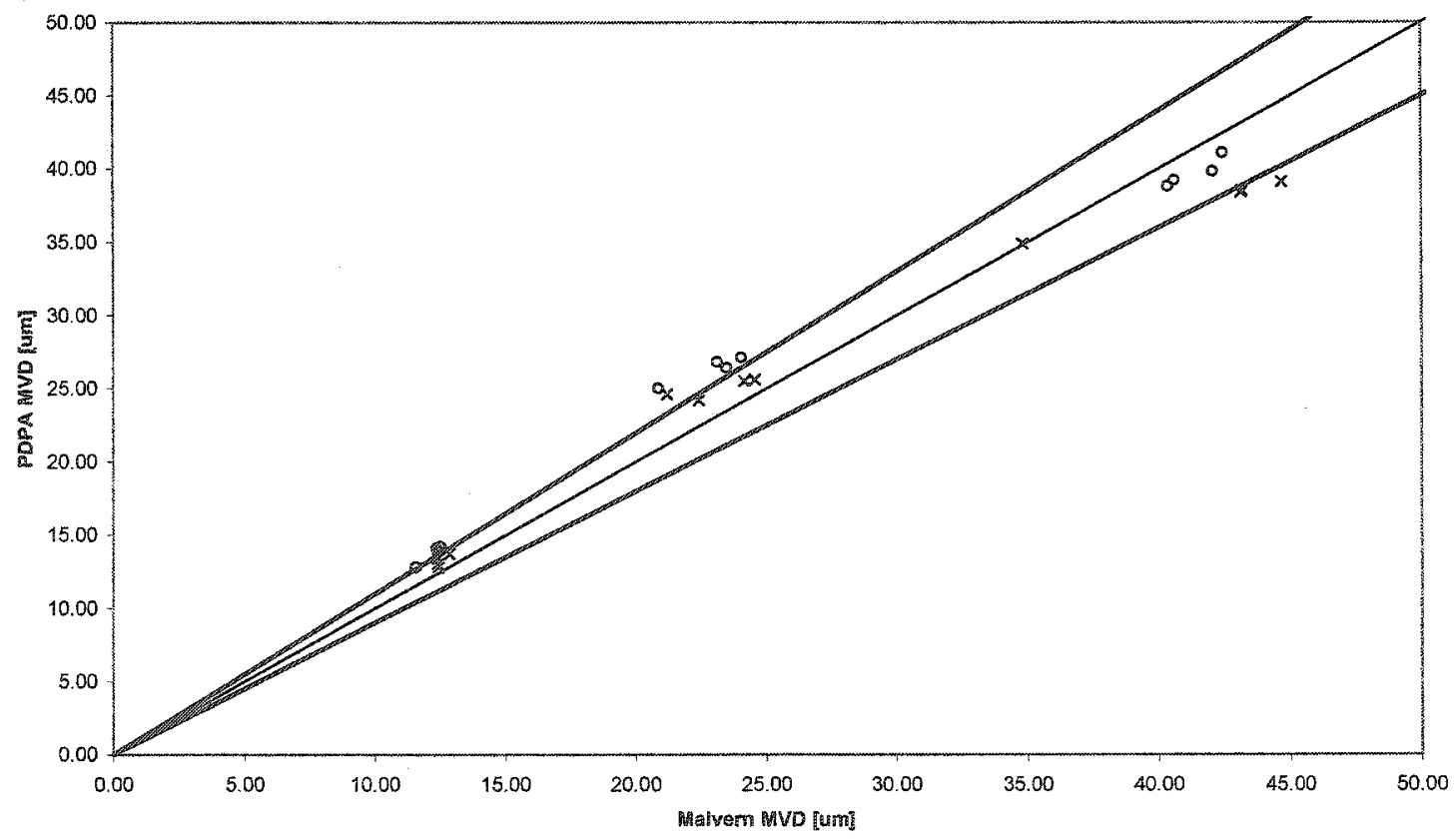

$\times 30 \mathrm{~m} / \mathrm{s} \odot 50 \mathrm{~m} / \mathrm{s}-1 \mathrm{i}-10 \%$ -

Figure 5.11: Measured PDPA MVD vs. Measured Malvern MVD at various airspeeds. 


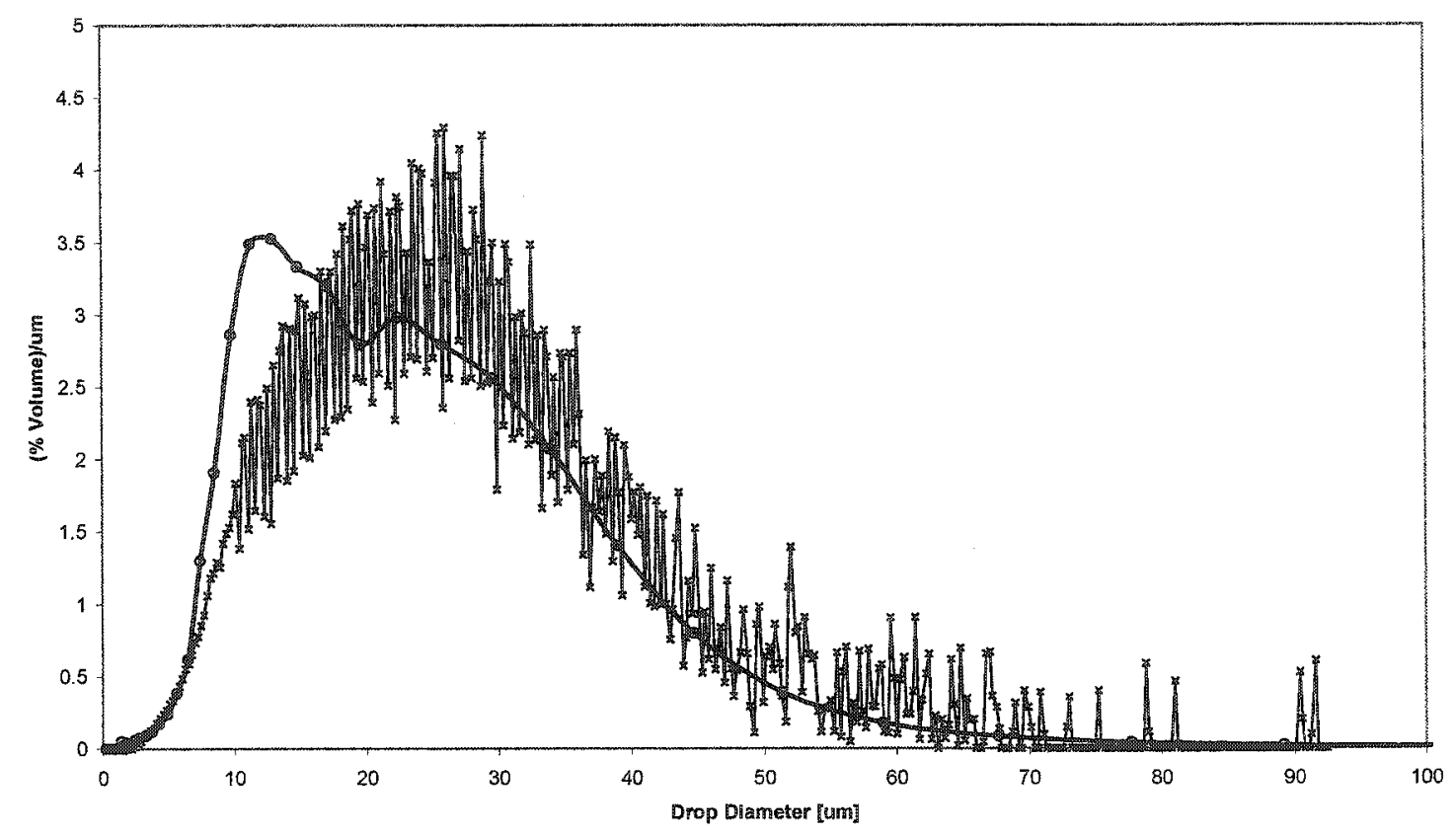

$\rightarrow-$ Malvem TP26 $\rightarrow$ - PDPA TP26

Figure 5.12: Overlay of Malvern and PDPA measurements of Droplet Spectrum for Test Point 26 of Table 5.6b.

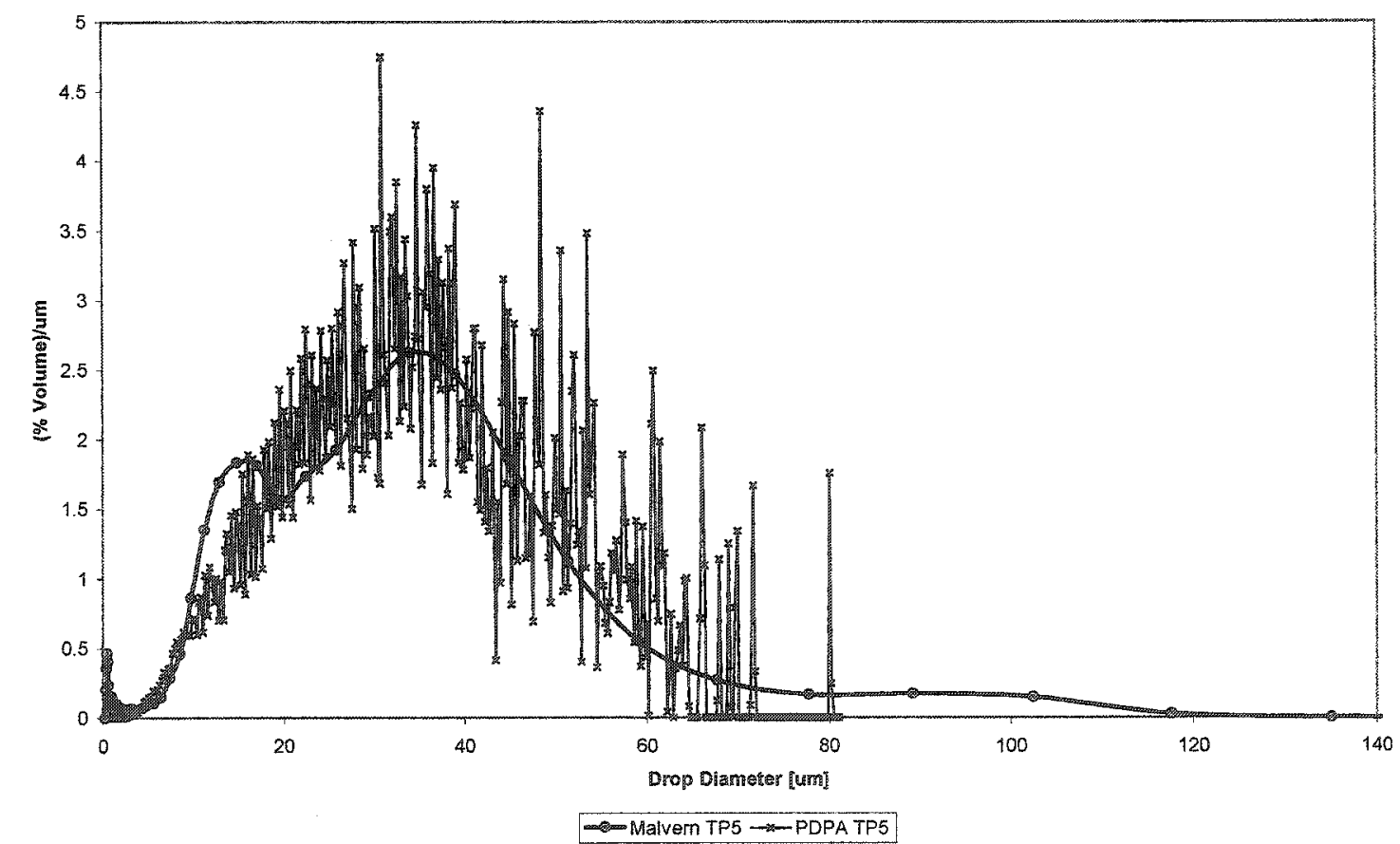

Figure 5.13: Overlay of Malvern and PDPA measurements of Droplet Spectrum for Test Point 5 of Table 5.6 a. 


\section{Appendix A \\ Computation of Collision Efficiency for a Cylinder in Cross-Fiow}

When determining the droplet collision efficiency, the droplets are assumed to be perfect spheres and their respective diameter and density give them a distinct momentum (inertia) and drag coefficient. The steady potential flow field around the object is computed and the droplet trajectories are then found. Finstad, et al. (1988) presents this method for a cylinder using a digital computer as a check to the original work done by Langmuir and Blodgett (1946) for a cylinder in cross-flow. The beauty in Finstad's work is that a non-linear regression was used to collapse the results for collision efficiency into a single equation involving the Stokes number $(K)$ and Langmuir's parameter $(\Phi)$ where;

$$
K=\frac{\rho_{d} D_{d}{ }^{2} U}{9 \mu D_{c}}
$$

and

$$
\Phi=\frac{\operatorname{Re}_{d}{ }^{2}}{K}=\frac{9 \rho_{a}^{2} D_{c}}{\rho_{d} \mu}
$$

For cases where $\Phi>100$, the overall collision efficiency is given by:

$$
\begin{aligned}
& E_{c y l}=\left[1.066 K^{-6.16 \times 10^{-3}} \exp \left(-1.103 K^{-0.688}\right)-0.028\right] \\
& -\left[6.37 \times 10^{-3}(\Phi-100)^{0.381}\right] \\
& \times\left[3.641 K^{-0.498} \exp \left(-1.497 K^{-0.694}\right)-0.045\right]
\end{aligned}
$$

(Finstad, et al., 1988)

However, for cases where $\Phi<100$ Langmuir's original formulation can be used as interpreted by Stallabrass (1978). 
Langmuir, et al. (1946) begins by defining the droplet "range" $(\lambda)$, which is the theoretical range of the droplet if it were projected into still air with the velocity $U$. If Stokes law $\left(\mathrm{C}_{\mathrm{d}} \operatorname{Re}_{\mathrm{d}} / 24=1\right)$ holds for the droplet, $\lambda_{s}$ can be computed by:

$$
\lambda_{s}=\frac{2 \rho_{d}\left(D_{d} / 2\right)^{2} U}{9 \mu}=\frac{\rho_{d} D_{d}{ }^{2} U}{18 \mu}
$$

and the ratio of $\lambda / \lambda_{s}$ can be determined by:

$$
\lambda / \lambda_{s}=\left(1 / \operatorname{Re}_{d}\right) \int_{0}^{R e_{d}} \frac{24}{C_{d} R} d R
$$

Table 1 of Langmuir, et al. (1946) contains tabulated results of $\lambda / \lambda_{\mathrm{s}}$ for various values of $R e_{d}$. The table has been reproduced as Table 2.1 of this document. Because of the rigor involved in solving equation (A1.5), Stallabrass (1978) suggests an empirical relation for determining $\lambda / \lambda_{s}$ :

$$
\lambda / \lambda_{s}=\frac{1}{1+0.1206 \operatorname{Re}_{d}^{0.59}}
$$

The results of equation (A1.6) have been tabulated alongside the Langmuir's results for equation (A1.5) in order to validate the accuracy of the empirical approximation. Over the applicable range of $5 \leq \mathrm{Re}_{\mathrm{d}} \leq 500$ the maximum difference between Langmuir's results and Stallabrass' approximation is less than $1.5 \%$. The collision efficiency is computed by first determining Stokes number $(K)$ as in equation (A1.1). For values where $K$ is small, i.e. $K \leq 3.0$ the parameter $K_{o}$ is used in determining $E$. $K_{o}$ is defined by Langmuir's equation 40 . If $\mathrm{K} \leq 3.0$; 


$$
K_{o}=0.125+(K+0.125) \lambda / \lambda_{s}
$$

Using Stallarass' approximation for the range ratio (equation A1.6) in (A1.7) the equation becomes:

$$
K_{o}=0.125+\frac{(K-0.125)}{\left(1+0.1206 \operatorname{Re}_{d}^{0.59}\right)}
$$

Finally the collision efficiency is given by:

$$
E_{c y l}=0.457\left(\log _{10} 8 K_{o}\right)^{1.634}
$$

For larger values of Stokes number, i.e. $K>3.0$; Langmuir uses the parameter $H_{e}$ to determine the collision efficiency. By Langmuir's equation 43 :

If $\mathrm{K}>3.0$ :

$$
H_{e}=1+0.5708 \cdot\left(C_{d} \operatorname{Re}_{d} / 24\right)-0.73 \times 10^{-4} \operatorname{Re}_{d}{ }^{1.38}
$$

Computed values for $C_{d} R_{d} / 24$ are presented in table 1 of Langmuir et al., (1946) and Stallabrass (1978) offers an empirical relationship providing similar accuracy to his approximation for determining $\lambda \lambda_{\mathrm{s}}$ over the applicable range of Reynolds numbers.

$$
C_{d} \operatorname{Re}_{d} / 24=1+0.212 \operatorname{Re}_{d}^{0.6}+2.6 \times 10^{-4} \operatorname{Re}_{d}^{1.38}
$$

Substituting (A1.11) into (A1.10):

$$
H_{e}=\pi / 2+0.121 \operatorname{Re}_{d}^{0.6}+0.754 \times 10^{-4} \operatorname{Re}_{d}{ }^{1.38}
$$

where $\pi / 2=1.5708$. The collision efficiency can then be determined with Langmuir's equation 42 :

$$
E_{c y l}=\frac{K}{\left(K+H_{e}\right)}
$$


The method presented above for has been used wherever the collision efficiency of a cylinder in cross flow is required unless otherwise stated. 


\section{Appendix B}

Modified Version of Makkonen's Model for Modeling Ice Accretion on Wires

The following section describes the Makkonen (1984) method for modeling of ice accretion on a rotating cylinder in cross flow. The method assumes that the cylinder rotates at a rate fast enough to ensure that the ice accretes symmetrically about the axis of the cylinder. The fundamental parameter used by the technique to describe the ice accretion is the icing intensity 1 . The icing intensity is defined as the ice accretion rate divided by the upwind facing surface area of the cylinder, and can be computed by:

$$
I=\frac{2}{\pi} E \cdot n \cdot U \cdot L W C
$$

Where:

$E \quad=$ collision efficiency of the cylinder

$n \quad$ = freezing fraction

$U \quad=$ free stream velocity

$L W C=$ cloud liquid water content

The collision efficiency $(E)$ is computed as presented in appendix $A$ above. The freezing fraction $(n)$ can be calculated from the heat balance on the upstream facing surface of the cylinder and is equivalent to the fraction of the LWC that actually freezes to the cylinder. The freezing fraction is defined as:

$$
n=\frac{\pi h}{2 E \cdot U \cdot L W C \cdot L_{f}}\left[-T_{a i r}+\frac{k L_{v}}{c_{p} P_{a t m}}\left(e_{o}-e_{a}\right)-\frac{r U^{2}}{2 c_{p}}\right]-\frac{T_{a i r}}{L_{f}}\left(c_{w}+\frac{\pi \sigma \cdot a}{2 E \cdot U \cdot L W C}\right)
$$


In equation (B1.2), $h$ is the convective heat transfer coefficient, $L_{f}$ is the latent heat of fusion of water at $0^{\circ} \mathrm{C}, T_{\text {air }}$ is the atmospheric temperature, $k=0.62, L_{v}$ is the latent heat of vaporization of water at $0^{\circ} \mathrm{C}, c_{p}$ is the specific heat of air at constant pressure, $P_{a t m}$ is the atmospheric pressure, $e_{o}$ and $e_{a}$ are the saturation water vapor pressures over water at $0^{\circ} \mathrm{C}$ and $T_{\text {air }}$ respectively, $r$ is the overall recovery factor $(r=0.79), c_{w}$ is the specific heat capacity of water, $\sigma$ is the StefanBoltzmann constant $\left(\sigma=5.670 \times 10^{-8} \mathrm{~J}^{\circ} \mathrm{K}^{-4} \mathrm{~m}^{-2} \mathrm{~s}^{-1}\right)$ and $a=8.1 \times 10^{7}{ }^{\circ} \mathrm{K}^{3}$. The complete derivation of equation (B1.2) is available in Appendix B of Makkonen (1984).

The overall heat transfer coefficient $h$ is written as a function of the cylinder Nusselt number $(\mathrm{Nu})$ :

$$
h=\frac{k_{a} \cdot N u}{D_{c y l}}
$$

Where $k_{a}$ is the molecular conductivity of air and $D_{c y l}$ is the outside diameter of the cylinder (this includes the ice accreted on the cylinder if applicable). The Nusselt number is parameterized by:

$$
N u=0.032 \operatorname{Re}_{c y l}{ }^{0.85}
$$

and $\mathrm{Re}_{c y l}$ is the Reynolds number based on cylinder diameter given by:

$$
\operatorname{Re}_{c y l}=\frac{\rho_{a} D_{c y l} U}{\mu_{a}}
$$

Equation (B1.4) is a linear correlation of Achenbach's (1997) data for a cylinder in cross flow. The relationship is valid for a range or Reynolds numbers 
corresponding to $1 \times 10^{4}<\mathrm{Re}_{c y l}<1 \times 10^{6}$ as described in section $2 \mathrm{~b}$ of Makkonen (1984).

Equation (B1.2) is used to compute the fraction of liquid water that actually freezes to the upstream face of the rotating cylinder. A freezing fraction of $n=1$ corresponds to the case where all the water that strikes the cylinder freezes and is considered as dry growth. There may be a small region of wet growth near the stagnation line, but as long as the water freezes downstream and no water is shed off the cylinder the freezing fraction is considered as unity. In the case where $n<1$, some fraction of liquid water is lost from the cylinder due to shedding and the ice accretion is considered wet. For the purpose of applying this model to the multicylinder technique only conditions that yield rime icing should be used to minimize the error associated with the calculation of runback and shedding. Consequently the mean surface temperature $T_{s}$ is computed and confirmed to be much less than $0^{\circ} \mathrm{C}$ as a second check to attest that no water is lost from the cylinder. $T_{s}$ is found by an iterative numerical solution using Ridders' method of the heat balance equation for the dry growth process:

$$
\frac{2}{\pi} E \cdot U \cdot L W C\left(L_{f}+c_{w} T_{a i r}-c_{i} T_{s}\right)=h\left[\left(T_{s}-T_{a i r}\right)+\frac{k L_{s}}{c_{p} P_{a t m}}\left(e_{s}-e_{a}\right)-\frac{r U^{2}}{2 c_{p}}\right]+\sigma a\left(T_{s}-T_{a i r}\right)
$$

Where $c_{i}$ is the specific heat of ice, $L_{s}$ is the latent heat of sublimation of $T_{S}$, and $e_{i}$ is the saturation water vapor pressure over ice at temperature $T_{s}$. The derivation of equation (B1.6) is available in appendix B of Makkonen (1984). 
In order to compute the mass of ice that would accrete on a cylinder during a given time, a time dependant solution is employed. As the accretion grows in size it remains symmetric about the axis of the cylinder and the change in outside diameter affects the collision efficiency and the freezing fraction. If the cloud properties are assumed to remain constant with time (which should be the case in an icing wind tunnel) equation (B1.1) can be re-written as:

$$
I(t)=\frac{2}{\pi} E(t) \cdot n(t) \cdot U \cdot L W C
$$

The mass of ice $M_{i}$ per unit length to accrete on the cylinder during time $t_{i}$ is given by:

$$
M_{i}=\int_{0}^{i} I(t) \frac{\pi}{2} D(t) d t=U \cdot L W C \cdot \int_{0}^{i} E(t) h(t) D(t) d t
$$

Where $D(t)$ is the outside diameter of the ice at time $t_{i}$. To calculate the total mass to accrete on a given cylinder a time stepping is used with the first step being the clean cylinder. Each time through a time step the collision efficiency $E\left(t_{i}\right)$, the freezing fraction $n\left(t_{i}\right)$, the ice density of the new layer grown in the current time step $\rho_{i c e}\left(t_{i}\right)$, and the average ice density of the entire accretion are computed. The total mass of ice is computed as a function of the mass from the previous step by:

$$
M_{i}=M_{i-1}+I_{i-1} \frac{\pi}{2} D_{i-1} \Delta t
$$

Where $i$ denotes the current time step and $i-1$ denotes the previous step. The diameter of the ice accretion is found from: 


$$
D_{i}=\left[\frac{4\left(M_{i}-M_{i-1}\right)}{\pi \cdot \rho_{i c e_{i}}}+D_{i-1}^{2}\right]^{1 / 2}
$$

The ice density is found by equation (2.11) as shown in section 2.4.2.2. Since the time over which ice is allowed to accrete on the cylinders is relatively short and the change in diameter is not severe (in most cases) the solution is relatively independent of the size of time step selected. The run lengths range from 10 to 180 seconds and normally the computation can be broken up into 10 to 30 time steps with very little change in accreted mass or outside diameter. 


\section{Appendix C \\ Weighted Least-Squares Linear Regression of a 2 Dimensional Cartesian System through the Origin}

The derivation of the equations in Appendix $C$ was developed with the help of several internet references, most notably:

http://www.env.wustl.edu/REU/2002/LinearRegressionEqs.pdf

For the purpose of determining when the theoretically accreted masses computed using the method presented in appendix $A$ best match those actually measured with the rotating multicylinder a straight line through the origin is used. Letting the measured masses be the independent variable and denoting them $x_{i}$, the dependant variable $y_{i}$ (in this case the computed masses), can be expressed as:

$$
y_{i}=f\left(x_{i}\right)+\varepsilon_{i}
$$

Where $\varepsilon_{i}$ is the random-variable error term associated with each set of ordered pairs $\left(x_{i}, y_{i}\right)$. If a data set contains ' $n$ ' sets of variables or ordered pairs, the best fit line through them is obtained by minimizing the residual sum of squares (RSS). The RSS (also denoted $S^{2}$ ) is defined as the sum of the squared random-variable error terms over the entire data set.

$$
S^{2}=\sum_{i=1}^{n} \varepsilon_{i}{ }^{2}=\sum_{i=1}^{n}\left(y_{i}-f\left(x_{i}\right)\right)^{2}
$$


A weighting factor $w_{i}$ can be used to reduce or increase the effect a given ordered pair has on the overall solution. The weighting factor is simply multiplied by the squared random-variable error for each term:

$$
S_{w}^{2}=\sum_{i=1}^{n} w_{i} \varepsilon_{i}^{2}=\sum_{i=1}^{n} w_{i}\left(y_{i}-f\left(x_{i}\right)\right)^{2}
$$

A linear function through the origin where $y$ is expressed as a function of $x$ can be written in the form;

$$
y=f(x)=m x
$$

where $m$ is the slope of the line. Substituting equation (C1.4) into (C1.3) the weighted residual sum of squares through the origin is obtained.

$$
S_{w}^{2}=\sum_{i=1}^{n} w_{i}\left(y_{i}-m x_{i}\right)^{2}
$$

The slope of the best fit line through a set of points is found by minimizing equation (C1.5) with respect to $\mathrm{m}$ :

$$
\frac{\partial S_{x}^{2}}{\partial m}=\sum_{i=1}^{n}\left(2 m w_{i} x_{i}^{2}-2 w_{i} y_{i} x_{i}\right)=0
$$

So,

$$
m=\frac{\sum_{i=1}^{n} w_{i} y_{i} x_{i}}{\sum_{i=1}^{n} w_{i} x_{i}^{2}}
$$

The coefficient of determination $r^{2}$ is the ratio of the variation of $y$ as determined by the regression. It is defined as the difference between the total 
sum of squares (TSS) and the residual sum of squares (RSS). The TSS is effectively the weighted variation of $y_{i}$ from the mean value. So,

$$
r^{2}=\frac{T S S-R S S}{T S S}=\frac{\sum_{i=1}^{n} w_{i}\left(y_{i}-y_{m}\right)^{2}-\sum_{i=1}^{n} w_{i}\left(m x_{i}-y_{i}\right)^{2}}{\sum_{i=1}^{n} w_{i}\left(y_{i}-y_{m}\right)^{2}}
$$

where $y_{m}$ is the weighted mean of all the $y$ values in the data set:

$$
y_{m}=\frac{\sum_{i=1}^{n} w_{i} y_{i}}{\sum_{i=1}^{n} w_{i}}
$$




\section{Appendix D \\ Procedure used in the Replication of the Inter-Facility Comparison Study}

This appendix outlines the procedure used in the replication of the inter-facility comparison study. The items used in the test are shown in Figure 3.1. Before each test run was initiated the copper plate which is used to cut into the ice was placed into the heater. The plate has a cut out in it that fits snugly around the cylinder so that the ice is melted right to the cylinder's surface.

Once the run has been completed the tunnel is stopped but the airflow through the nozzles is left on along with the refrigeration system. This kept the temperature in the test section sub zero and helped to prevent the ice accretion from melting. The Plexiglas window in the forward section was removed so that access to the accretion could be achieved. Photographs of the accretion should be taken at this time if they are desired. Wearing the insulated gloves, the operator removed the hot plate from the heater and mounted it to the holder. The spacers were used along the wall of the tunnel to correctly align the hot plate holder to the tunnel centerline. Using the spacer as a guide the hot plate was pressed firmly yet slowly into the accretion until the plate makes contact with the cylinder. Slightly jiggling the plate up and down ensured that the ice is melted completely to the cylinder's surface. Immediately after the cut is completed, the compressed air canister was used to freeze the area where the cut was made to prevent further melting. Similar cuts are made using the spacers 1.5 inches port 
and starboard of the centerline. If the hot plate cooled, it was necessary to use a propane torch to quickly heat the plate again. If this is the case care must was not to over heat the plate as to cause excessive melting of the accretion near the plate. After the cuts were made the hot plate was removed from the holder and placed back in the heater.

A data card was then attached to the holder and the card was slid into one of the cuts made by the hot plate. The circular cut out on the card should fit firmly against the 1.5" cylinder and the top and bottom of the card should be aligned with the horizontal axis of the tunnel. The pencil was used to carefully trace the ice profile onto the data card without damaging the ice. This was difficult at times since fragile feathers and crevasses formed along the ice profile. The pencil is made from a thin pipe that is bent with a $90^{\circ}$ elbow. The pipe is just large enough to snuggly fit a piece of $3 \mathrm{~mm}$ pencil lead. The $90^{\circ}$ elbow allows the ice profile to be traced while avoiding the effect of parallax that might occur using a standard pencil. Once the entire profile had been traced the card was pulled out of the cut and flipped on the holder. The card was then reinserted into another of the cuts and a tracing of that profile was taken on the backside of the card. Again the card should fit snuggly around the cylinder and the top and bottom should be aligned with the horizontal axis of the tunnel. A second card was then used to record the profile of the final cut. After all tree profiles have been traced the data cards are labeled with the date, run number, and location (centerline, starboard of centerline, or port of centerline). 
The heat gun was used to remove the ice accretion and the cylinder was dried using a clean rag. The floor of the test section was also dried to prevent ice from forming due to the water that melted off the accretion while the cuts were made or while the accretion was being removed. Once all the ice has been removed from the test section the window was replaced and the next test point was run.

In order to easily compare the tracings by superimposing them on top of one another the tracings were digitized using a scanner. Prior to scanning in the tracings they were traced over with a very thin black marker to ensure that they could be scanned properly. To properly compare the images it is important that datum references were used to make sure that the tracings are properly aligned. A balsa wood board with three small nails was used for this purpose. The three nails fit into three holes that have been punched in the data cards. When the nails were fit through the holes and the balsa wood board was flush with the top and side of the scanner, the image was sure to be properly aligned. The scanned image was then converted into a series non-dimensional coordinates using a Matlab script. The forward most point on the leading edge of the cylinder (along the centerline of the tunnel) was used as the datum for the coordinate file. This point becomes $(0,0)$ and the rest of the points were normalized by the chord (in this case 1.5 inches). The coordinate files can then be plotted in Excel or Tecplot for visualization purposes. 